\title{
Evaluating Halogen-Bond Strength as a Function of Molecular Structure Using Nuclear Magnetic Resonance Spectroscopy and Computational Analysis
}

Quang Minh Dang, Jeffrey H. Simpson, Carol A. Parish and Michael C. Leopold*

Department of Chemistry, Gottwald Science Center, University of Richmond, Richmond, VA 23173

Table of Contents:

- Experimental Details:

○ Table S1: Benchmarking electronic energies of XB donor iodopentafluorobenzene (IPFB), XB acceptor trimethylphosphine oxide $\left(\mathrm{Me}_{3} \mathrm{PO}\right)$, and $\mathrm{XB}$ adduct IPFB- $\mathrm{Me}_{3} \mathrm{PO}$ calculated from various functionals and basis sets. - p. S3

○ Figure S1 to S2: ${ }^{19} \mathrm{~F}-{ }^{1} \mathrm{H}$ HOESY spectra of dexamethasone in $\mathrm{d}_{5}$-pyridine - pp. S4-S5

○ Figure S3: ${ }^{19} \mathrm{~F}-{ }^{1} \mathrm{H}$ HOESY spectrum of I-PFB with quinuclidine in $\mathrm{d}_{12}$-cyclohexane - p. S6

○ Additional details for determining $K_{\mathrm{a}}$ value from NMR titration curve - p. S7

○ Python Code for non-linear regression analysis of binding isotherm (titration curves) - pp. S8-S12

- Results \& Discussion:

○ Figure S4 to S7: Geometry optimized XB adducts of $\mathrm{XB}$ acceptor tributylphosphine oxide $\left(\mathrm{Bu}_{\mathbf{3}} \mathbf{P O}\right)$ with XB donors halobenzenes (pp. S13-S14); and perfluorohalobenzenes (pp. S15-S16).

○ Figure S8 to S9: Geometry optimized control adducts of hexane with XB donors halobenzenes (p. S17); and haloperfluorobenzenes (p. S18).

○ Figure S10: Superimposition of gas-phase geometry optimized XB adduct IPFB-Bu $\mathbf{P O}$ on geometries optimized in PCM cyclohexane, benzene, carbon tetrachloride, and diethyl ether - p. S19

○ Table S2: A comparison of gas-phase and PCM solvent-phase interaction energies $\left(\Delta \mathrm{E}_{\text {int }}\right)$, bond distances, and bond angles of XB adduct IPFB-Bu 3 PO - p. S19

○ Figure S11 to S12: ${ }^{1} \mathrm{H}$ NMR spectra of halobenzene XB donors in cyclohexane - pp. S20-S21

○ Figure S13 to S14: ${ }^{19}$ F NMR spectra of perfluorohalobenzene XB donors in cyclohexane - pp. S22-S23

○ Figure S15 to S17: ${ }^{1} \mathrm{H}$ NMR titration analysis of $\mathbf{X B}$ acceptor $\mathbf{B u}_{3} \mathbf{P O}$ with the following halobenzenes XB donors (in cyclohexane) - pp. S24-S26

O Figure S18 to $\mathbf{S 2 0}:{ }^{19} \mathrm{~F}$ NMR titration analysis of $\mathbf{X B}$ acceptor $\mathbf{B u}_{\mathbf{3}} \mathbf{P O}$ with the following haloperfluorobenzenes XB donors (in cyclohexane) - pp. S27-S29

o Figure S21 to S40: ${ }^{19}$ F NMR titration analysis of XB donor I-PFB with the following XB acceptors (in either cyclohexane or benzene): hexane/control (p. S30), dibutyl sulfoxide $\left(\mathrm{Bu}_{2} \mathrm{SO}\right)(\mathrm{p} . \mathrm{S} 31)$, 5-nonanone $\left(\mathrm{Bu}_{2} \mathrm{CO}\right)$ (p. S32), trimethylphosphine oxide ( $\left.\mathrm{Me}_{3} \mathrm{PO}\right)$ (p. S33), triethylphosphine oxide (Et $\left.{ }_{3} \mathrm{PO}\right)(\mathrm{p} . \mathrm{S} 34)$, $\mathrm{Bu}_{3} \mathrm{PO}$ (p. S35), trioctylphosphine oxide (Oct $\left.{ }_{3} \mathrm{PO}\right)$ (p. S36), triphenylphosphine oxide $\left(\mathrm{Ph}_{3} \mathrm{PO}\right)(\mathrm{p} . \mathrm{S} 37)$, $\mathrm{Oct}_{3} \mathrm{PO}$ (p. S38), trioctylphosphine sulfide (Oct $\left.{ }_{3} \mathrm{PS}\right)$ (p. S39), trioctylphosphine selenide (Oct $\left.{ }_{3} \mathrm{PSe}\right)(\mathrm{p} . \mathrm{S} 40)$, 


\section{Table of Contents (cont.):}

\section{- Results \& Discussion (cont):}

triethylamine $\left(\mathrm{Et}_{3} \mathrm{~N}\right)(\mathrm{p} . \mathrm{S} 41)$, tributylamine $\left(\mathrm{Bu}_{3} \mathrm{~N}\right)(\mathrm{p} . \mathrm{S} 42)$, trioctylamine $\left(\mathrm{Oct}_{3} \mathrm{~N}\right)(\mathrm{p} . \mathrm{S} 43)$, quinuclidine (p. S44), diethylamine $\left(\mathrm{Et}_{2} \mathrm{NH}\right)(\mathrm{p} . \mathrm{S} 45)$, dibutylamine $\left(\mathrm{Bu}_{2} \mathrm{NH}\right)(\mathrm{p} . \mathrm{S} 46)$, dioctylamine $\left(\mathrm{Oct}_{2} \mathrm{NH}\right)(\mathrm{p} . \mathrm{S} 47)$, butylamine $\left(\mathrm{BuNH}_{2}\right)$ (p. S48), and octylamine $\left(\mathrm{OctNH}_{2}\right)$ (p. S49).

O Figure S41 to S52: Geometry optimized XB adducts of XB donor I-PFB with the following XB acceptors:

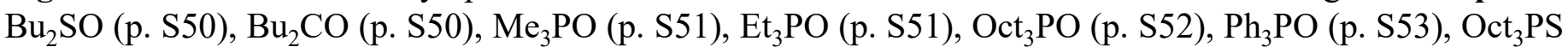
(p. S54), Oct ${ }_{3} P S e(p . S 55), P h_{3} P S$ (p. S56), $P_{3} P S e(p . S 56), E_{3} N(p . S 57), B_{3} N$ (p. S57), Oct ${ }_{3}$ N (p. S58), quinuclidine (p. S58), $\mathrm{Et}_{2} \mathrm{NH}$ (p. S59), $\mathrm{Bu}_{2} \mathrm{NH}$ (p. S59), $\mathrm{Oct}_{2} \mathrm{NH}$ (p. S60), $\mathrm{EtNH}_{2}$ (p. S60), BuNH $\mathrm{B}_{2}(\mathrm{p} . \mathrm{S} 61)$, and $\mathrm{OctNH}_{2}$ (p. S61).

○ Figure S53 to S57: ${ }^{19} \mathrm{~F}$ NMR spectra of XB donor I-PFB in different solvents: dichloromethane, chloroform, para-xylene, toluene, benzene, carbon tetrachloride, diethyl ether, acetonitrile, tetrahydrofuran, and triethylamine - pp. S62-S66

○ Figure S58 to S66: ${ }^{19} \mathrm{~F}$ NMR titration analysis of $\mathbf{X B}$ donor I-PFB with $\mathbf{X B}$ acceptor $\mathbf{B u} \mathbf{P}_{\mathbf{3}} \mathbf{P O}$ in various solvents including dichloromethane (p. S67), chloroform (p. S68), para-xylene (p. S69), toluene (p. S70), carbon tetrachloride (p. S71), diethyl ether (p. S72), acetonitrile (p. S73), tetrahydrofuran (p. S74), and triethylamine (p. S75).

○ Figure S67 to S70: ${ }^{19} \mathrm{~F}-{ }^{1} \mathrm{H}$ HOESY spectra of I-PFB with Oct $_{3} \mathbf{P O}$ in $\mathrm{d}_{12}$-cyclohexane with the following NMR mixing time $\left(\mathrm{d}_{8}\right): 400 \mathrm{~ms}, 600 \mathrm{~ms}, 750 \mathrm{~ms}, 800 \mathrm{~ms}$, $900 \mathrm{~ms}$, and $1200 \mathrm{~ms}-\mathrm{pp}$. S76-S79

○ Figure S71: ${ }^{19} \mathrm{~F}-{ }^{1} \mathrm{H}$ HOESY signal/noise $(\mathrm{S} / \mathrm{N})$ analysis of I-PFB with Oct $_{\mathbf{3}} \mathbf{P O}$ with the following NMR mixing time $\left(\mathrm{d}_{8}\right): 400 \mathrm{~ms}, 600 \mathrm{~ms}, 750 \mathrm{~ms}, 800 \mathrm{~ms}, 900 \mathrm{~ms}$, and $1200 \mathrm{~ms}$. - p. S80

○ Figure S72 to S73: ${ }^{19} \mathrm{~F}-{ }^{1} \mathrm{H}$ HOESY spectra of I-PFB with $\mathbf{B u}_{\mathbf{3}} \mathbf{P O}$ and $\mathbf{O c t}_{\mathbf{3}} \mathbf{P O}$ in $\mathrm{d}_{6}$-benzene (p. S81) and d-chloroform (p. S82).

○ Figure S74: ${ }^{19} \mathrm{~F}$ NMR titration analysis of XB donor I-PFB with XB acceptor Oct $\mathbf{3}$ PO in chloroform. - p. S83

- $\quad$ References - p. S84 
Table S1. Benchmarking Electronic Energies of XB Donor Iodopentafluorobenzene (IPFB), XB Acceptor Trimethylphosphine Oxide $\left(\mathrm{Me}_{3} \mathrm{PO}\right)$, and $\mathrm{XB}$ Adduct IPFB- $\mathrm{Me}_{3} \mathrm{PO}$ calculated from various Functionals and Basis Sets.
Functional/Basis Set
$\mathrm{E}_{\text {IPFB }}$
$(\mathrm{au})$
$\mathrm{E}_{\mathrm{Me} 3 \mathrm{PO}}$
$\mathrm{E}_{\text {IPFB-Me3PO }}$
$\Delta \mathrm{E}_{\text {int }}$
(au)
$\Delta \mathrm{E}_{\mathrm{int}}$ $(\mathrm{kcal} / \mathrm{mol})$

CCSD(T)/cc-pVTZ//
CCSD/cc-pVDZ
CCSD/cc-pVTZ//
CCSD/cc-pVDZ
M06-2X/cc-pVTZ//
M06-2X/cc-pVDZ
M06-2X/def2-TZVP//
M06-2X/def2-TZV
M06-2X/6-311++G(2d,p)//
M06-2X/6-31+G(d)
M06-2X/cc-pVDZ

M06-2X/DGDZVP

$\begin{array}{llllll}-1019.25395337 & -534.578325915 & -1553.84005715 & -0.00777786 & -4.88068502 \\ -1019.25395337 & -534.578326027 & -1553.84005715 & -0.00777775 & -4.88061474 \\ -1023.45770348 & -536.335881219 & -1559.80817269 & -0.01458799 & -9.15410451\end{array}$

$\begin{array}{lllll}-1023.47101322 & -536.326891518 & -1559.81183652 & -0.01393178 & -8.74232706\end{array}$

$\begin{array}{lllll}-1023.41205678 & -536.318548305 & -1559.74499325 & -0.01438817 & -9.02871178\end{array}$

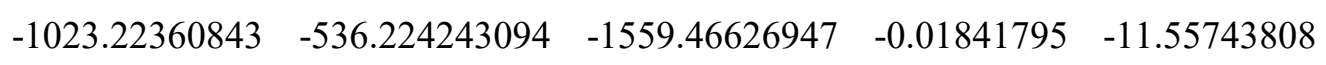

wB97-XD/cc-pVTZ//

wB97-XD/cc-pVDZ

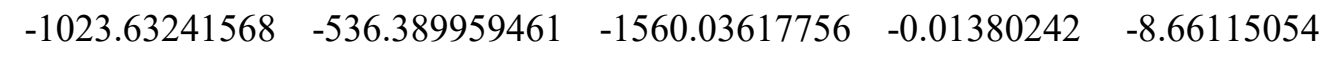

wB97-XD/def2-TZVP//

wB97-XD/def2-TZV

$\begin{array}{lllll}-1023.66494450 & -536.387152180 & -1560.06507898 & -0.01298230 & -8.14651798\end{array}$

wB97-XD/6-311++G(2d,p)//

wB97-XD/6-31+G(d)

$\begin{array}{lllll}-1023.59503038 & -536.318406512 & -1559.98555832 & -0.07212143 & -45.25688901\end{array}$

wB97-XD/DGDZVP

$\begin{array}{lllll}-1023.27712859 & -536.211053205 & -1559.50507694 & -0.01689515 & -10.60186582\end{array}$

B3LYP-D3/cc-pVTZ//

B3LYP-D3/cc-pVDZ

$\begin{array}{llllll}-1023.89210016 & -536.495495302 & -1560.40408594 & -0.01649048 & -10.34793339\end{array}$

B3LYP-D3/def2-TZVP//

B3LYP-D3/def2-TZV

$\begin{array}{lllll}-1023.92341879 & -536.491367929 & -1560.43051517 & -0.01572845 & -9.86975412\end{array}$

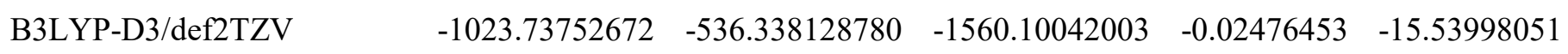

$\begin{array}{llllll}\text { B3LYP-D3/6-311++G(2d,p)// } & -1023.85722283 & -536.482625549 & -1560.35619042 & -0.01634204 & -10.25478774 \\ \text { B3LYP-D3/6-31+G(d) } & & & \end{array}$

$\begin{array}{lllllll}\text { B3LYP-D3/DGDZVP } & -1023.74557067 & -536.380996321 & -1560.14446776 & -0.01790077 & -11.23290454\end{array}$ 

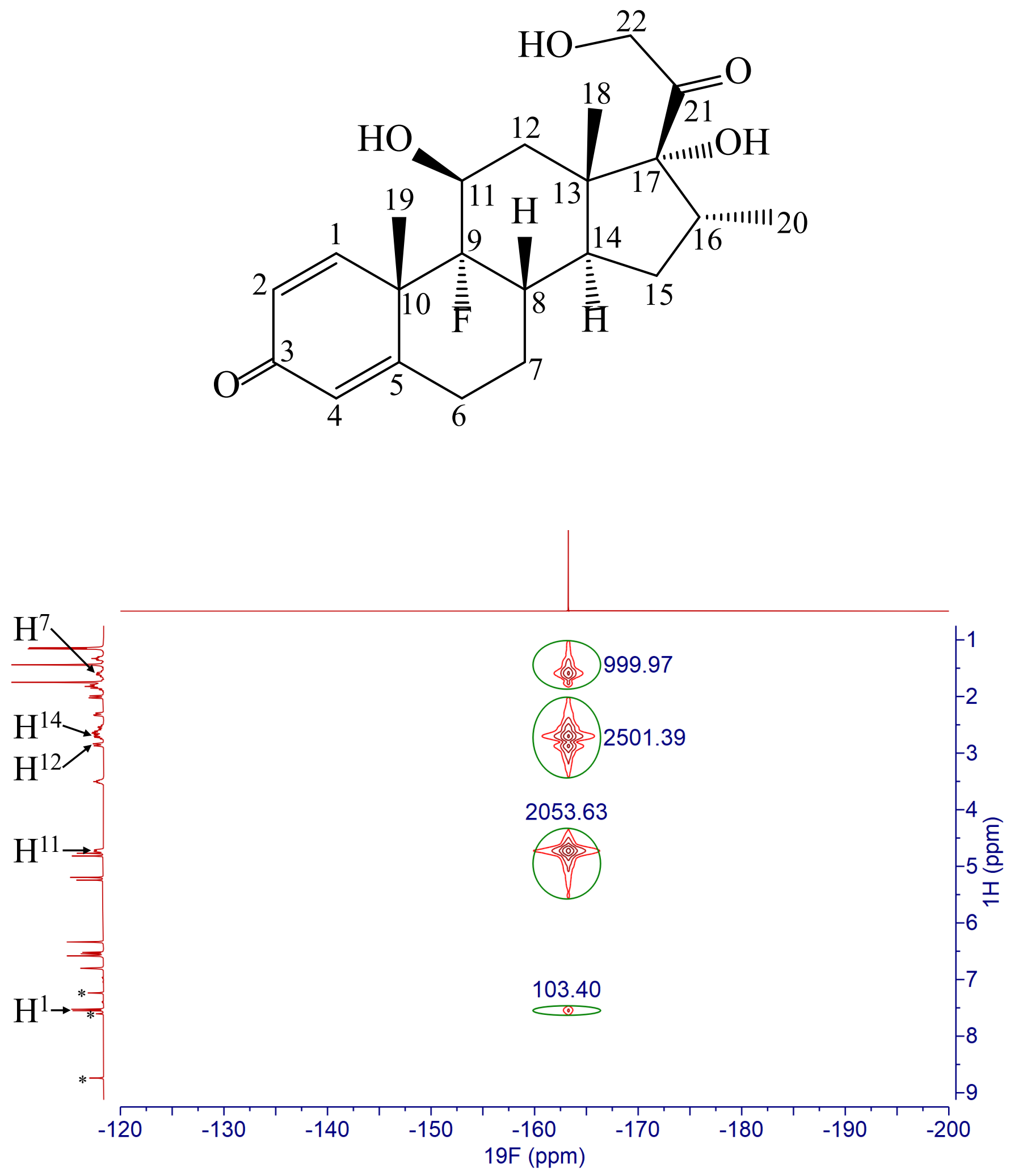

Figure S1. ${ }^{19} \mathrm{~F}-{ }^{1} \mathrm{H}$ HOESY spectrum of dexamethasone in $\mathbf{d}_{5}$-pyridine (residual solvent peaks denoted by *) with cross peaks representing the couplings of the fluorine atom and $\mathrm{H}^{1}, \mathrm{H}^{7}, \mathrm{H}^{11}, \mathrm{H}^{12}$, and $\mathrm{H}^{14}$ and their cross-peak intensities in $1^{\text {st }}$ trial. 

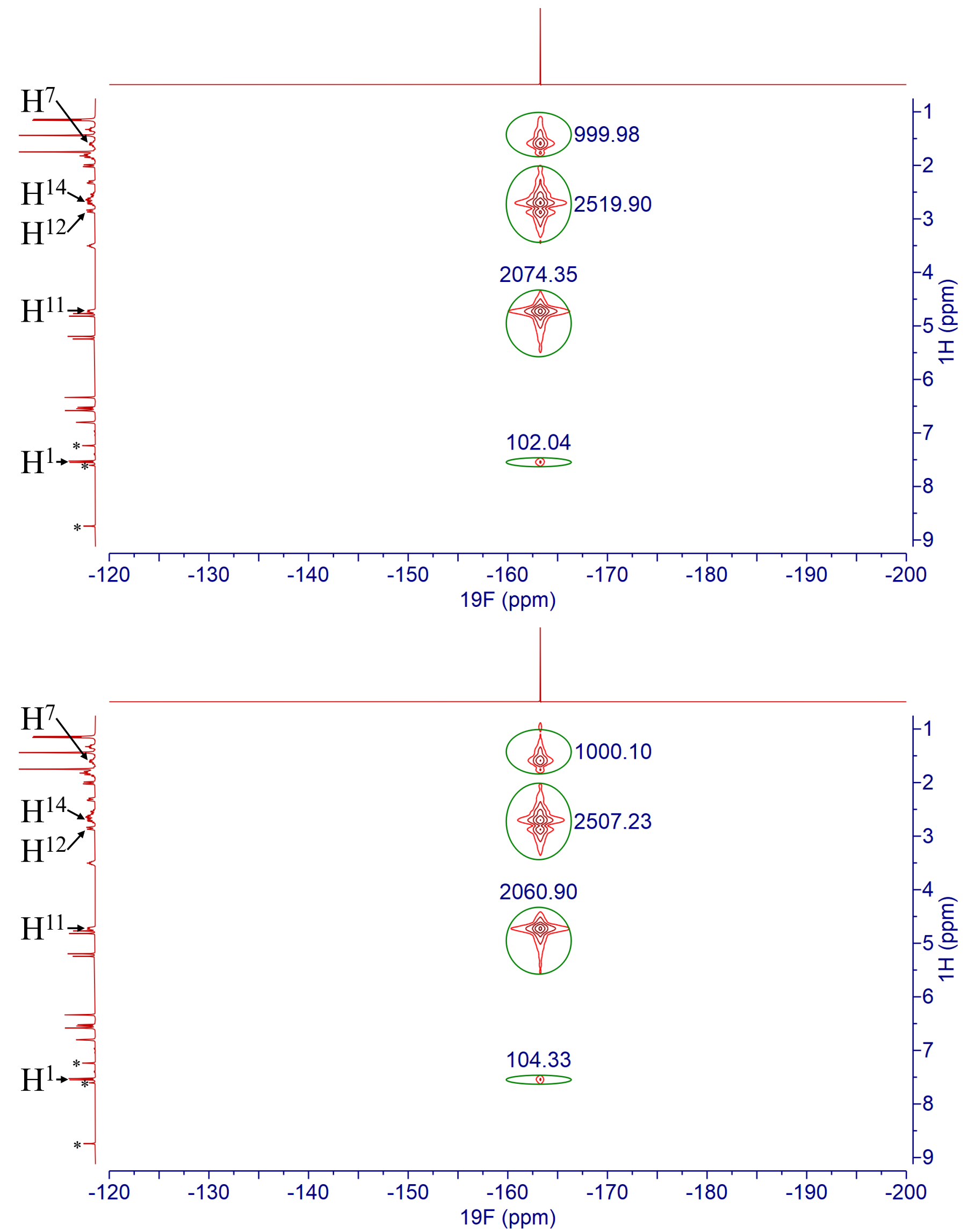

Figure S2. ${ }^{19} \mathrm{~F}-{ }^{1} \mathrm{H}$ HOESY spectrum of dexamethasone in $\mathbf{d}_{5}$-pyridine (residual solvent peaks denoted by *) with cross peaks representing the couplings of the fluorine atom and $\mathrm{H}^{1}, \mathrm{H}^{7}, \mathrm{H}^{11}, \mathrm{H}^{12}$, and $\mathrm{H}^{14}$ and their cross-peak intensities in $2^{\text {nd }}$ (top) and $3^{\text {rd }}$ (bottom) trials. 


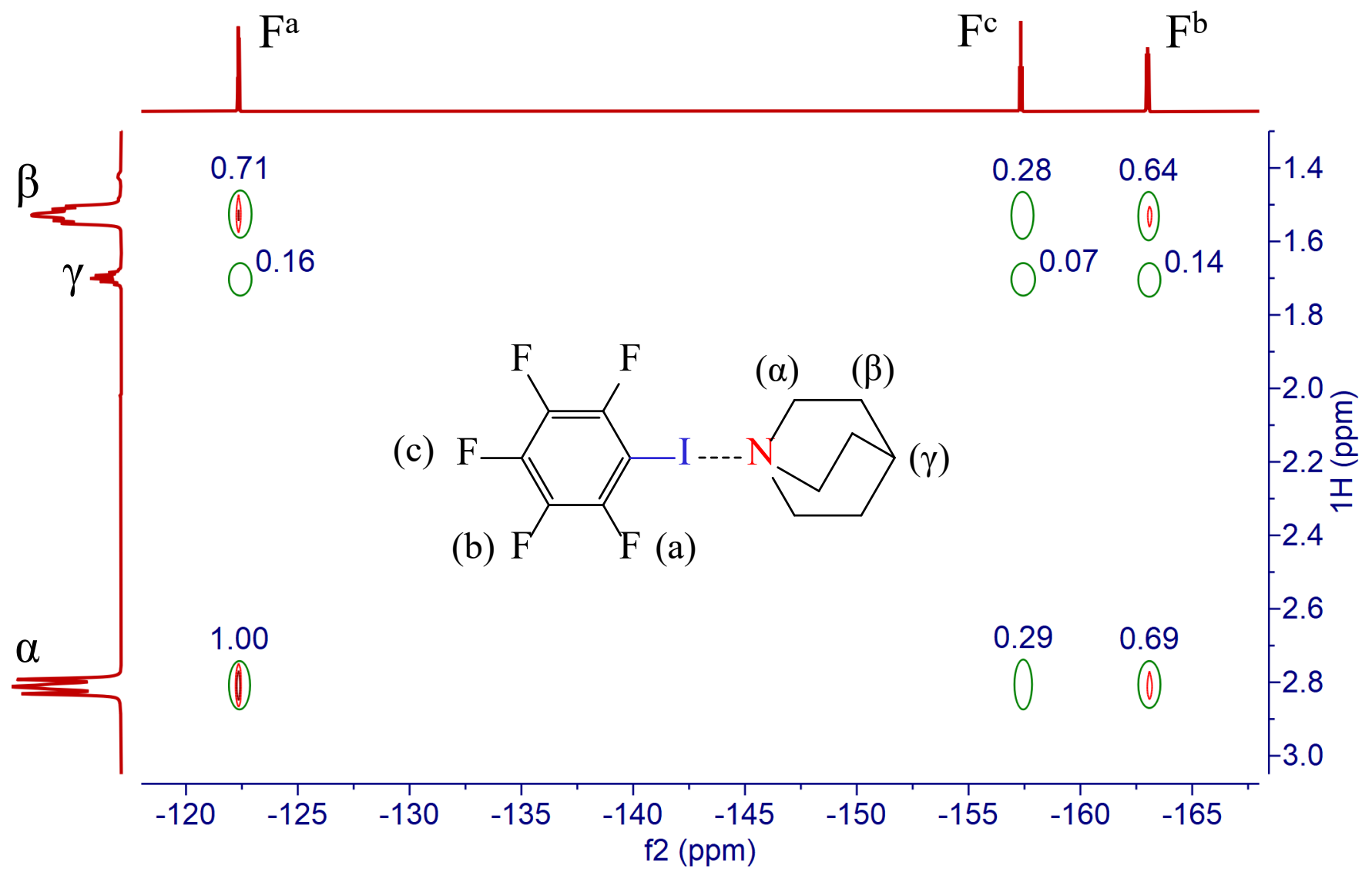

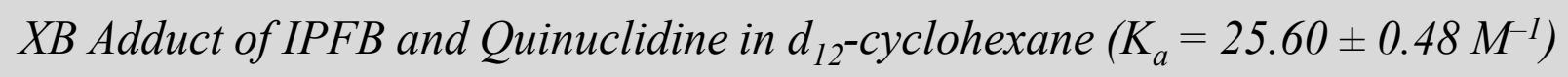

$\begin{array}{cccc} & \mathrm{F}^{\mathrm{a}} & \mathrm{F}^{\mathrm{b}} & \mathrm{F}^{\mathrm{c}} \\ \alpha & 1.00 & 0.69 & 0.29 \\ \beta & 0.71 & 0.64 & 0.28 \\ \gamma & 0.16 & 0.14 & 0.07\end{array}$

Figure S3. ${ }^{19} \mathrm{~F}-{ }^{1} \mathrm{H}$ HOESY spectrum and accompanying table of cross-peak intensities of the XB adduct of XB donor iodopentafluorobenzene (I-PFB) $(0.0525 \mathrm{M})$ with XB acceptor quinuclidine (1.0 $\mathrm{M})$ in $\mathbf{d}_{\mathbf{1 2}}$-cyclohexane with cross peaks representing the couplings of ${ }^{19} \mathrm{~F}-{ }^{1} \mathrm{H}$ pairs. 


\section{Determination of $K_{\mathrm{a}}$ values from NMR binding isotherms (titration curves)/details:}

Non-linear regression analyses were performed to yield relevant equilibrium association constants $\left(\mathrm{K}_{\mathrm{a}}\right)$ of the XB adducts, a representation of XB strength, from the corresponding NMR binding isotherms (titration curves) based on the two following equations: ${ }^{1-3}$

$$
\begin{gathered}
\Delta \delta=\left(\delta_{\max }-\delta_{\mathrm{o}}\right) \frac{[\mathrm{DA}]}{\left[\mathrm{D}_{\mathrm{o}}\right]} \\
{[\mathrm{DA}]=\frac{1}{2}\left[\left[\mathrm{D}_{\mathrm{O}}\right]+\left[\mathrm{A}_{\mathrm{O}}\right]+\frac{1}{\mathrm{~K}_{\mathrm{a}}}-\sqrt{\left(\left[\mathrm{D}_{\mathrm{O}}\right]+\left[\mathrm{A}_{\mathrm{O}}\right]+\frac{1}{\mathrm{~K}_{\mathrm{a}}}\right)^{2}-4\left[\mathrm{D}_{\mathrm{O}}\right]\left[\mathrm{A}_{\mathrm{O}}\right]}\right]}
\end{gathered}
$$

\section{Notes:}

- $\Delta \delta$ is the observed change in NMR chemical shift of the XB donor's aromatic substituent of interest at a certain XB acceptor concentration (measured against the chemical shift at $\left[\mathrm{A}_{\mathrm{o}}\right]=0 \mathrm{M}$ ).

- $\delta_{\max }$ is the hypothetical NMR chemical shift of the fully bound XB donor ([DA] $=\max ; 100 \%$ bound).

- $\delta_{\mathrm{o}}$ is the NMR chemical shift of the free $\mathrm{XB}$ donor at $\left[\mathrm{A}_{\mathrm{o}}\right]=0 \mathrm{M}$.

- $[\mathrm{DA}]$ is the concentration of XB donor-acceptor adduct.

- $\left[\mathrm{D}_{\mathrm{o}}\right]$ is the total concentration of bound and unbound $\mathrm{XB}$ donor (this stays constant).

- $\left[\mathrm{A}_{\mathrm{o}}\right]$ is the total concentration of bound and unbound XB acceptor (this varies during titrations).

- $\mathrm{K}_{\mathrm{a}}$ is the association constant, used as a measure of the strength of the XB interaction between $\mathrm{XB}$ donor and acceptor.

In the two equations, $\delta_{\max }, \mathrm{K}_{\mathrm{a}}$, and [DA] are unknown variables, all of which are included in the expression of $\Delta \delta$. While $\delta_{\max }$ and $\mathrm{K}_{\mathrm{a}}$ are constants that are characteristic of each titration, [DA] takes on a certain value for each $\left[\mathrm{D}_{\mathrm{o}}\right]-\left[\mathrm{A}_{\mathrm{o}}\right]$ pair. Non-linear regression analyses of the binding isotherm plots will yield curve-fitted $\Delta \delta$ corresponding to each $\left[\mathrm{D}_{\mathrm{o}}\right]-\left[\mathrm{A}_{\mathrm{o}}\right]$ pair and also determine the values of $\delta_{\max }, \mathrm{K}_{\mathrm{a}}$, and [DA].

All regression analyses to determine Ka values were performed using an in-house designed Python code (pp. 8-12) that was based on curve-fitting methods reported in the literature for similar measurements. ${ }^{1-3}$ The Python program reports additional data concerning the binding isotherms not provided by other reported methods, such as percentage of XB donor that is bound and predicted $\delta_{\text {max }}$ (equation 1), and facilitates more efficient data transfer. For validation, all analyses conducted with the Python program were compared to results of using http://supramolecular.org methodology developed by Thordarson. ${ }^{1}$ 


\section{Python code for non-linear regression analysis of binding isotherms (titration curves):}

import numpy as np

import matplotlib.pyplot as plt

import seaborn as sns

from scipy.optimize import minimize

sns.set()

\section{Inputs}

\#\#\# Please input the donor concentration:

DonorConcentration $=0.0525$

\#\#\# Please input the acceptor concentrations:

AcceptorConcentrations $=n p \cdot \operatorname{array}([$

0 ,

0.0284 ,

0.0605 ,

0.1026 ,

0.2070

0.3069 ,

0.4045 ,

0.5116

0.6046 ,

0.7081 ,

])

\#\#\# Please input the chemical shifts

ActualChemicalShifts $=\mathrm{np} \cdot \operatorname{array}([$

-118.879 ,

-119.199 ,

-119.447 ,

-119.66 ,

-119.862 ,

-119.938 , 
-119.986 ,

-120.01 ,

-120.04 ,

-120.059 ,

])

\#\#\# Please input the starting point of (Predicted Ka, Predicted Delta Chemical Shift Max) for the optimization

Predicted_Ka_DeltaChemicalShiftMax $=[20,1.8]$

\section{Regression analysis functions}

def get_ $D$ (input):

res=input-input[0]

return res

def report(reportstring, input):

$\operatorname{print}\left(\mathrm{f}^{\prime} \backslash 033[1 \mathrm{~m}\right.$ \{reportstring\}: 1033[0m $\ln ['$, ", $\ln$ ".join(input.astype(str)),"]")

DeltaActualChemicalShifts $=$ get_D(ActualChemicalShifts $)$

def $\mathrm{c}(\mathrm{Ka})$ :

$\mathrm{t} 1=$ DonorConcentration + AcceptorConcentrations $+1 / \mathrm{Ka}$

$\mathrm{t} 2=4 *$ DonorConcentration * AcceptorConcentrations

DonorAcceptorAdductConcentration $=1 / 2 *(\mathrm{t} 1-\mathrm{np} \cdot \operatorname{sqrt}(\mathrm{np} \cdot$ power(t1, 2) $-\mathrm{t} 2))$

return DonorAcceptorAdductConcentration

def c_PercentageBound(Ka):

return $\mathrm{c}(\mathrm{Ka}) /$ DonorConcentration*100

def $\mathrm{d}$ (DeltaChemicalShiftMax, Ka):

return DeltaChemicalShiftMax * $\mathrm{c}(\mathrm{Ka}) * 1 /$ DonorConcentration

def opt_func(params):

$\mathrm{Ka}=$ params$[0]$

DeltaChemicalShiftMax $=$ params[1]

return np.sqrt(np.sum(np.power(DeltaActualChemicalShifts - d(DeltaChemicalShiftMax, Ka), 2)))

res $=$ minimize(opt_func, Predicted_Ka_DeltaChemicalShiftMax, method="nelder-mead", options $=\{$ "xatol": 1e-8, "disp": True $\}$ )

Ka, DeltaChemicalShiftMax $=$ res. $x$ 


\section{Outputs}

print('\033[1m Ka: $1033[0 \mathrm{~m}$ ',round(Ka,3))

print(' $1033[1 \mathrm{~m}$ Delta Chemical Shift $(\Delta \delta)$ Max: $1033[0 \mathrm{~m}$ ',round(DeltaChemicalShiftMax,3))

$\operatorname{print}(' 1033[1 \mathrm{~m}$ Donor Concentration $\backslash 033[0 \mathrm{~m}$ ',DonorConcentration)

report('Acceptor Concentrations',AcceptorConcentrations.round(3))

report('Actual Chemical Shifts ( $\delta$ )',ActualChemicalShifts)

report('Actual Delta Chemical Shifts $(\Delta \delta)$ ',DeltaActualChemicalShifts.round(3))

report('Calculated Chemical Shifts

(ס)',(ActualChemicalShifts[0]+d(DeltaChemicalShiftMax,Ka)).round(3))

report('Calculated Delta Chemical Shifts $(\Delta \delta)$ ',d(DeltaChemicalShiftMax, Ka).round(3))

report('Donor-Acceptor Adduct Concentration',c(Ka).round(4))

report('Percentage of Donor Bound',c_PercentageBound(Ka).round(4))

$\mathrm{ax}=$ plt.plot(AcceptorConcentrations, $\mathrm{d}($ DeltaChemicalShiftMax, Ka),color='r')

plt.scatter(AcceptorConcentrations, DeltaActualChemicalShifts)

Ka: 23.2

Delta Chemical Shift $(\Delta \delta)$ Max: -1.245

Donor Concentration 0.0525

Acceptor Concentrations:

$[0.0$,

0.028

0.06 ,

0.103 ,

0.207 ,

0.307 ,

0.404 ,

0.512 ,

0.605 ,

0.708 ]

Actual Chemical Shifts ( $\delta$ ):

[-118.879, 
-119.199 ,

-119.447 ,

-119.66 ,

-119.862 ,

-119.938 ,

-119.986 ,

-120.01 ,

-120.04 ,

-120.059 ]

Actual Delta Chemical Shifts $(\Delta \delta)$ :

[0.0,

-0.32 ,

-0.568 ,

-0.781 ,

-0.983 ,

-1.059 ,

-1.107 ,

-1.131 ,

-1.161 ,

$-1.18]$

Calculated Chemical Shifts (ס):

[-118.879,

-119.199 ,

-119.449 ,

-119.65 ,

-119.866 ,

-119.948 ,

-119.99 ,

-120.018 ,

-120.034 ,

-120.047 ]

Calculated Delta Chemical Shifts $(\Delta \delta)$ :

[ -0.0 ,

-0.32 ,

-0.57 ,

-0.771 ,

-0.987 ,

-1.069 ,

-1.111 ,

-1.139 ,

-1.155 ,

-1.168 ]

Donor-Acceptor Adduct Concentration:

[0.0, 
0.0135 ,

0.0241 ,

0.0325 ,

0.0416 ,

0.0451 ,

0.0469 ,

0.048 ,

0.0487 ,

0.0493 ]

Percentage of Donor Bound:

[0.0,

25.6987,

45.816,

61.9211,

79.3229,

85.8643,

89.2443,

91.4928,

92.8039,

93.8593 ] 

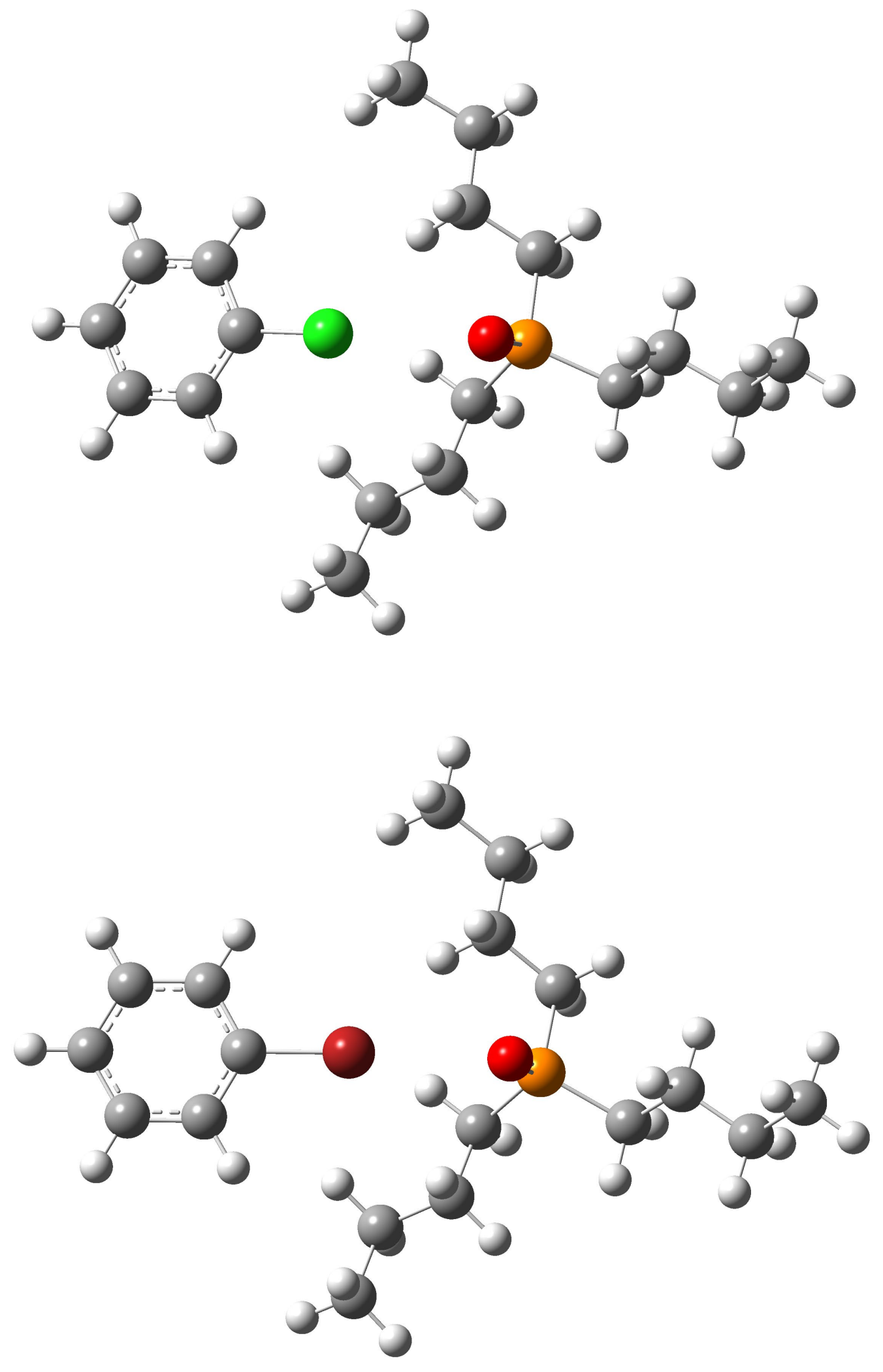

Figure S4. Geometry optimized $\mathrm{XB}$ adducts of $\mathrm{XB}$ acceptor tributylphosphine oxide $\left(\mathrm{Bu}_{3} \mathbf{P O}\right)$ with $\mathrm{XB}$ donors chlorobenzene (top) and bromobenzene (bottom). 


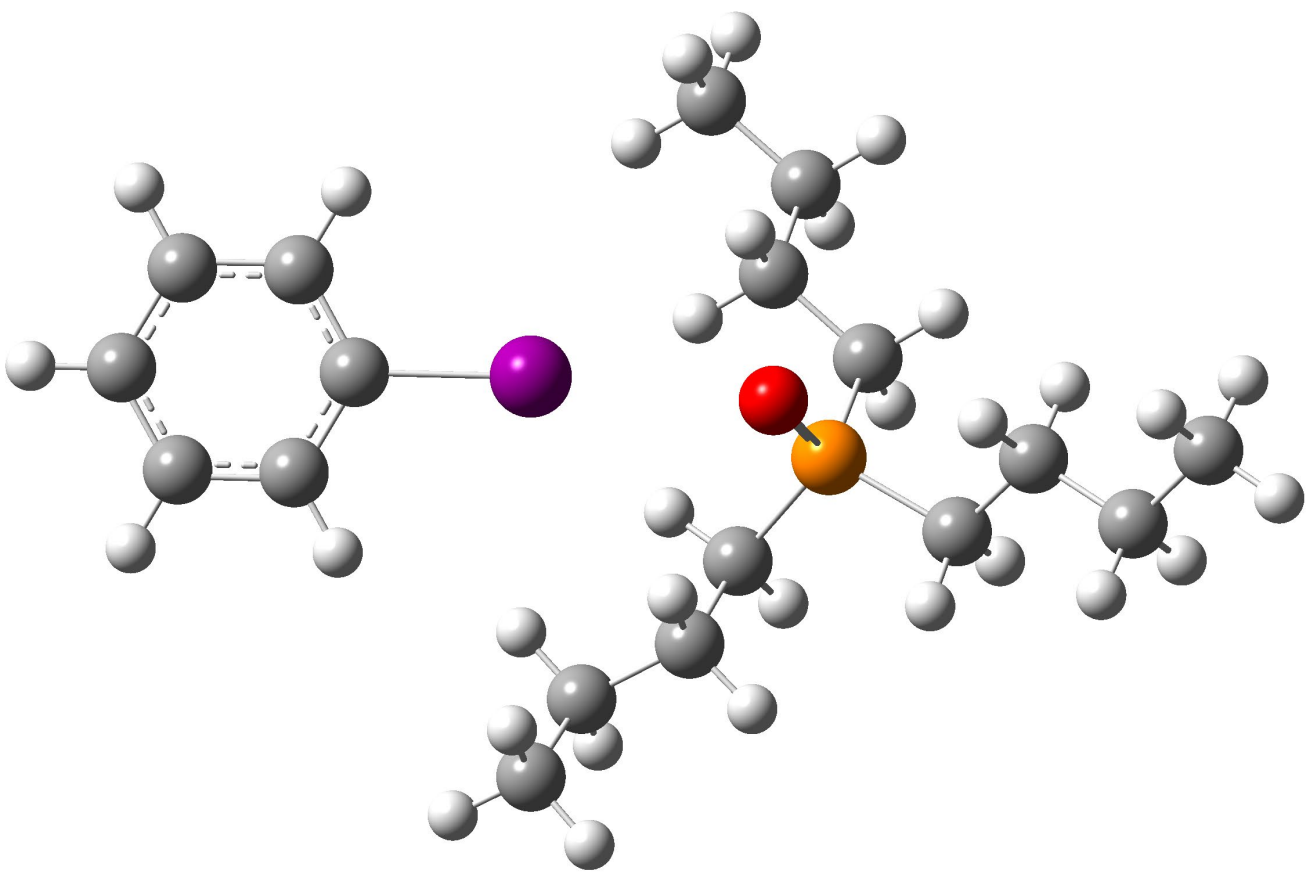

Figure S5. Geometry optimized $X B$ adduct of $X B$ acceptor tributylphosphine oxide $\left(\mathbf{B u}_{\mathbf{3}} \mathbf{P O}\right)$ with XB donor iodobenzene. 

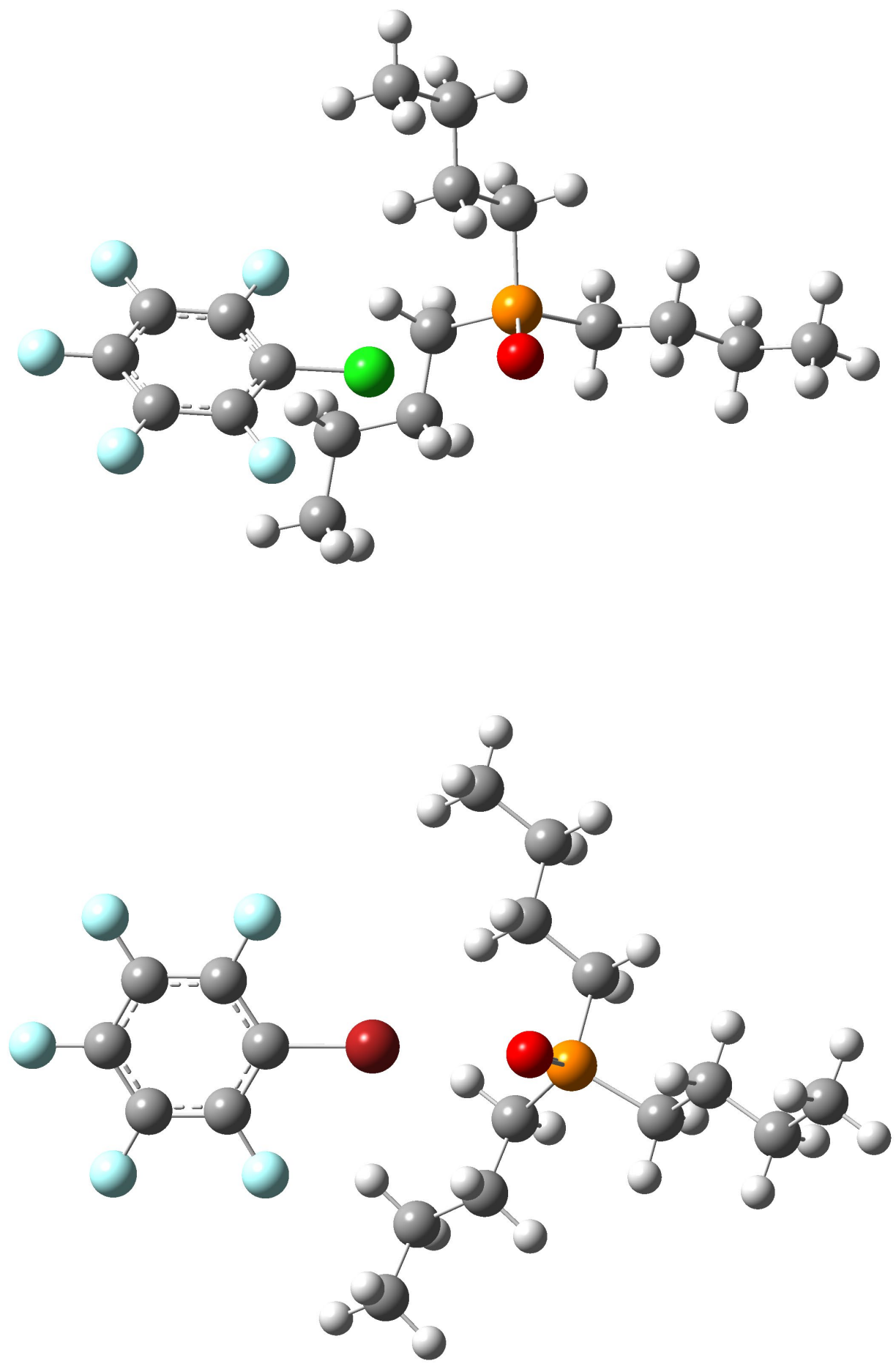

Figure S6. Geometry optimized $\mathrm{XB}$ adducts of $\mathrm{XB}$ acceptor tributylphosphine oxide $\left(\mathrm{Bu}_{3} \mathbf{P O}\right)$ with $\mathrm{XB}$ donors chloropentafluorobenzene (Cl-PFB) (top) and bromopentafluorobenzene (Br-PFB) (bottom). 


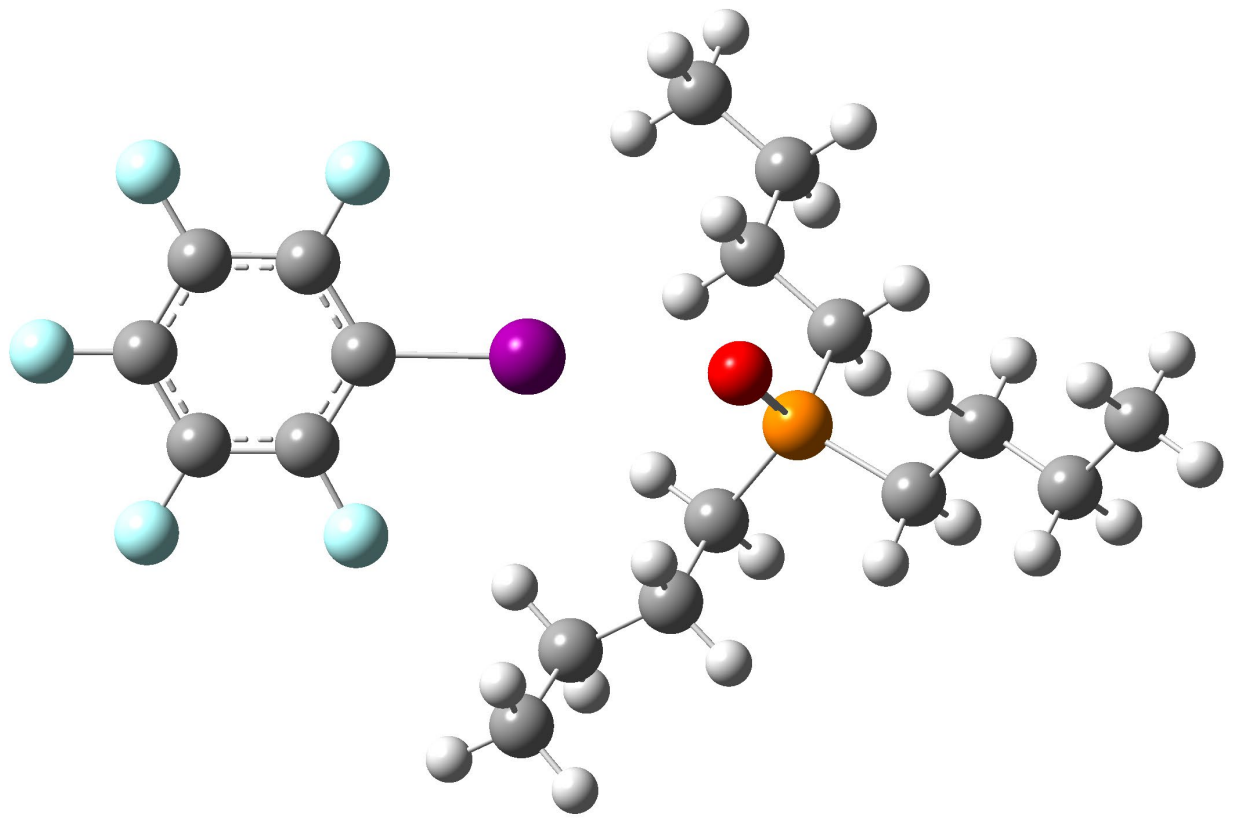

Figure S7. Geometry optimized $\mathrm{XB}$ adduct of $\mathrm{XB}$ acceptor tributylphosphine oxide $\left(\mathbf{B u}_{\mathbf{3}} \mathbf{P O}\right)$ with $\mathrm{XB}$ donor iodopentafluorobenzene (I-PFB). 

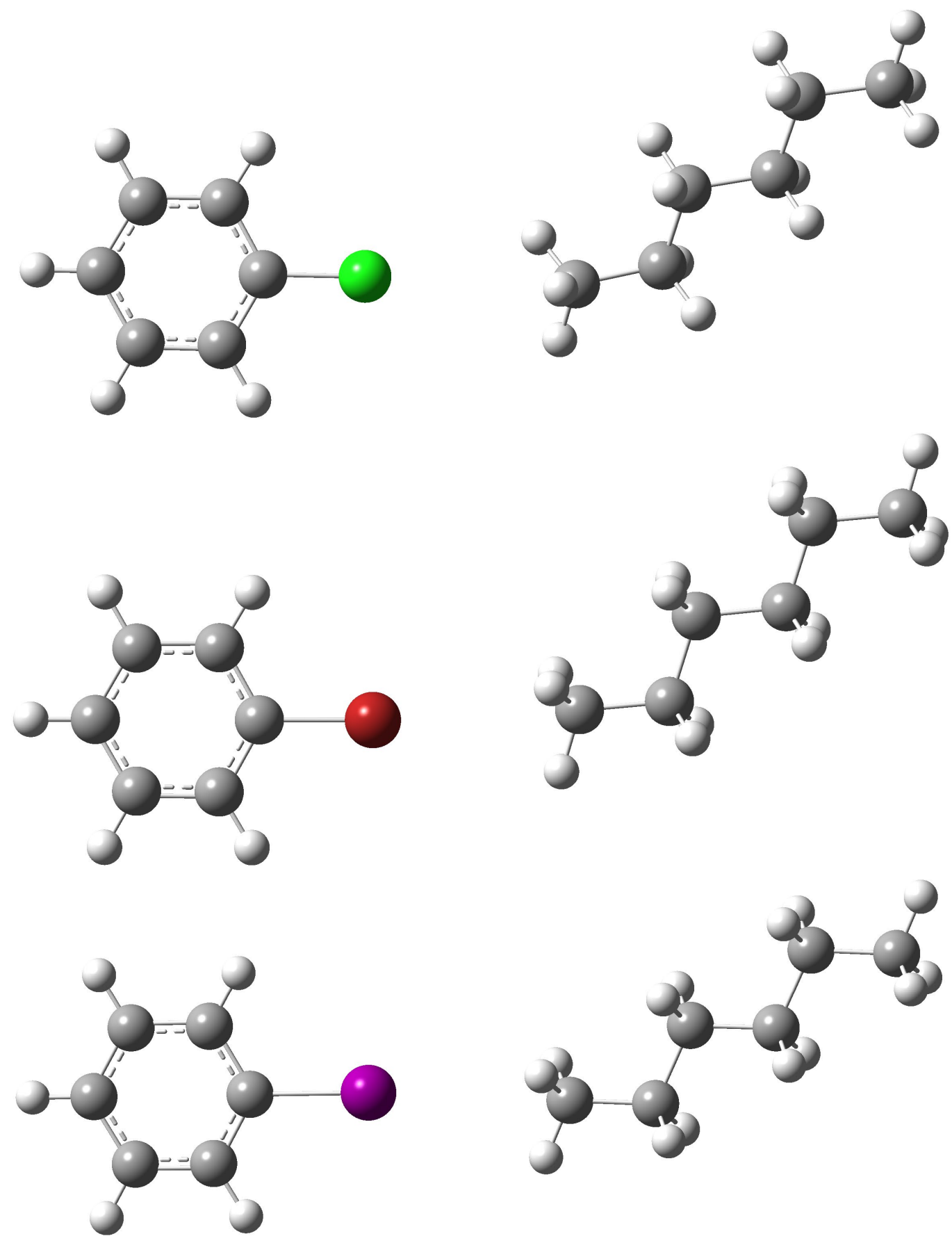

Control Adducts with Hexane

$$
\Delta \mathrm{E}_{\text {int }}(\mathrm{kcal} / \mathrm{mol}) \quad \mathrm{X}-\mathrm{B} \text { bond distance }(\AA) \quad \mathrm{R}-\mathrm{X}-\mathrm{B} \text { bond angle }(\theta)
$$

$\begin{array}{cccc}\text { Chlorobenzene } & -0.06 & 3.60 & 177.0 \\ \text { Bromobenzene } & -0.10 & 3.49 & 177.0 \\ \text { Iodobenzene } & -0.14 & 3.58 & 177.1\end{array}$

Figure S8. Geometry optimized control adducts of hexane with XB donors chlorobenzene (top), bromobenzene (middle), and iodobenzene (bottom). 

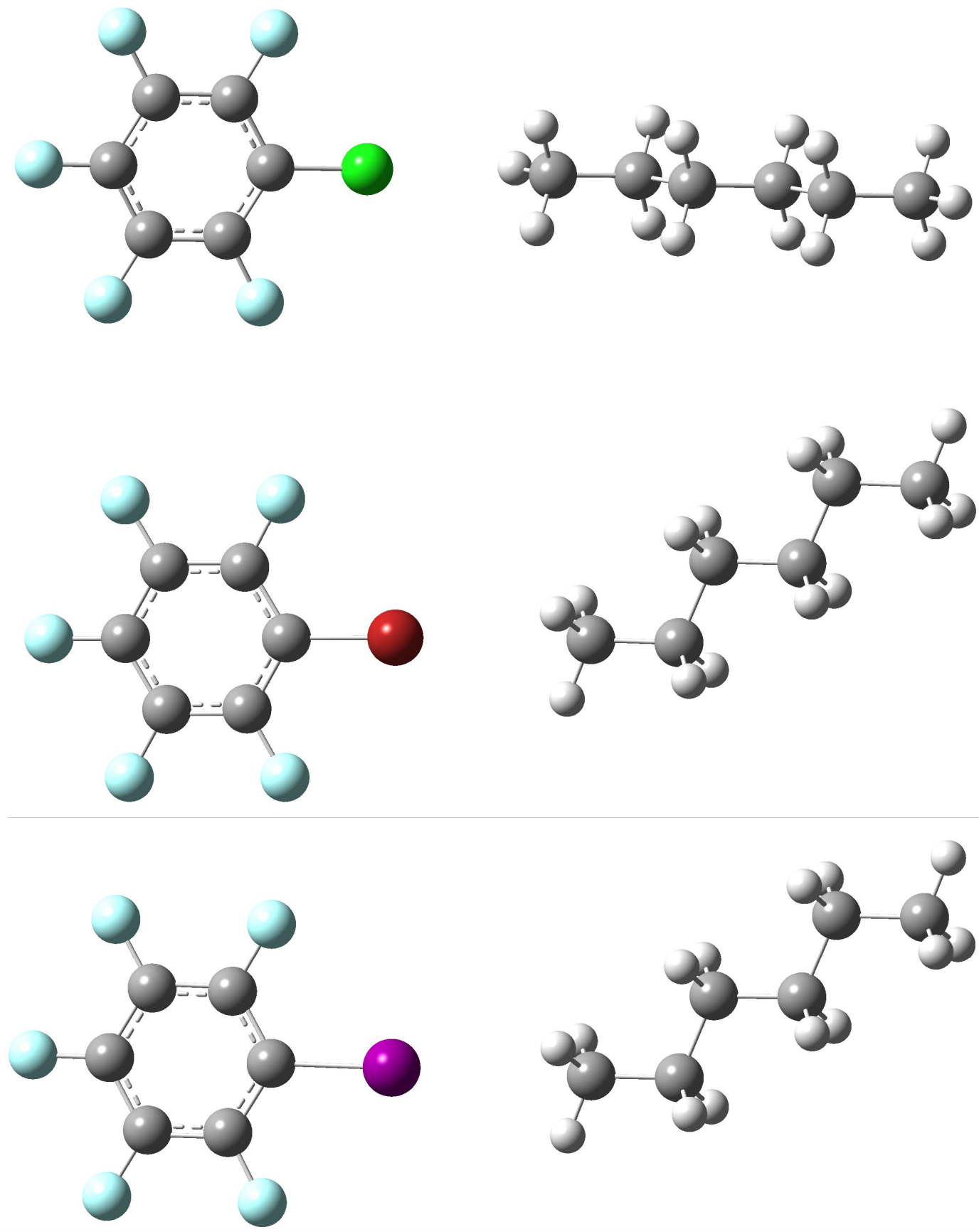

Control Adducts with Hexane

$$
\Delta \mathrm{E}_{\text {int }}(\mathrm{kcal} / \mathrm{mol}) \quad \mathrm{X}-\mathrm{B} \text { bond distance }(\AA) \quad \mathrm{R}-\mathrm{X}-\mathrm{B} \text { bond angle }(\theta)
$$

$\begin{array}{cccc}\text { Cl-PFB } & -0.10 & 3.34 & 177.3 \\ \text { Br-PFB } & -0.14 & 3.39 & 179.2 \\ \text { I-PFB } & -0.19 & 3.46 & 179.2\end{array}$

Figure S9. Geometry optimized control adducts of hexane with XB donors chloropentafluorobenzene (Cl-PFB) (top), bromopentafluorobenzene (Br-PFB) (middle), and iodopentafluorobenzene (bottom). 


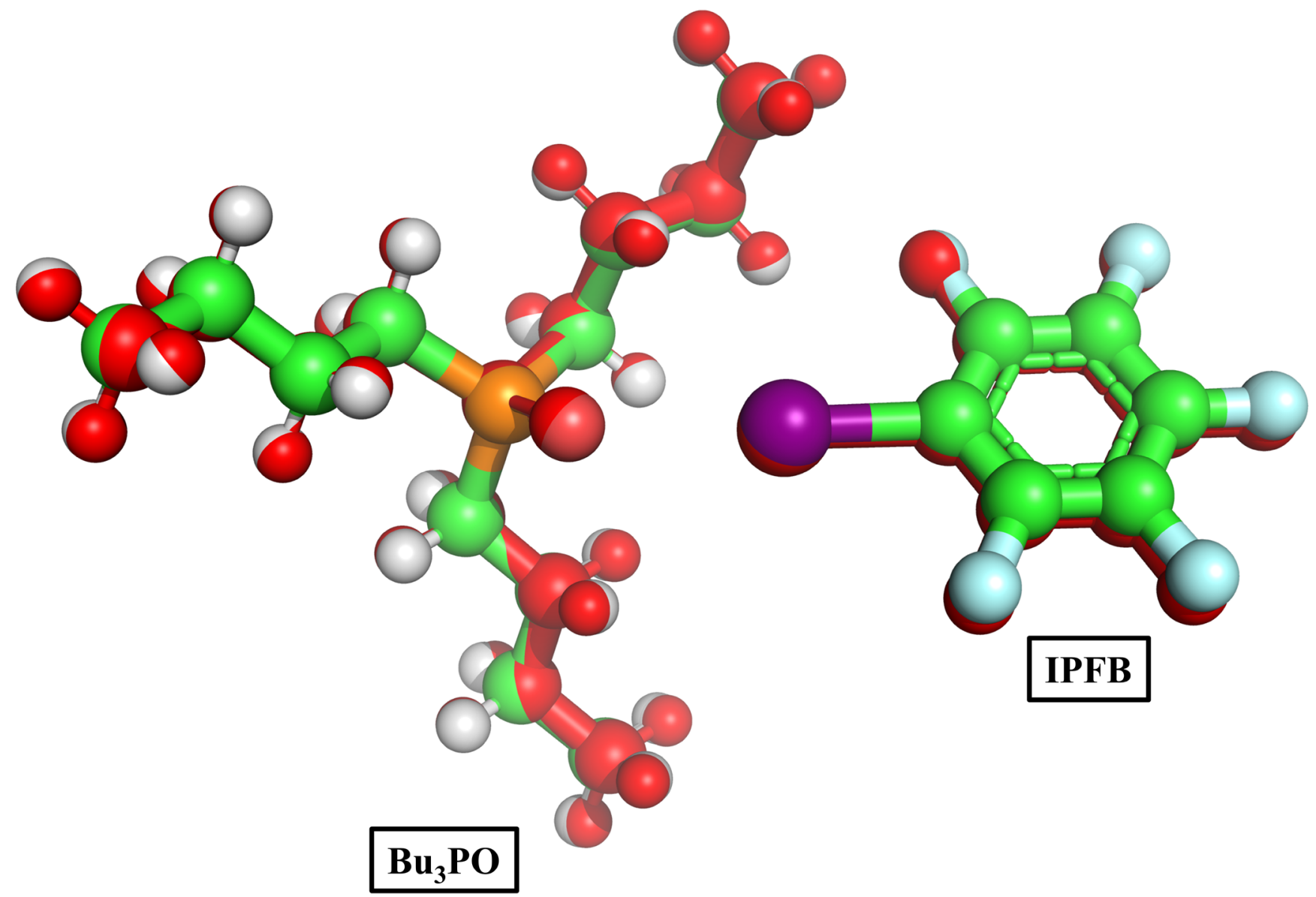

Figure S10. Superimposition of gas-phase geometry optimized XB adduct (red) of XB acceptor tributylphosphine oxide $\left(\mathrm{Bu}_{3} \mathrm{PO}\right)$ with $\mathrm{XB}$ donor iodopentafluorobenzene (I-PFB) on geometries optimized in PCM cyclohexane (RMSD $=0.100 \AA$ ), benzene $($ RMSD $=0.105 \AA)$, carbon tetrachloride $(\mathrm{RMSD}=0.105 \AA)$, and diethyl ether $(\mathrm{RMSD}=0.105 \AA)$.

Table S2. A Comparison of Gas-phase and PCM Solvent-phase Interaction Energies $\left(\Delta \mathrm{E}_{\text {int }}\right)$, Bond Distances, and Bond Angles of XB Adduct of XB Donor IPFB and XB Acceptor $\mathrm{Bu}_{3} \mathrm{PO}$ at the M062X/cc-pVTZ//MO6-2X/cc-pVDZ level of theory.

Solvent (e)

None (gas-phase)

Cyclohexane (2.02)

Benzene (2.27)

Carbon tetrachloride (2.23)

Diethyl ether (4.24)

Chloroform (4.71)
$\Delta \mathrm{E}_{\text {int }}$ ( $\mathrm{kcal} / \mathrm{mol})$

$-10.95$

$-9.76$

$-9.60$

$-9.60$

$-8.81$

$-8.55$
$\mathrm{X}-\mathrm{B}$ distance

(A)

2.74

2.72

2.72

2.72

2.72

2.72
$\mathrm{R}-\mathrm{X}-\mathrm{B}$ angle

$(\theta)$

175.9

176.8

176.9

176.9

177.3

177.2 
(c)<smiles>Clc1ccccc1</smiles>

(b) (a)
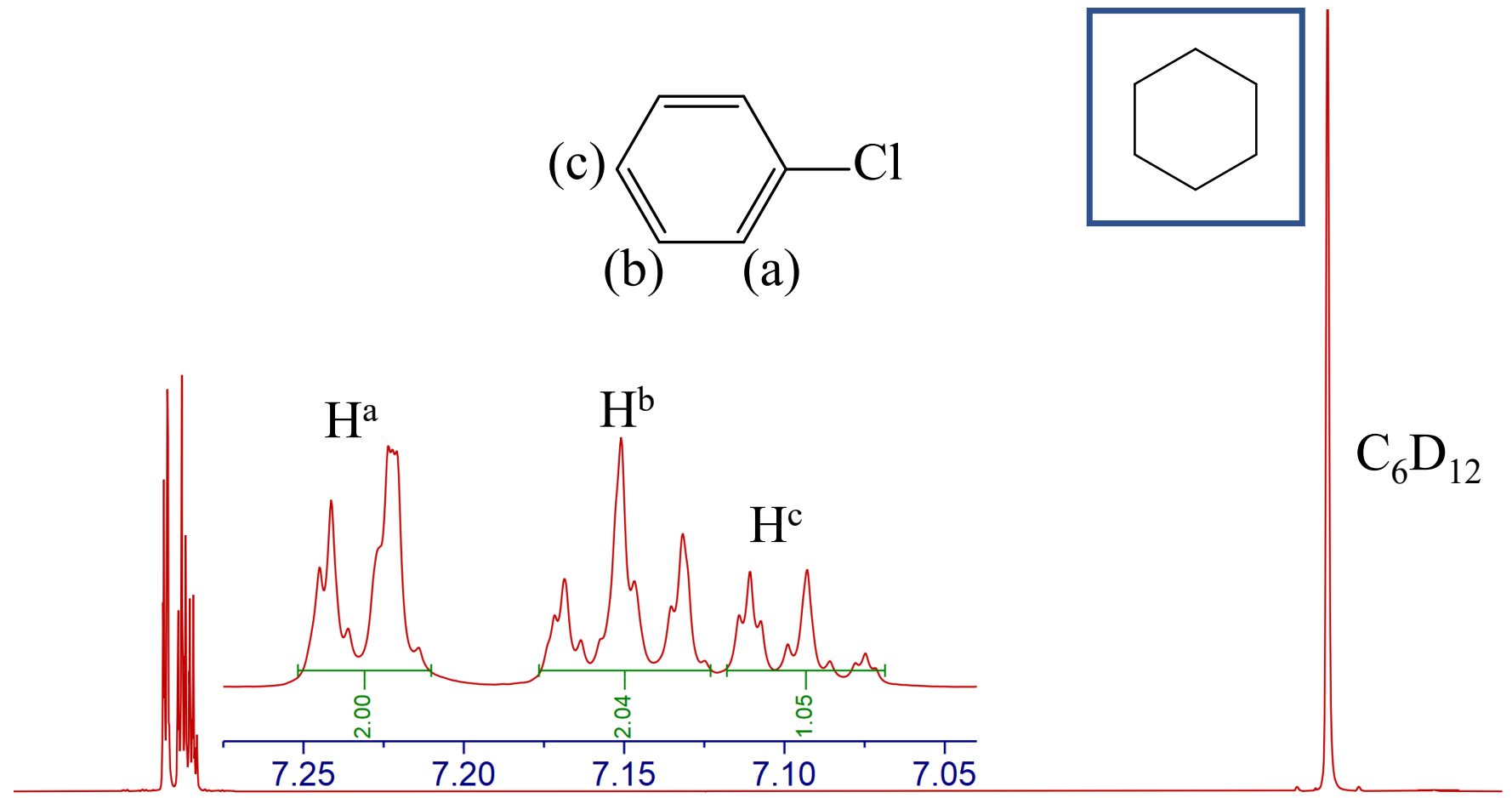

\begin{tabular}{|c|c|c|c|c|c|c|c|c|c|c|c|c|c|c|}
\hline 0 & 7.5 & 7.0 & 6.5 & 6.0 & 5.5 & 5.0 & $\begin{array}{l}4.5 \\
\text { f1 }\end{array}$ & $\begin{array}{l}4.0 \\
\mathrm{pm})\end{array}$ & 3.5 & 3.0 & 2.5 & 2.0 & 1.5 & 1.0 \\
\hline
\end{tabular}

(c)

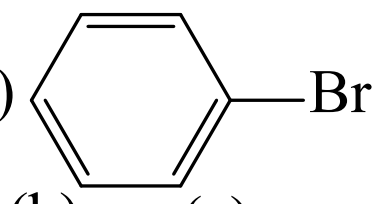

(b)

(a)
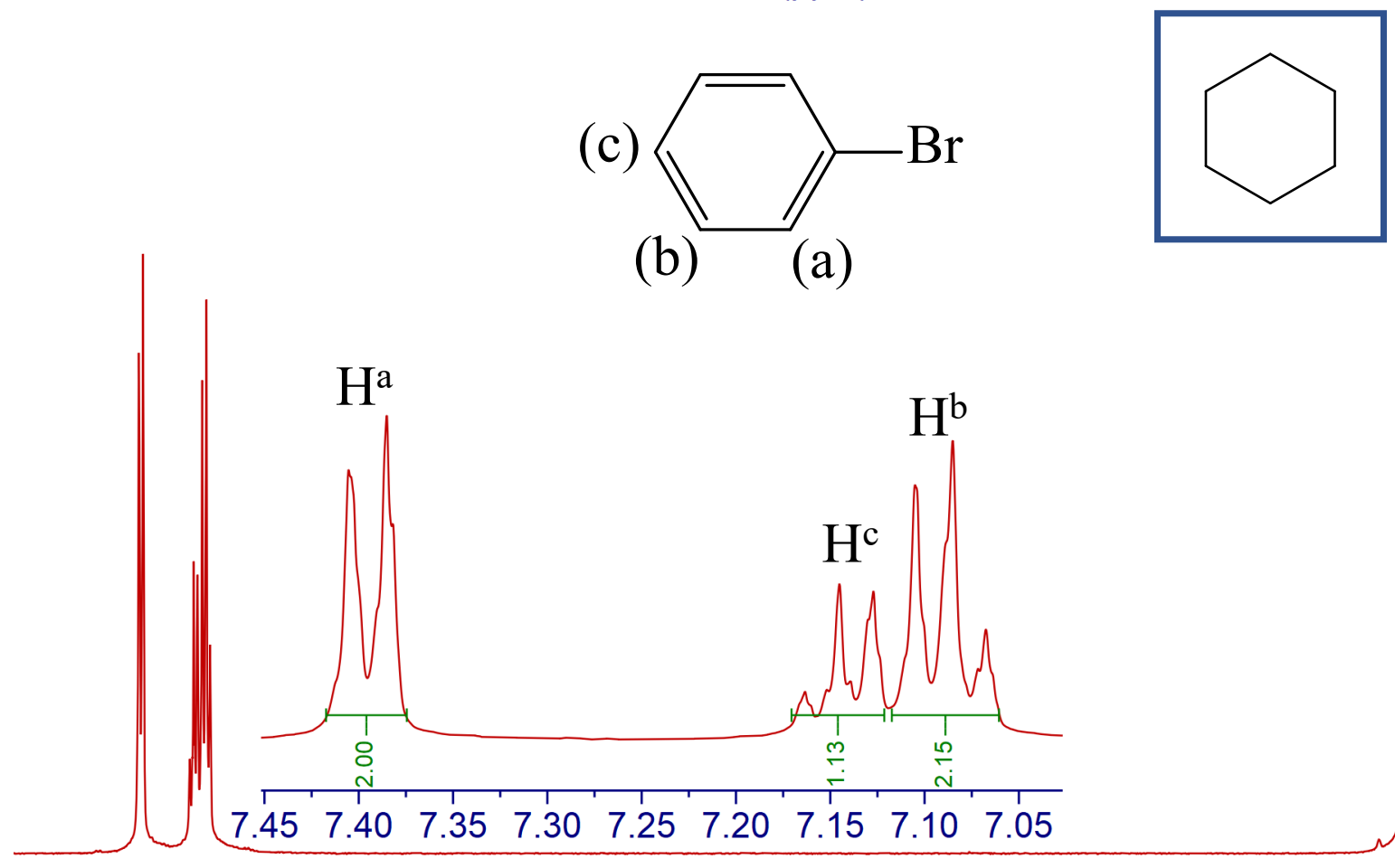

$\mathrm{C}_{6} \mathrm{D}_{12}$

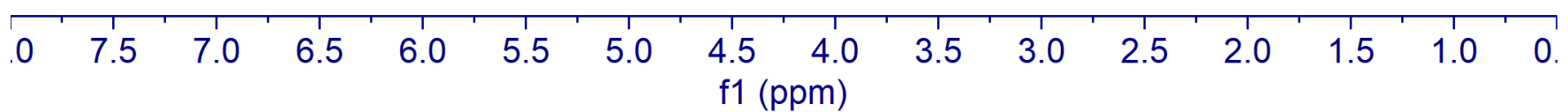

Figure S11. ${ }^{1} \mathrm{H}$ spectra of $0.05 \mathrm{M}$ chlorobenzene (top) and $0.0475 \mathrm{M}$ bromobenzene (bottom) in $\mathbf{d}_{12^{-}}$ cyclohexane at $298 \mathrm{~K}$. 


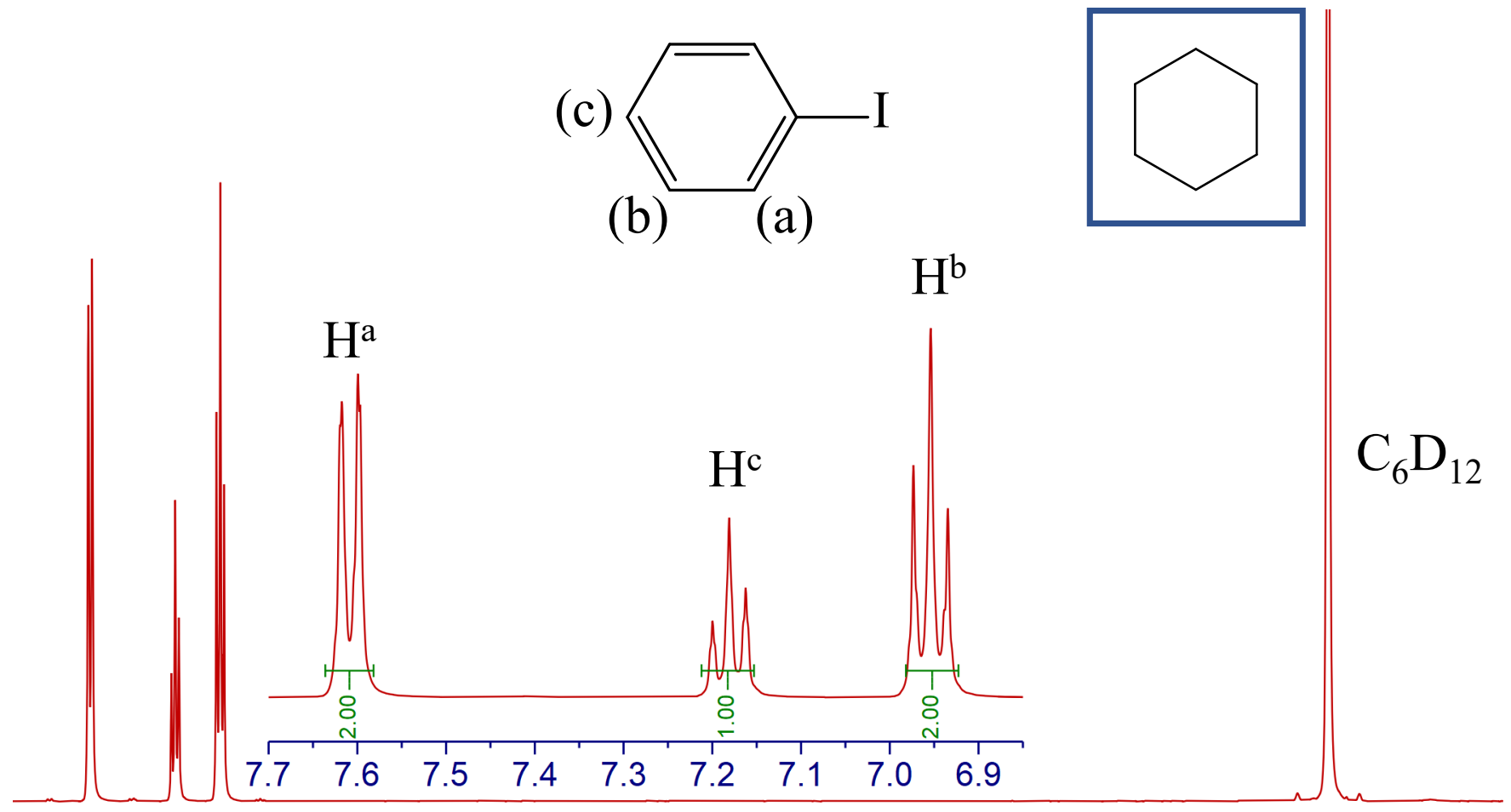

\begin{tabular}{|c|c|c|c|c|c|c|c|c|c|c|c|c|c|c|}
\hline 0 & 7.5 & 7.0 & 6.5 & 6.0 & 5.5 & 5.0 & $\begin{array}{c}4.5 \\
\mathrm{f} 1\end{array}$ & $\begin{array}{r}4.0 \\
\text { ppm) }\end{array}$ & 3.5 & 3.0 & 2.5 & 2.0 & 1.5 & 1.0 \\
\hline
\end{tabular}

Figure S12. ${ }^{1} \mathrm{H}$ spectra of $0.05 \mathrm{M}$ iodobenzene (top) in $\mathbf{d}_{\mathbf{1 2}}$-cyclohexane at $298 \mathrm{~K}$. 

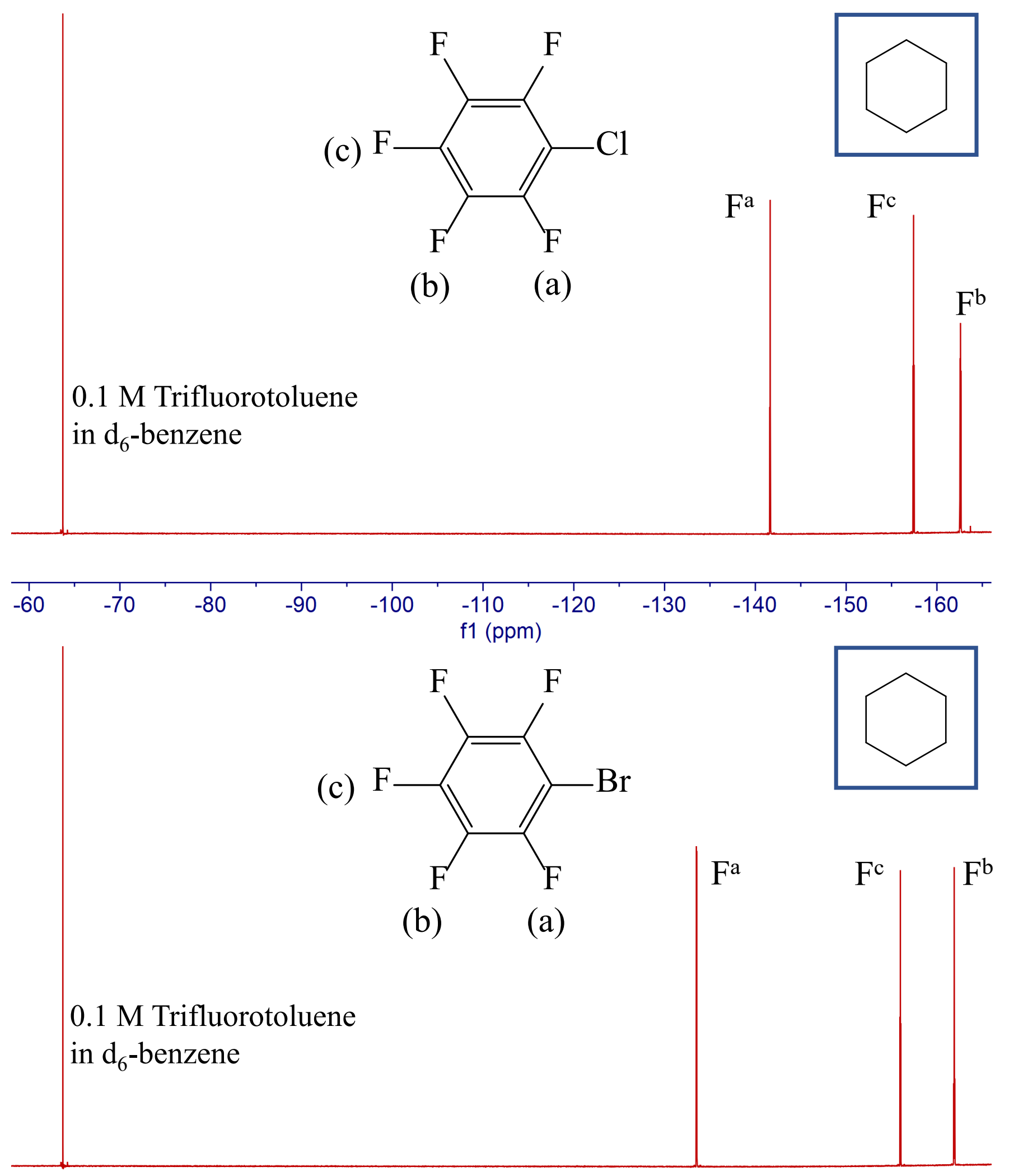

\begin{tabular}{|c|c|c|c|c|c|c|c|c|c|c|}
\hline-60 & -70 & -80 & -90 & -100 & $\begin{array}{l}-110 \\
\mathrm{f1}(\mathrm{ppm})\end{array}$ & -120 & -130 & -140 & -150 & -160 \\
\hline
\end{tabular}

Figure S13. ${ }^{19} \mathrm{~F}$ spectra of $0.0475 \mathrm{M}$ chloropentafluorobenzene (top) and $0.052 \mathrm{M}$ bromopentafluorobenzene (bottom) in cyclohexane at $298 \mathrm{~K}$. 


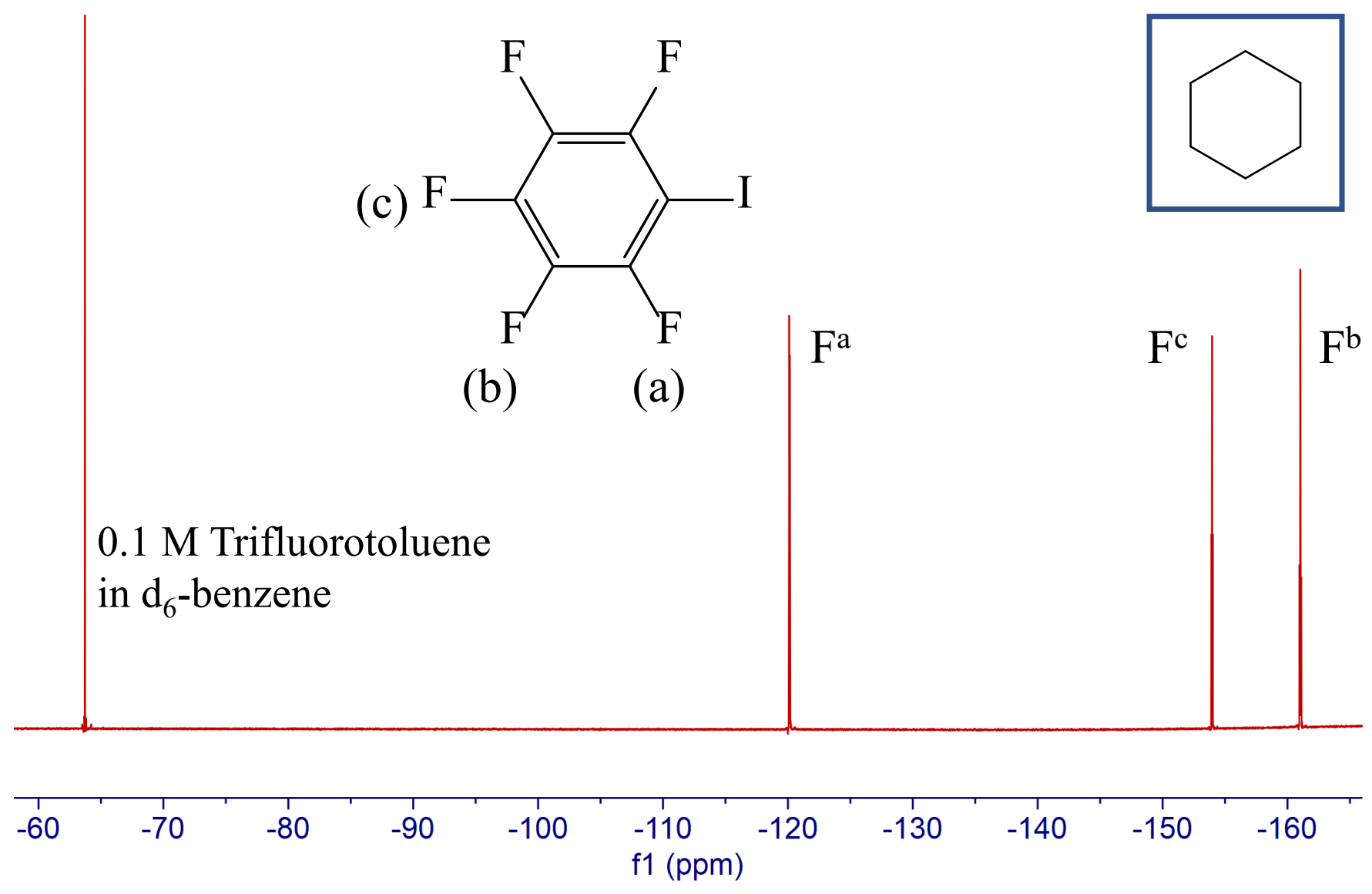

Figure S14. ${ }^{19} \mathrm{~F}$ spectra of $0.0525 \mathrm{M}$ iodopentafluorobenzene (top) in cyclohexane at $298 \mathrm{~K}$. 


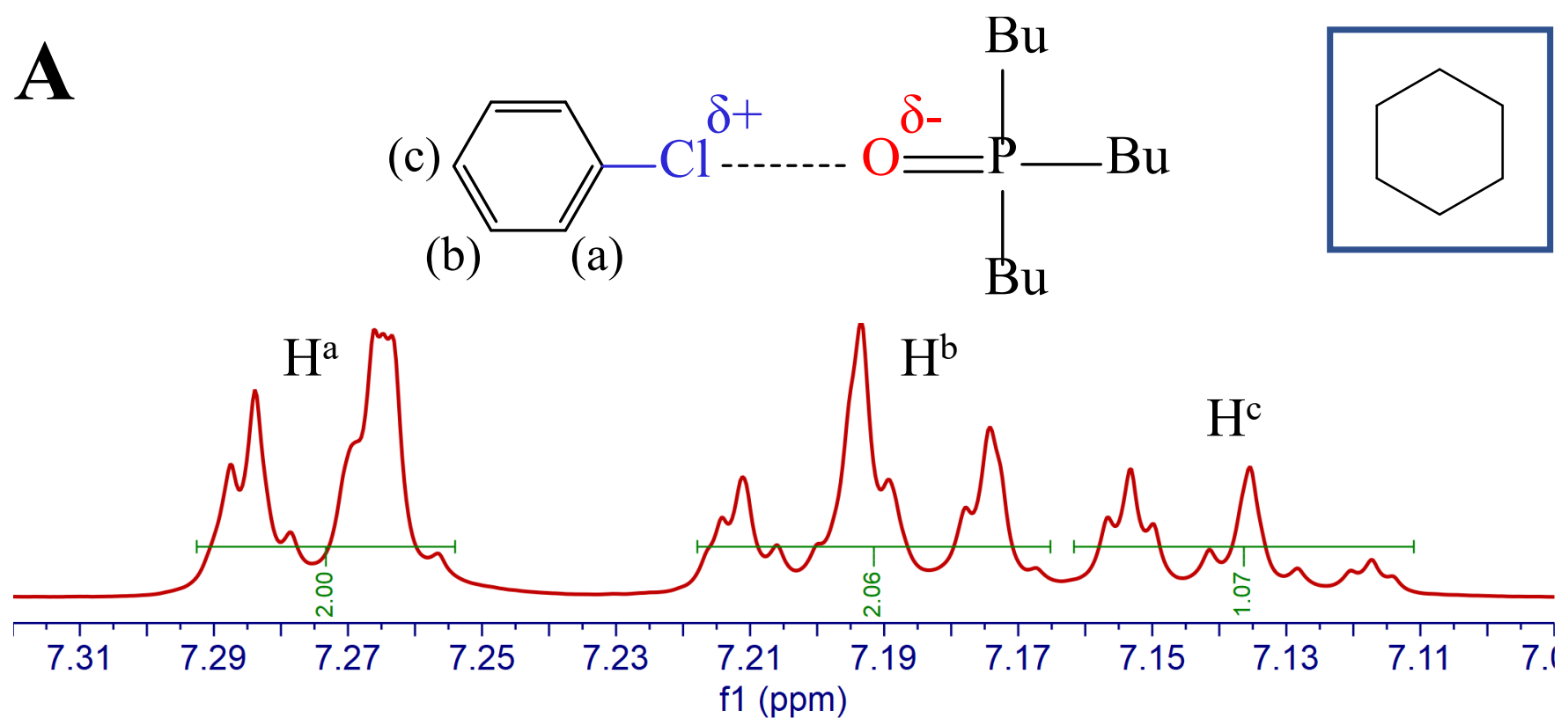

B
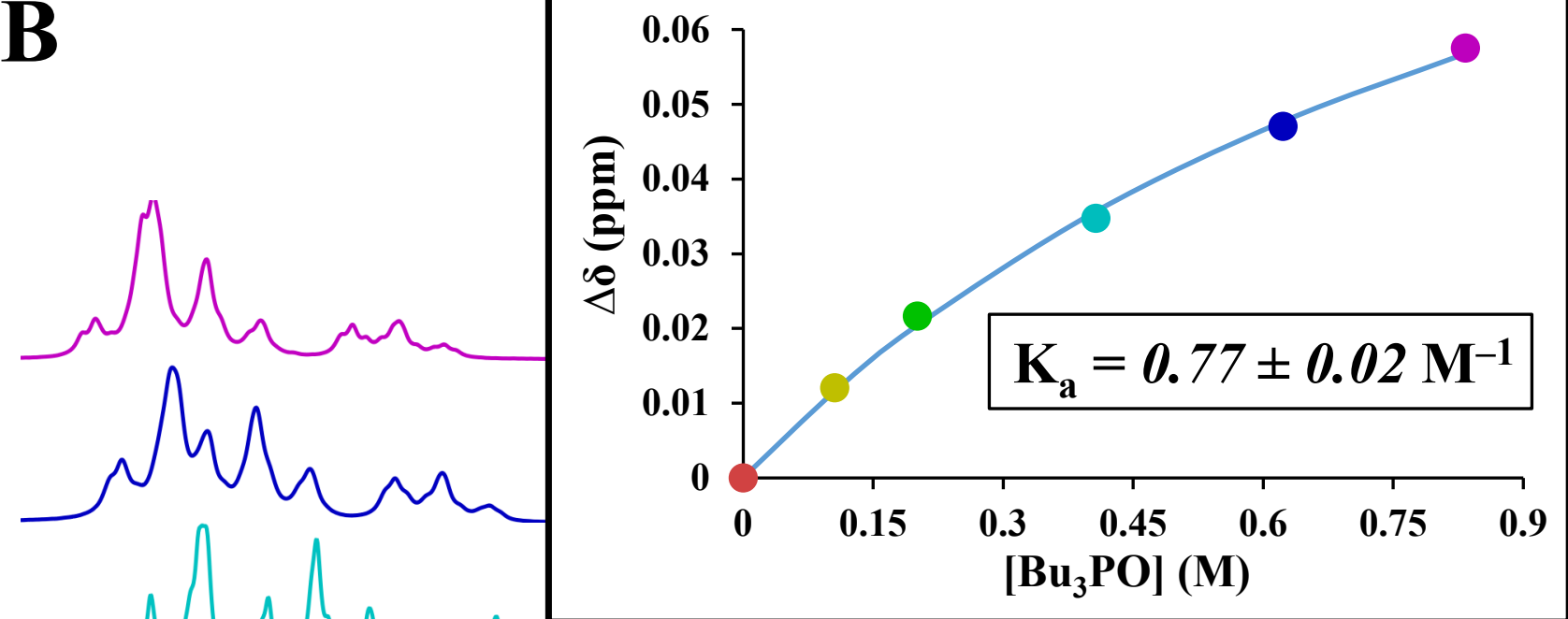

6
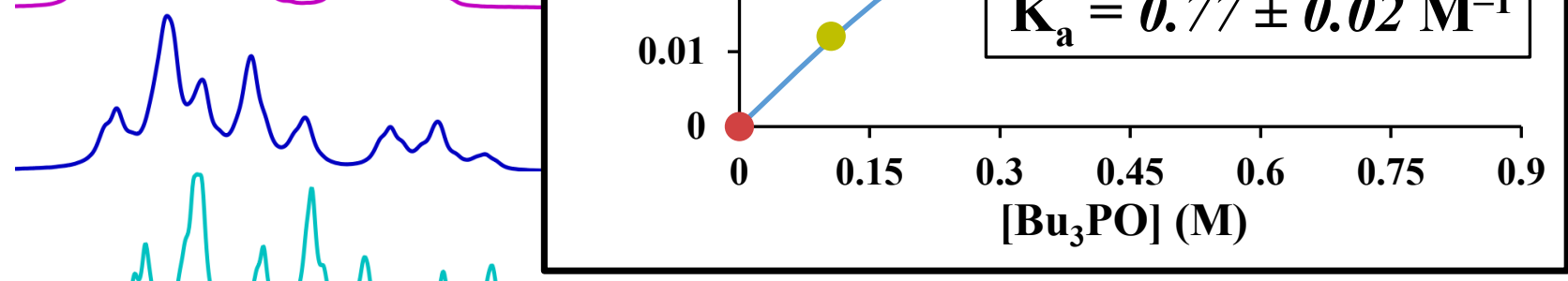

$-5$

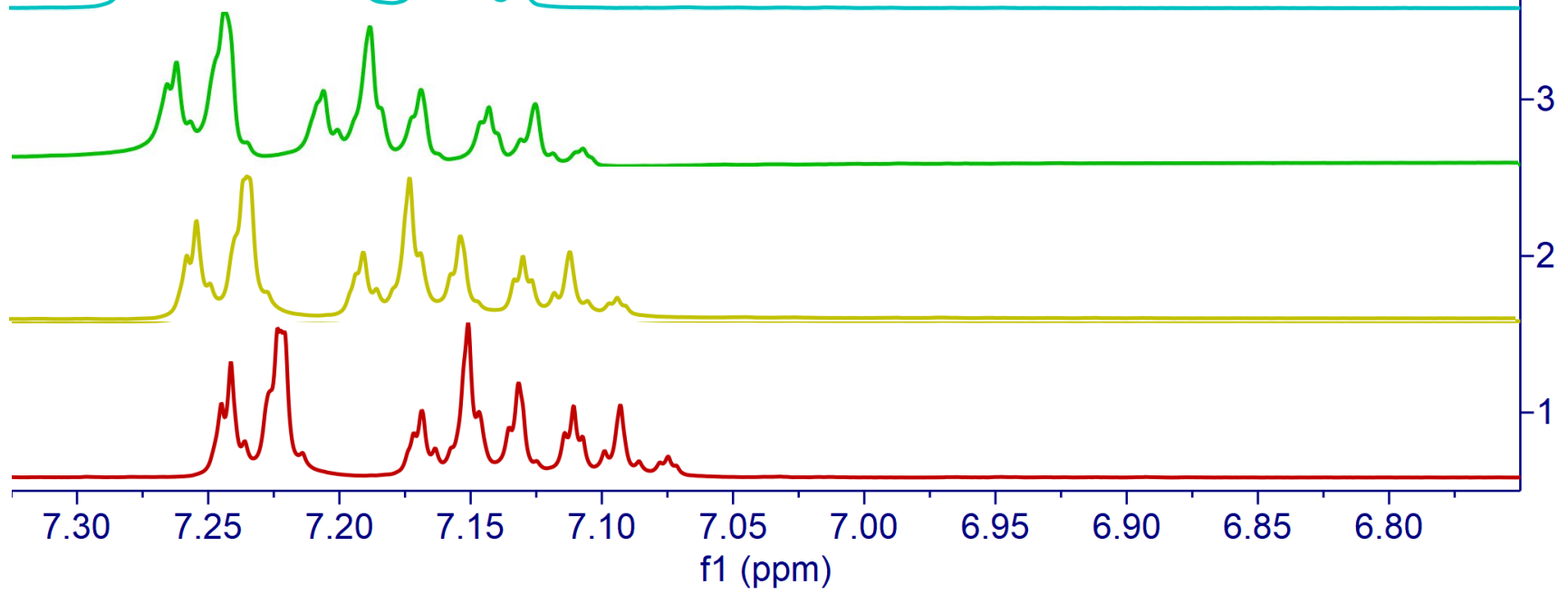

Figure S15. Representative NMR-titration experiment for XB donor chlorobenzene (0.05M) titrated with $\mathrm{XB}$ acceptor tributylphosphine oxide $\left(\mathbf{B u}_{\mathbf{3}} \mathbf{P O}\right)$ including (A) initial ${ }^{1} \mathrm{H}$ NMR spectrum of chlorobenzene prior to titration and (B) the change in the ortho $\mathrm{H}$ resonance shifts during addition of increasing concentrations of $\mathbf{B u}_{\mathbf{3}} \mathbf{P O}$ and the corresponding binding isotherm (inset) used for non-linear regression analysis and determination of the association constant $\left(\mathrm{K}_{\mathrm{a}}\right)$ that reflects $\mathrm{XB}$ interaction strength of the adduct (Solvent: $\mathbf{d}_{12}$-cyclohexane). 
(c)

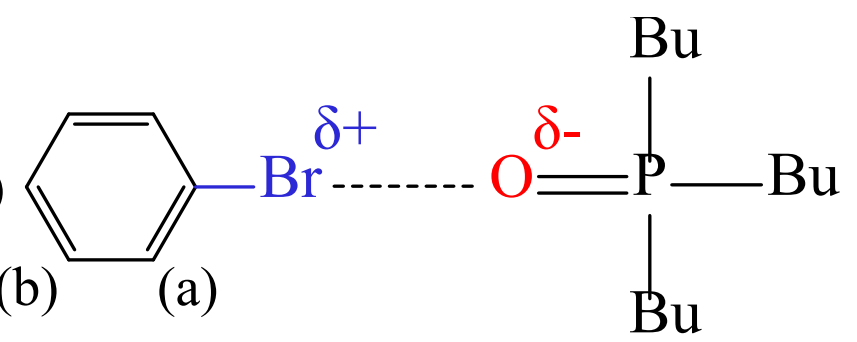

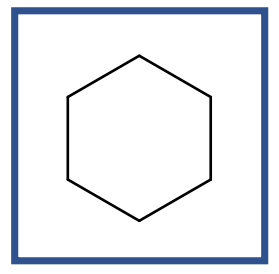

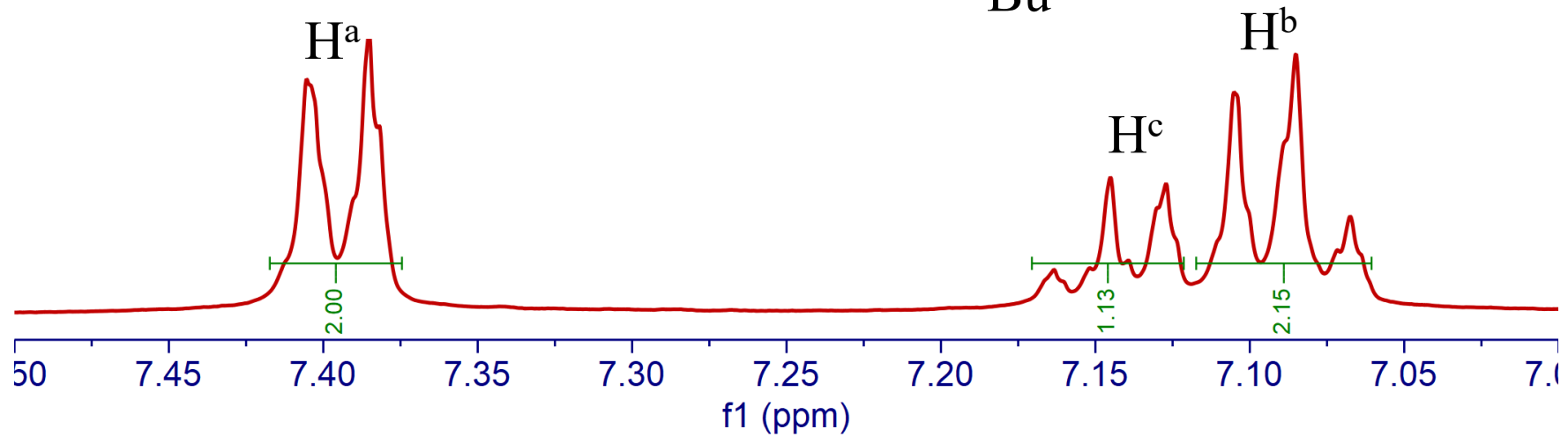

B

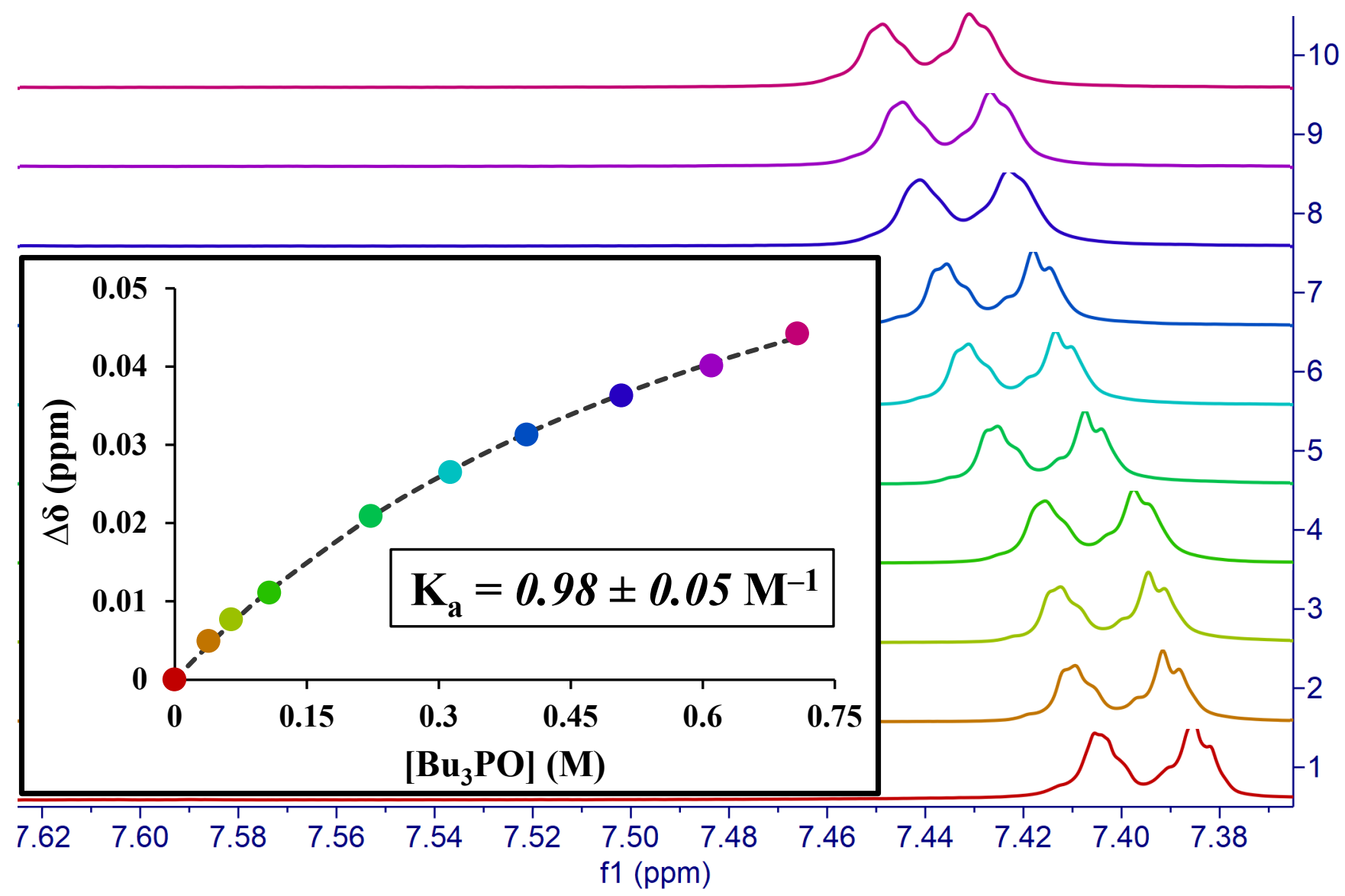

Figure S16. Representative NMR-titration experiment for XB donor bromobenzene $(0.0475 \mathrm{M})$ titrated with $\mathrm{XB}$ acceptor tributylphosphine oxide $\left(\mathbf{B u}_{3} \mathbf{P O}\right)$ including (A) initial ${ }^{1} \mathrm{H}$ NMR spectrum of bromobenzene prior to titration and (B) the change in the ortho $\mathrm{H}$ resonance shifts during addition of increasing concentrations of $\mathbf{B u}_{3} \mathbf{P O}$ and the corresponding binding isotherm (inset) used for non-linear regression analysis and determination of the association constant $\left(\mathrm{K}_{\mathrm{a}}\right)$ that reflects XB interaction strength of the adduct (Solvent: $\mathbf{d}_{12}$-cyclohexane). 


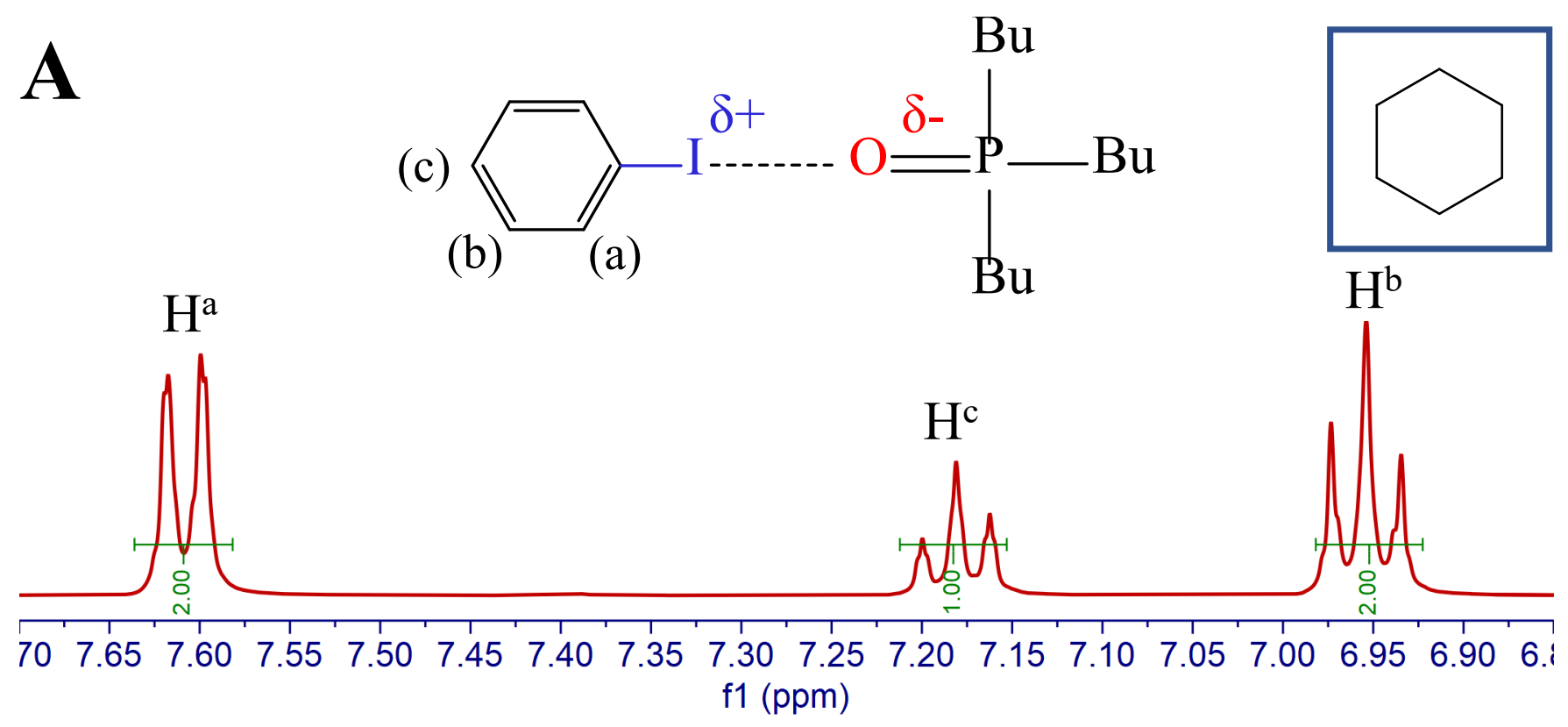

\section{B}

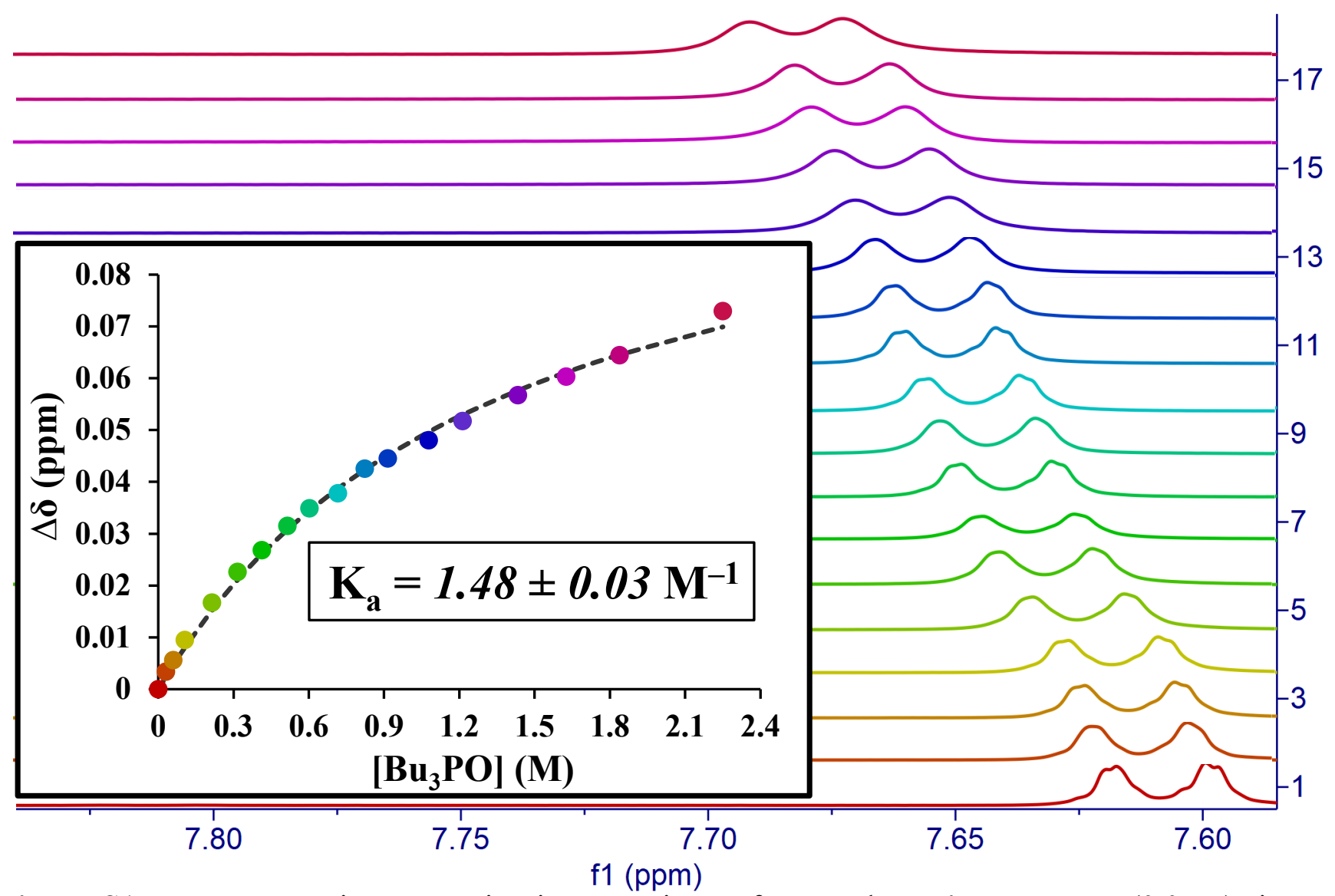

Figure S17. Representative NMR-titration experiment for $\mathrm{XB}$ donor iodobenzene $(0.05 \mathrm{M})$ titrated with $\mathrm{XB}$ acceptor tributylphosphine oxide $\left(\mathbf{B u}_{\mathbf{3}} \mathbf{P O}\right)$ including (A) initial ${ }^{1} \mathrm{H}$ NMR spectrum of iodobenzene prior to titration and (B) the change in the ortho $\mathrm{H}$ resonance shifts during addition of increasing concentrations of $\mathbf{B u}_{\mathbf{3}} \mathbf{P O}$ and the corresponding binding isotherm (inset) used for non-linear regression analysis and determination of the association constant $\left(\mathrm{K}_{\mathrm{a}}\right)$ that reflects $\mathrm{XB}$ interaction strength of the adduct (Solvent: $\mathbf{d}_{12}$-cyclohexane). 


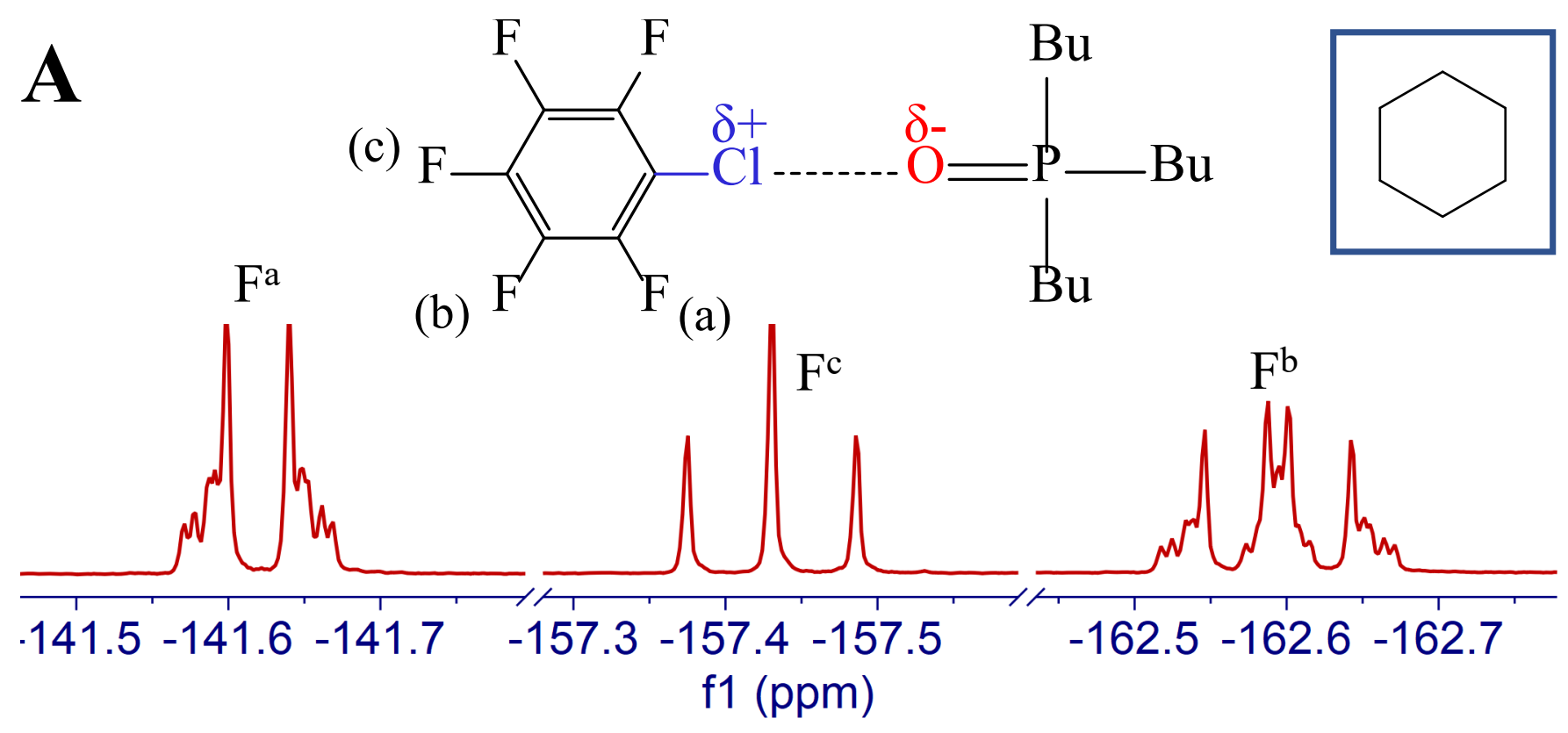

B

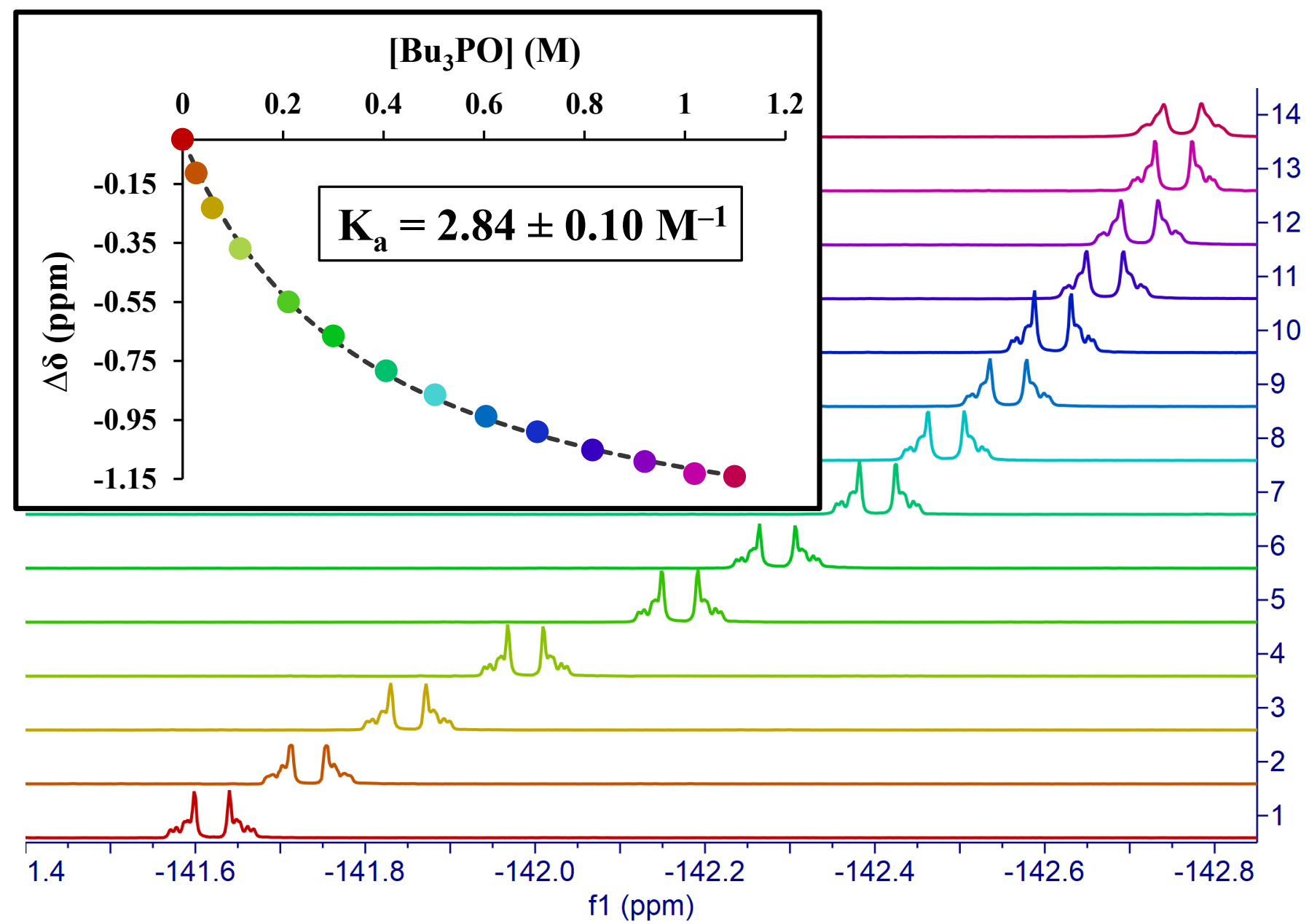

Figure S18. Representative NMR-titration experiment for XB donor chloropentafluorobenzene (ClPFB) $(0.0475 \mathrm{M})$ titrated with $\mathrm{XB}$ acceptor tributylphosphine oxide $\left(\mathbf{B u}_{\mathbf{3}} \mathbf{P O}\right)$ including (A) initial ${ }^{19} \mathrm{H}$ NMR spectrum of Cl-PFB prior to titration and (B) the change in the ortho F resonance shifts during addition of increasing concentrations of $\mathbf{B u}_{\mathbf{3}} \mathbf{P O}$ and the corresponding binding isotherm (inset) used for non-linear regression analysis and determination of the association constant $\left(\mathrm{K}_{\mathrm{a}}\right)$ that reflects $\mathrm{XB}$ interaction strength of the adduct (Solvent: cyclohexane). 

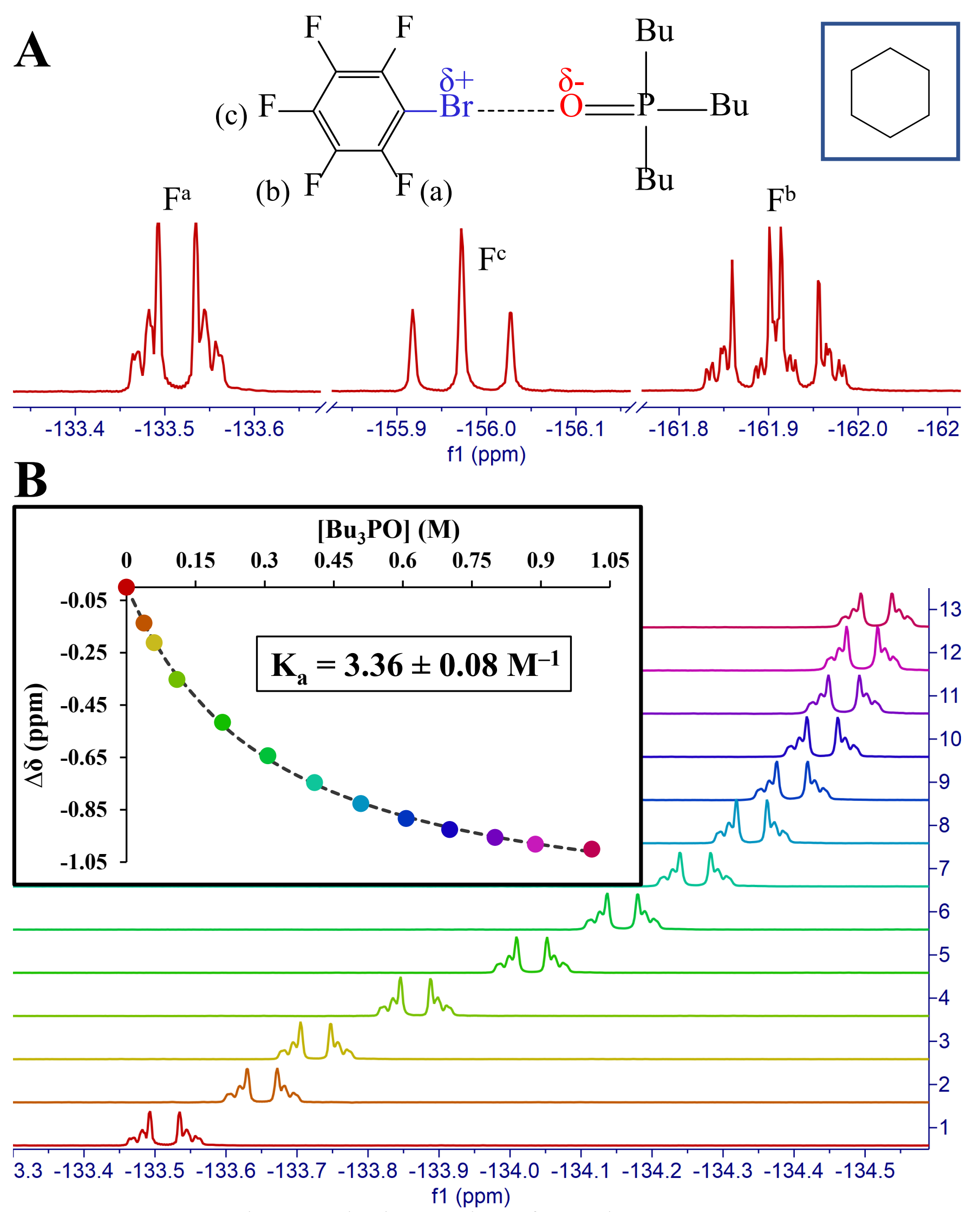

Figure S19. Representative NMR-titration experiment for XB donor bromopentafluorobenzene (BrPFB) $(0.052 \mathrm{M})$ titrated with $\mathrm{XB}$ acceptor tributylphosphine oxide $\left(\mathbf{B u}_{\mathbf{3}} \mathbf{P O}\right)$ including (A) initial ${ }^{19} \mathrm{H}$ NMR spectrum of Br-PFB prior to titration and (B) the change in the ortho $\mathrm{F}$ resonance shifts during addition of increasing concentrations of $\mathbf{B u}_{\mathbf{3}} \mathbf{P O}$ and the corresponding binding isotherm (inset) used for non-linear regression analysis and determination of the association constant $\left(\mathrm{K}_{\mathrm{a}}\right)$ that reflects $\mathrm{XB}$ interaction strength of the adduct (Solvent: cyclohexane). 


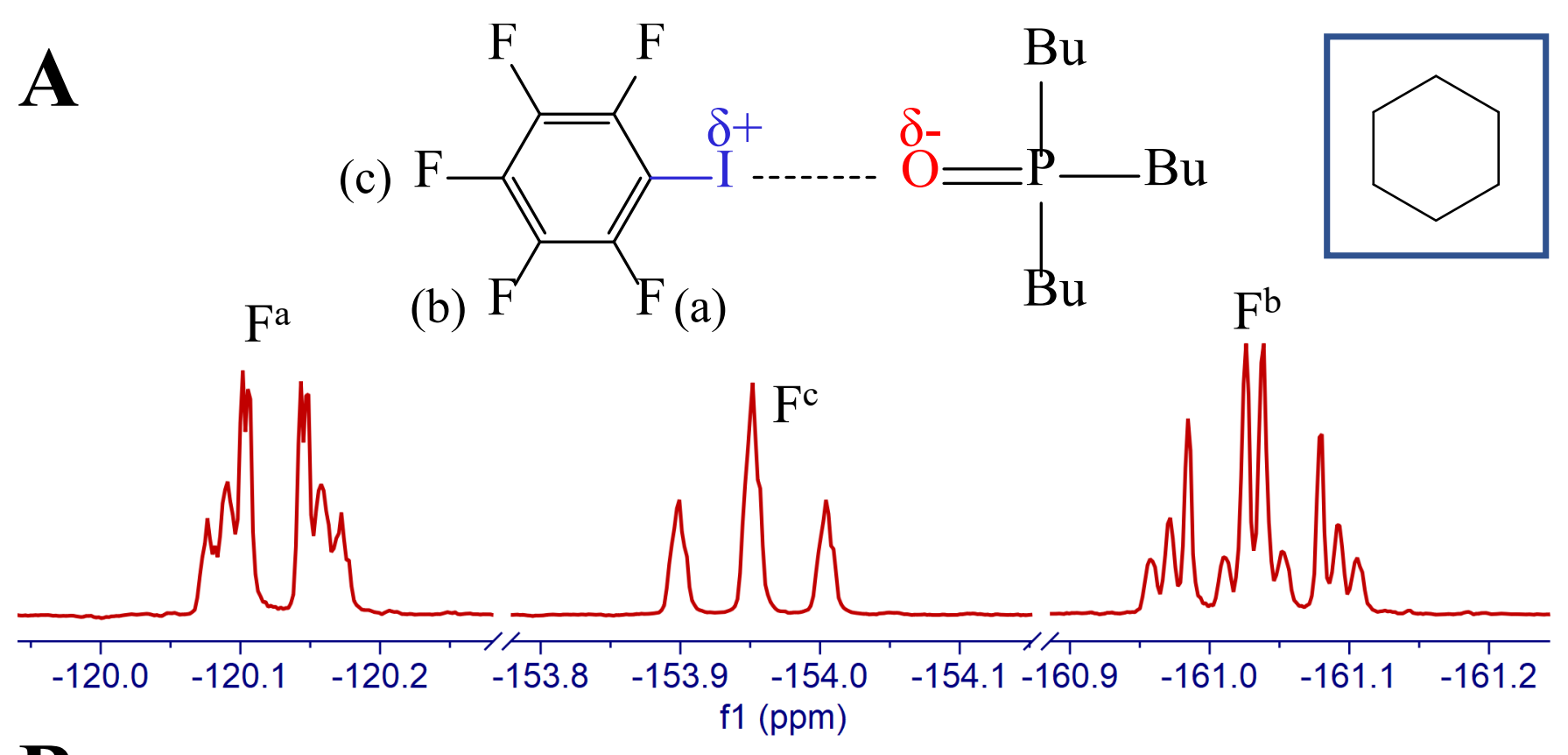

\section{B}

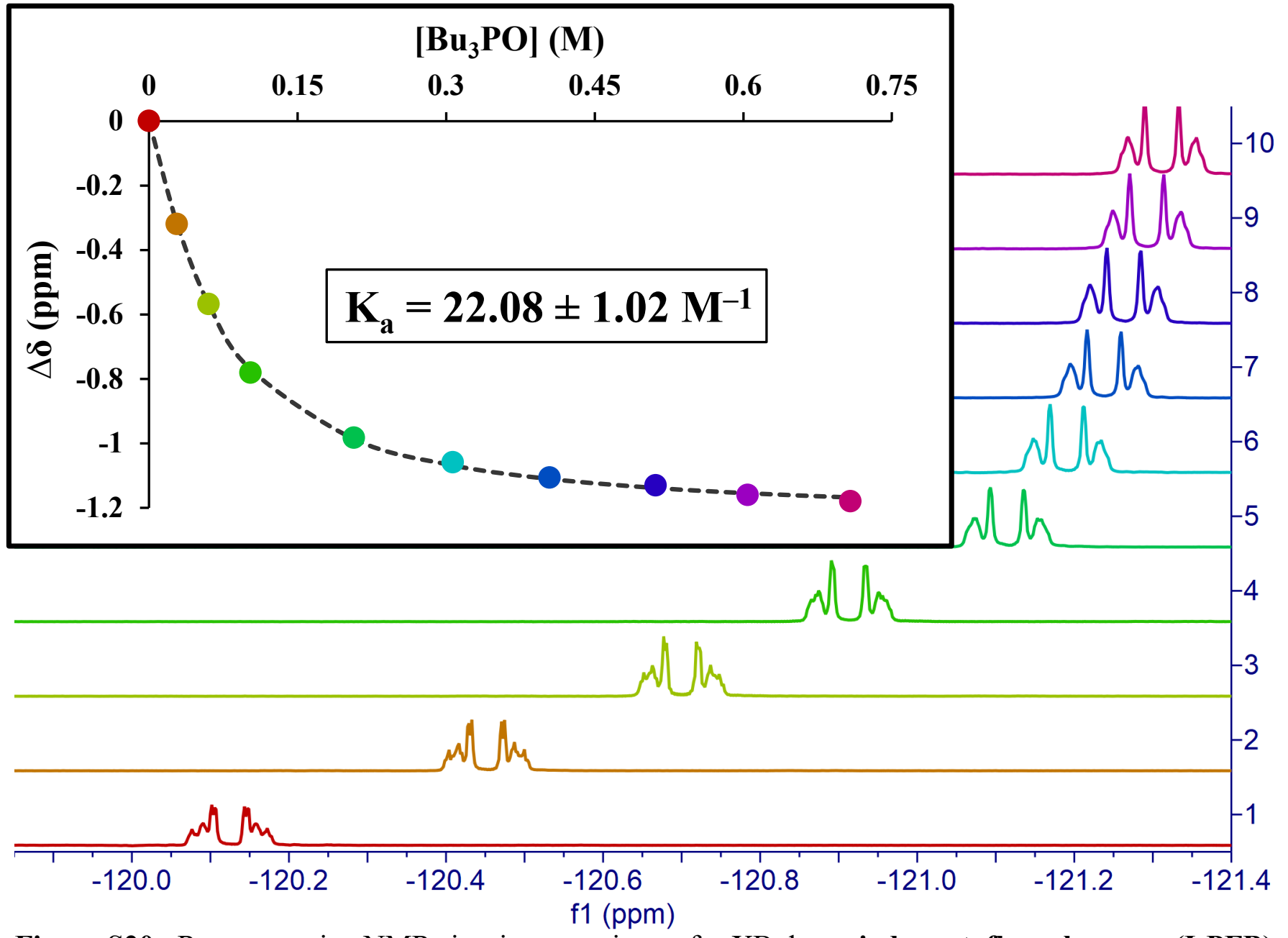

Figure S20. Representative NMR-titration experiment for XB donor iodopentafluorobenzene (I-PFB) $(0.0525 \mathrm{M})$ titrated with $\mathrm{XB}$ acceptor tributylphosphine oxide $\left(\mathbf{B u}_{\mathbf{3}} \mathbf{P O}\right)$ including (A) initial ${ }^{19} \mathrm{H}$ NMR spectrum of I-PFB prior to titration and (B) the change in the ortho $F$ resonance shifts during addition of increasing concentrations of $\mathbf{B u}_{\mathbf{3}} \mathbf{P O}$ and the corresponding binding isotherm (inset) used for nonlinear regression analysis and determination of the association constant $\left(\mathrm{K}_{\mathrm{a}}\right)$ that reflects XB interaction strength of the adduct (Solvent: cyclohexane). 


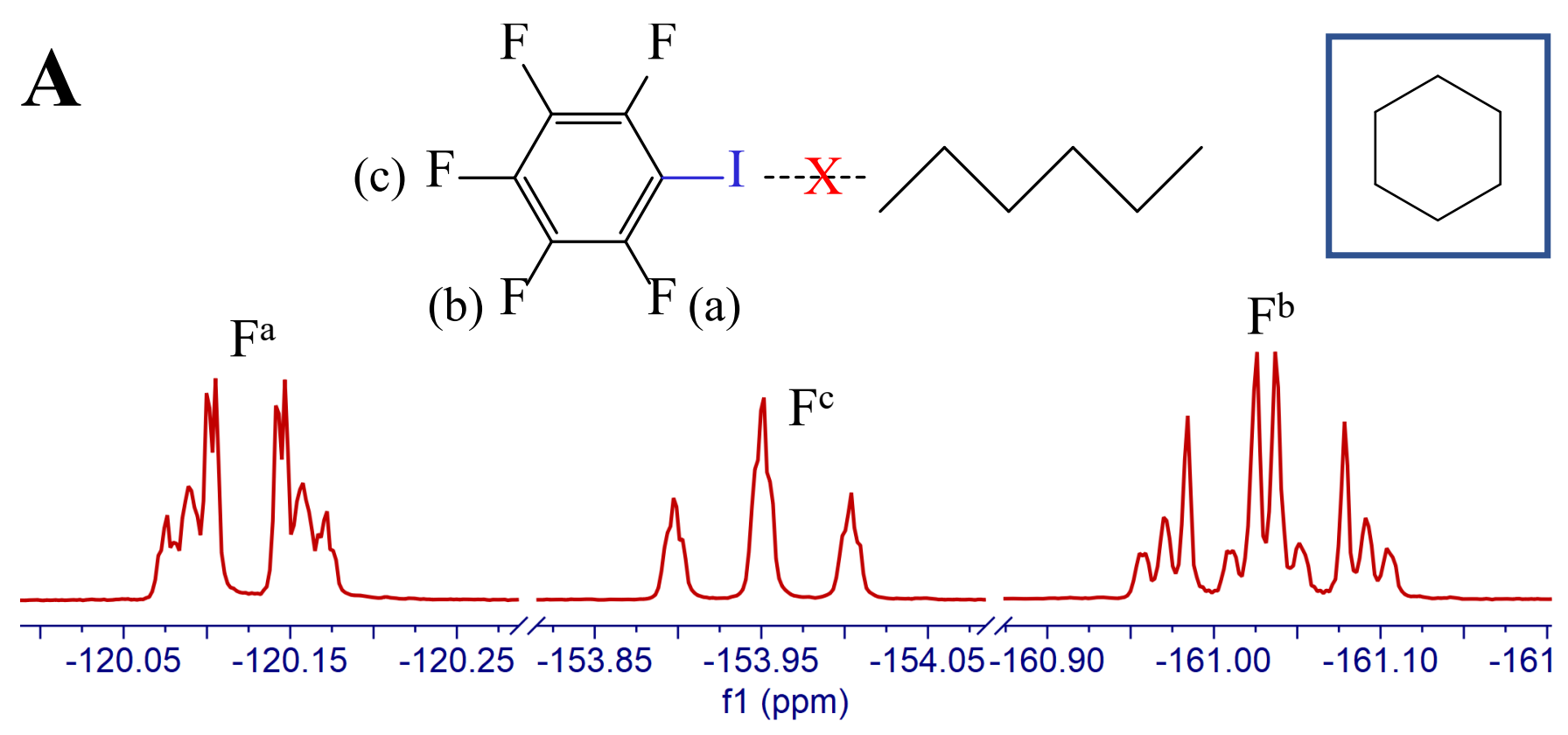

\section{B}

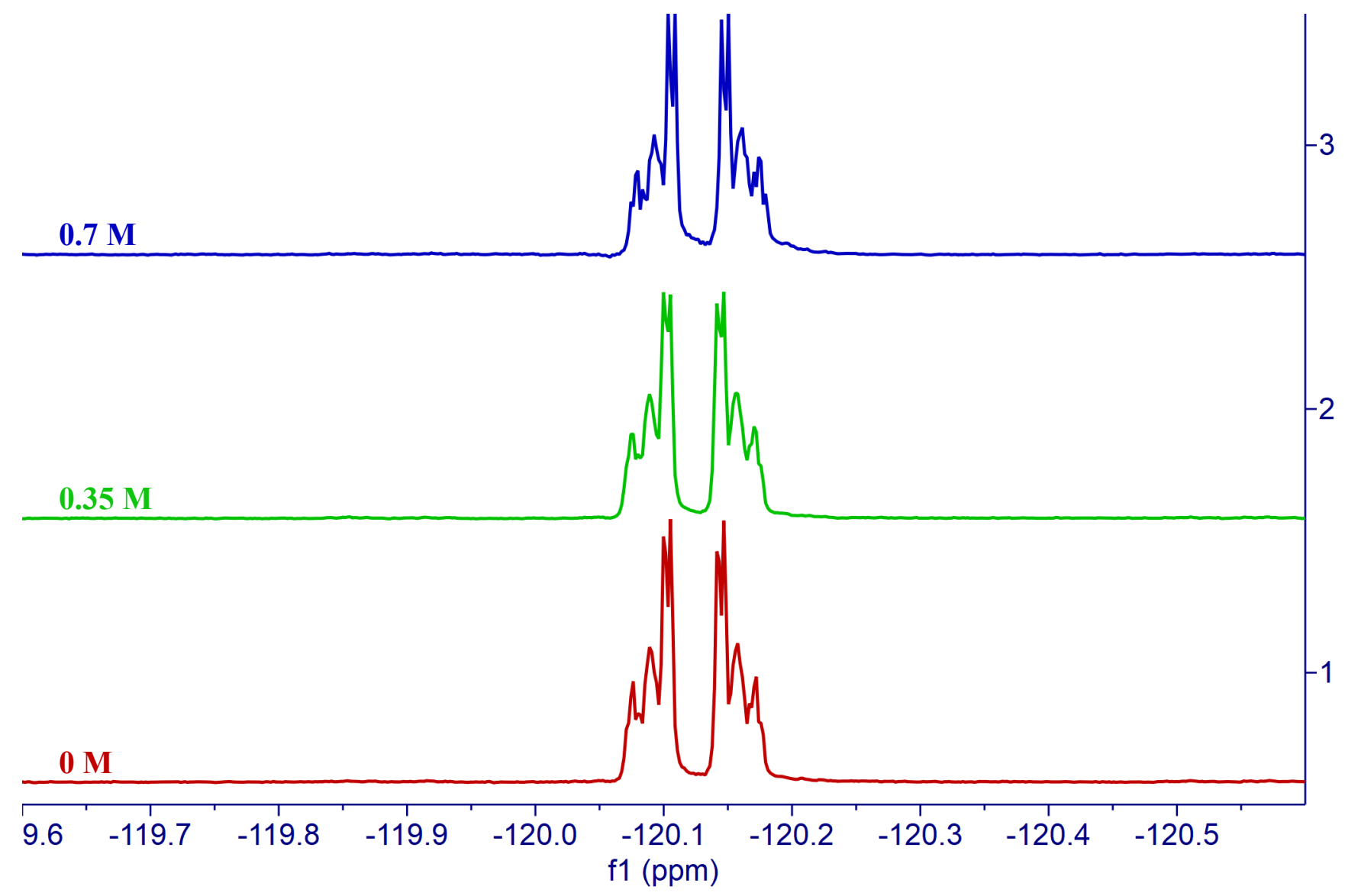

Figure S21. Representative control NMR-titration experiment for XB donor iodopentafluorobenzene (I-PFB) $(0.0525 \mathrm{M})$ titrated with hexane including (A) initial ${ }^{19} \mathrm{H}$ NMR spectrum of I-PFB prior to titration and (B) the lack of change in the ortho $\mathrm{F}$ resonance shifts during addition of increasing concentrations of hexane (Solvent: cyclohexane). 


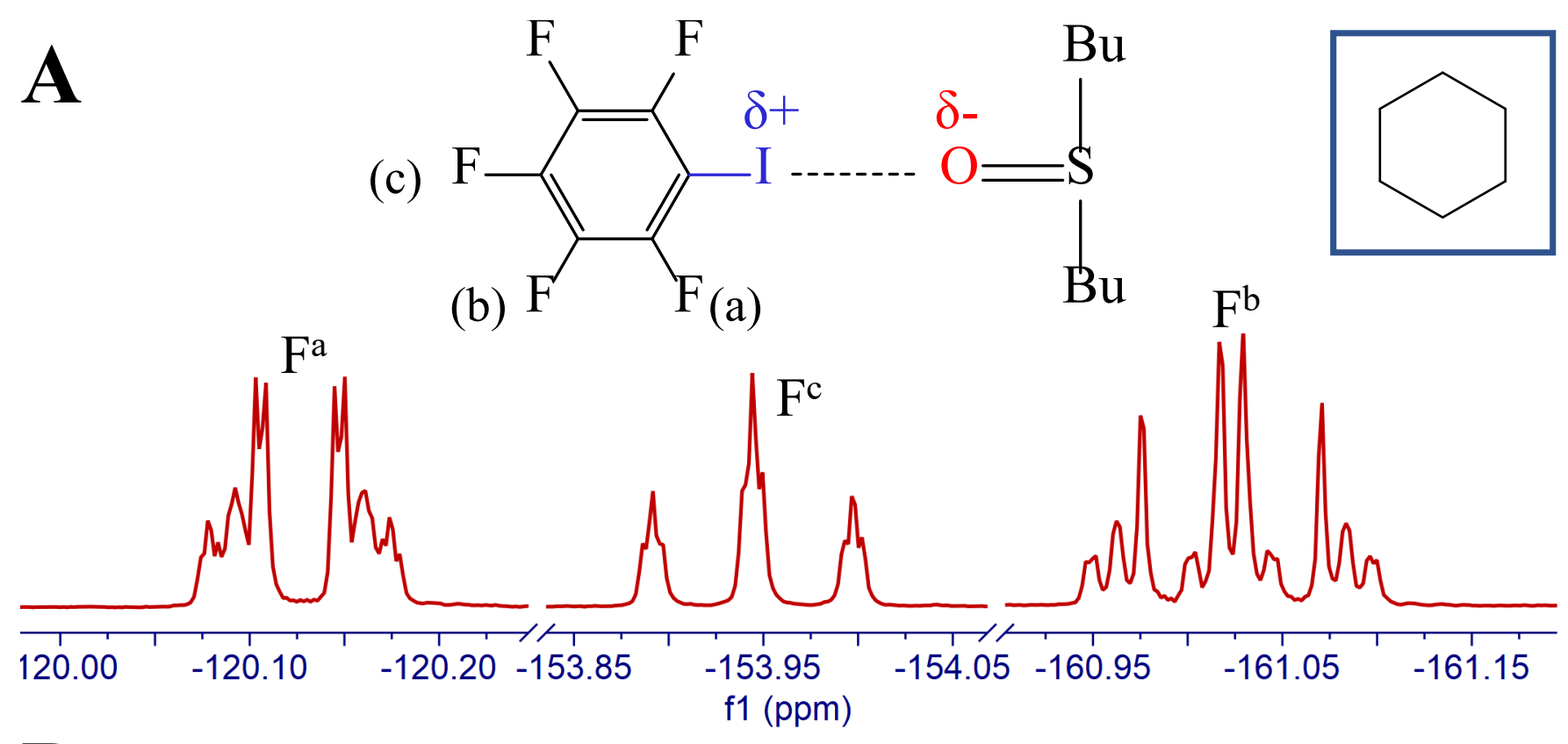

B

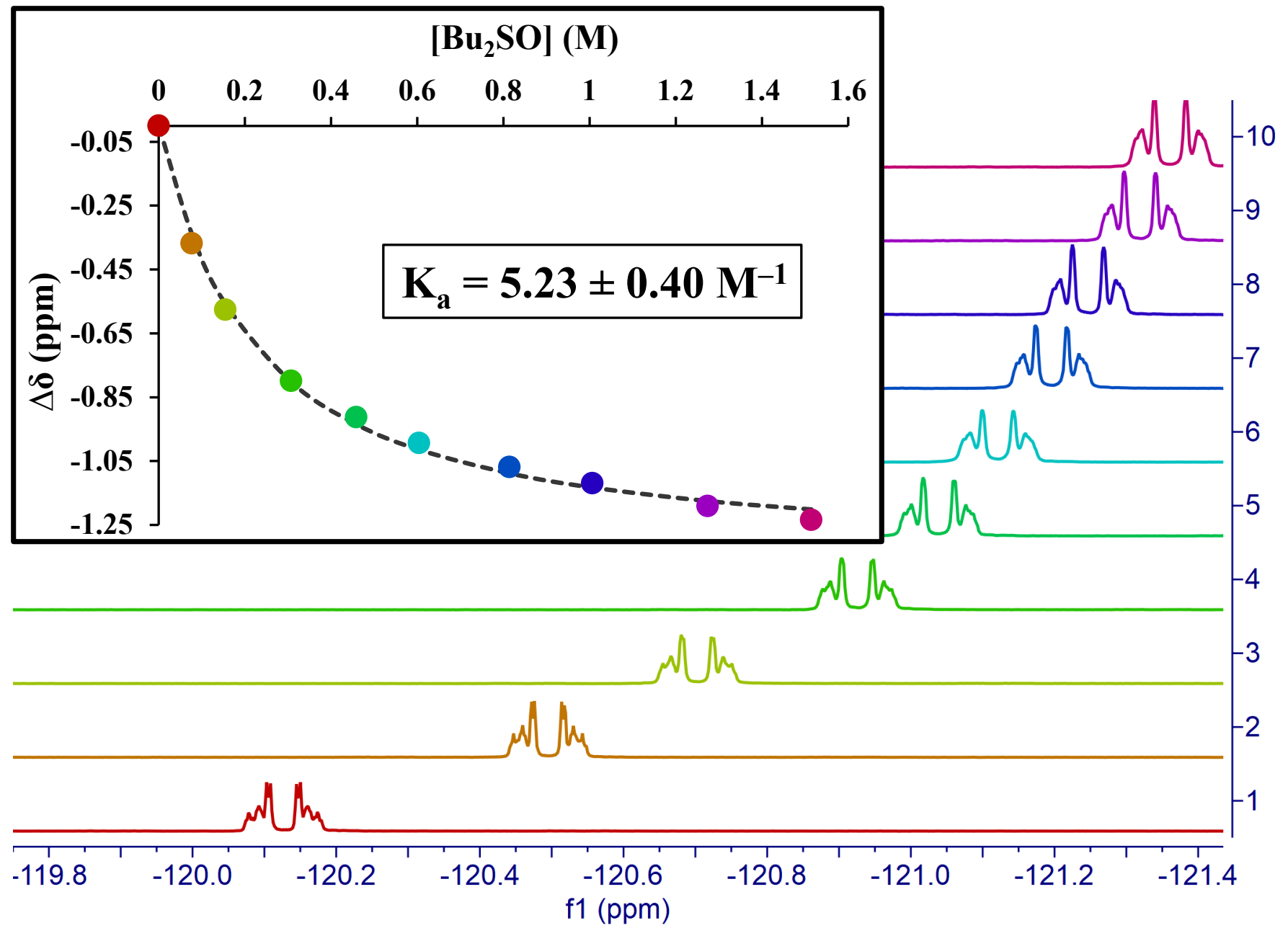

Figure S22. Representative NMR-titration experiment for XB donor iodopentafluorobenzene (I-PFB) $(0.0525 \mathrm{M})$ titrated with $\mathrm{XB}$ acceptor dibutyl sulfoxide $\left(\mathbf{B u}_{\mathbf{2}} \mathbf{S O}\right)$ including (A) initial ${ }^{19} \mathrm{H}$ NMR spectrum of I-PFB prior to titration and (B) the change in the ortho $F$ resonance shifts during addition of increasing concentrations of $\mathbf{B u}_{2} \mathbf{S O}$ and the corresponding binding isotherm (inset) used for nonlinear regression analysis and determination of the association constant $\left(\mathrm{K}_{\mathrm{a}}\right)$ that reflects XB interaction strength of the adduct (Solvent: cyclohexane). 

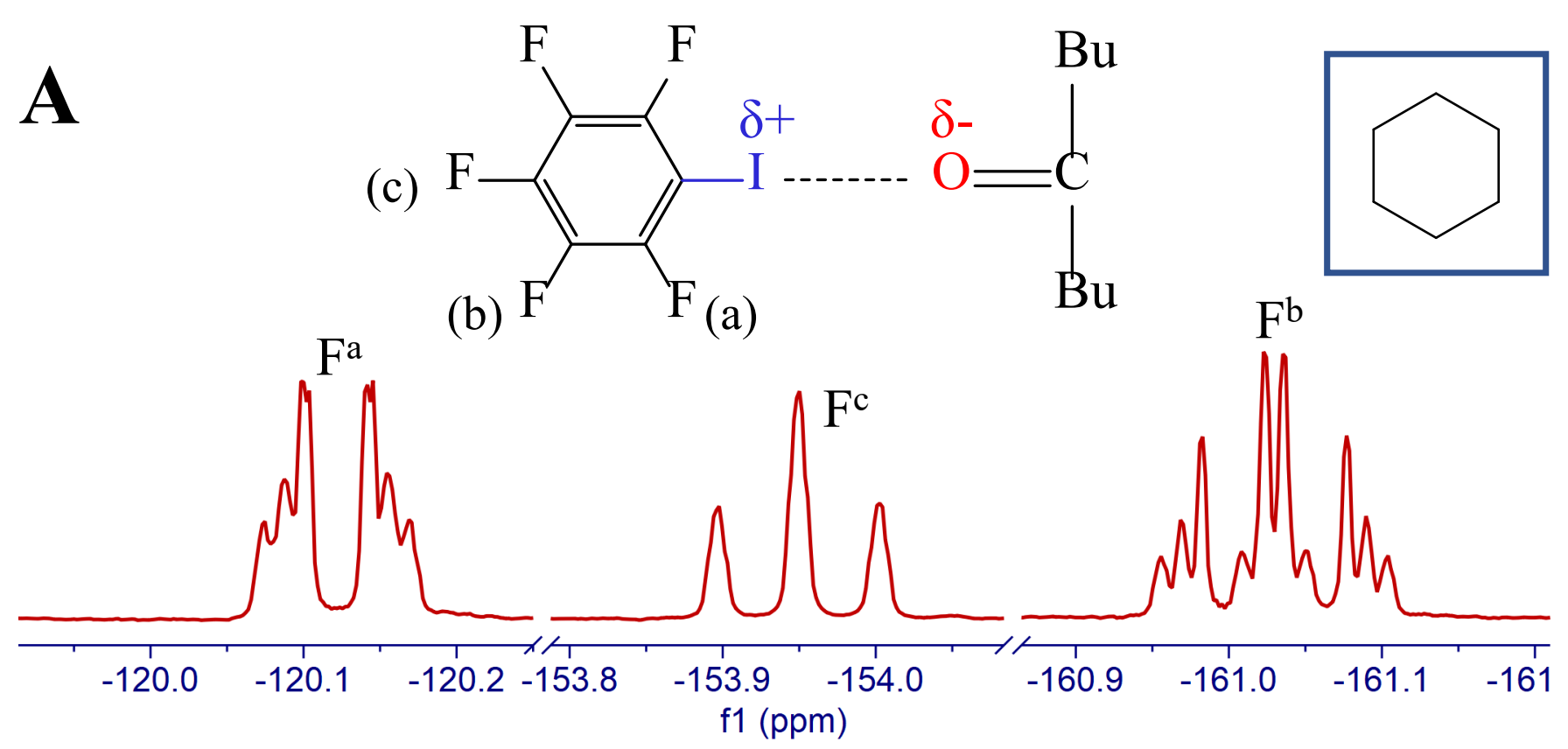

\section{B}

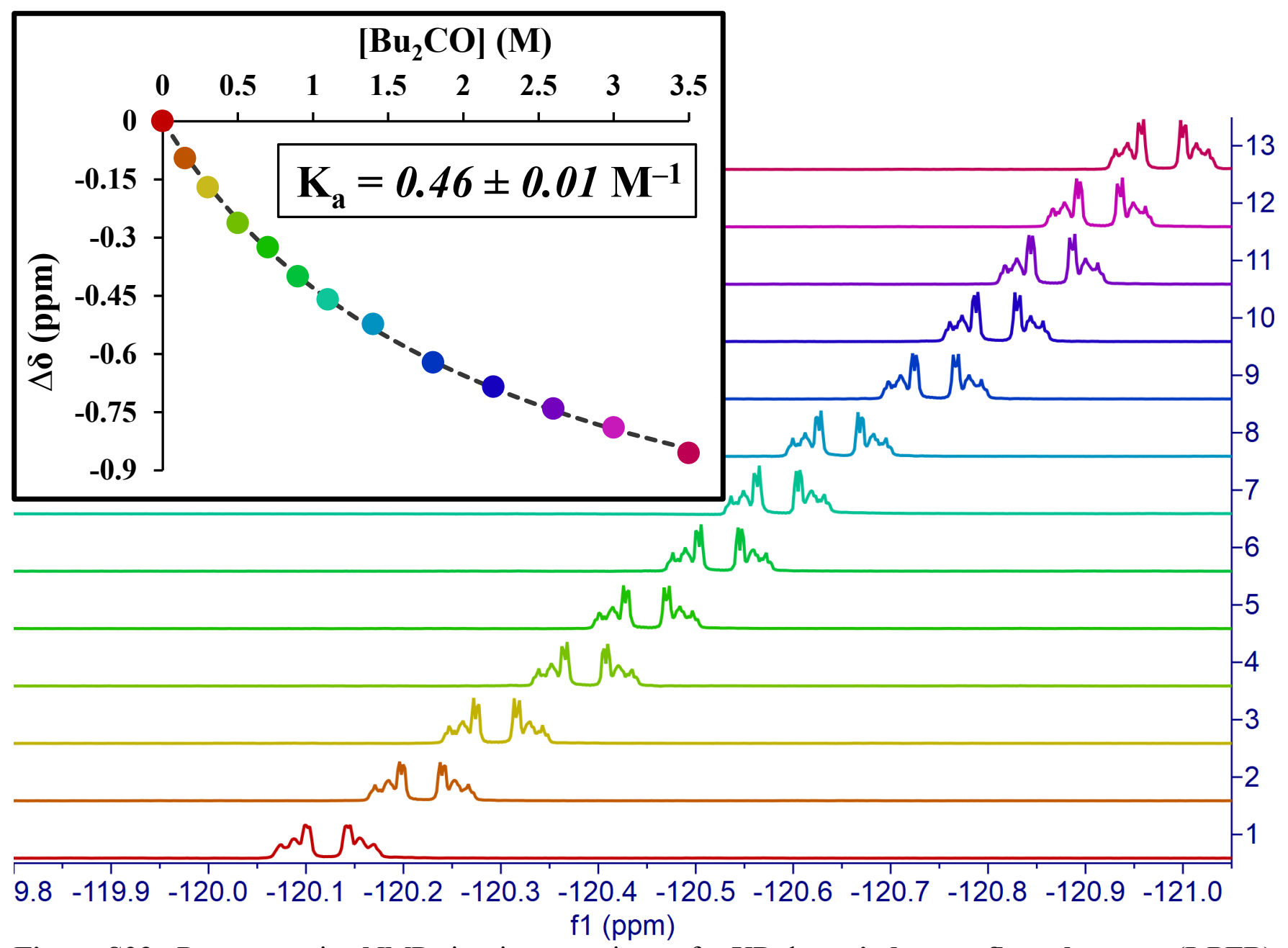

Figure S23. Representative NMR-titration experiment for XB donor iodopentafluorobenzene (I-PFB) $(0.0525 \mathrm{M})$ titrated with $\mathrm{XB}$ acceptor 5-nonanone $\left(\mathbf{B u}_{\mathbf{2}} \mathbf{C O}\right)$ including $(\mathbf{A})$ initial ${ }^{19} \mathrm{H}$ NMR spectrum of I-PFB prior to titration and $(B)$ the change in the ortho $\mathrm{F}$ resonance shifts during addition of increasing concentrations of $\mathbf{B u}_{2} \mathbf{C O}$ and the corresponding binding isotherm (inset) used for non-linear regression analysis and determination of the association constant $\left(\mathrm{K}_{\mathrm{a}}\right)$ that reflects $\mathrm{XB}$ interaction strength of the adduct (Solvent: cyclohexane). 


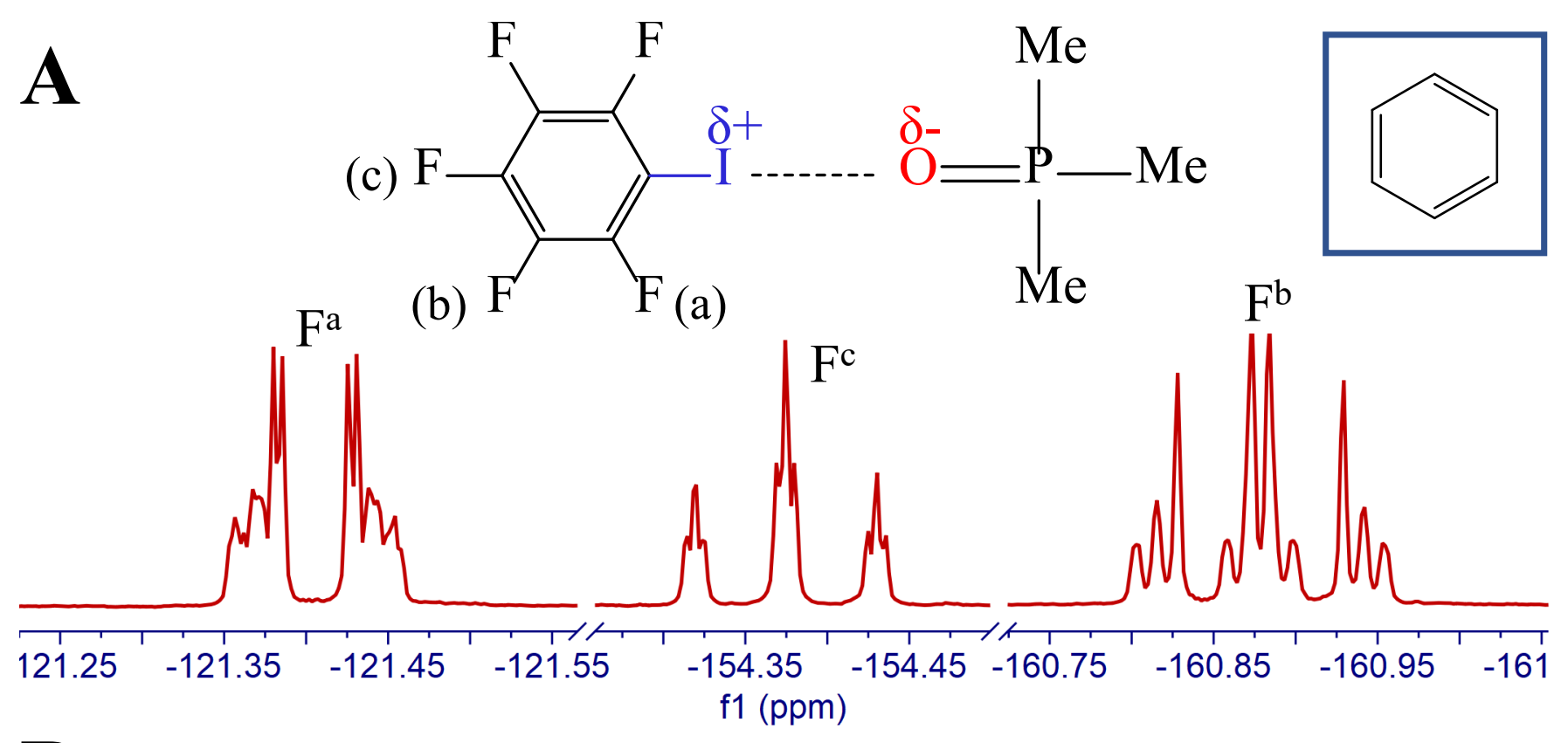

B

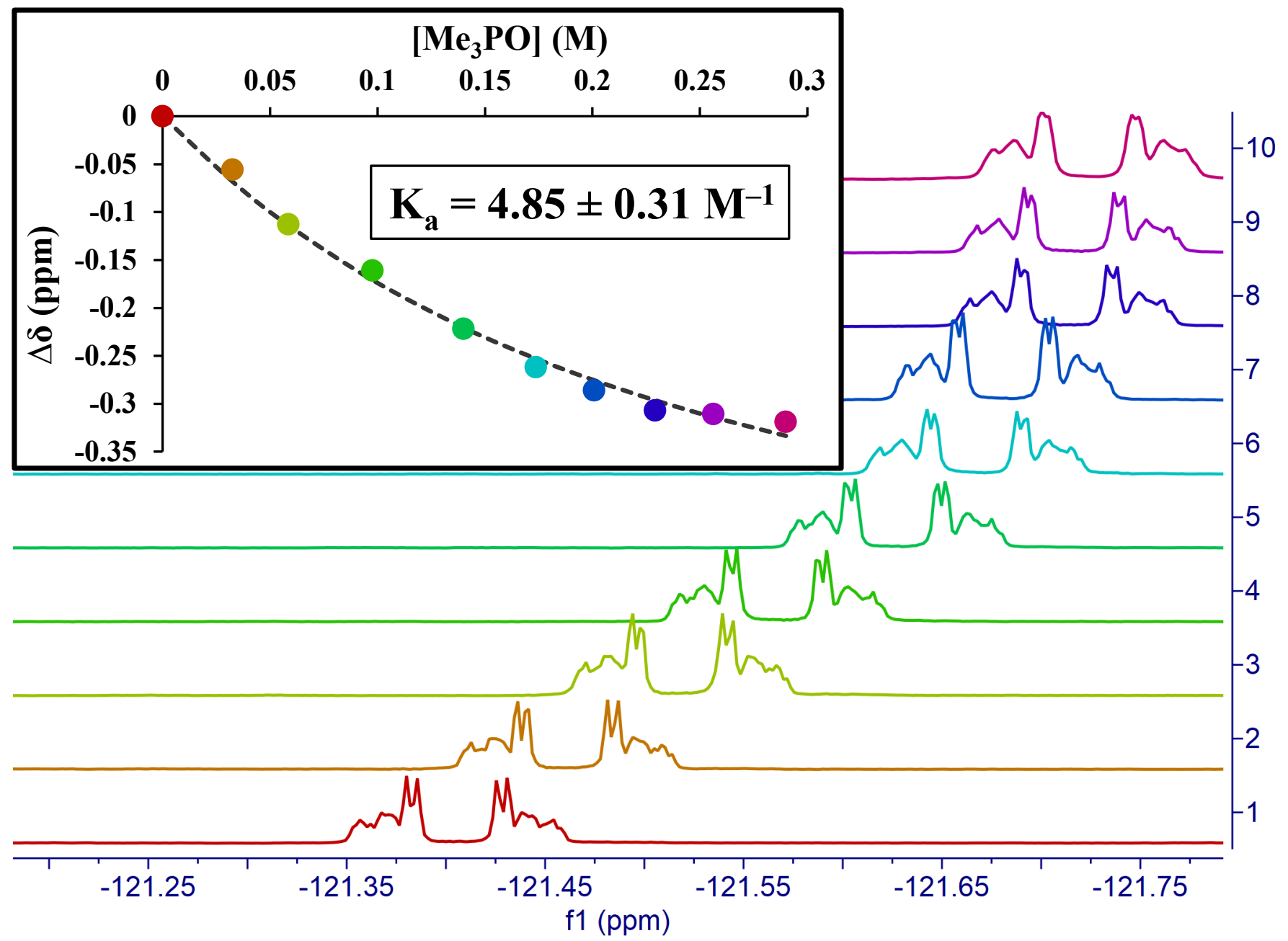

Figure S24. Representative NMR-titration experiment for XB donor iodopentafluorobenzene (I-PFB) $(0.0525 \mathrm{M})$ titrated with $\mathrm{XB}$ acceptor trimethylphosphine oxide (Me $\mathbf{P O}$ ) including (A) initial ${ }^{19} \mathrm{H}$ NMR spectrum of I-PFB prior to titration and (B) the change in the ortho F resonance shifts during addition of increasing concentrations of $\mathbf{M e}_{3} \mathbf{P O}$ and the corresponding binding isotherm (inset) used for non-linear regression analysis and determination of the association constant $\left(\mathrm{K}_{\mathrm{a}}\right)$ that reflects $\mathrm{XB}$ interaction strength of the adduct (Solvent: benzene). 


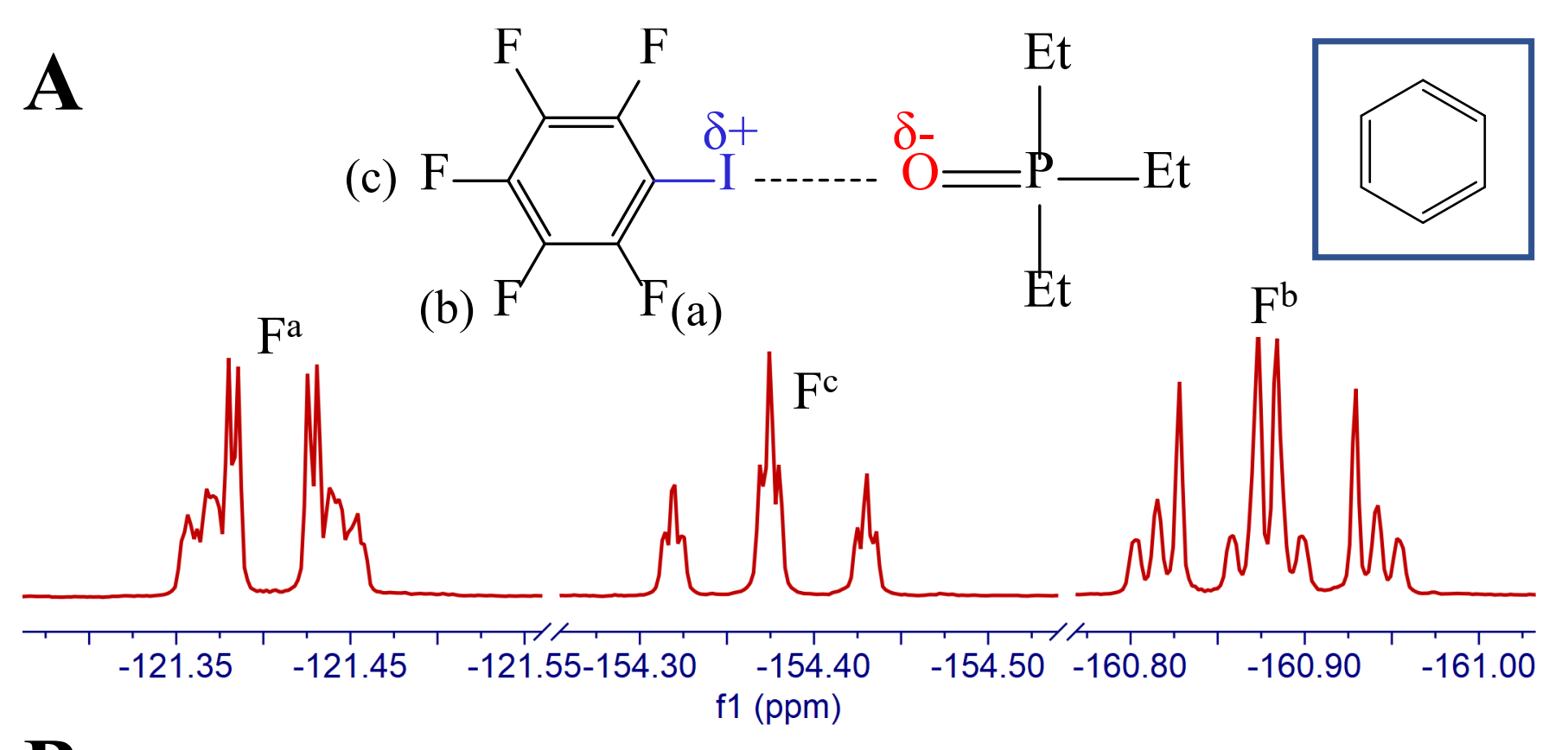

B

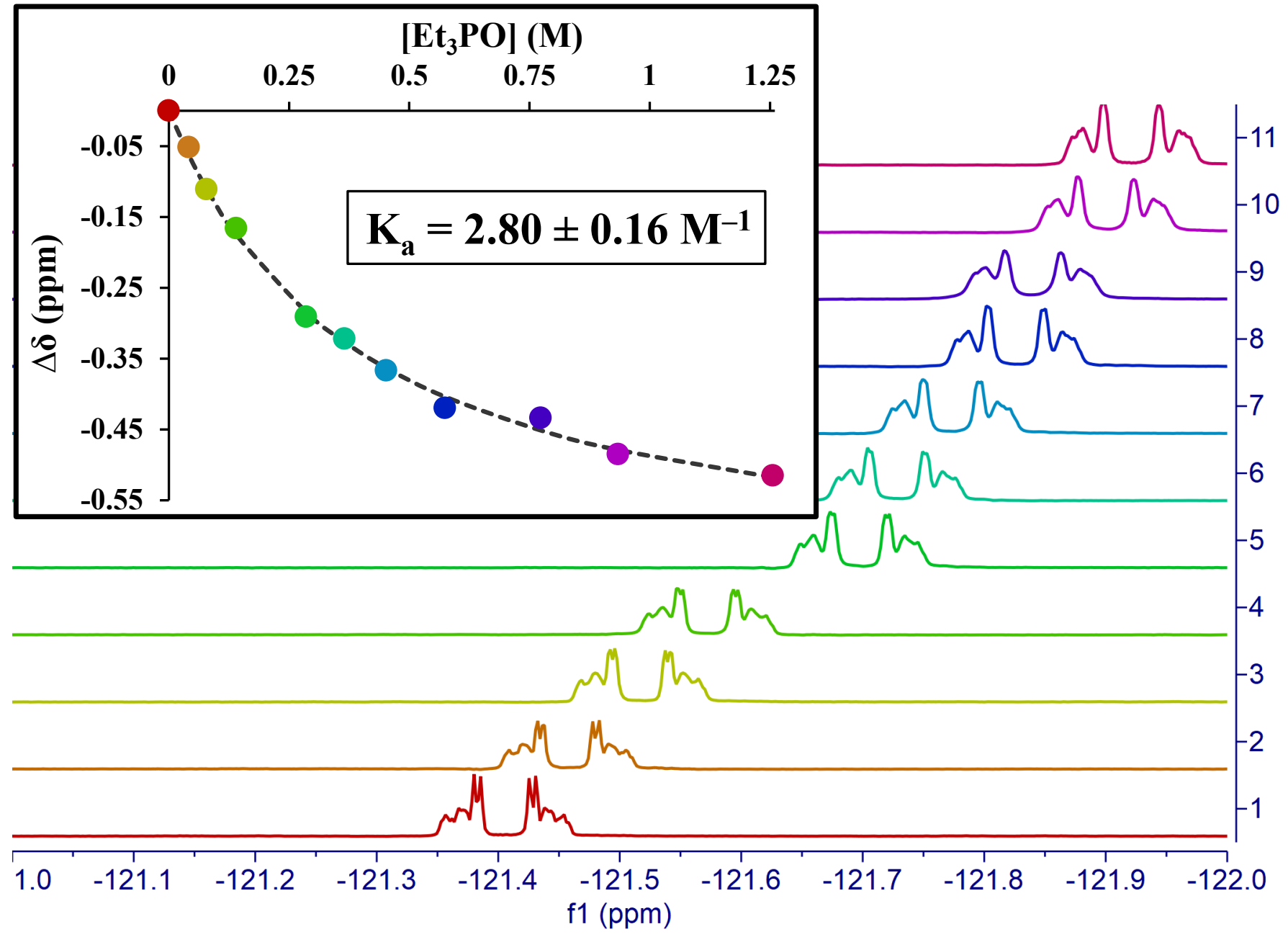

Figure S25. Representative NMR-titration experiment for XB donor iodopentafluorobenzene (I-PFB) $(0.0525 \mathrm{M})$ titrated with $\mathrm{XB}$ acceptor triethylphosphine oxide $\left(\mathbf{E t}_{\mathbf{3}} \mathbf{P O}\right)$ including (A) initial ${ }^{19} \mathrm{H}$ NMR spectrum of I-PFB prior to titration and (B) the change in the ortho $F$ resonance shifts during addition of increasing concentrations of $\mathbf{E t}_{\mathbf{3}} \mathbf{P O}$ and the corresponding binding isotherm (inset) used for nonlinear regression analysis and determination of the association constant $\left(\mathrm{K}_{\mathrm{a}}\right)$ that reflects XB interaction strength of the adduct (Solvent: benzene). 


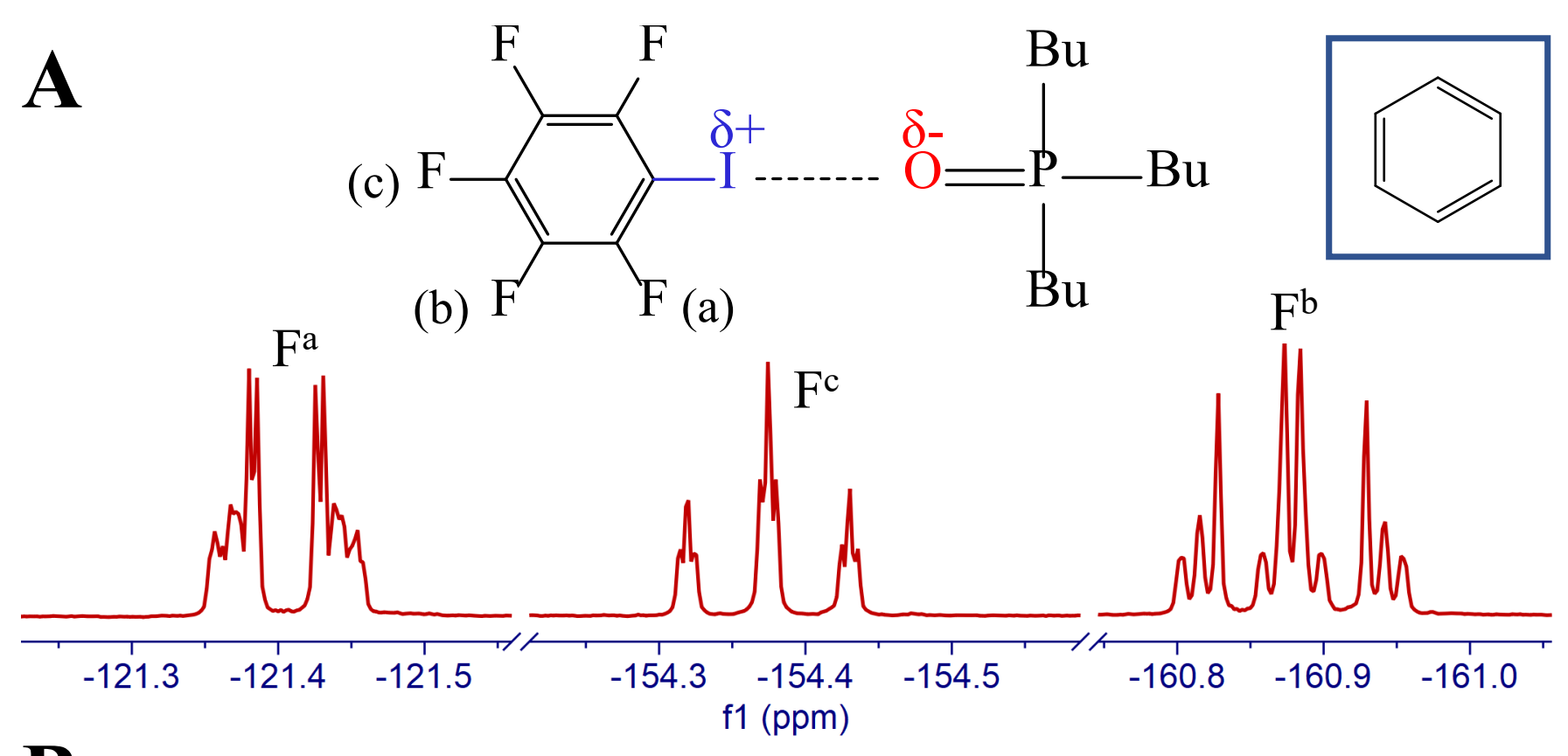

B

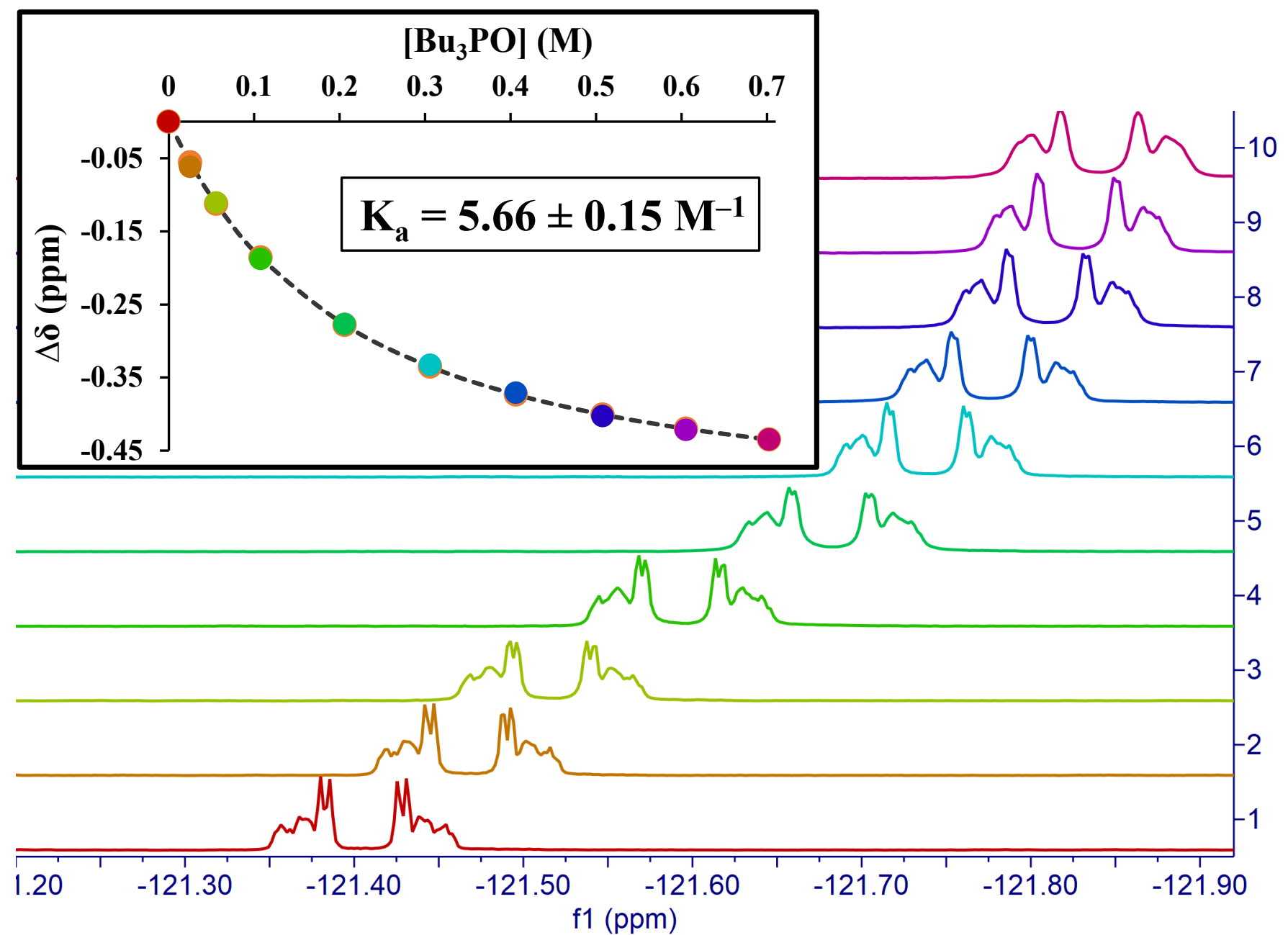

Figure S26. Representative NMR-titration experiment for XB donor iodopentafluorobenzene (I-PFB) $(0.0525 \mathrm{M})$ titrated with $\mathrm{XB}$ acceptor tributylphosphine oxide $\left(\mathbf{B u}_{\mathbf{3}} \mathbf{P O}\right)$ including (A) initial ${ }^{19} \mathrm{H}$ NMR spectrum of I-PFB prior to titration and (B) the change in the ortho F resonance shifts during addition of increasing concentrations of $\mathbf{B u}_{\mathbf{3}} \mathbf{P O}$ and the corresponding binding isotherm (inset) used for nonlinear regression analysis and determination of the association constant $\left(\mathrm{K}_{\mathrm{a}}\right)$ that reflects XB interaction strength of the adduct (Solvent: benzene). 


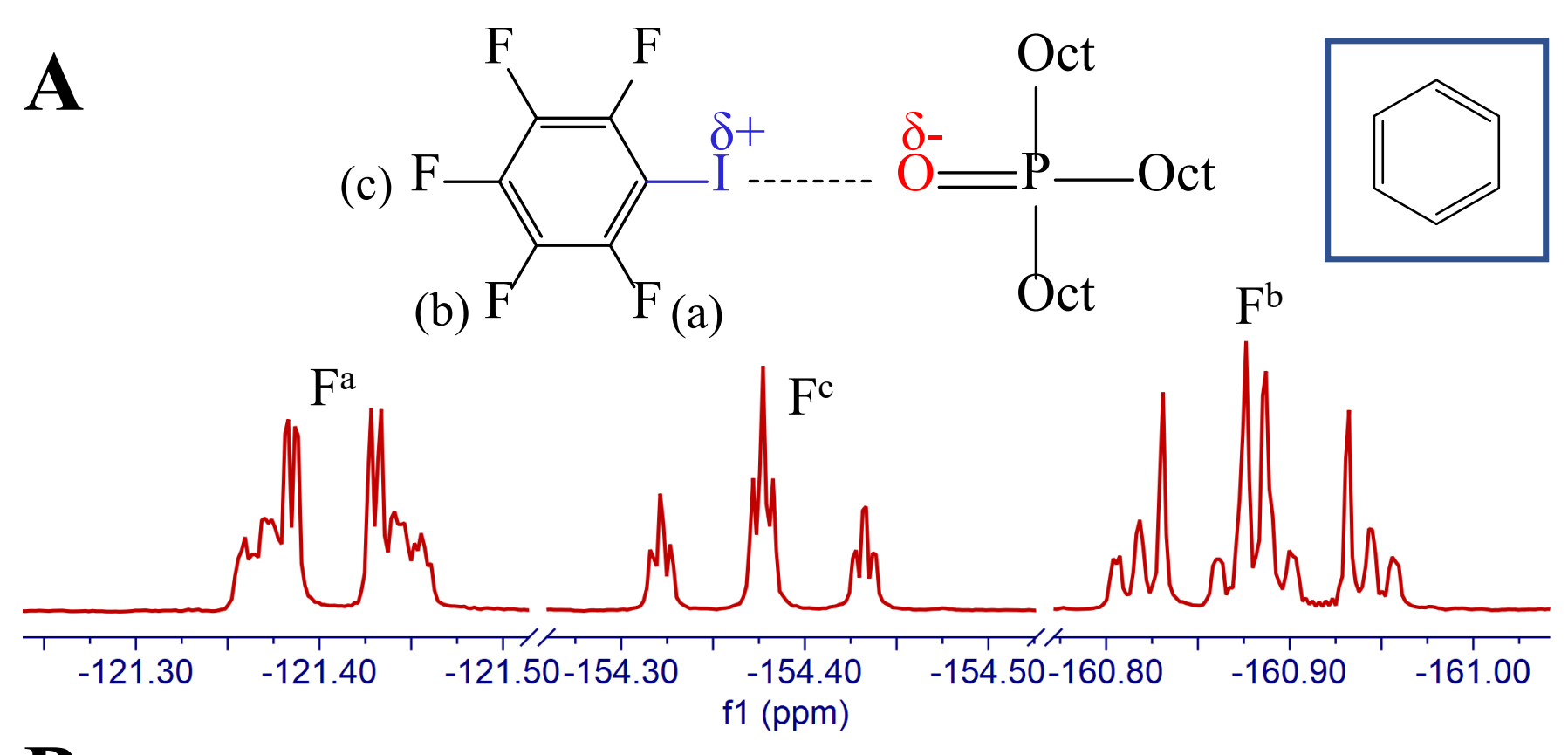

B

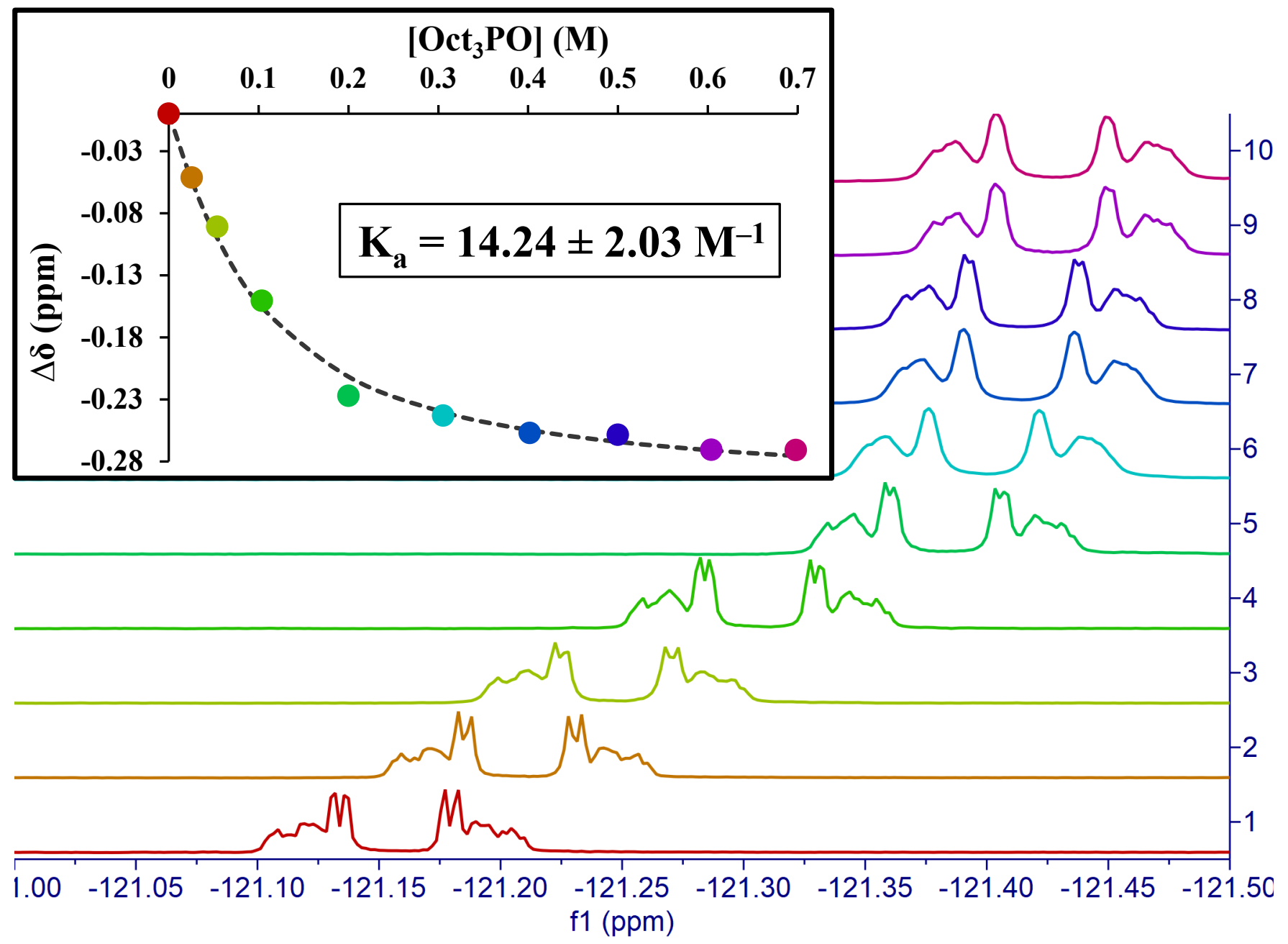

Figure S27. Representative NMR-titration experiment for XB donor iodopentafluorobenzene (I-PFB) $(0.0525 \mathrm{M})$ titrated with $\mathrm{XB}$ acceptor trioctylphosphine oxide $\left(\mathbf{O c t}_{\mathbf{3}} \mathbf{P O}\right)$ including (A) initial ${ }^{19} \mathrm{H}$ NMR spectrum of I-PFB prior to titration and (B) the change in the ortho F resonance shifts during addition of increasing concentrations of $\mathbf{O c t}_{\mathbf{3}} \mathbf{P O}$ and the corresponding binding isotherm (inset) used for nonlinear regression analysis and determination of the association constant $\left(\mathrm{K}_{\mathrm{a}}\right)$ that reflects XB interaction strength of the adduct (Solvent: benzene). 


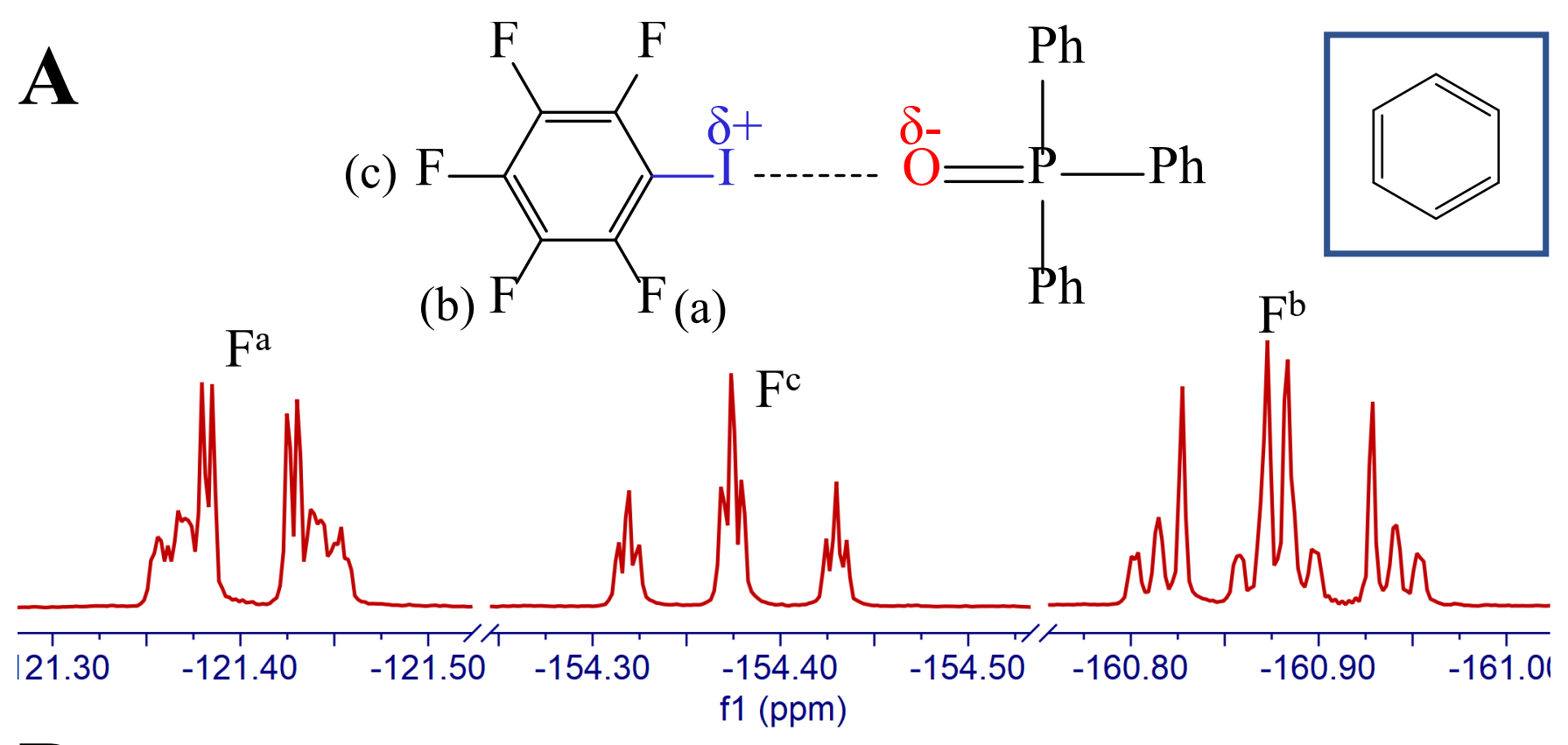

B

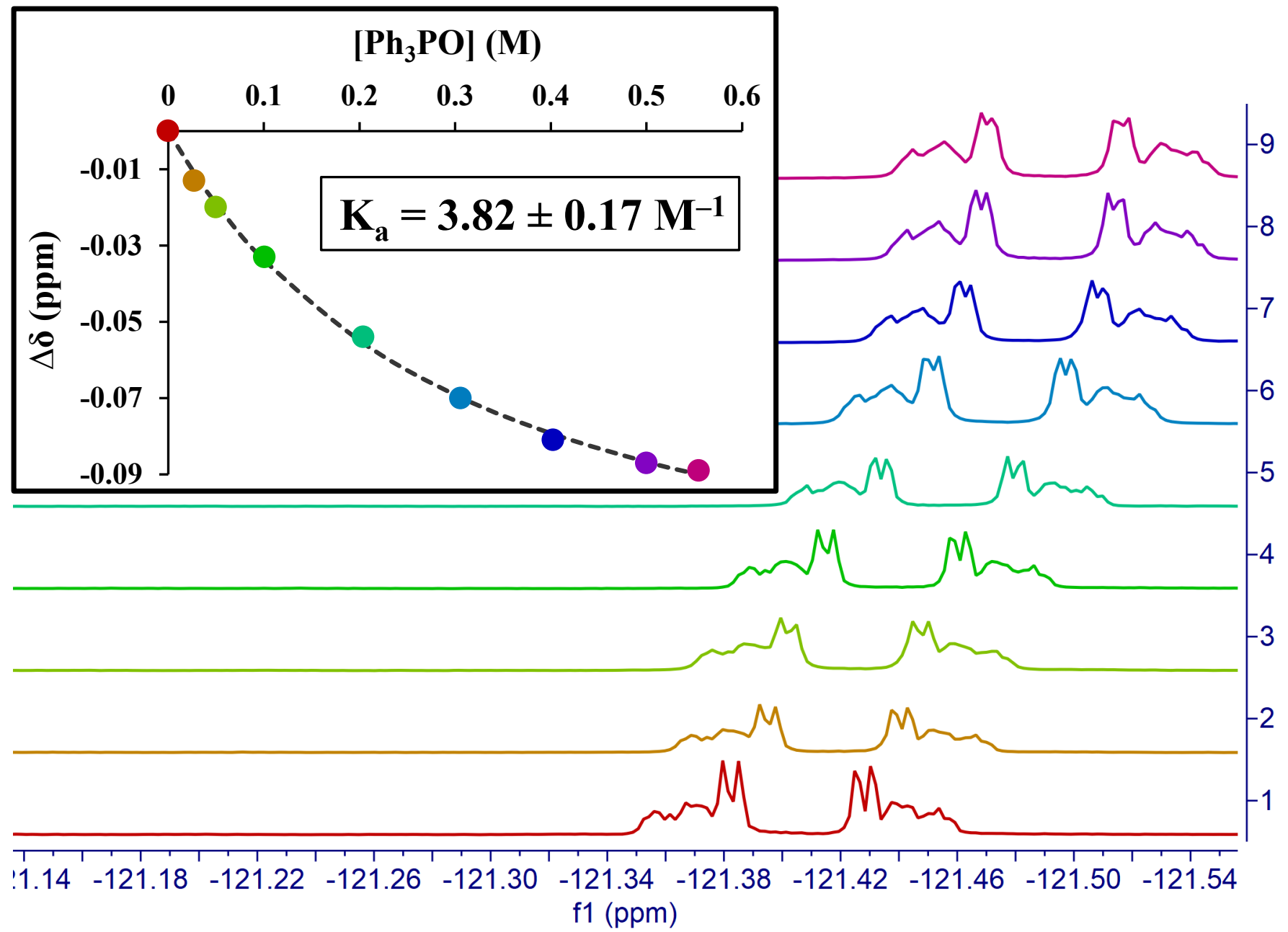

Figure S28. Representative NMR-titration experiment for XB donor iodopentafluorobenzene (I-PFB) $(0.0525 \mathrm{M})$ titrated with $\mathrm{XB}$ acceptor triphenylphosphine oxide $\left(\mathbf{P h}_{\mathbf{3}} \mathbf{P O}\right)$ including (A) initial ${ }^{19} \mathrm{H}$ NMR spectrum of I-PFB prior to titration and (B) the change in the ortho F resonance shifts during addition of increasing concentrations of $\mathbf{P h}_{\mathbf{3}} \mathbf{P O}$ and the corresponding binding isotherm (inset) used for non-linear regression analysis and determination of the association constant $\left(\mathrm{K}_{\mathrm{a}}\right)$ that reflects $\mathrm{XB}$ interaction strength of the adduct (Solvent: benzene). 


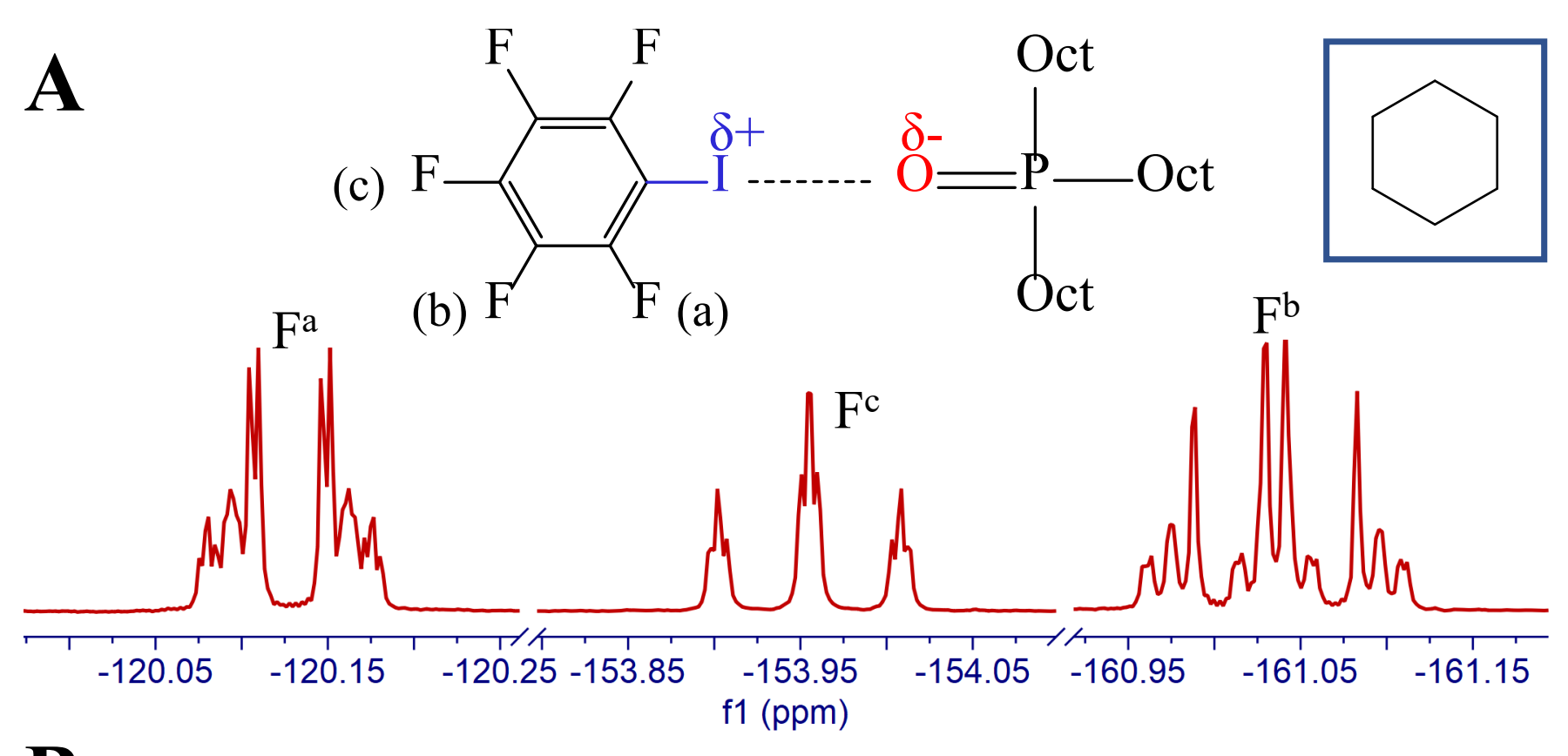

B

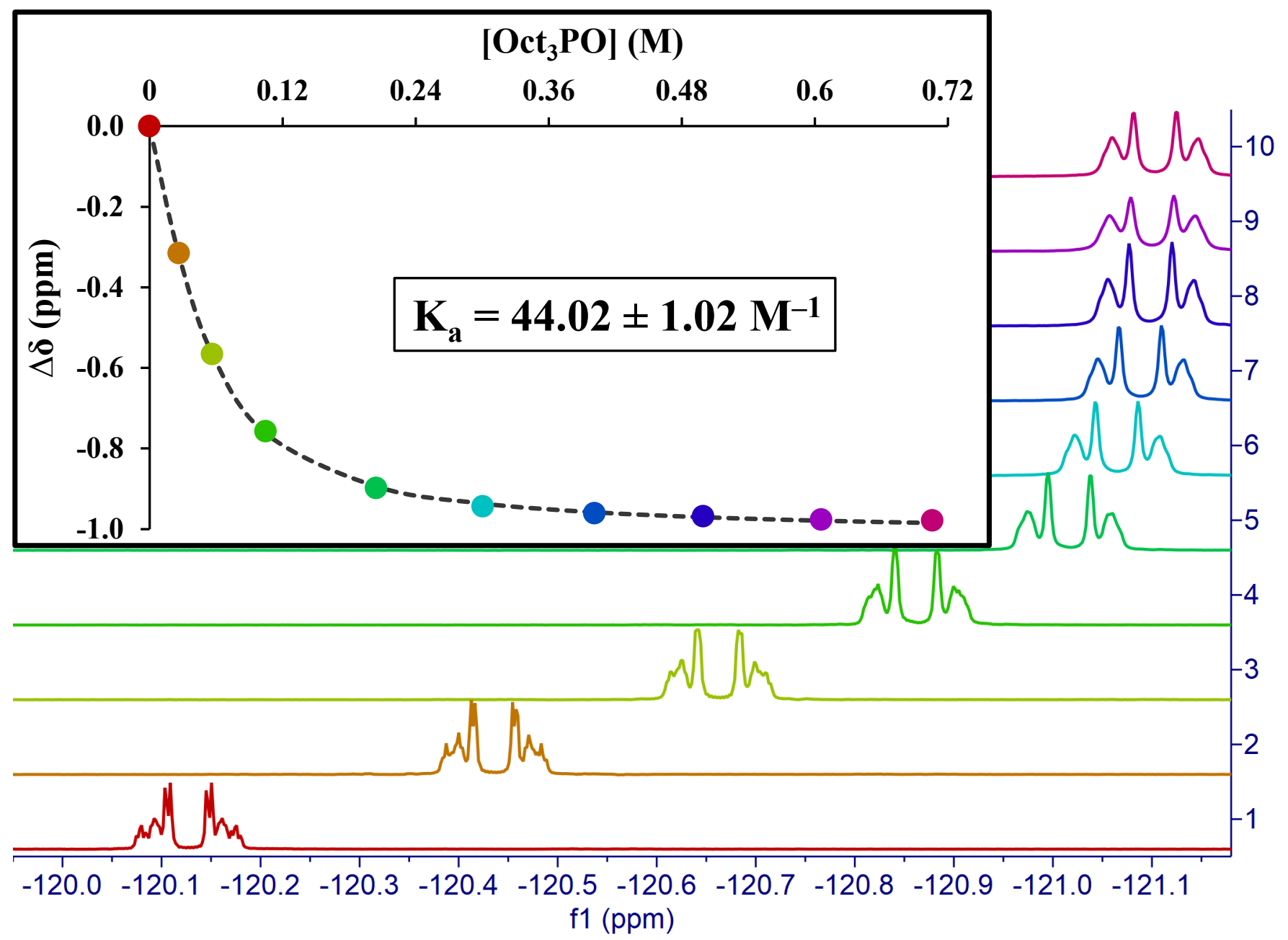

Figure S29. Representative NMR-titration experiment for XB donor iodopentafluorobenzene (I-PFB) $(0.0525 \mathrm{M})$ titrated with XB acceptor trioctylphosphine oxide $\left(\mathbf{O c t}_{\mathbf{3}} \mathbf{P O}\right)$ including (A) initial ${ }^{19} \mathrm{H}$ NMR spectrum of I-PFB prior to titration and (B) the change in the ortho $F$ resonance shifts during addition of increasing concentrations of $\mathbf{O c t}_{\mathbf{3}} \mathbf{P O}$ and the corresponding binding isotherm (inset) used for nonlinear regression analysis and determination of the association constant $\left(\mathrm{K}_{\mathrm{a}}\right)$ that reflects XB interaction strength of the adduct (Solvent: cyclohexane). 


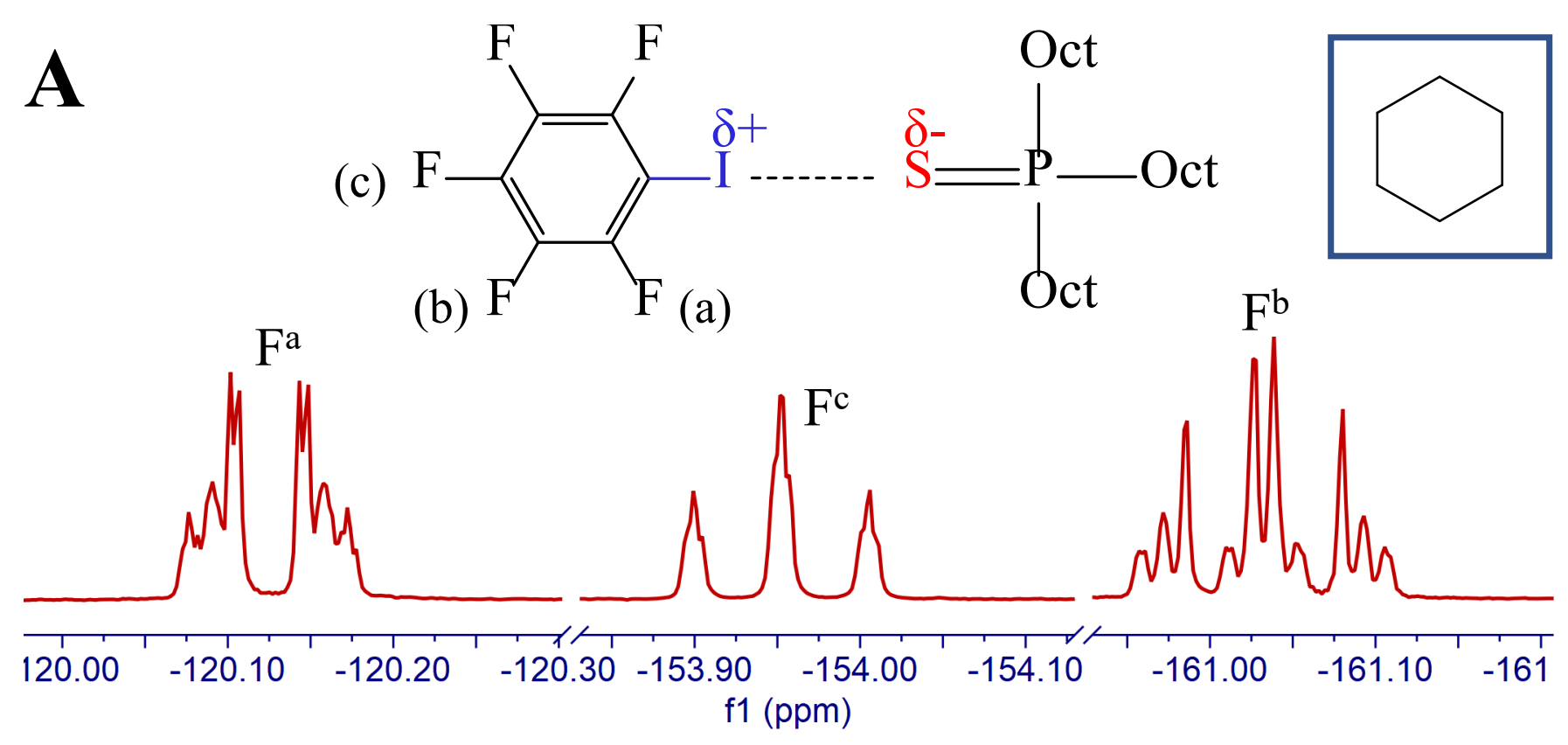

B

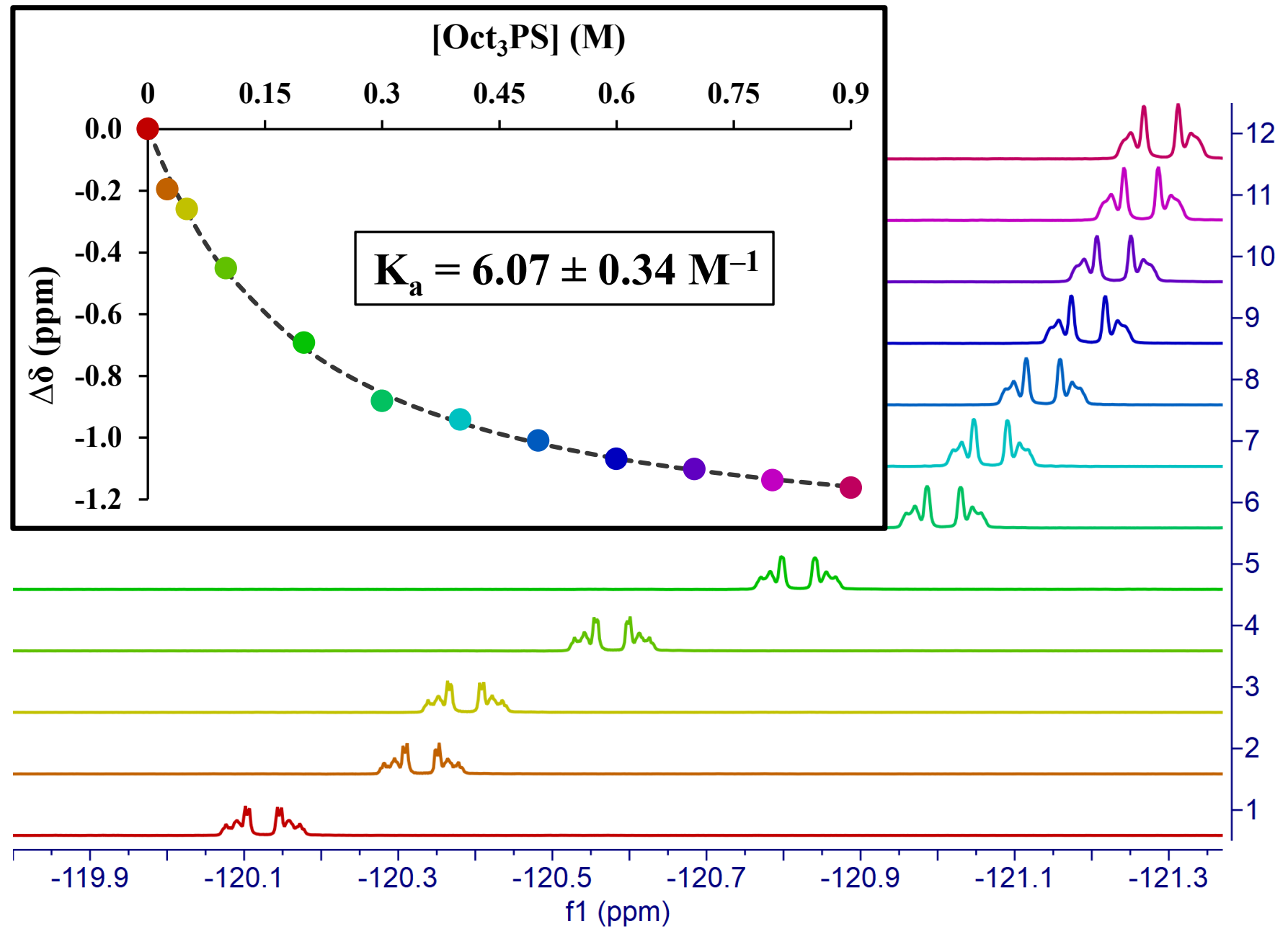

Figure S30. Representative NMR-titration experiment for XB donor iodopentafluorobenzene (I-PFB) $(0.0525 \mathrm{M})$ titrated with $\mathrm{XB}$ acceptor trioctylphosphine sulfide $\left(\mathbf{O c t}_{\mathbf{3}} \mathbf{P S}\right)$ including (A) initial ${ }^{19} \mathrm{H}$ NMR spectrum of I-PFB prior to titration and (B) the change in the ortho F resonance shifts during addition of increasing concentrations of $\mathbf{O c t}_{\mathbf{3}} \mathbf{P S}$ and the corresponding binding isotherm (inset) used for non-linear regression analysis and determination of the association constant $\left(\mathrm{K}_{\mathrm{a}}\right)$ that reflects $\mathrm{XB}$ interaction strength of the adduct (Solvent: cyclohexane). 


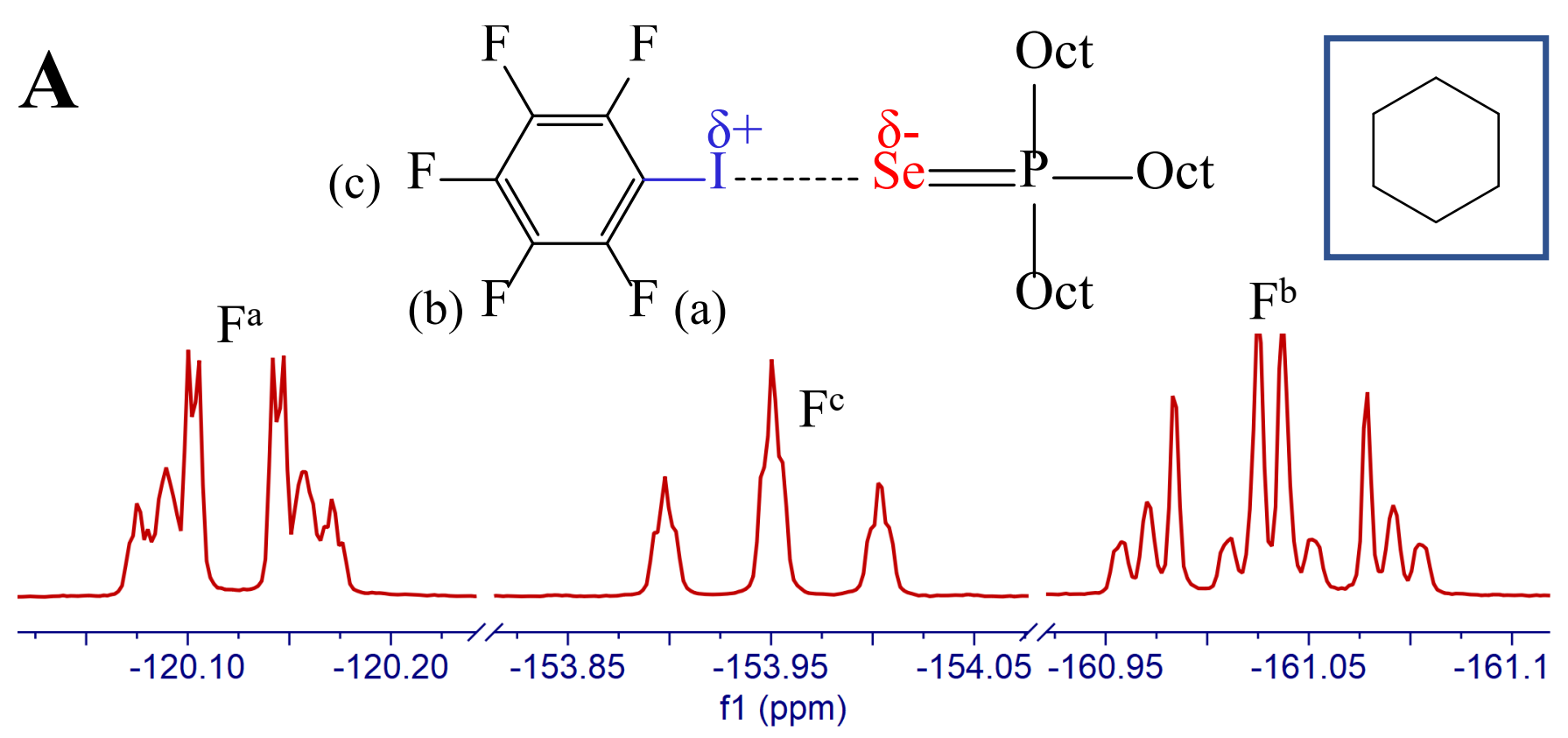

B

\section{[Oct ${ }_{3}$ PSe] (M)}

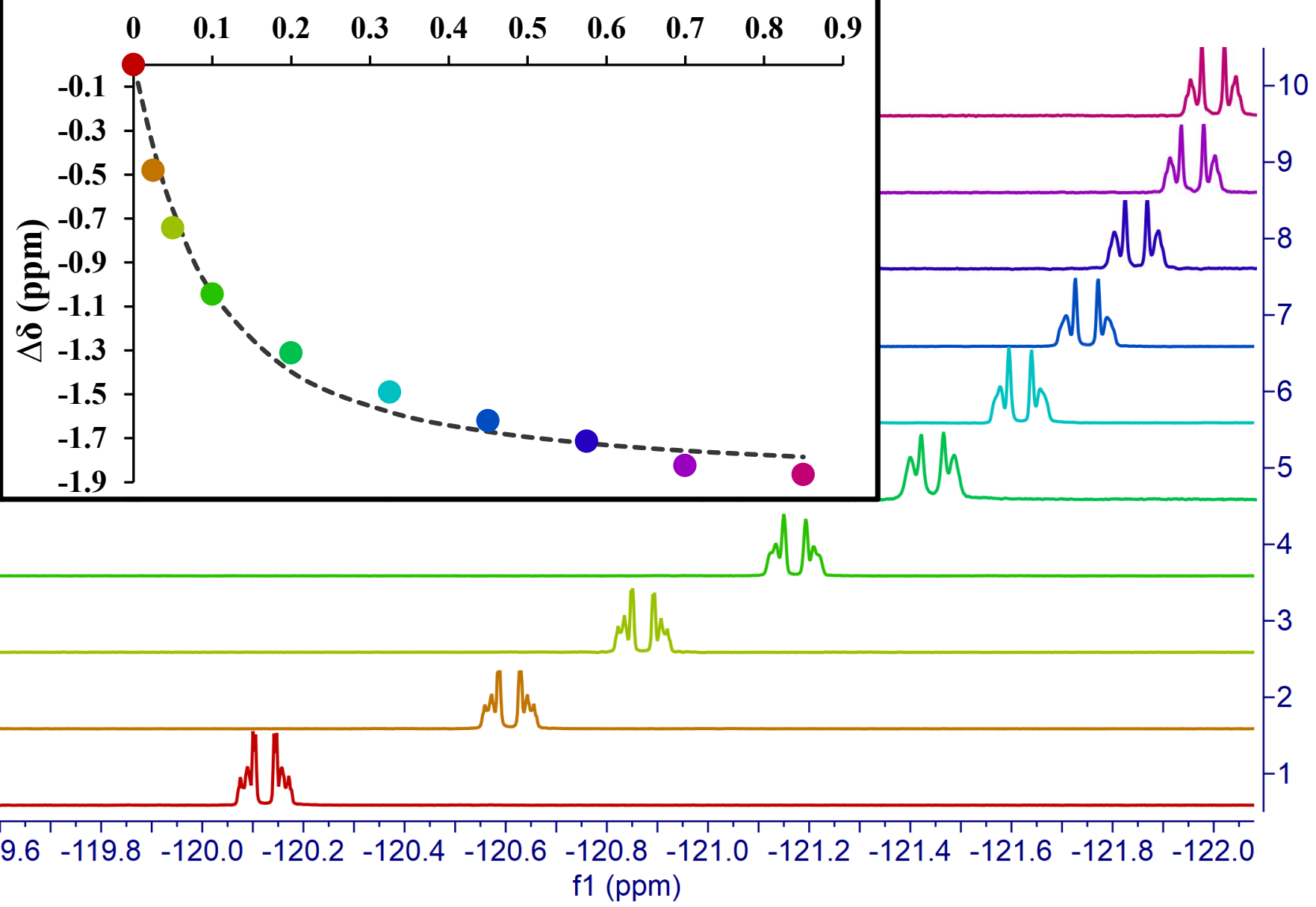

Figure S31. Representative NMR-titration experiment for XB donor iodopentafluorobenzene (I-PFB)

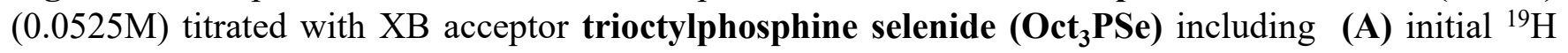
NMR spectrum of I-PFB prior to titration and (B) the change in the ortho F resonance shifts during addition of increasing concentrations of $\mathbf{O c t}_{\mathbf{3}} \mathbf{P S e}$ and the corresponding binding isotherm (inset) used for non-linear regression analysis and determination of the association constant $\left(\mathrm{K}_{\mathrm{a}}\right)$ that reflects $\mathrm{XB}$ interaction strength of the adduct (Solvent: cyclohexane). 


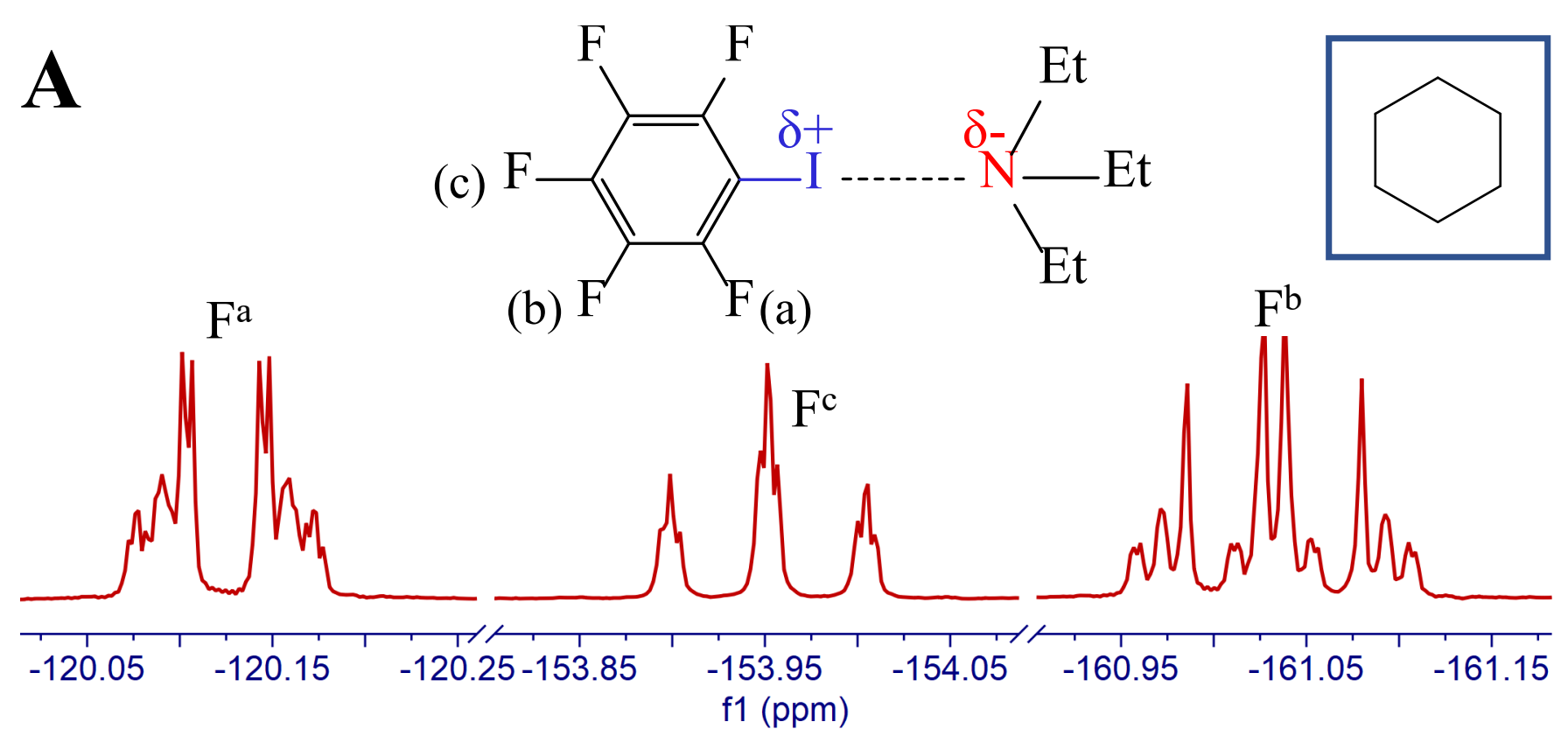

B

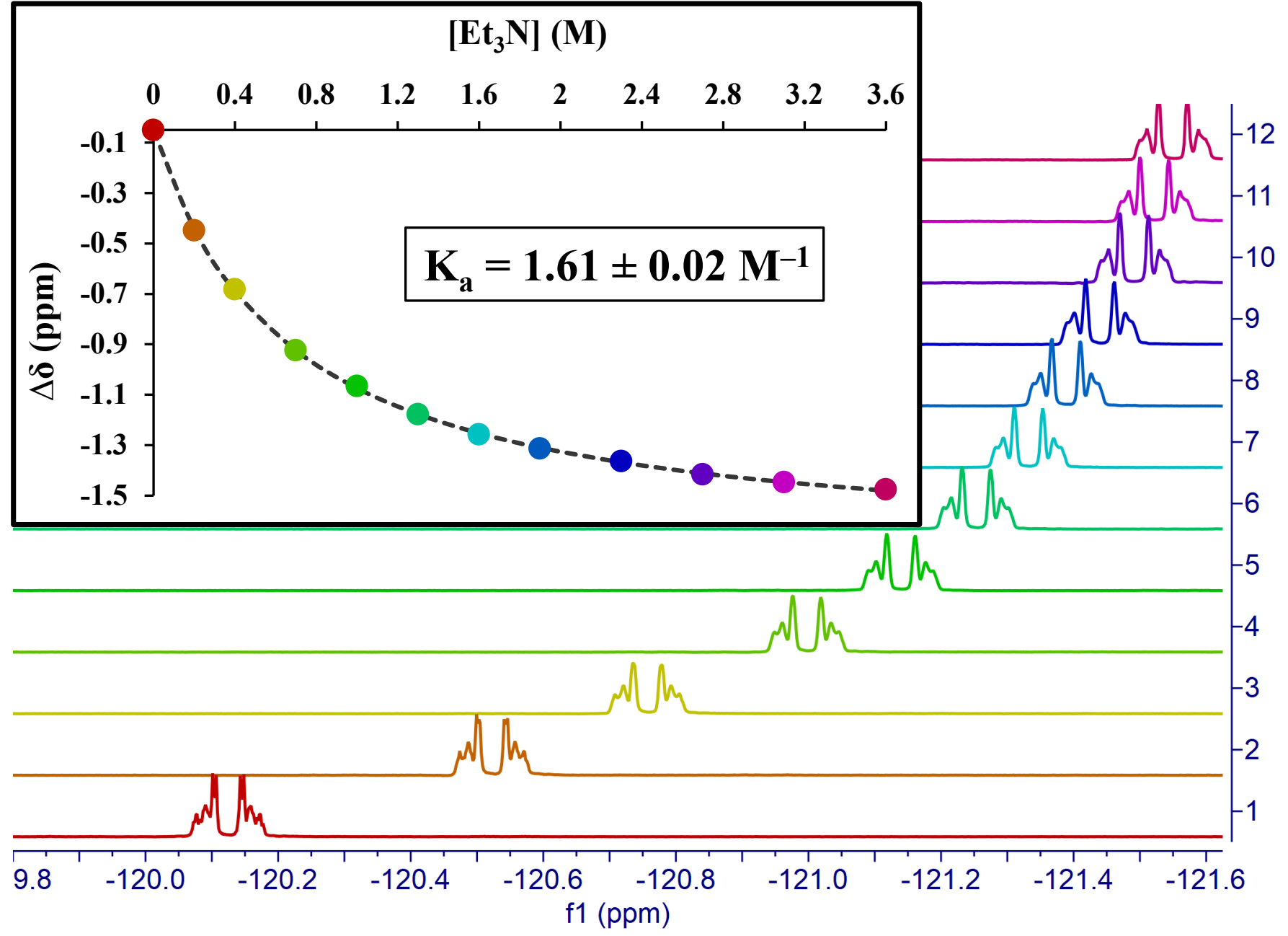

Figure S32. Representative NMR-titration experiment for XB donor iodopentafluorobenzene (I-PFB) $(0.0525 \mathrm{M})$ titrated with $\mathrm{XB}$ acceptor triethylamine $\left(\mathbf{E t}_{\mathbf{3}} \mathbf{N}\right)$ including (A) initial ${ }^{19} \mathrm{H}$ NMR spectrum of I-PFB prior to titration and (B) the change in the ortho $\mathrm{F}$ resonance shifts during addition of increasing concentrations of $\mathbf{E t}_{\mathbf{3}} \mathbf{N}$ and the corresponding binding isotherm (inset) used for non-linear regression analysis and determination of the association constant $\left(\mathrm{K}_{\mathrm{a}}\right)$ that reflects $\mathrm{XB}$ interaction strength of the adduct (Solvent: cyclohexane). 


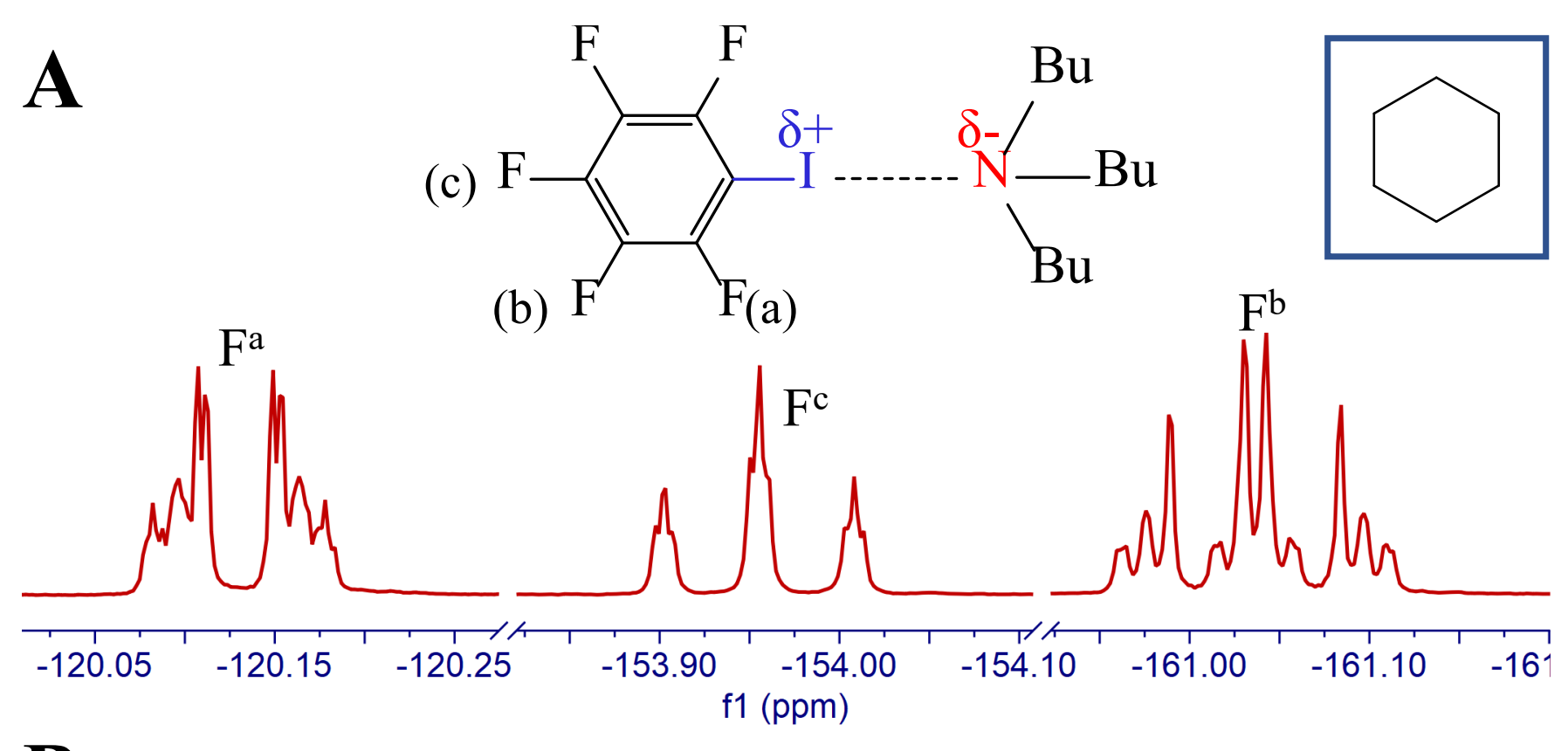

\section{B}

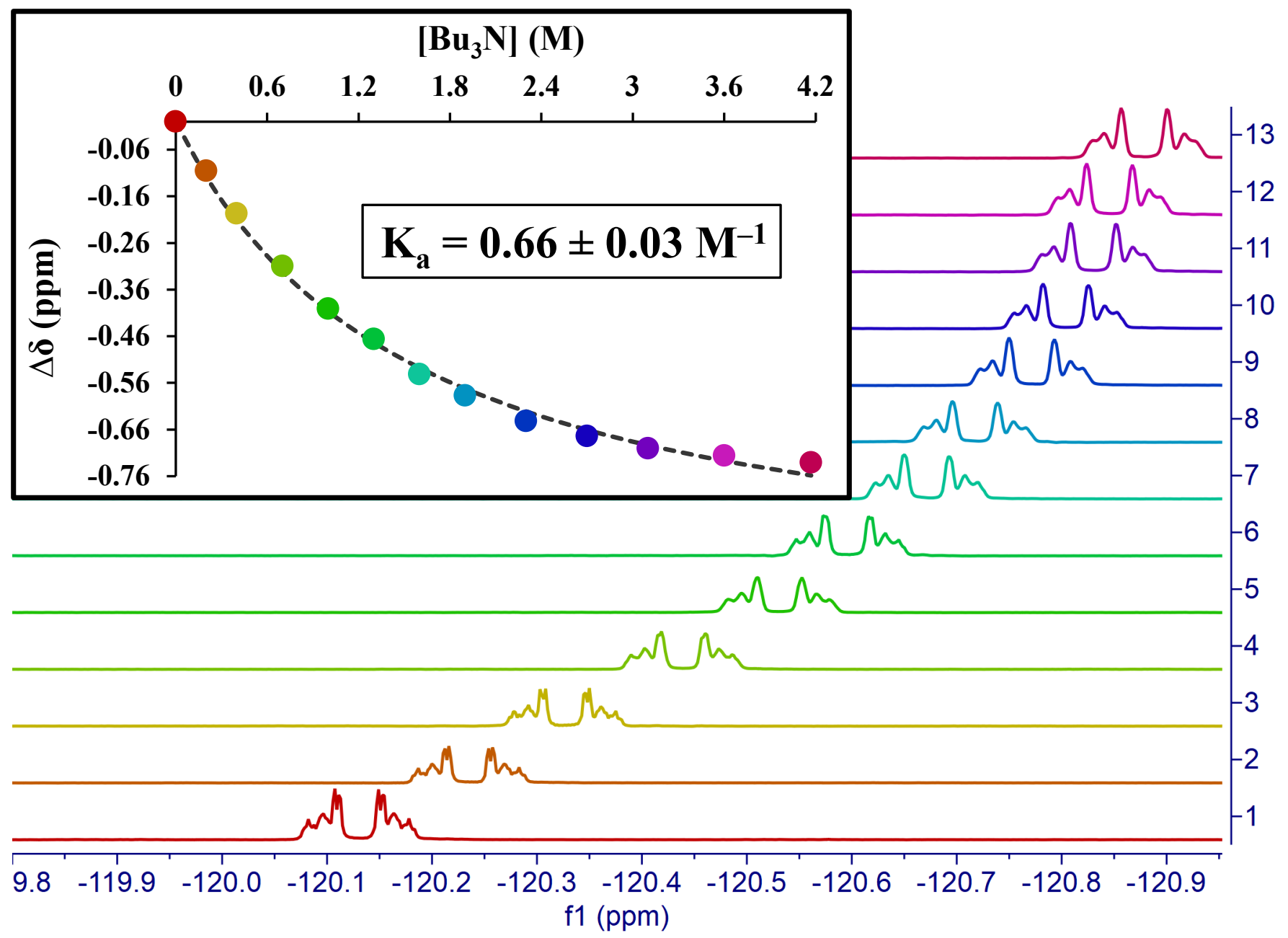

Figure S33. Representative NMR-titration experiment for XB donor iodopentafluorobenzene (I-PFB) $(0.0525 \mathrm{M})$ titrated with $\mathrm{XB}$ acceptor tributylamine $\left(\mathbf{B u}_{\mathbf{3}} \mathbf{N}\right)$ including $(\mathbf{A})$ initial ${ }^{19} \mathrm{H}$ NMR spectrum of I-PFB prior to titration and (B) the change in the ortho $\mathrm{F}$ resonance shifts during addition of increasing concentrations of $\mathbf{B u}_{3} \mathbf{N}$ and the corresponding binding isotherm (inset) used for non-linear regression analysis and determination of the association constant $\left(\mathrm{K}_{\mathrm{a}}\right)$ that reflects $\mathrm{XB}$ interaction strength of the adduct (Solvent: cyclohexane). 


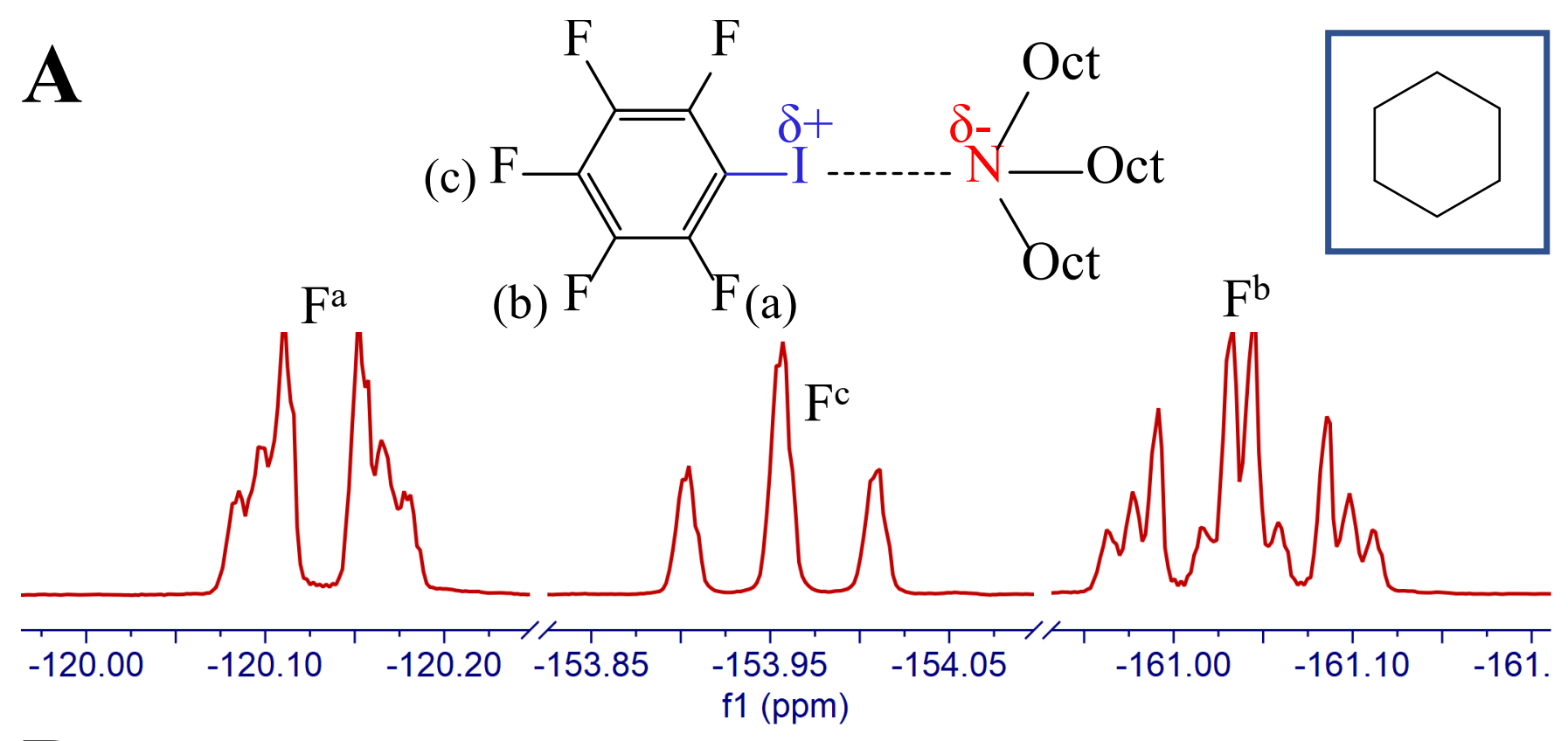

B

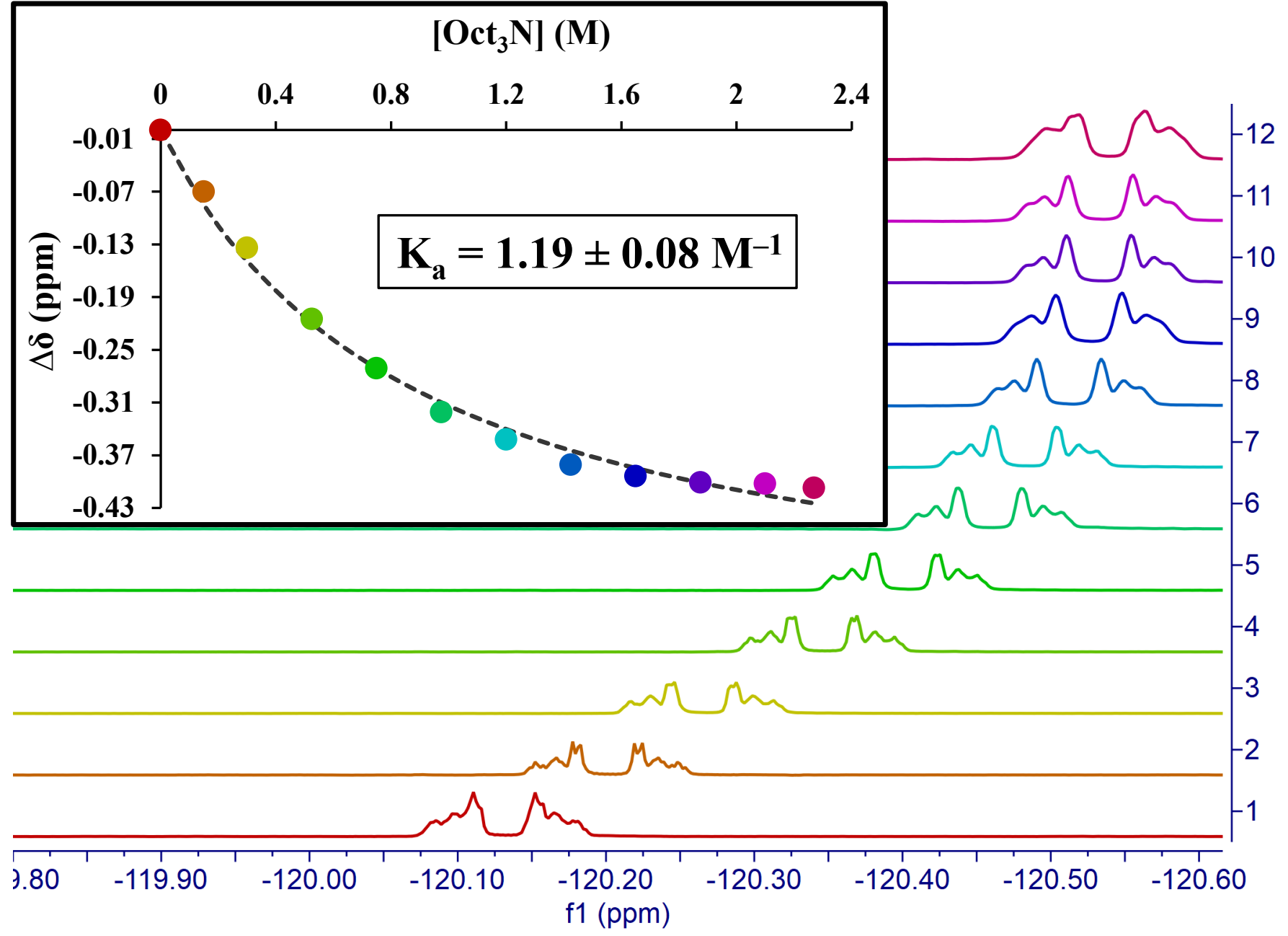

Figure S34. Representative NMR-titration experiment for XB donor iodopentafluorobenzene (I-PFB) $(0.0525 \mathrm{M})$ titrated with $\mathrm{XB}$ acceptor trioctylamine $\left(\mathbf{O c t}_{\mathbf{3}} \mathbf{N}\right)$ including $(\mathbf{A})$ initial ${ }^{19} \mathrm{H}$ NMR spectrum of I-PFB prior to titration and (B) the change in the ortho $\mathrm{F}$ resonance shifts during addition of increasing concentrations of $\mathbf{O c t}_{\mathbf{3}} \mathbf{N}$ and the corresponding binding isotherm (inset) used for non-linear regression analysis and determination of the association constant $\left(\mathrm{K}_{\mathrm{a}}\right)$ that reflects $\mathrm{XB}$ interaction strength of the adduct (Solvent: cyclohexane). 


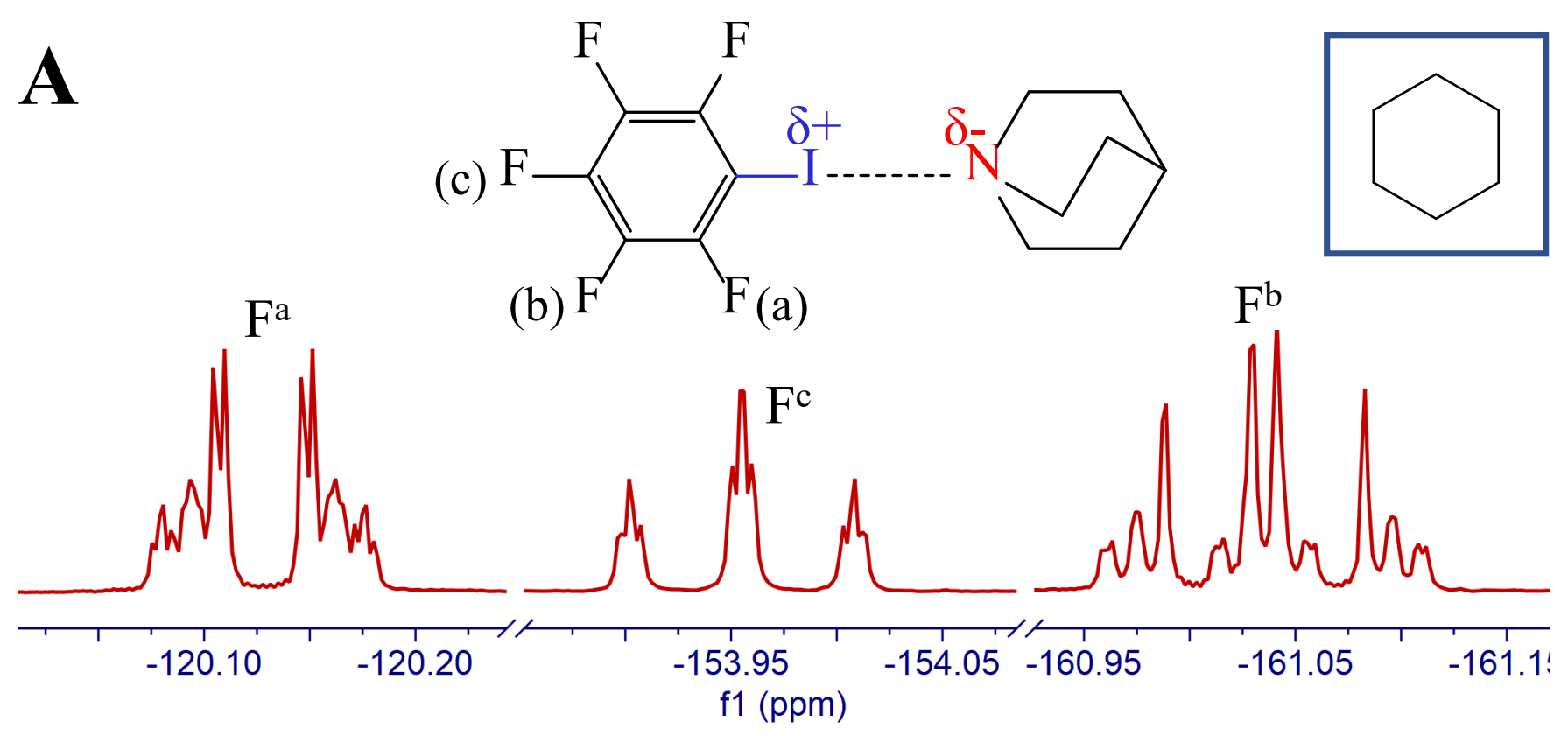

B

[Quinuclidine] (M)

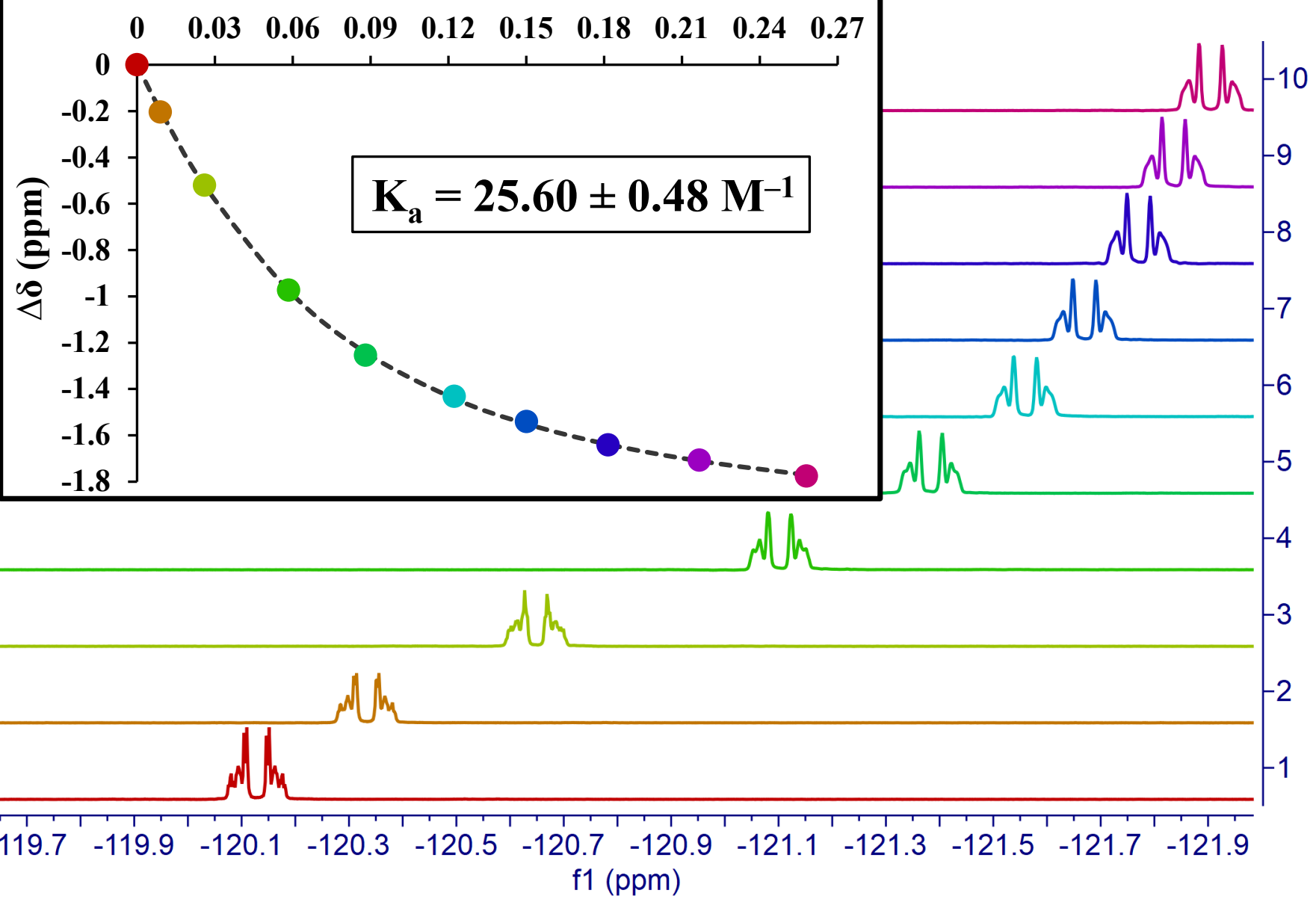

Figure S35. Representative NMR-titration experiment for XB donor iodopentafluorobenzene (I-PFB) $(0.0525 \mathrm{M})$ titrated with XB acceptor quinuclidine including (A) initial ${ }^{19} \mathrm{H}$ NMR spectrum of I-PFB prior to titration and (B) the change in the ortho $\mathrm{F}$ resonance shifts during addition of increasing concentrations of quinuclidine and the corresponding binding isotherm (inset) used for non-linear regression analysis and determination of the association constant $\left(\mathrm{K}_{\mathrm{a}}\right)$ that reflects XB interaction strength of the adduct (Solvent: cyclohexane). 


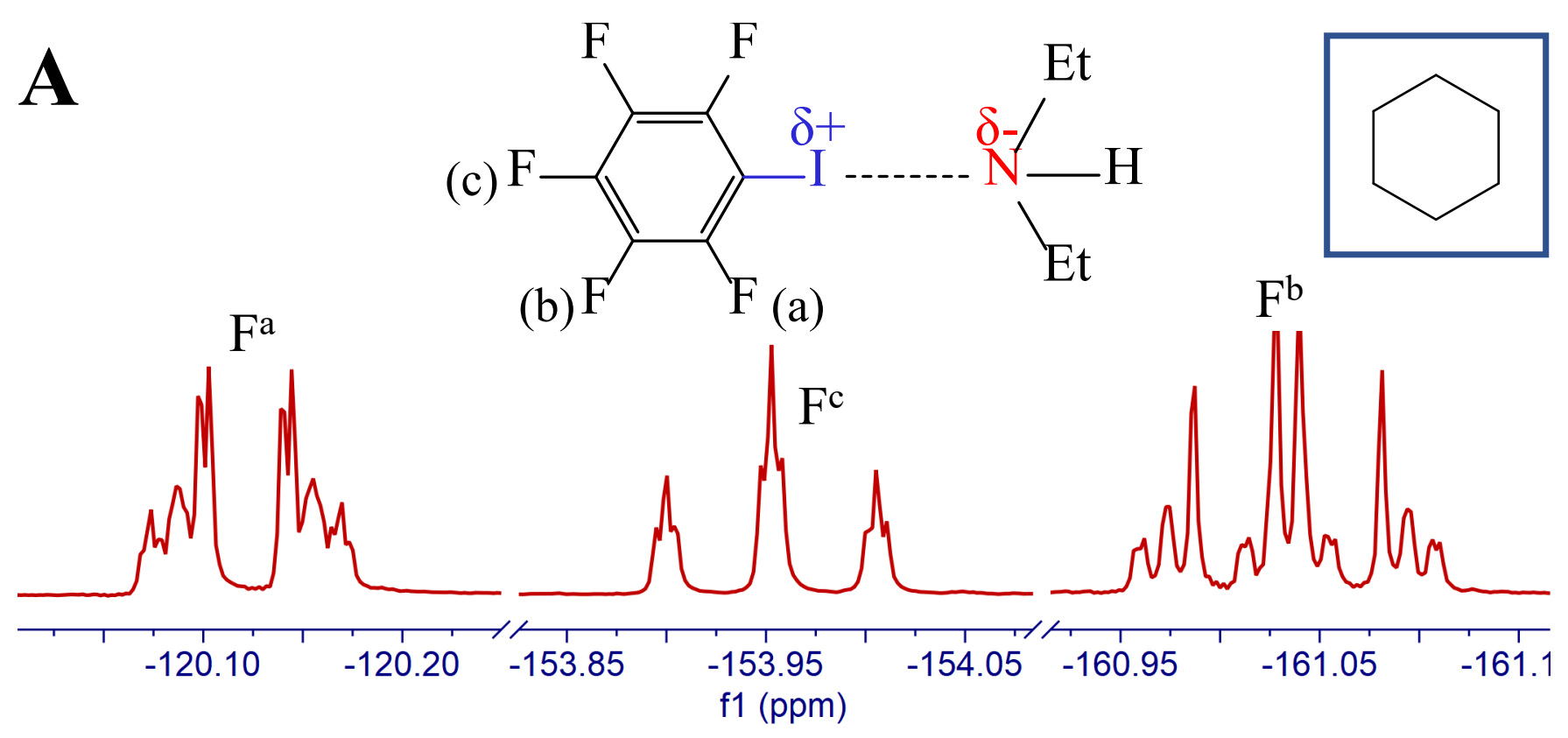

B

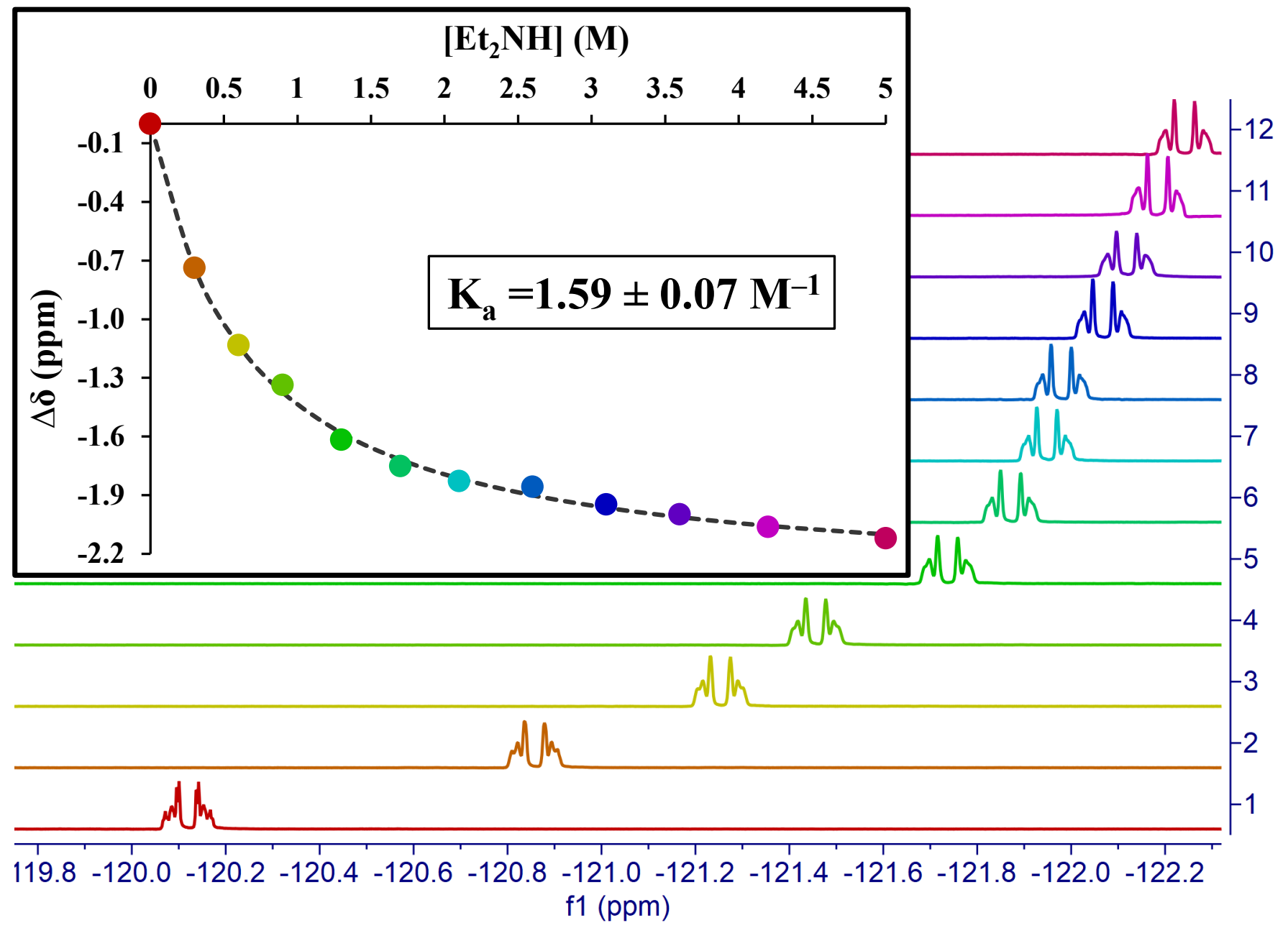

Figure S36. Representative NMR-titration experiment for XB donor iodopentafluorobenzene (I-PFB) $(0.0525 \mathrm{M})$ titrated with XB acceptor diethylamine (Et $\left.\mathbf{t}_{\mathbf{2}} \mathbf{N H}\right)$ including (A) initial ${ }^{19} \mathrm{H}$ NMR spectrum of I-PFB prior to titration and (B) the change in the ortho $\mathrm{F}$ resonance shifts during addition of increasing concentrations of $\mathbf{E t}_{\mathbf{2}} \mathbf{N H}$ and the corresponding binding isotherm (inset) used for non-linear regression analysis and determination of the association constant $\left(\mathrm{K}_{\mathrm{a}}\right)$ that reflects $\mathrm{XB}$ interaction strength of the adduct (Solvent: cyclohexane). 


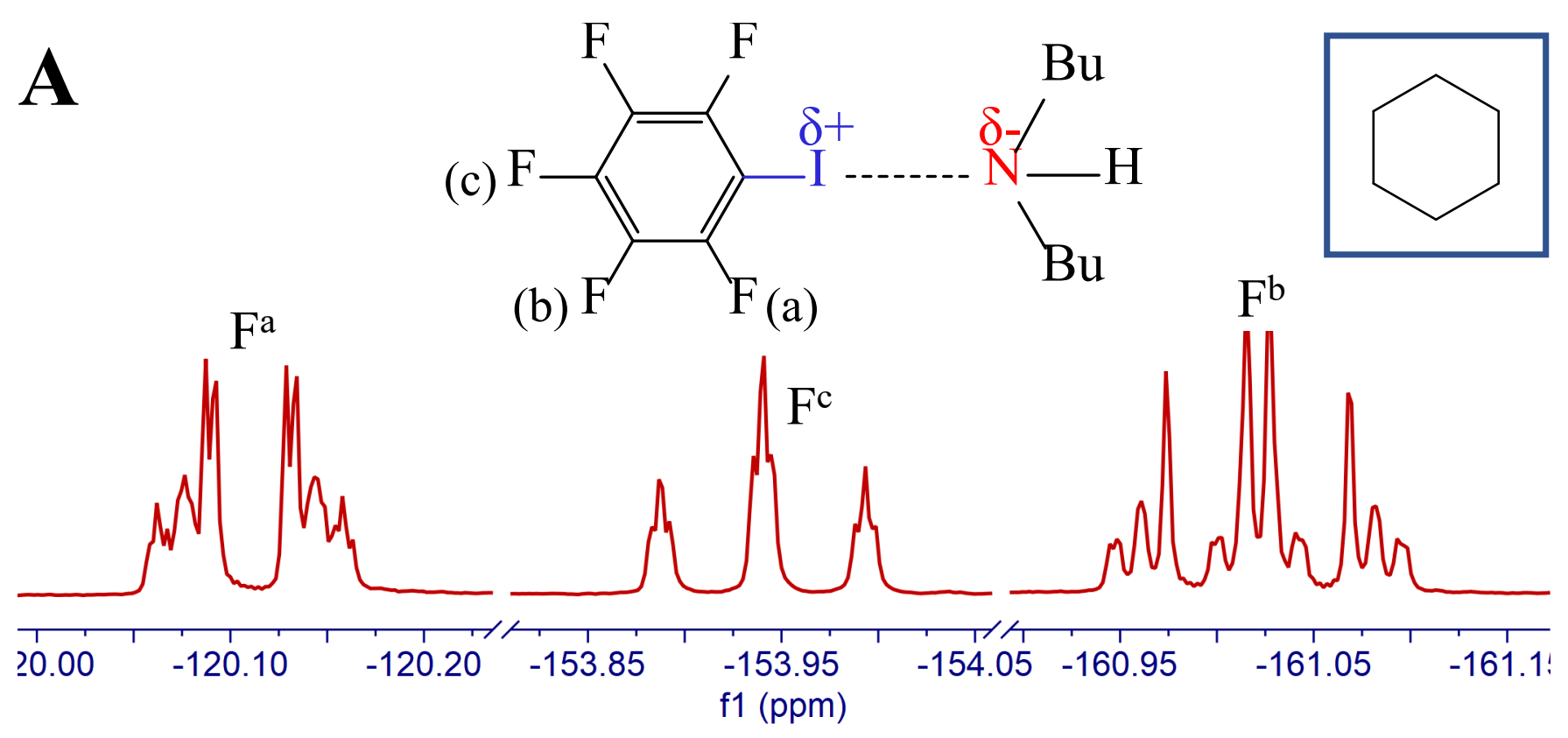

B

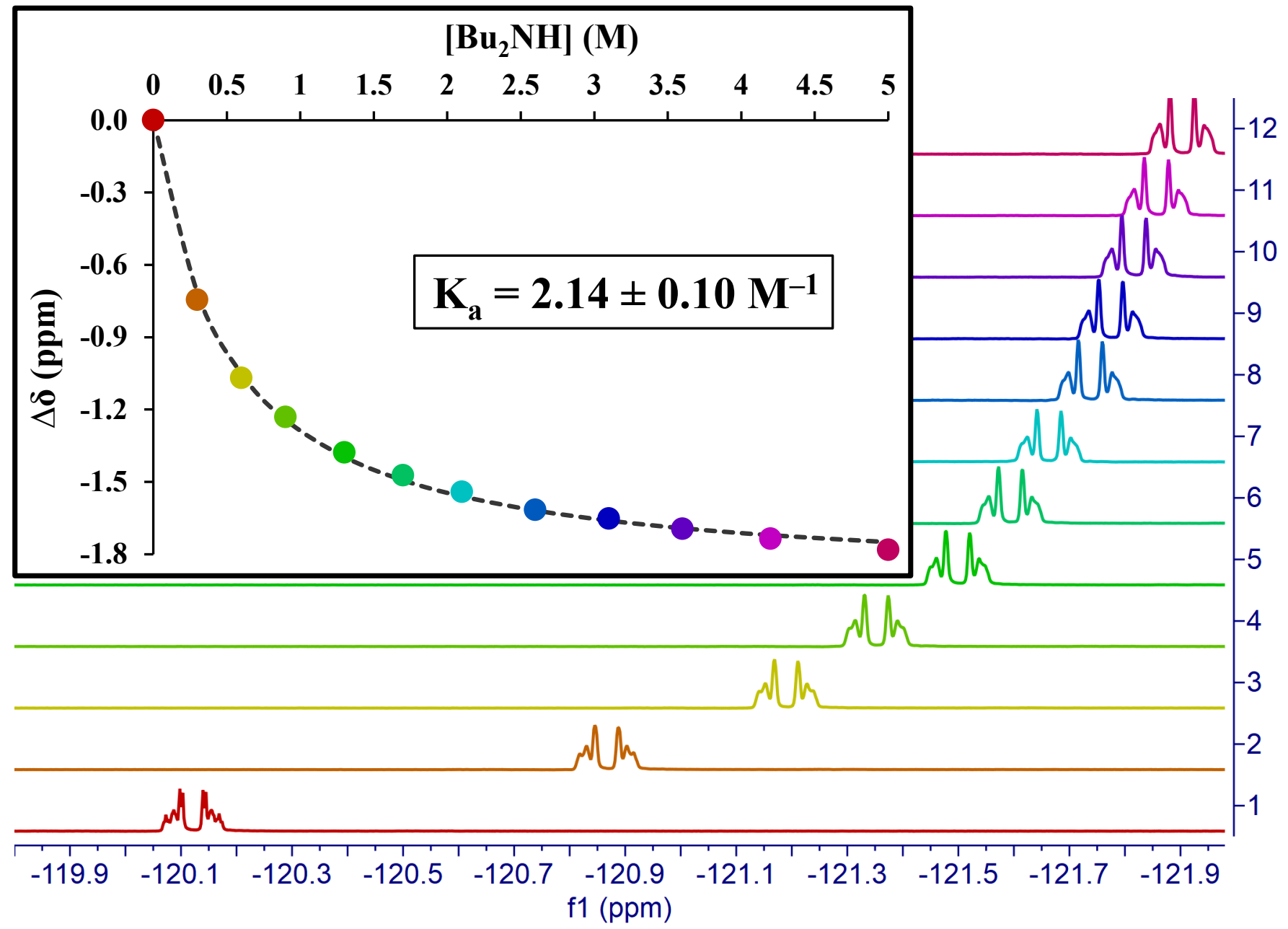

Figure S37. Representative NMR-titration experiment for XB donor iodopentafluorobenzene (I-PFB) $(0.0525 \mathrm{M})$ titrated with $\mathrm{XB}$ acceptor dibutylamine $\left(\mathbf{B u}_{\mathbf{2}} \mathbf{N H}\right)$ including $(\mathbf{A})$ initial ${ }^{19} \mathrm{H}$ NMR spectrum of I-PFB prior to titration and (B) the change in the ortho $F$ resonance shifts during addition of increasing concentrations of $\mathbf{B u}_{\mathbf{2}} \mathbf{N H}$ and the corresponding binding isotherm (inset) used for non-linear regression analysis and determination of the association constant $\left(\mathrm{K}_{\mathrm{a}}\right)$ that reflects $\mathrm{XB}$ interaction strength of the adduct (Solvent: cyclohexane). 

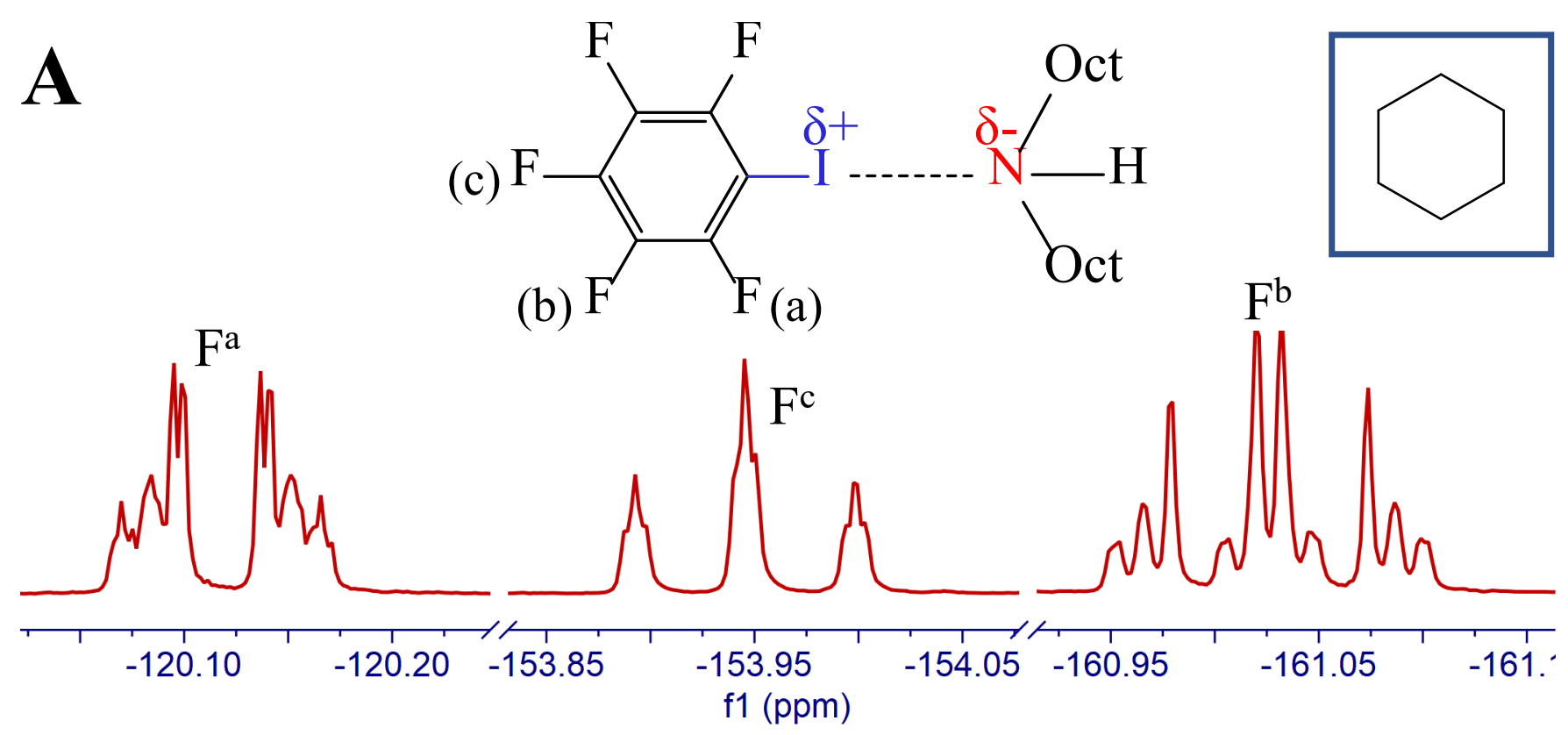

B

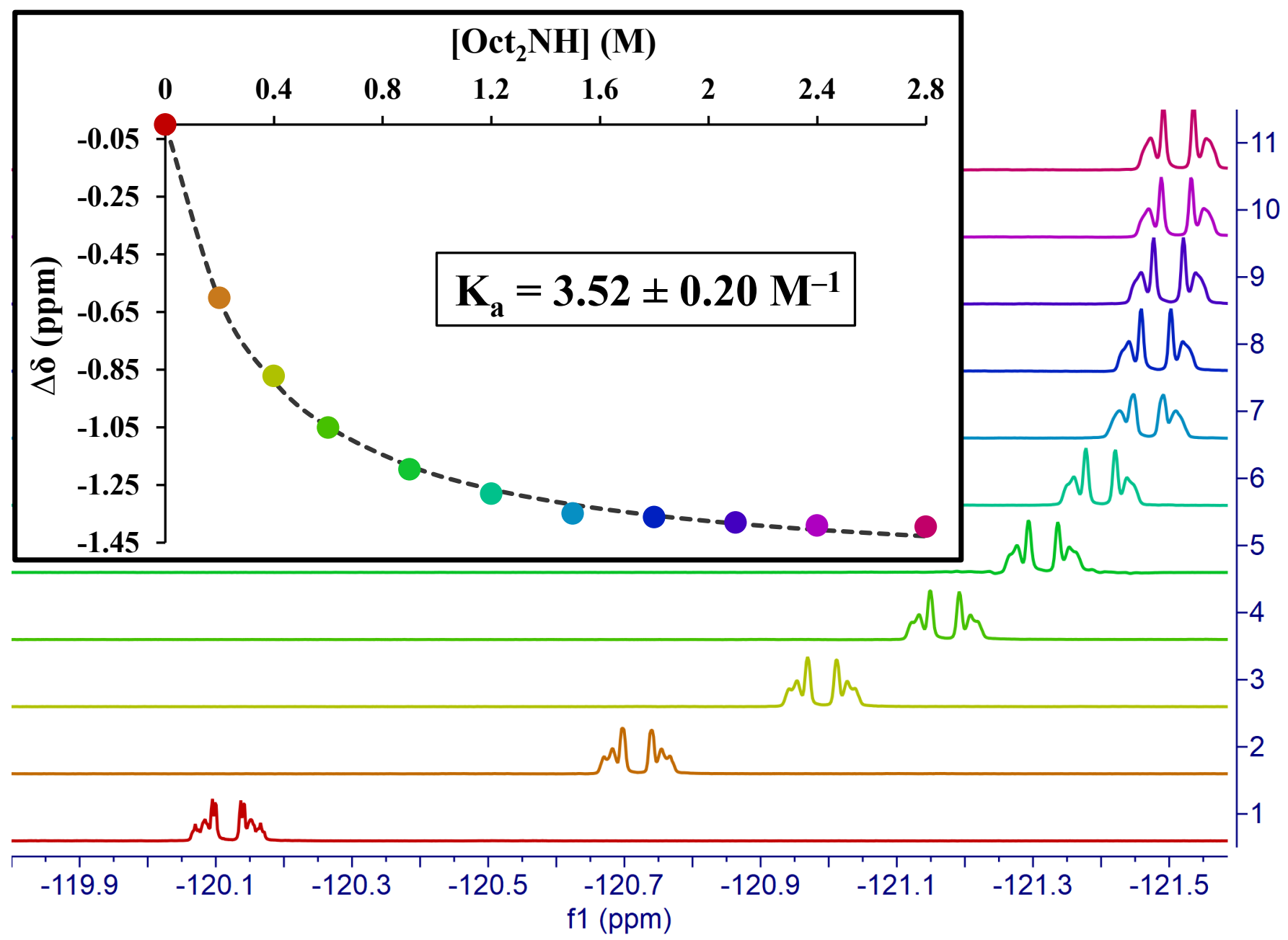

Figure S38. Representative NMR-titration experiment for XB donor iodopentafluorobenzene (I-PFB) $(0.0525 \mathrm{M})$ titrated with XB acceptor dioctylamine (Oct $\left.{ }_{\mathbf{2}} \mathbf{N H}\right)$ including (A) initial ${ }^{19} \mathrm{H}$ NMR spectrum of I-PFB prior to titration and (B) the change in the ortho $F$ resonance shifts during addition of increasing concentrations of $\mathbf{O c t}_{\mathbf{2}} \mathbf{N H}$ and the corresponding binding isotherm (inset) used for non-linear regression analysis and determination of the association constant $\left(\mathrm{K}_{\mathrm{a}}\right)$ that reflects $\mathrm{XB}$ interaction strength of the adduct (Solvent: cyclohexane). 


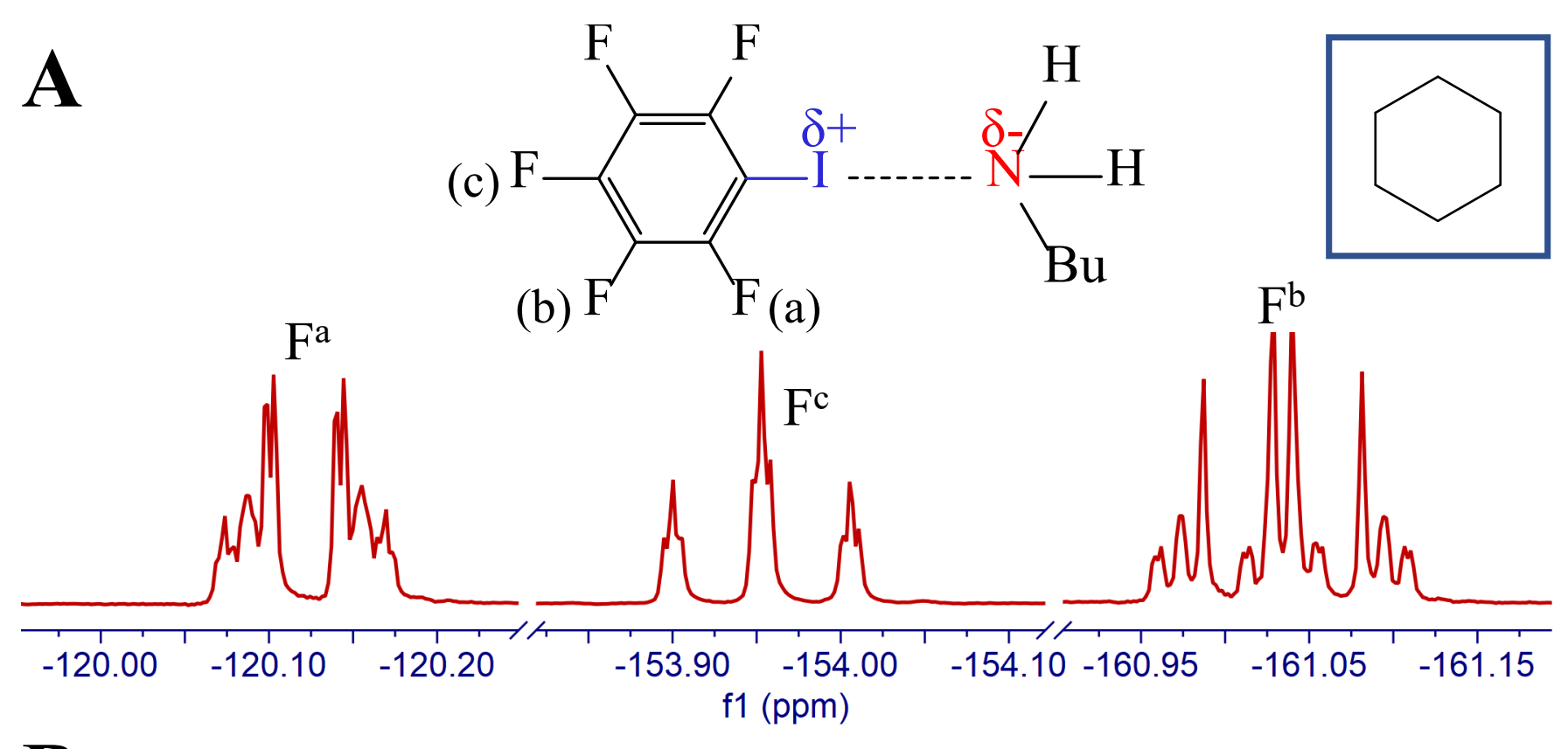

B

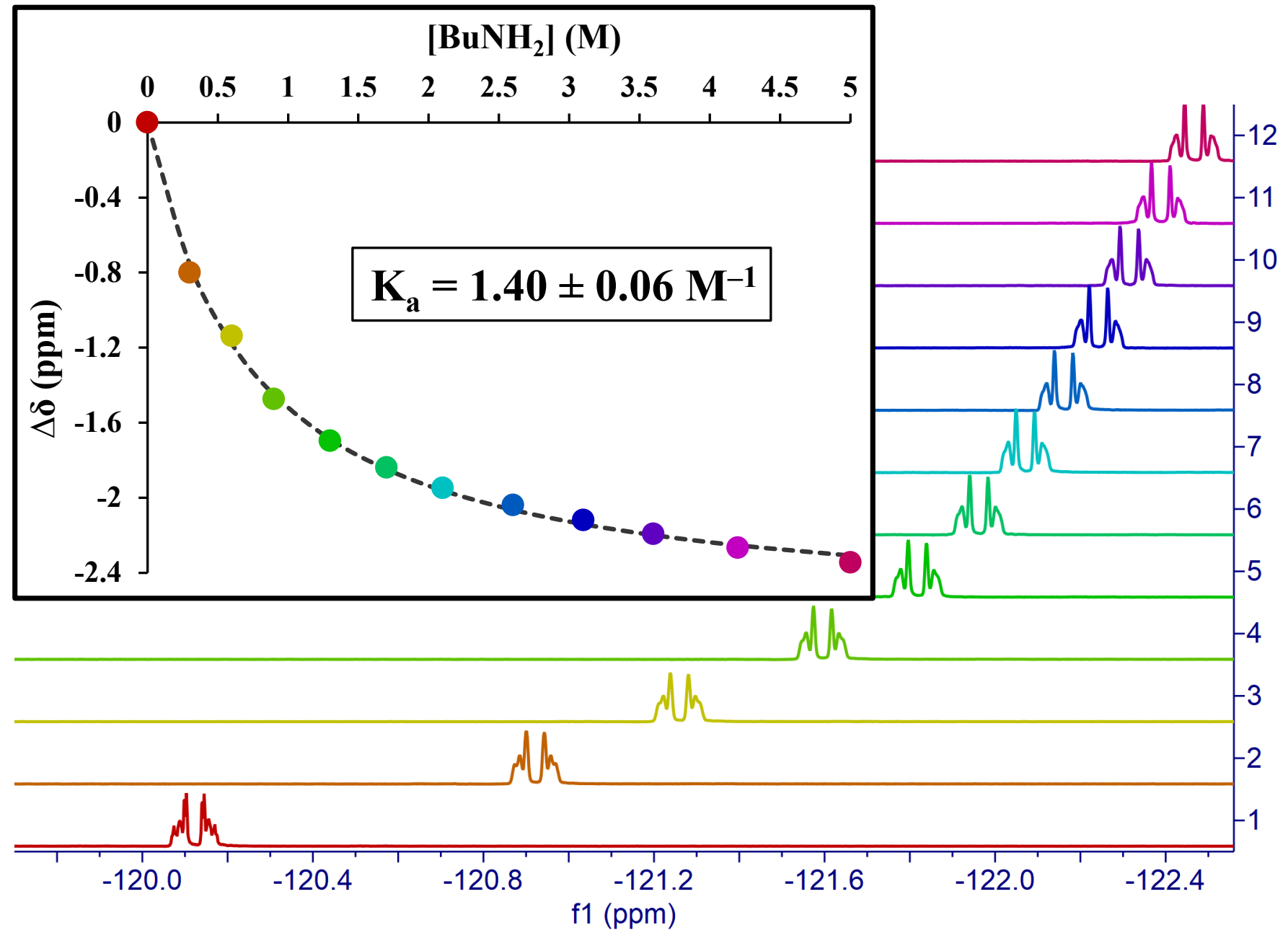

Figure S39. Representative NMR-titration experiment for XB donor iodopentafluorobenzene (I-PFB) $(0.0525 \mathrm{M})$ titrated with XB acceptor butylamine $\left(\mathbf{B u N H}_{2}\right)$ including (A) initial ${ }^{19} \mathrm{H}$ NMR spectrum of I-PFB prior to titration and (B) the change in the ortho $\mathrm{F}$ resonance shifts during addition of increasing concentrations of $\mathbf{B u N H}_{2}$ and the corresponding binding isotherm (inset) used for non-linear regression analysis and determination of the association constant $\left(\mathrm{K}_{\mathrm{a}}\right)$ that reflects $\mathrm{XB}$ interaction strength of the adduct (Solvent: cyclohexane). 


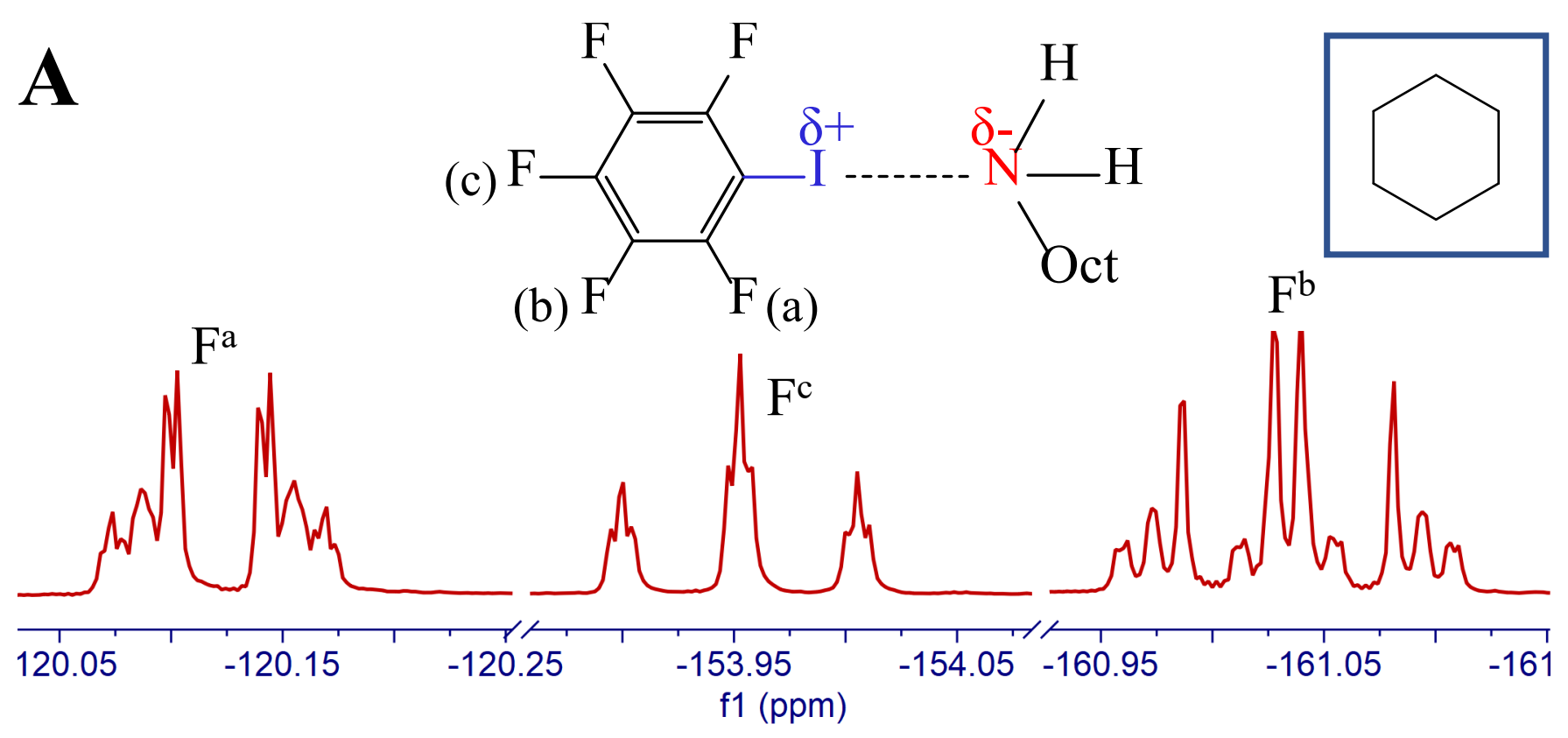

\section{B}

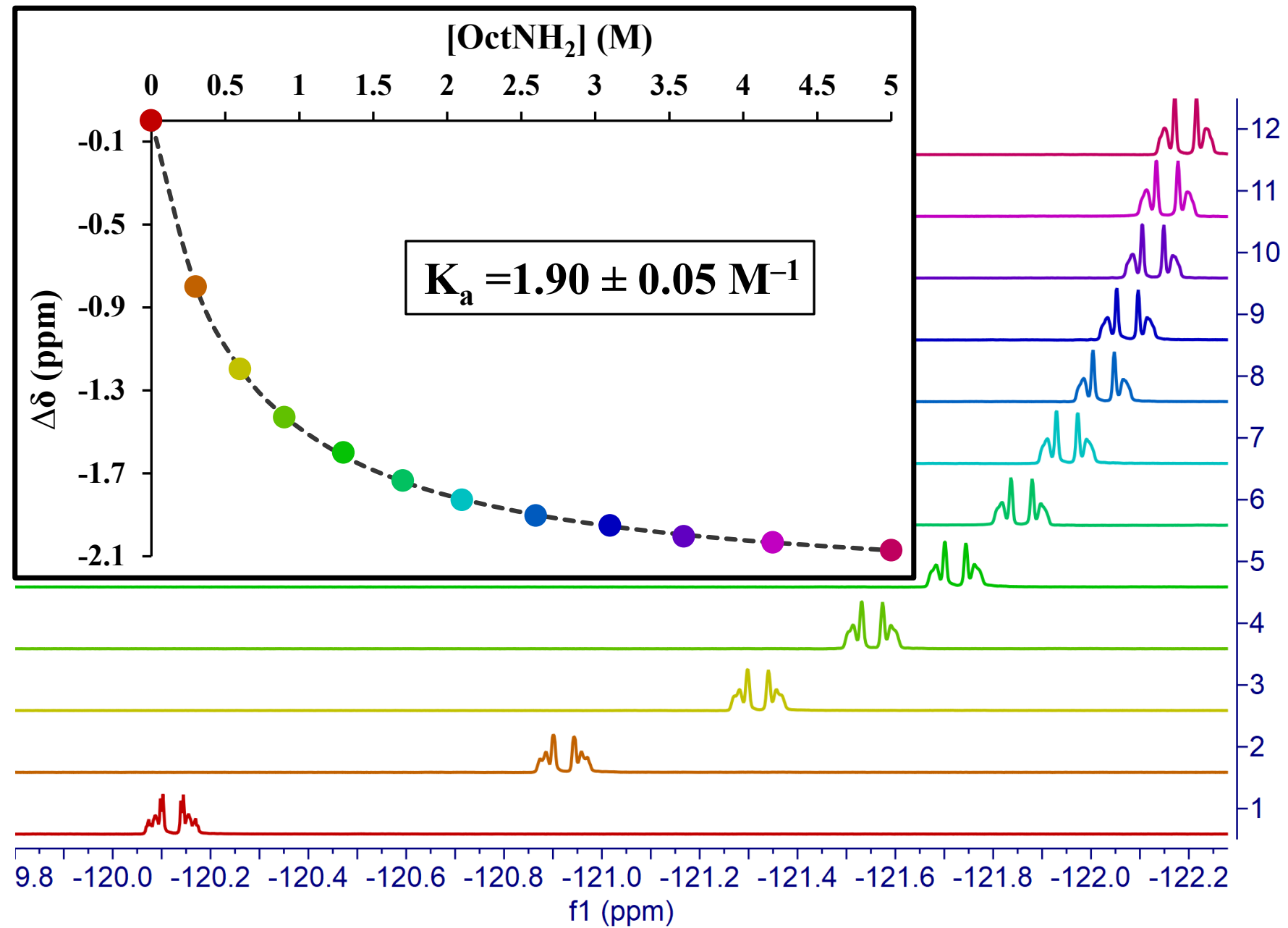

Figure S40. Representative NMR-titration experiment for XB donor iodopentafluorobenzene (I-PFB) $(0.0525 \mathrm{M})$ titrated with XB acceptor octylamine $\left(\mathbf{O c t} \mathbf{N H}_{2}\right)$ including (A) initial ${ }^{19} \mathrm{H}$ NMR spectrum of I-PFB prior to titration and (B) the change in the ortho $\mathrm{F}$ resonance shifts during addition of increasing concentrations of $\mathbf{O c t N H}_{2}$ and the corresponding binding isotherm (inset) used for non-linear regression analysis and determination of the association constant $\left(\mathrm{K}_{\mathrm{a}}\right)$ that reflects $\mathrm{XB}$ interaction strength of the adduct (Solvent: cyclohexane). 

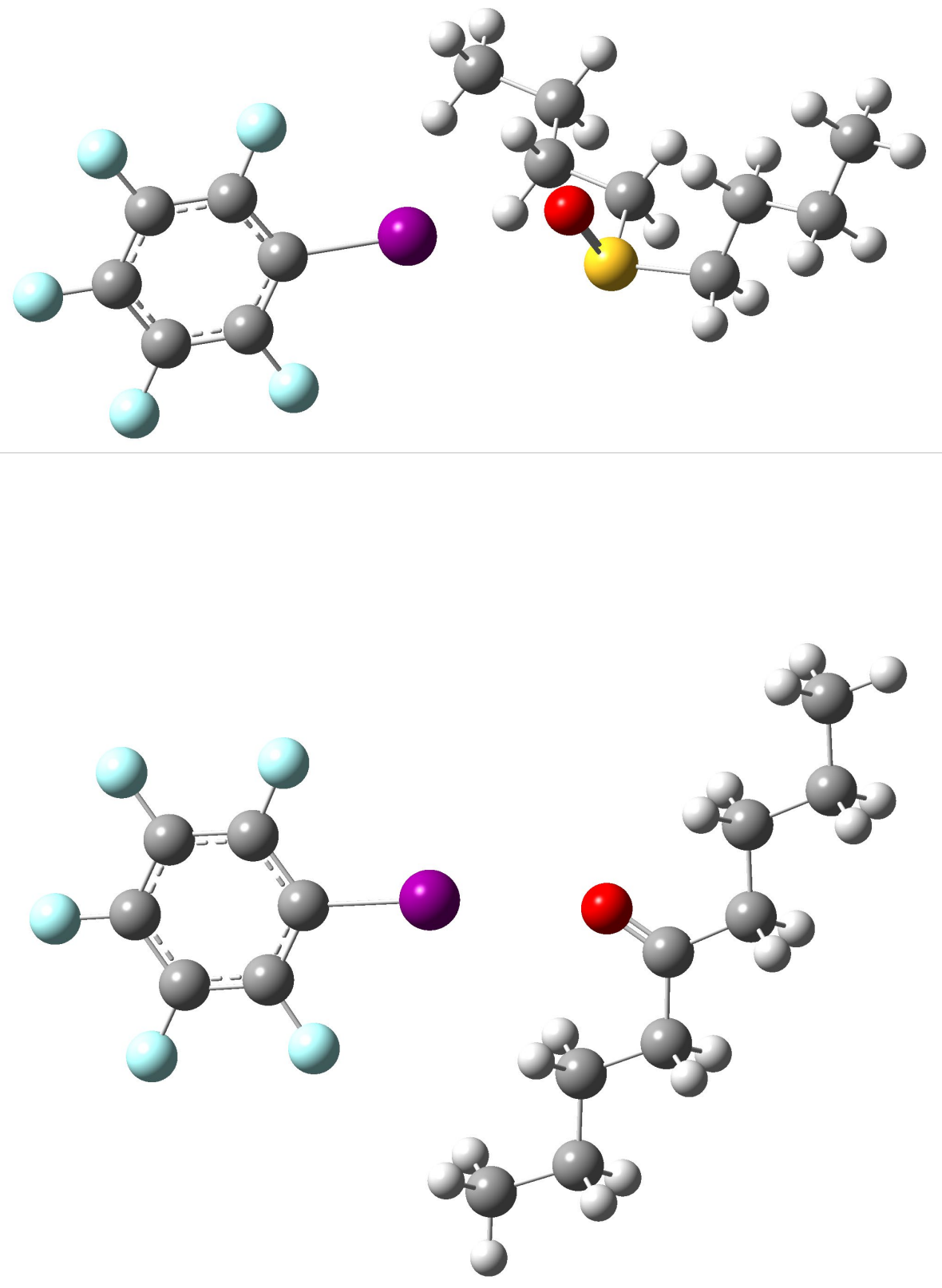

Figure S41. Geometry optimized XB adducts of XB donor iodopentafluorobenzene (I-PFB) with XB acceptors dibutyl sulfoxide $\left(\mathrm{Bu}_{2} \mathrm{SO}\right)$ (top) and 5-nonanone $\left(\mathrm{Bu}_{2} \mathrm{CO}\right)$ (bottom). 

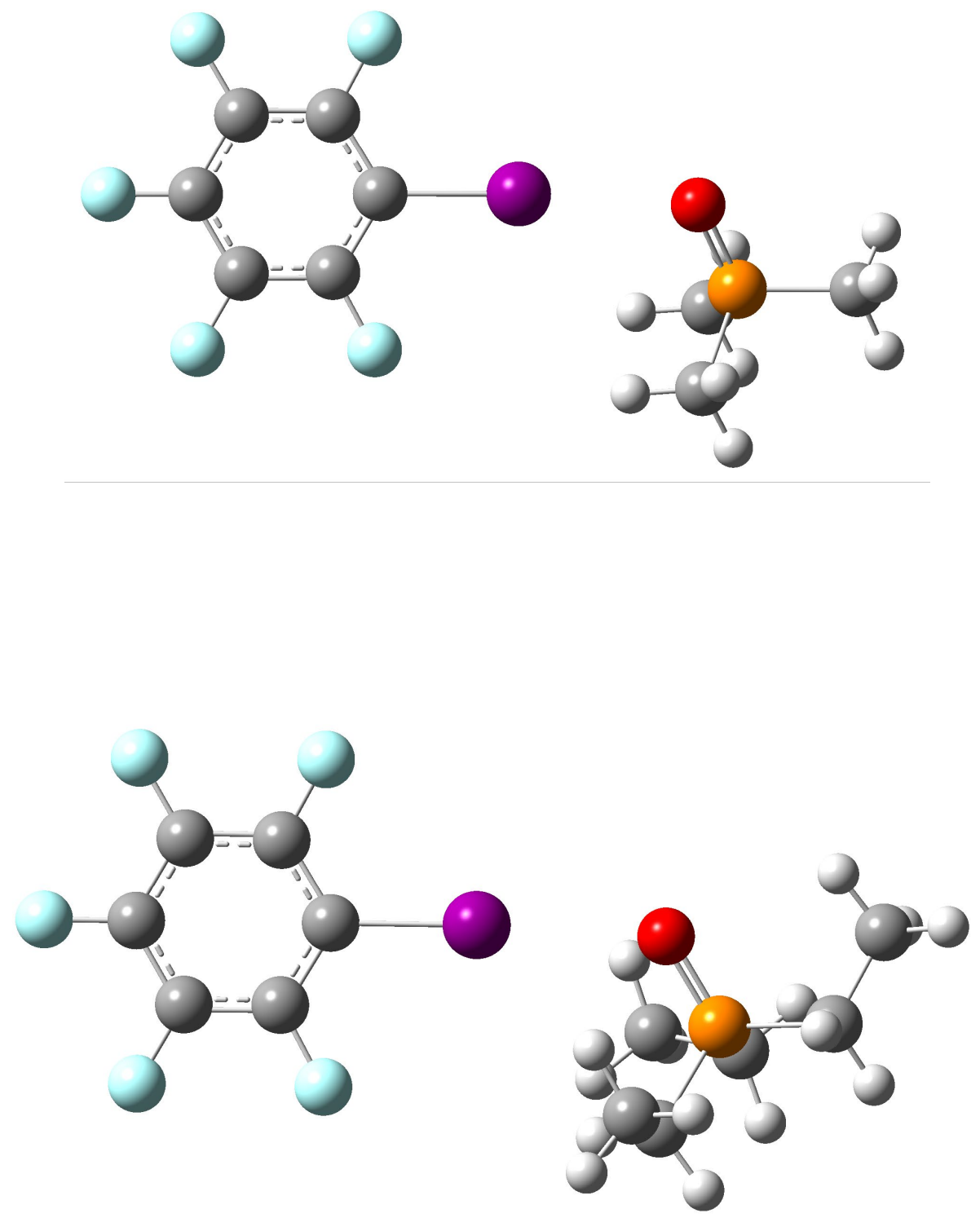

Figure S42. Geometry optimized XB adducts of XB donor iodopentafluorobenzene (I-PFB) with XB acceptors trimethylphosphine oxide $\left(\mathrm{Me}_{3} \mathbf{P O}\right)$ (top) and triethylphosphine oxide (Et $\left.{ }_{3} \mathbf{P O}\right)$ (bottom). 


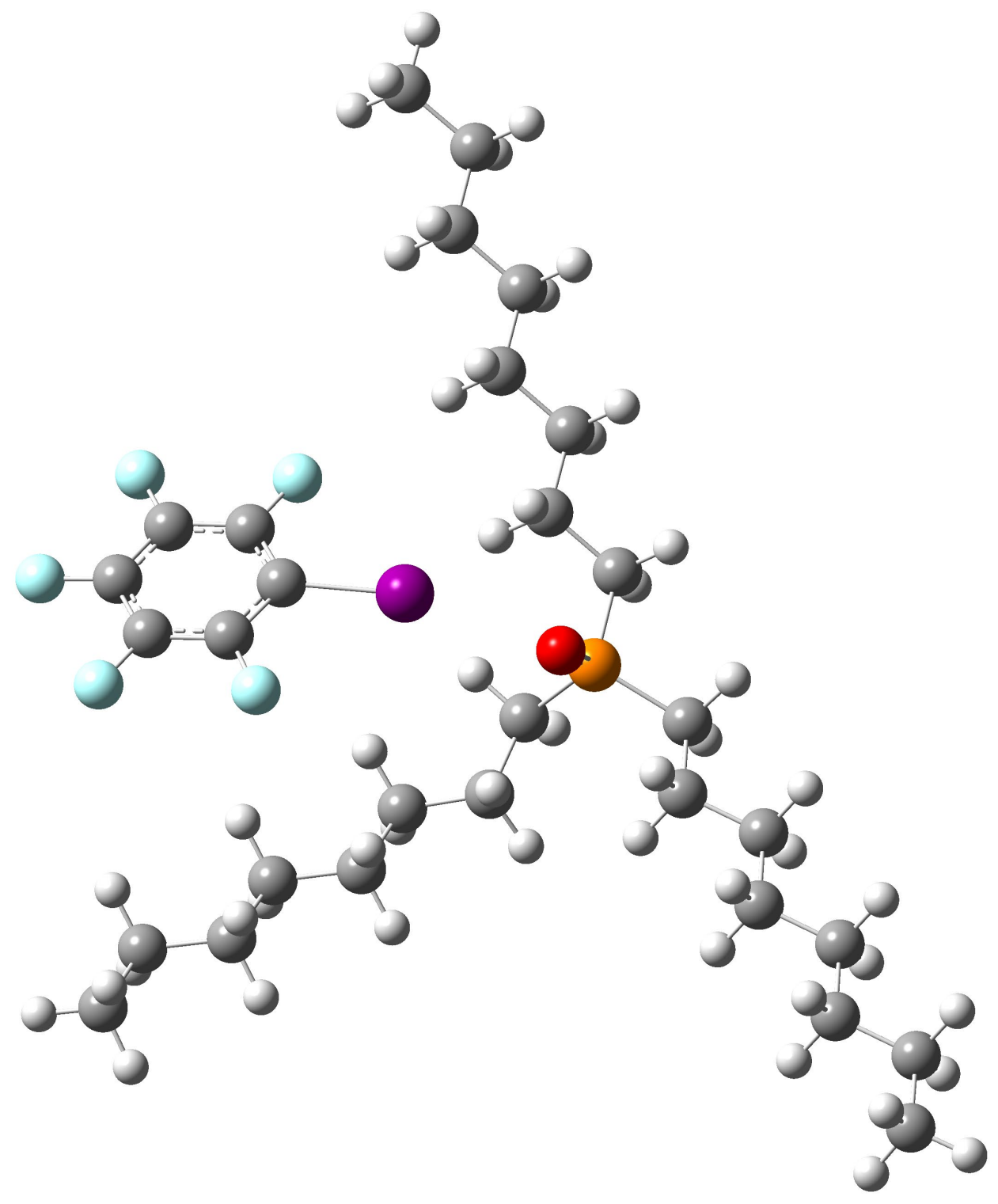

Figure S43. Geometry optimized XB adducts of XB donor iodopentafluorobenzene (I-PFB) with XB acceptor trioctylphosphine oxide $\left(\operatorname{Oct}_{3} \mathbf{P O}\right)$. 

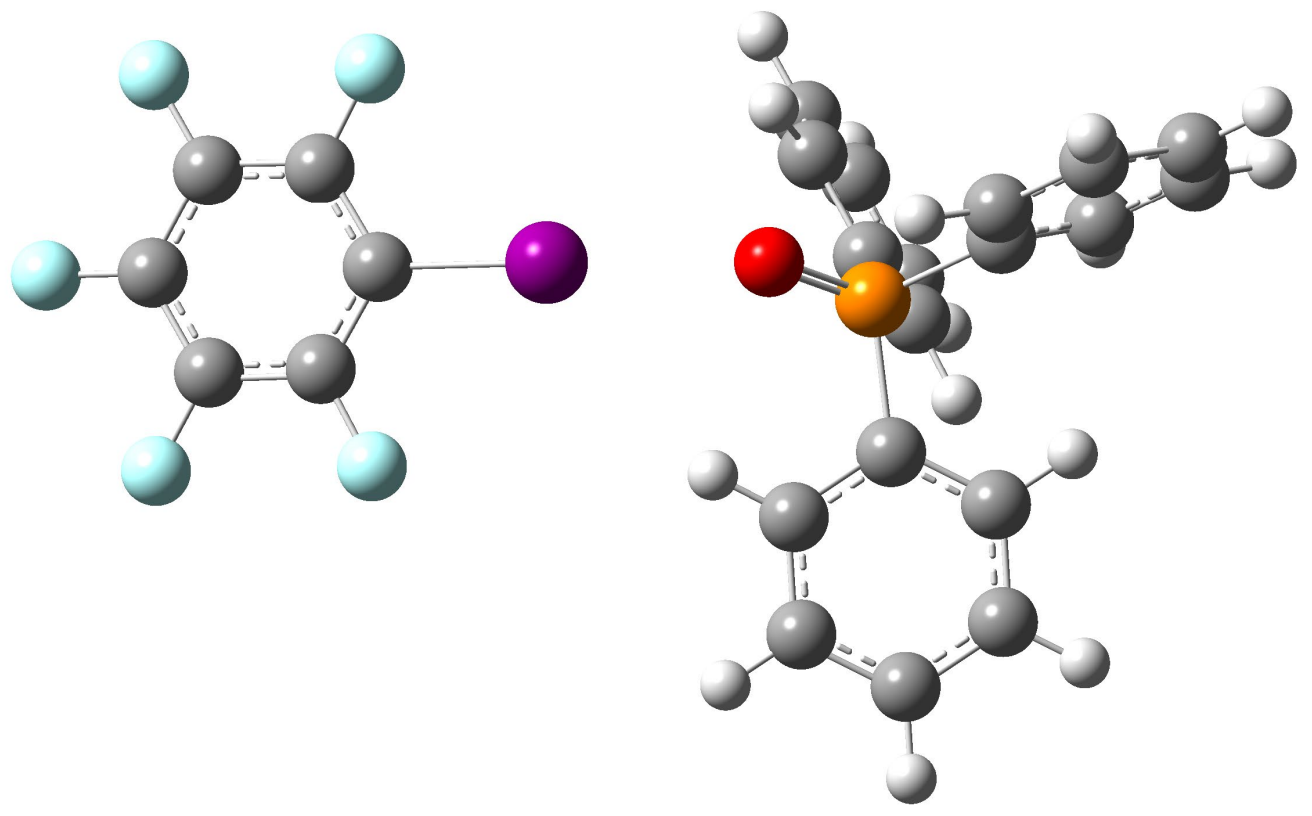

Figure S44. Geometry optimized XB adducts of XB donor iodopentafluorobenzene (I-PFB) with XB acceptor triphenylphosphine oxide $\left(\mathrm{Ph}_{3} \mathbf{P O}\right)$. 


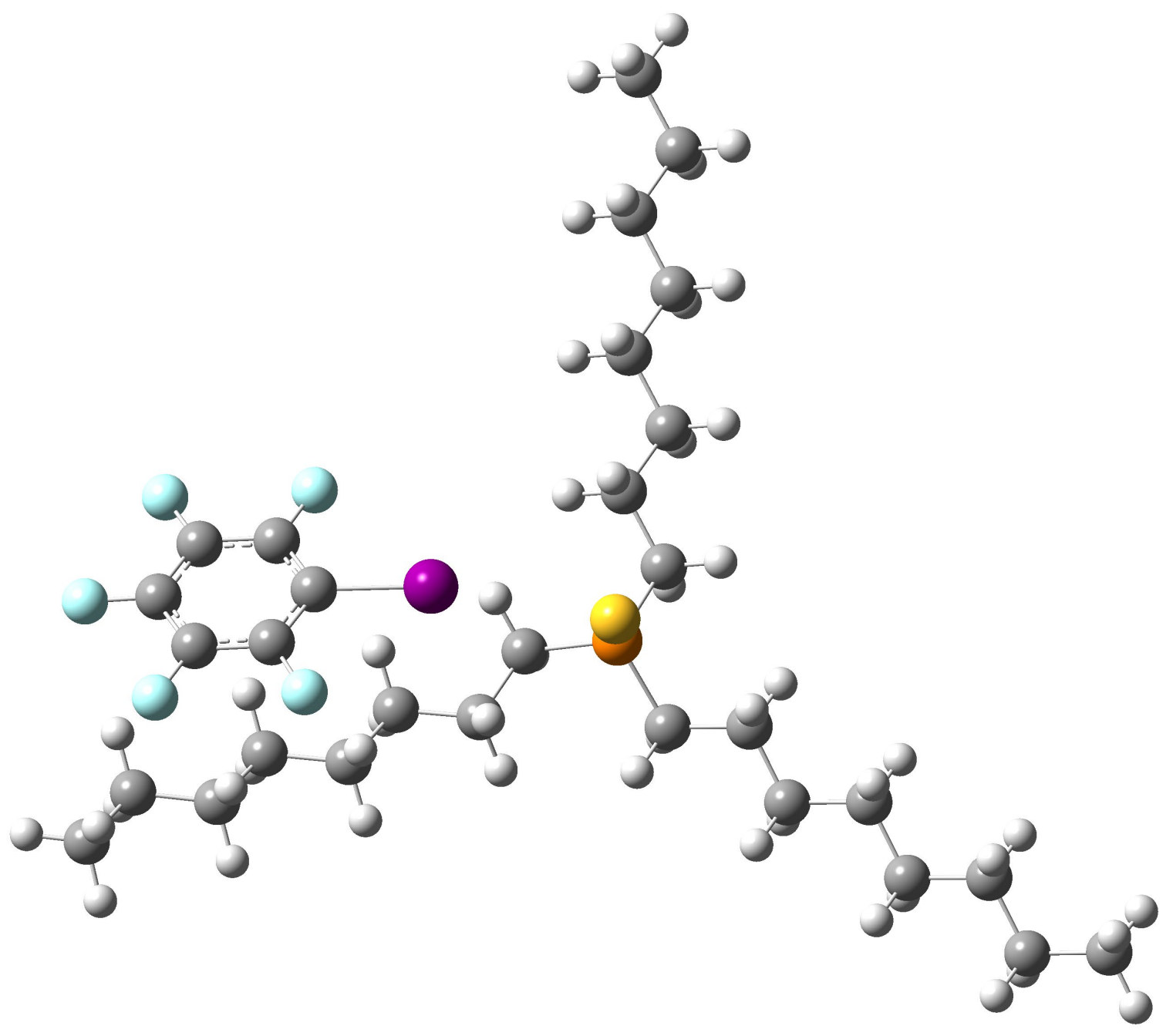

Figure S45. Geometry optimized XB adduct of XB donor iodopentafluorobenzene (I-PFB) with XB acceptor trioctylphosphine sulfide ( $\left.\mathrm{Oct}_{3} \mathrm{PS}\right)$. 


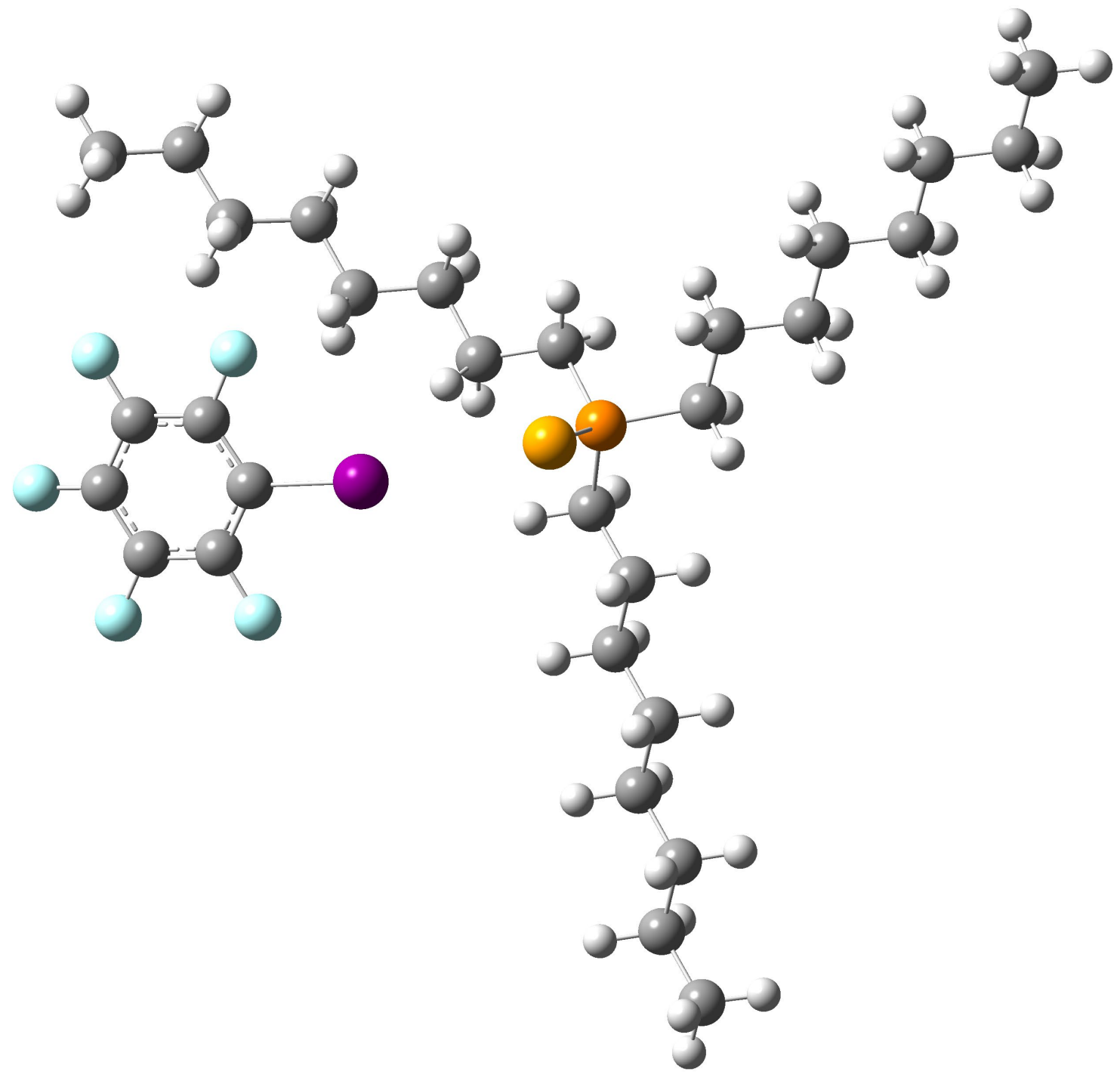

Figure S46. Geometry optimized XB adduct of XB donor iodopentafluorobenzene (I-PFB) with XB acceptor trioctylphosphine selenide ( Oct $_{3}$ PSe). 

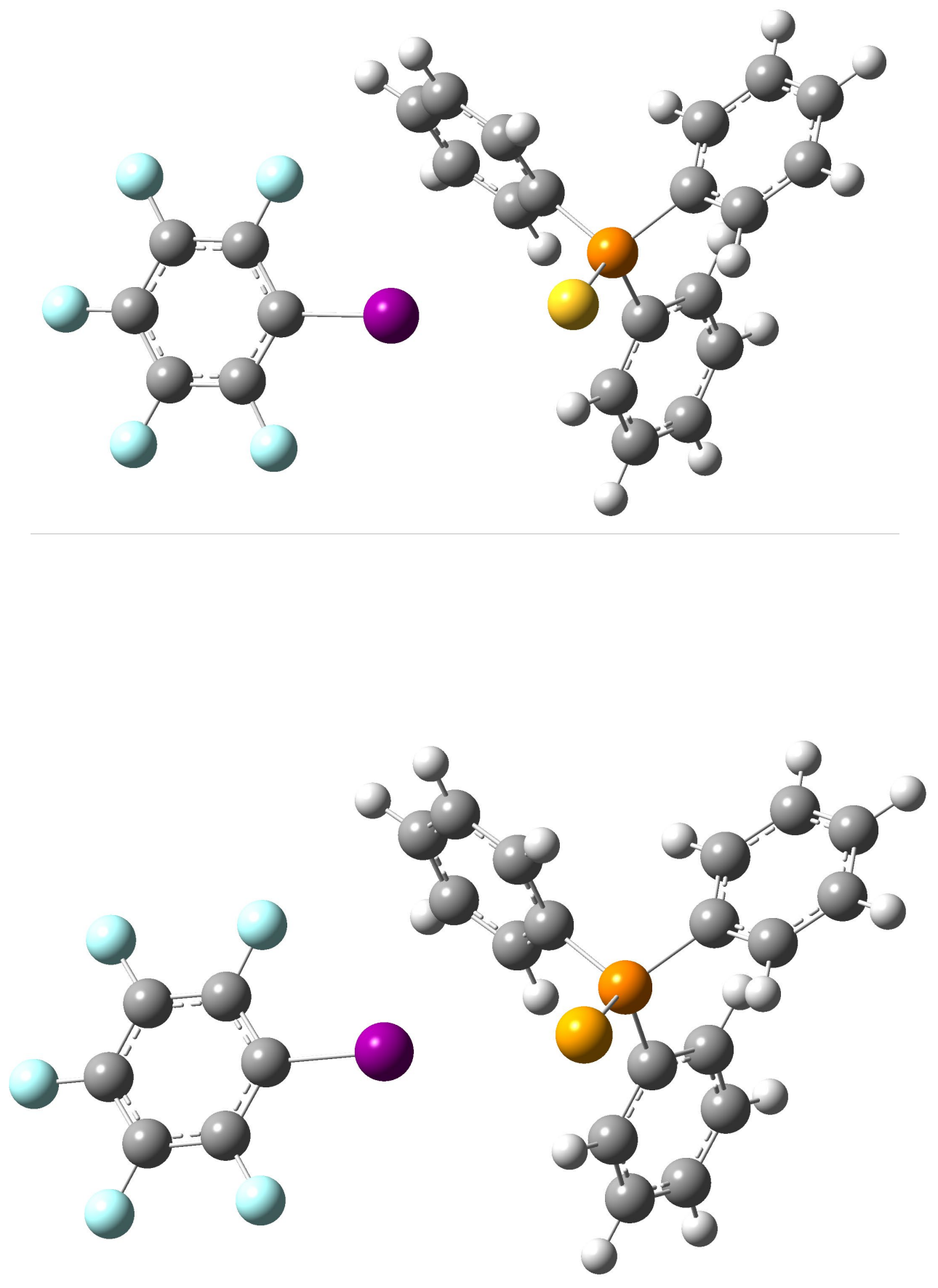

Figure S47. Geometry optimized XB adducts of XB donor iodopentafluorobenzene (I-PFB) with XB acceptors triphenylphosphine sulfide $\left(\mathbf{P h}_{3} \mathbf{P S}\right)$ (top) and triphenylphosphine selenide $\left(\mathbf{P h}_{3} \mathbf{P S e}\right)$ (bottom). 

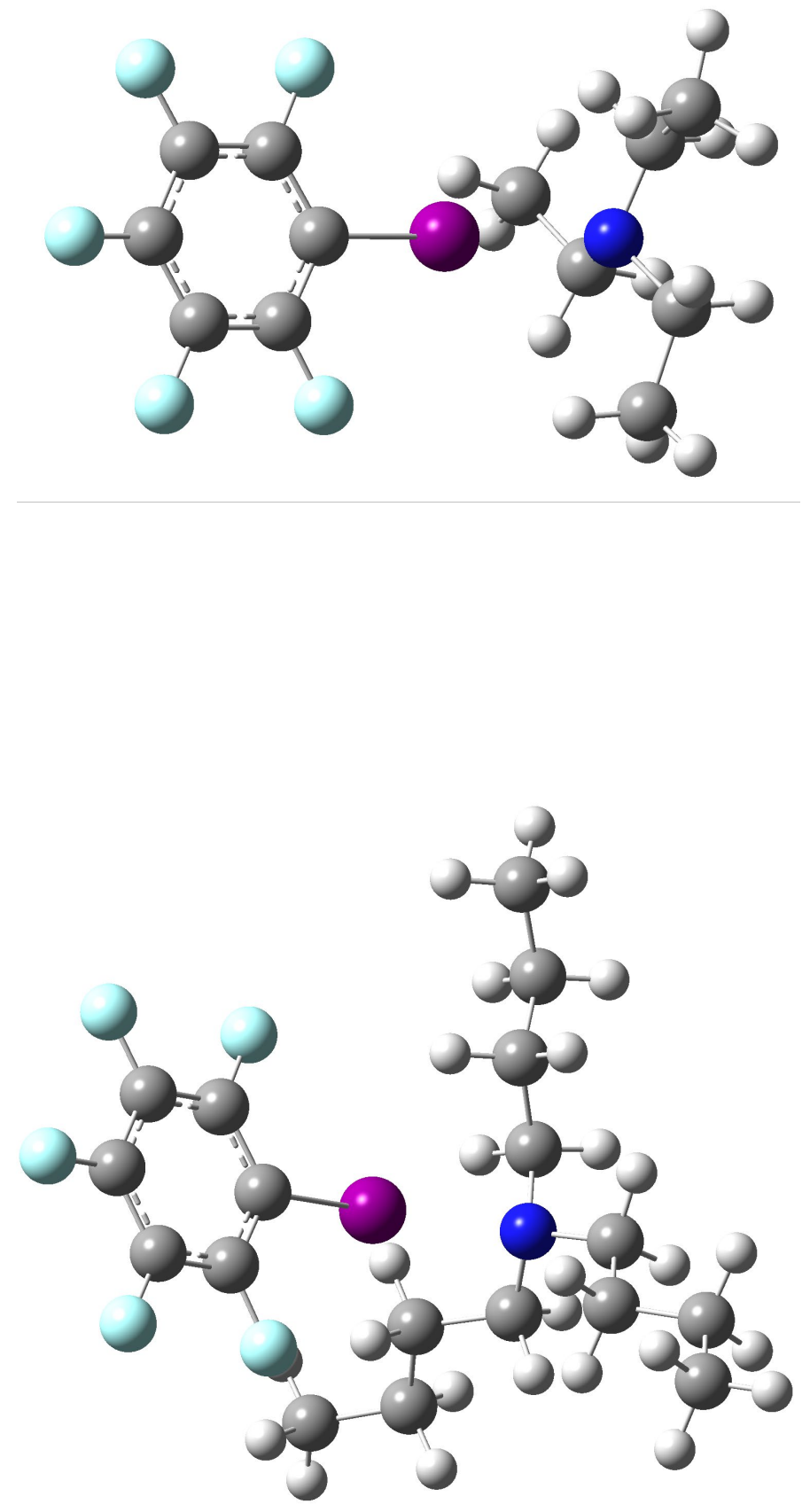

Figure S48. Geometry optimized XB adducts of XB donor iodopentafluorobenzene (I-PFB) with XB acceptors triethylamine $\left(\mathbf{E t}_{3} \mathbf{N}\right)$ (top) and tributylamine $\left(\mathrm{Bu}_{3} \mathbf{N}\right)$ (bottom). 

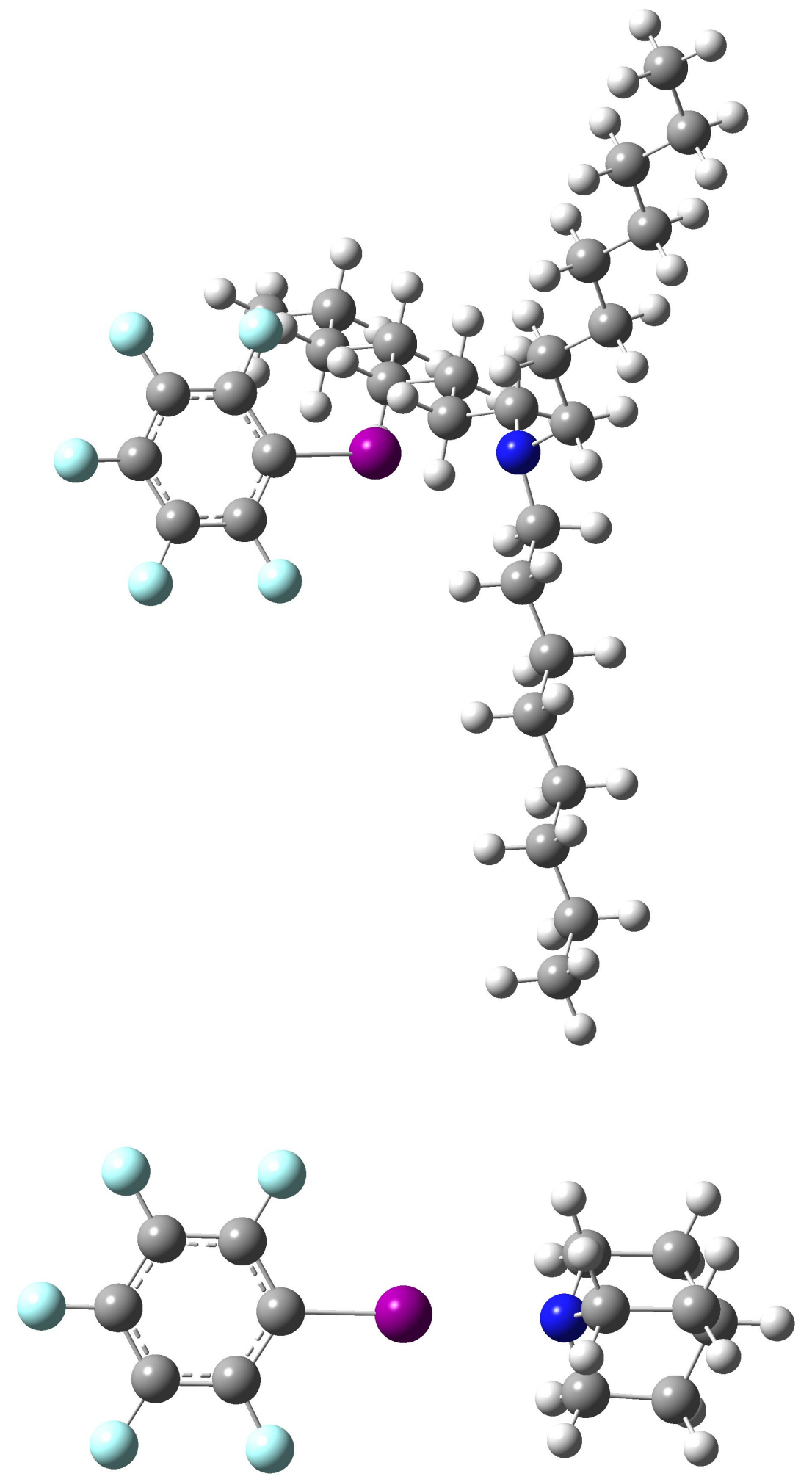

Figure S49. Geometry optimized XB adducts of XB donor iodopentafluorobenzene (I-PFB) with XB acceptors trioctylamine $\left(\mathbf{O c t}_{3} \mathbf{N}\right)$ (top) and quinuclidine (bottom). 

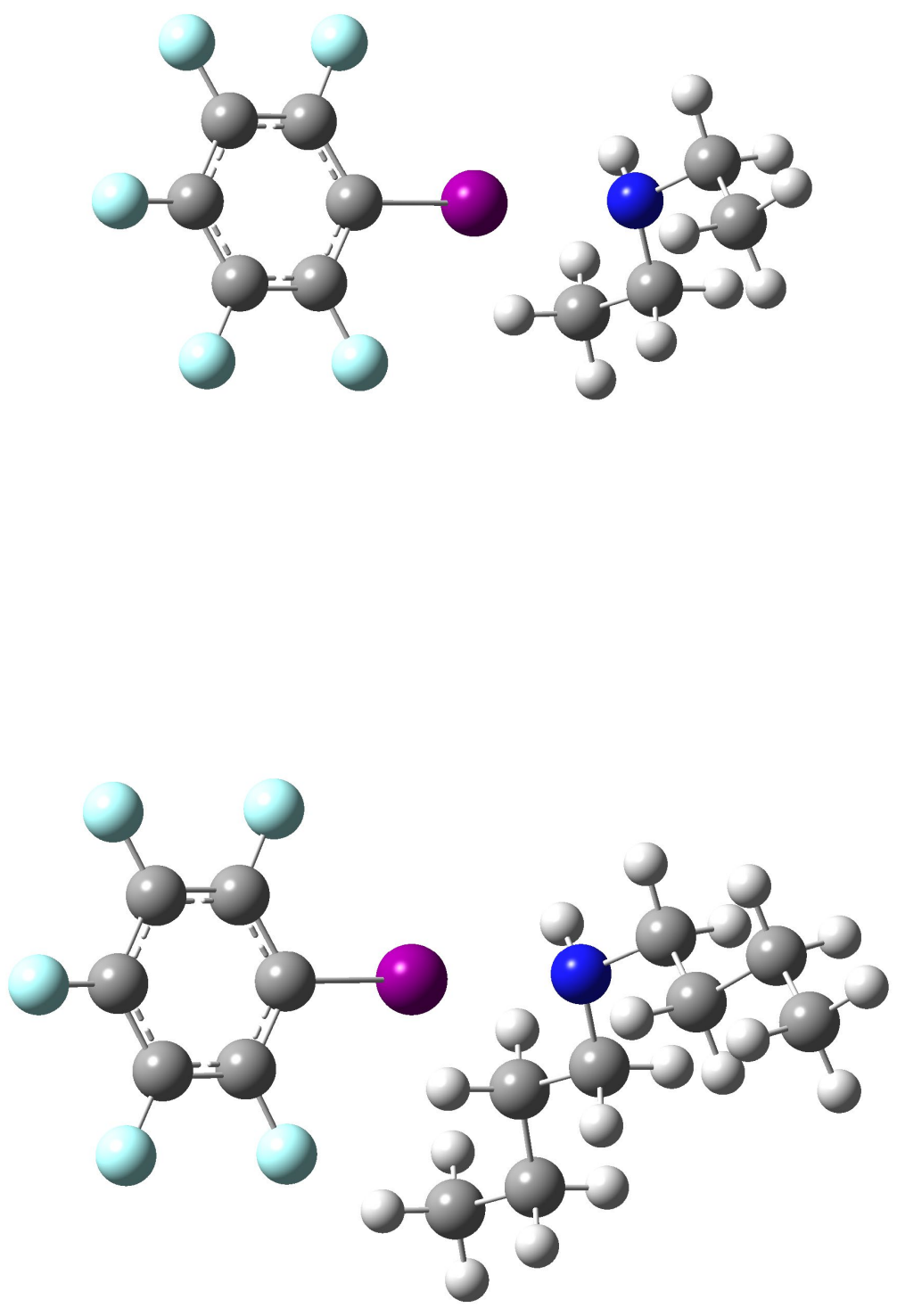

Figure S50. Geometry optimized XB adducts of XB donor iodopentafluorobenzene (I-PFB) with XB acceptors diethylamine ( $\left.\mathbf{E t}_{2} \mathbf{N H}\right)$ (top) and dibutylamine $\left(\mathbf{B u}_{2} \mathbf{N H}\right)$ (bottom). 

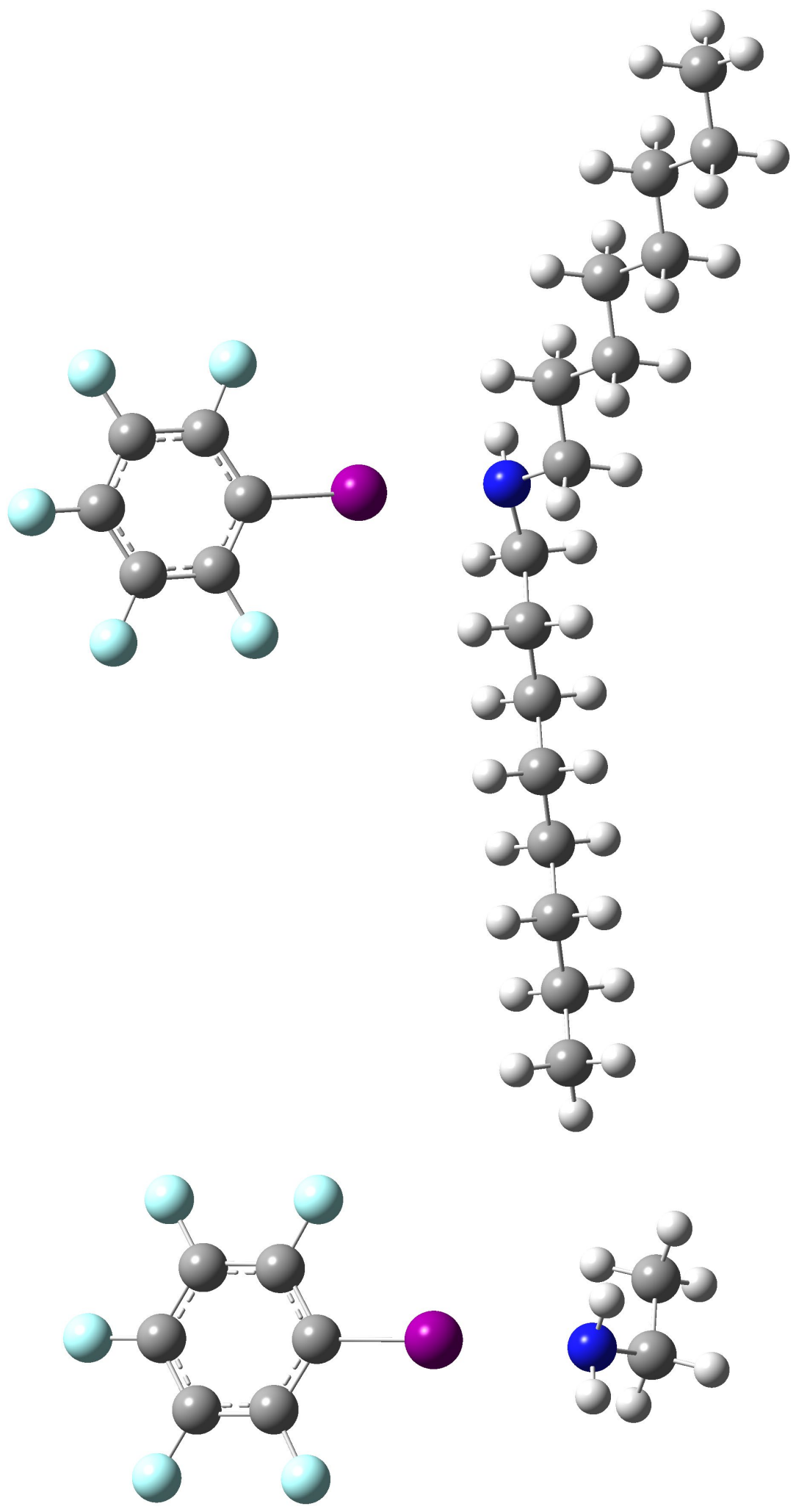

Figure S51. Geometry optimized XB adducts of XB donor iodopentafluorobenzene (I-PFB) with XB acceptors dioctylamine $\left(\mathbf{O c t} \mathbf{}_{2} \mathbf{N H}\right)$ (top) and ethylamine $\left(\mathbf{E t} \mathbf{N H}_{2}\right)$ (bottom). 

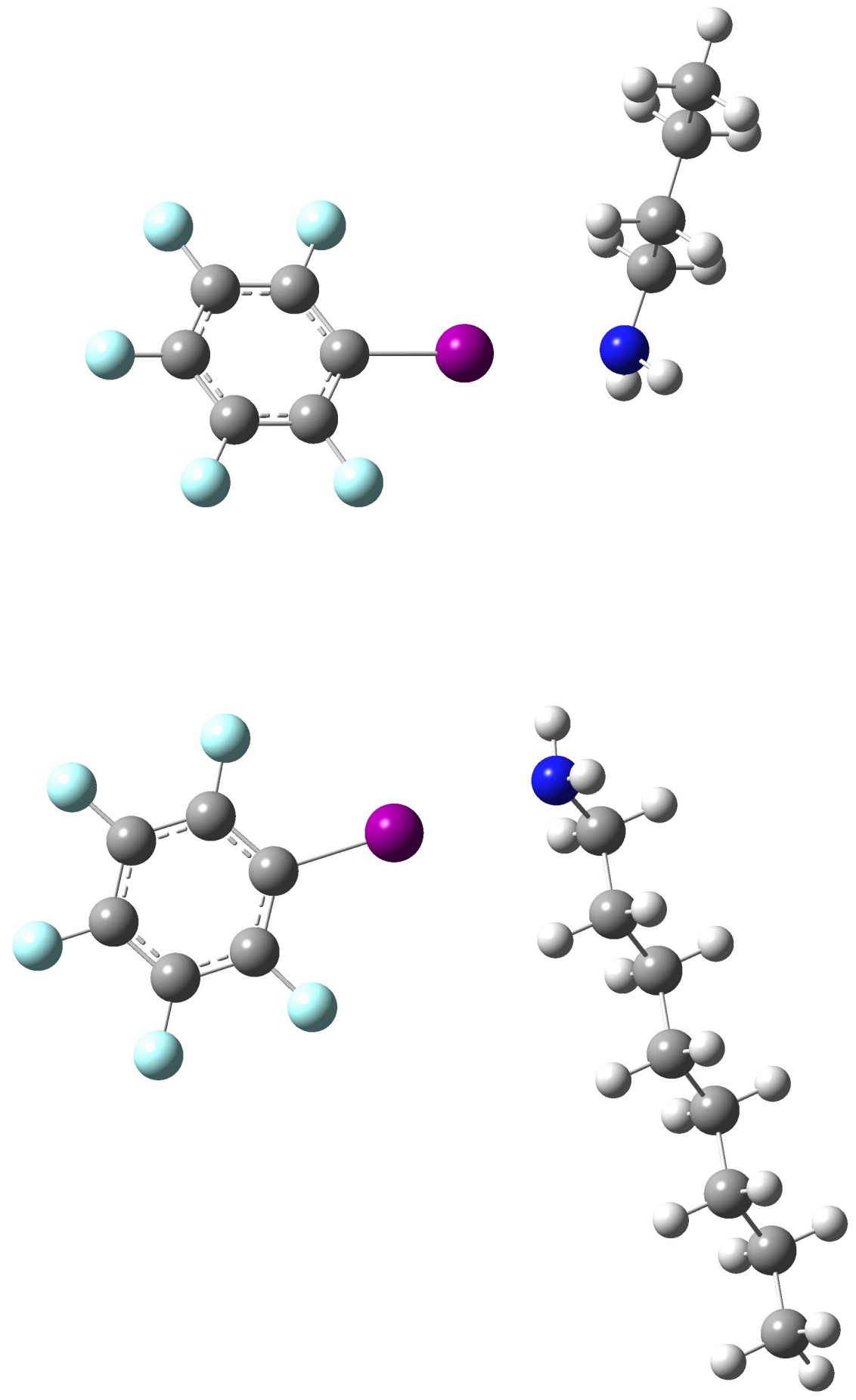

Figure S52. Geometry optimized XB adducts of XB donor iodopentafluorobenzene (I-PFB) with XB acceptors butylamine $\left(\mathbf{B u N H}_{2}\right)$ (top) and octylamine $\left(\mathbf{O c t N H}_{2}\right)$ (bottom). 


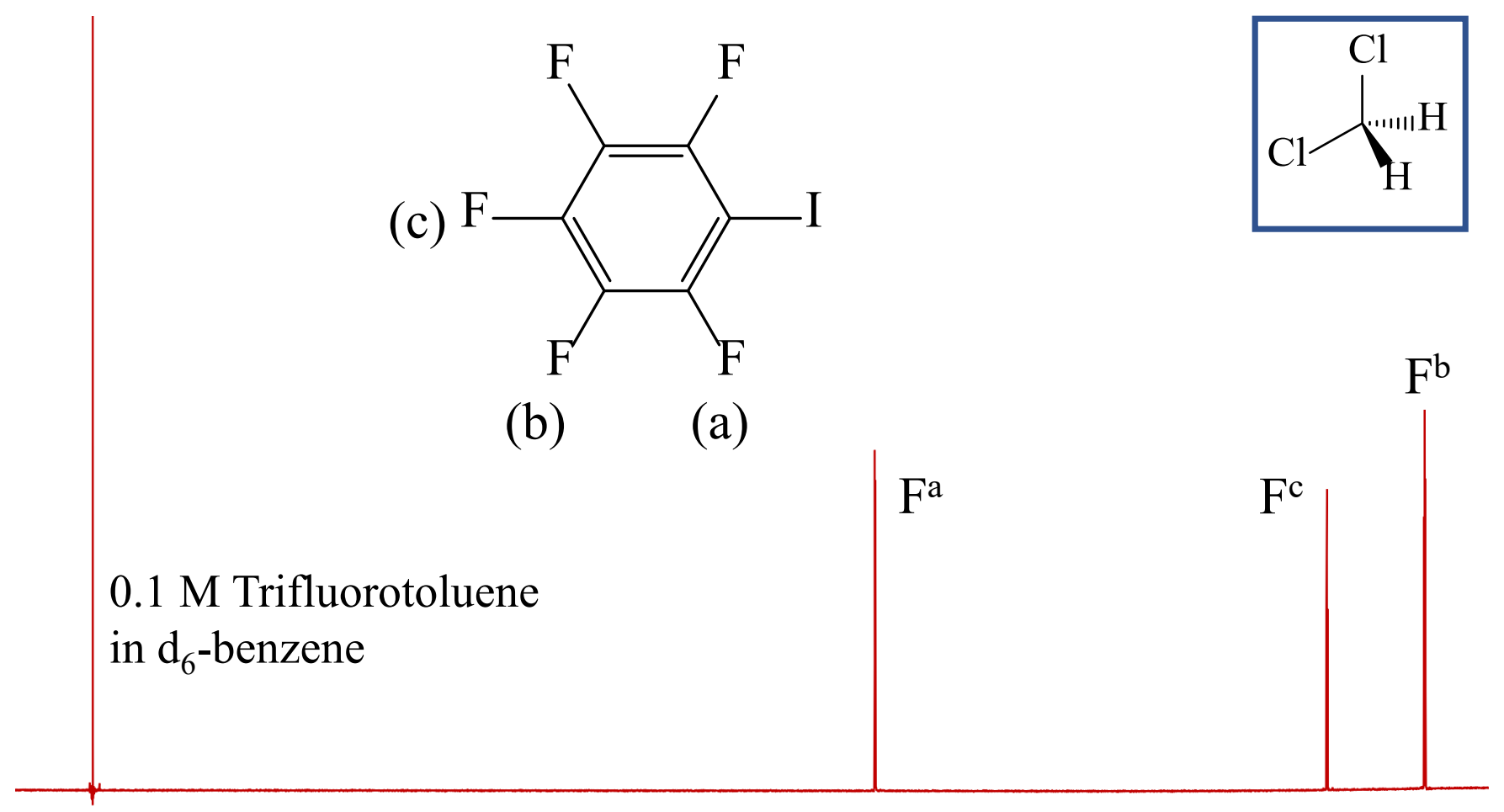

\begin{tabular}{|c|c|c|c|c|c|c|c|c|c|c|}
\hline-60 & -70 & -80 & -90 & -100 & $\begin{array}{l}-110 \\
\text { f1 (ppm) }\end{array}$ & -120 & -130 & -140 & -150 & -160 \\
\hline
\end{tabular}
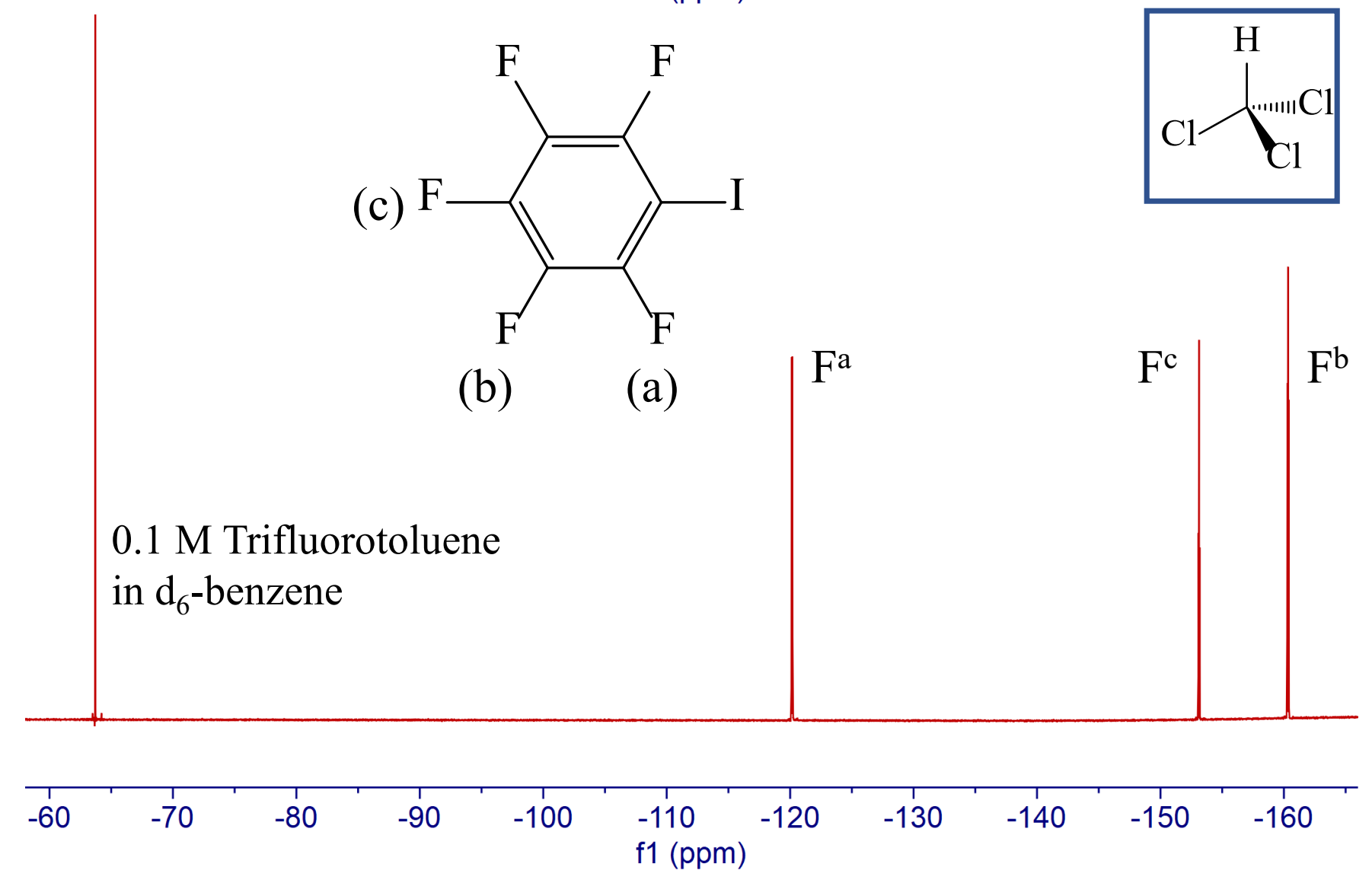

Figure S53. ${ }^{19} \mathrm{~F}$ spectra of $0.0525 \mathrm{M}$ iodopentafluorobenzene in dichloromethane (top) and chloroform (bottom) at $298 \mathrm{~K}$. 

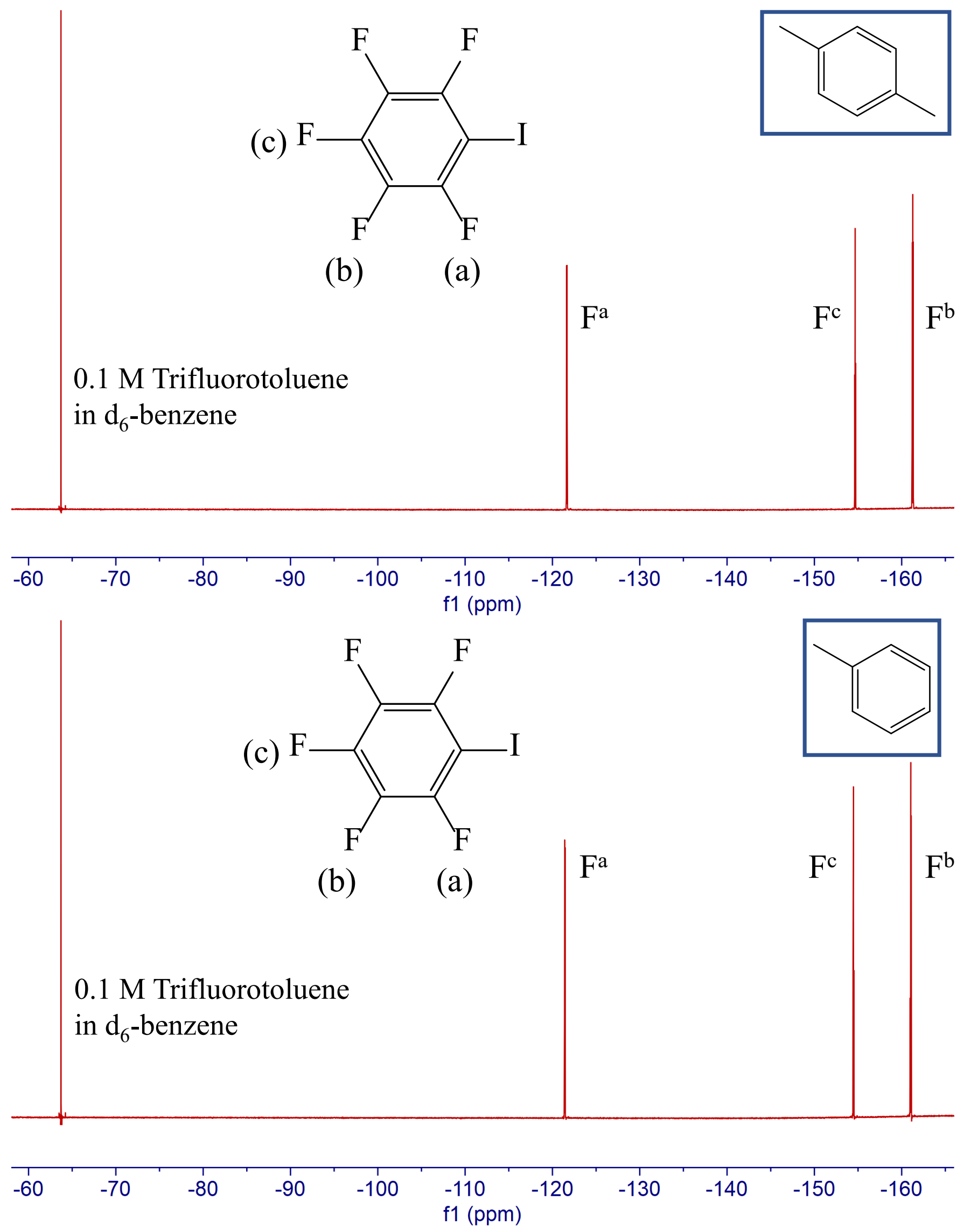

Figure S54. ${ }^{19} \mathrm{~F}$ spectra of $0.0525 \mathrm{M}$ iodopentafluorobenzene in para-xylene (top) and toluene (bottom) at $298 \mathrm{~K}$. 

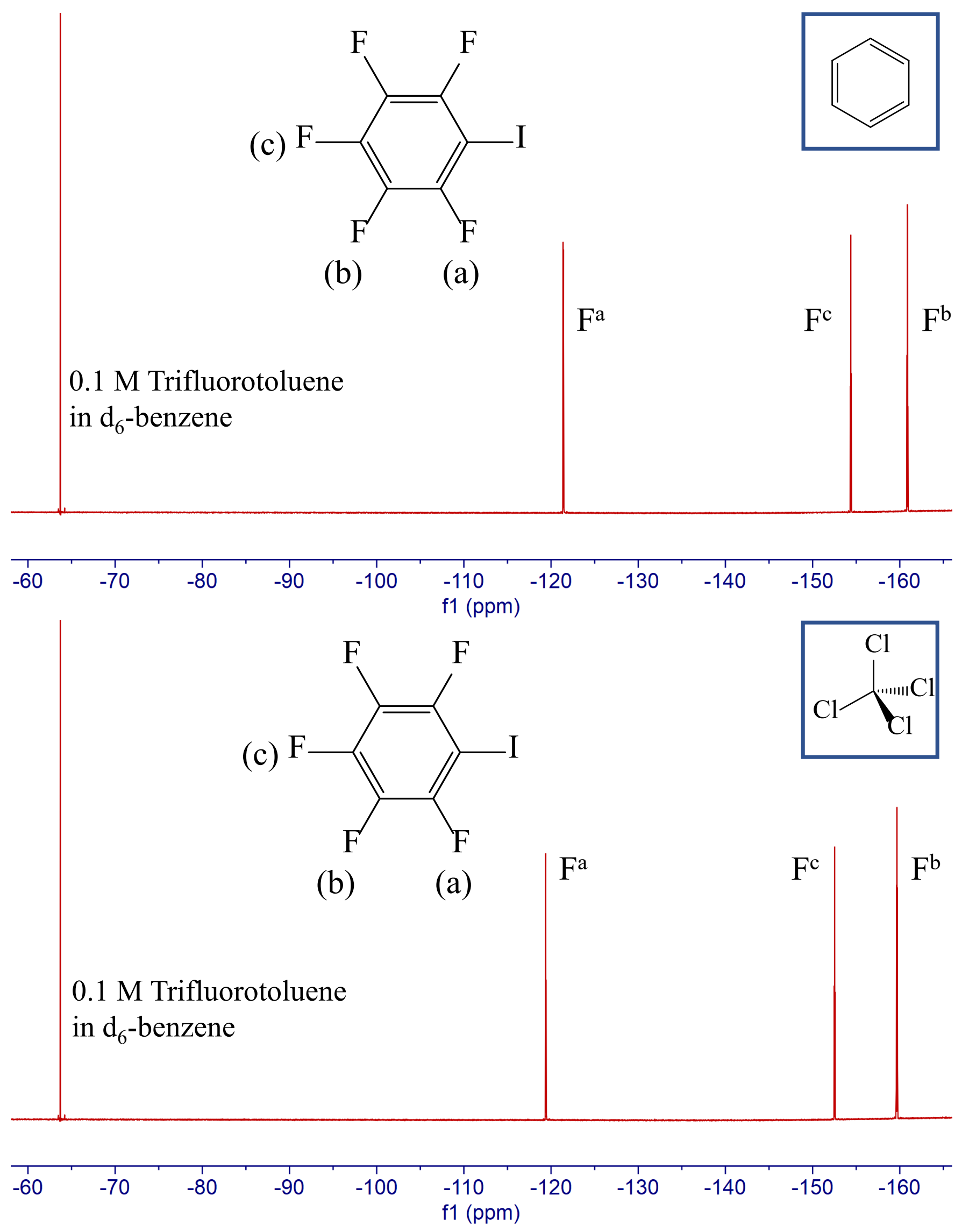

Figure S55. ${ }^{19} \mathrm{~F}$ spectra of $0.0525 \mathrm{M}$ iodopentafluorobenzene in benzene (top) and carbon tetrachloride (bottom) at $298 \mathrm{~K}$. 

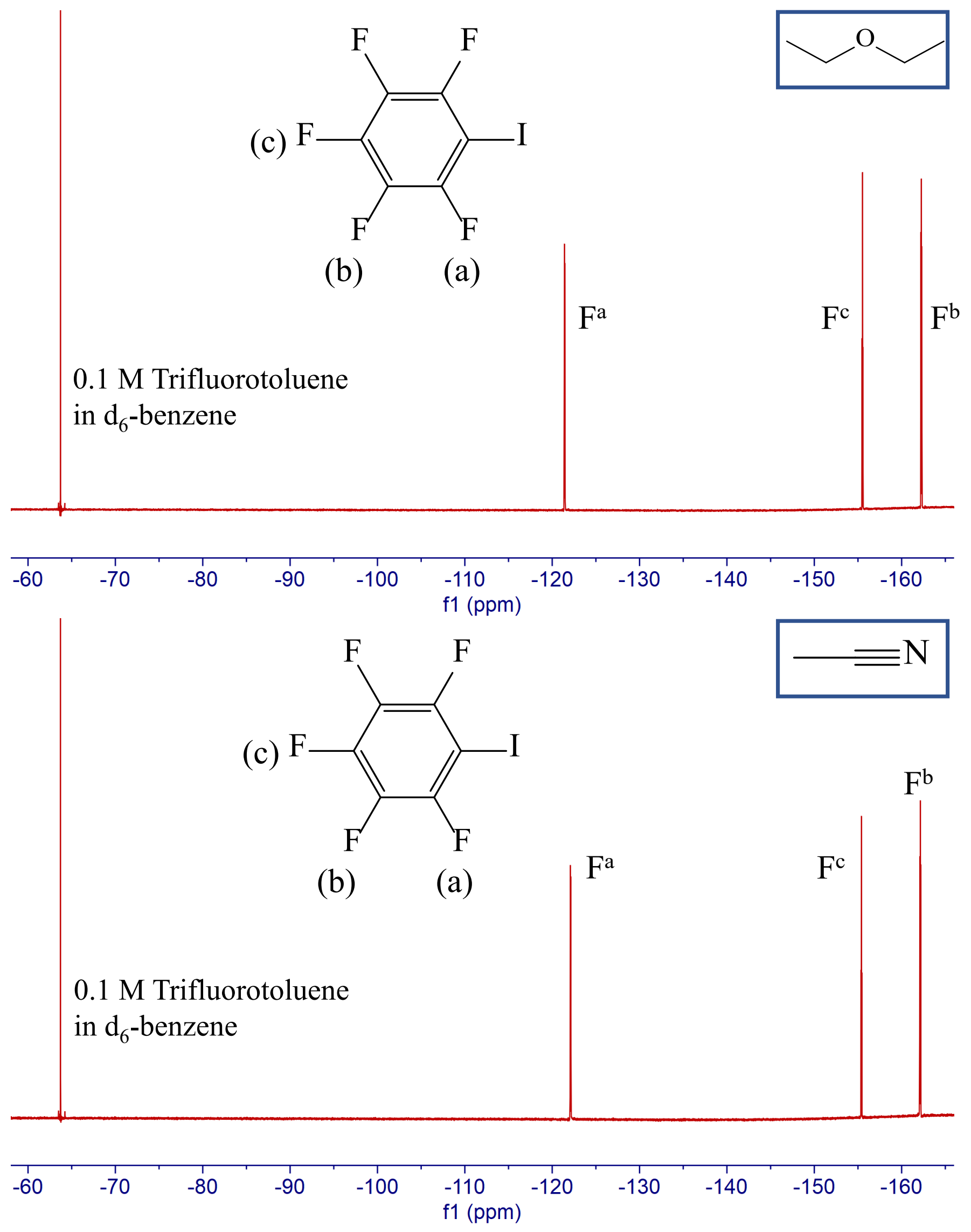

Figure S56. ${ }^{19} \mathrm{~F}$ spectra of $0.0525 \mathrm{M}$ iodopentafluorobenzene in diethyl ether (top) and acetonitrile (bottom) at $298 \mathrm{~K}$. 

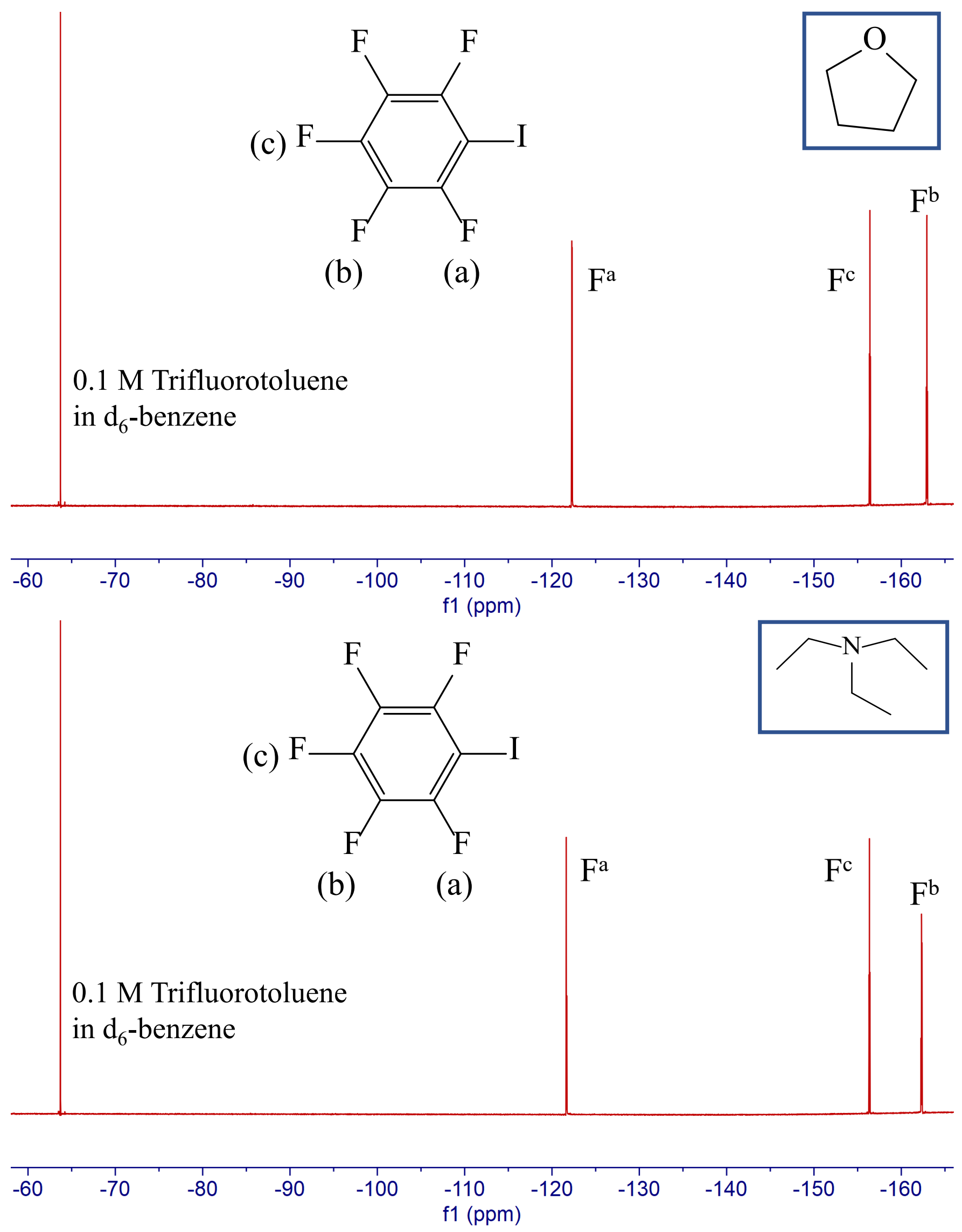

Figure S57. ${ }^{19} \mathrm{~F}$ spectra of $0.0525 \mathrm{M}$ iodopentafluorobenzene in tetrahydrofuran (top) and triethylamine (bottom) at $298 \mathrm{~K}$. 


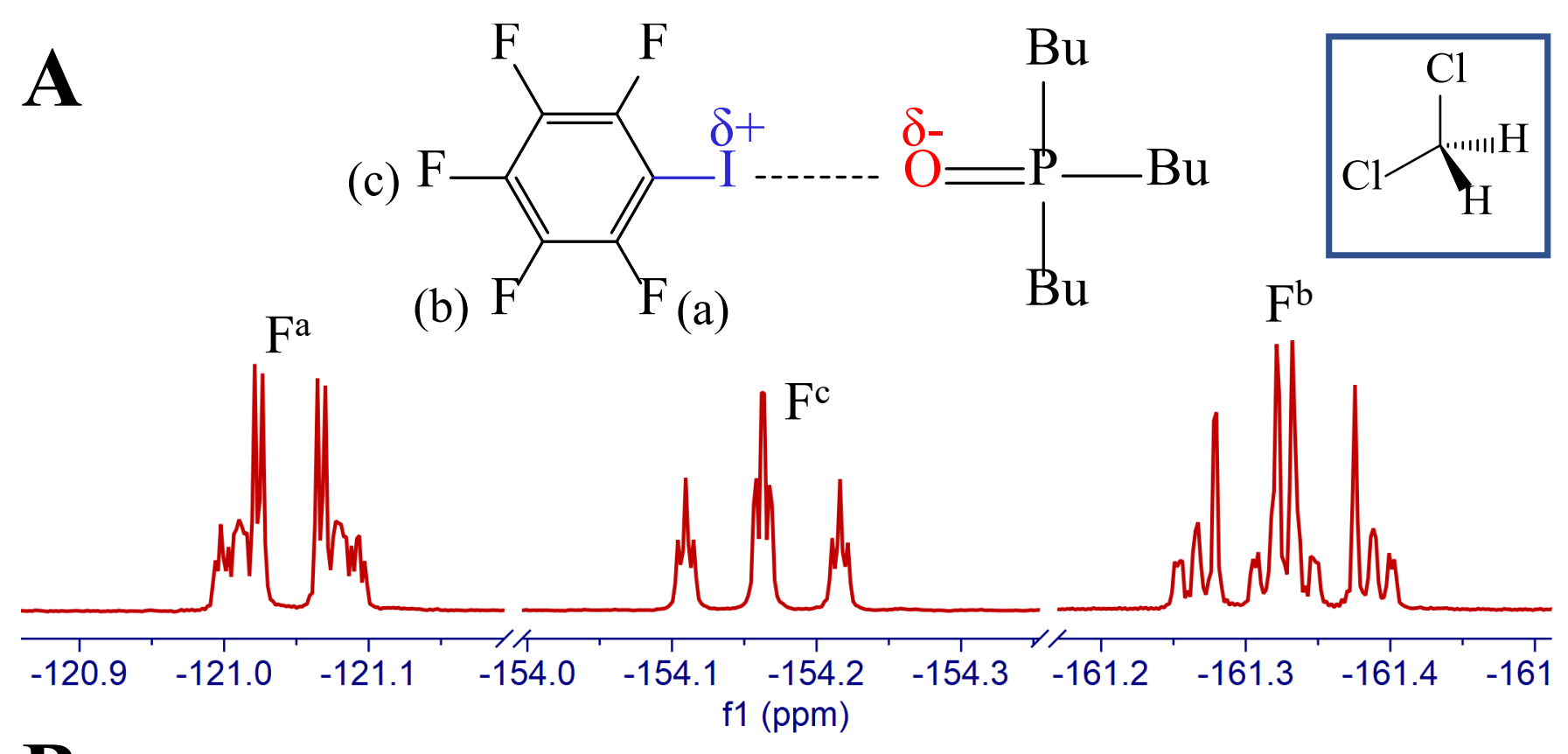

B

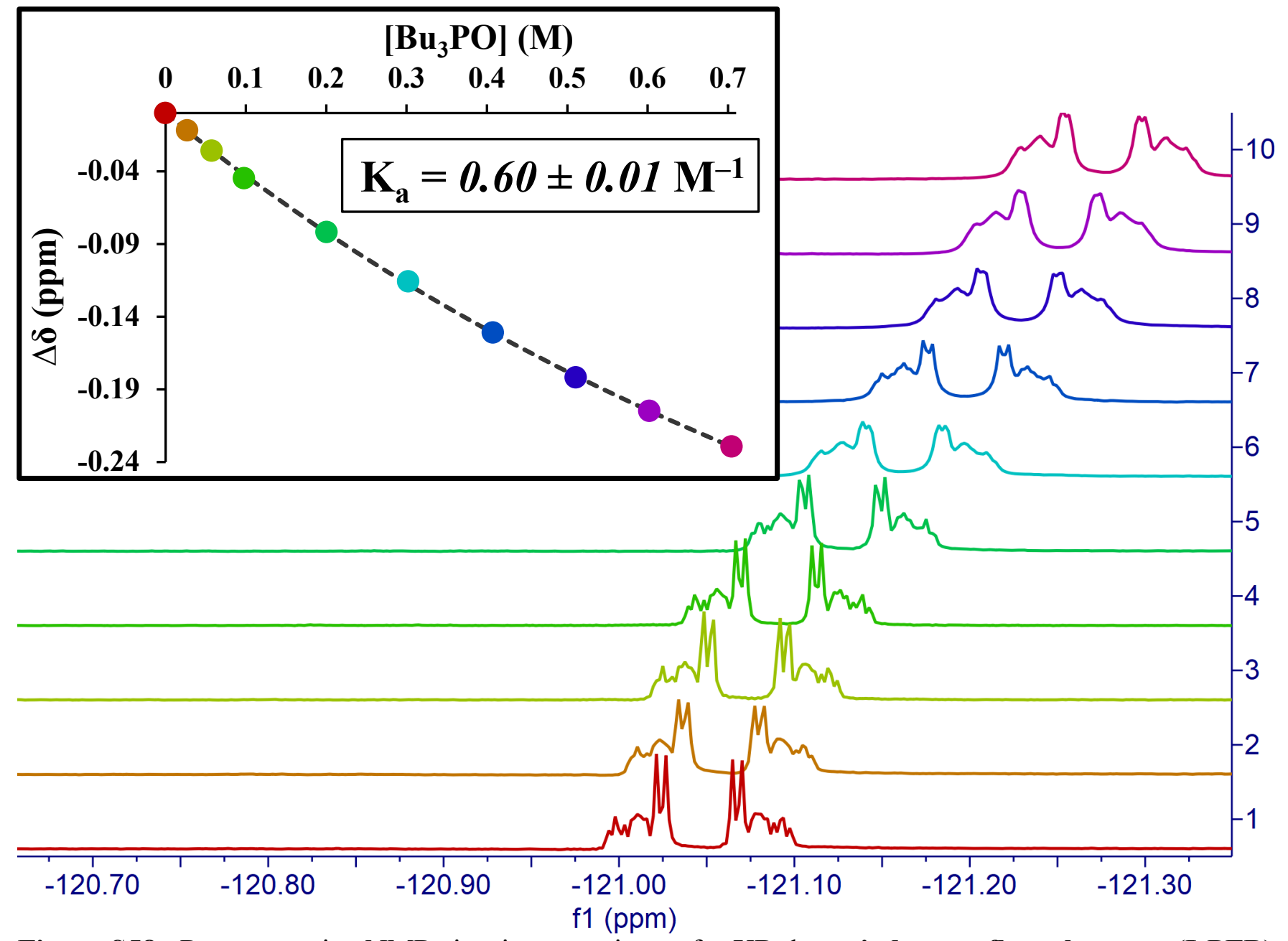

Figure S58. Representative NMR-titration experiment for XB donor iodopentafluorobenzene (I-PFB) $(0.0525 \mathrm{M})$ titrated with $\mathrm{XB}$ acceptor tributylphosphine oxide $\left(\mathbf{B u}_{\mathbf{3}} \mathbf{P O}\right)$ including $(\mathbf{A})$ initial ${ }^{19} \mathrm{H}$ NMR spectrum of I-PFB prior to titration and (B) the change in the ortho F resonance shifts during addition of increasing concentrations of $\mathbf{B u}_{\mathbf{3}} \mathbf{P O}$ and the corresponding binding isotherm (inset) used for nonlinear regression analysis and determination of the association constant $\left(\mathrm{K}_{\mathrm{a}}\right)$ that reflects XB interaction strength of the adduct (Solvent: dichloromethane). 


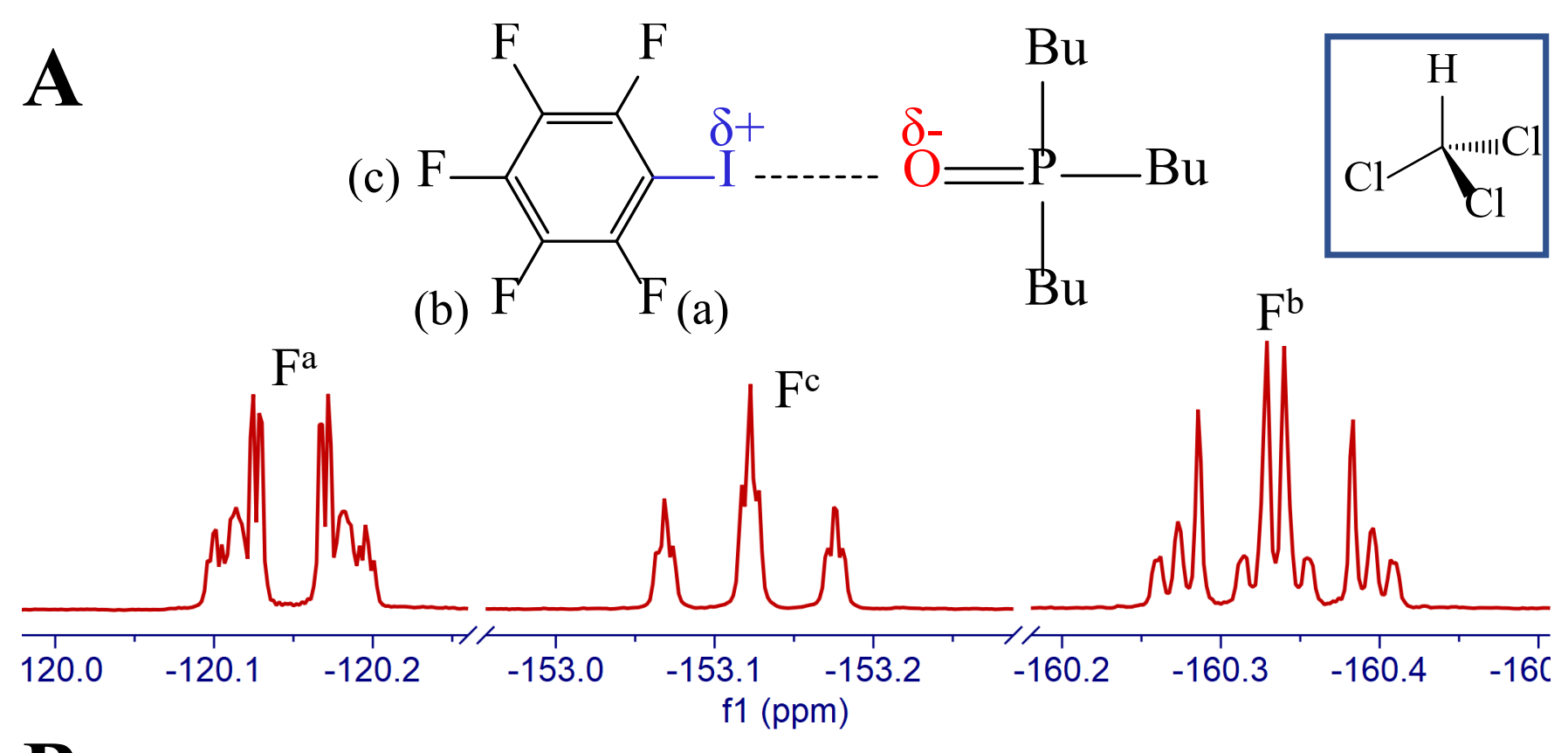

B

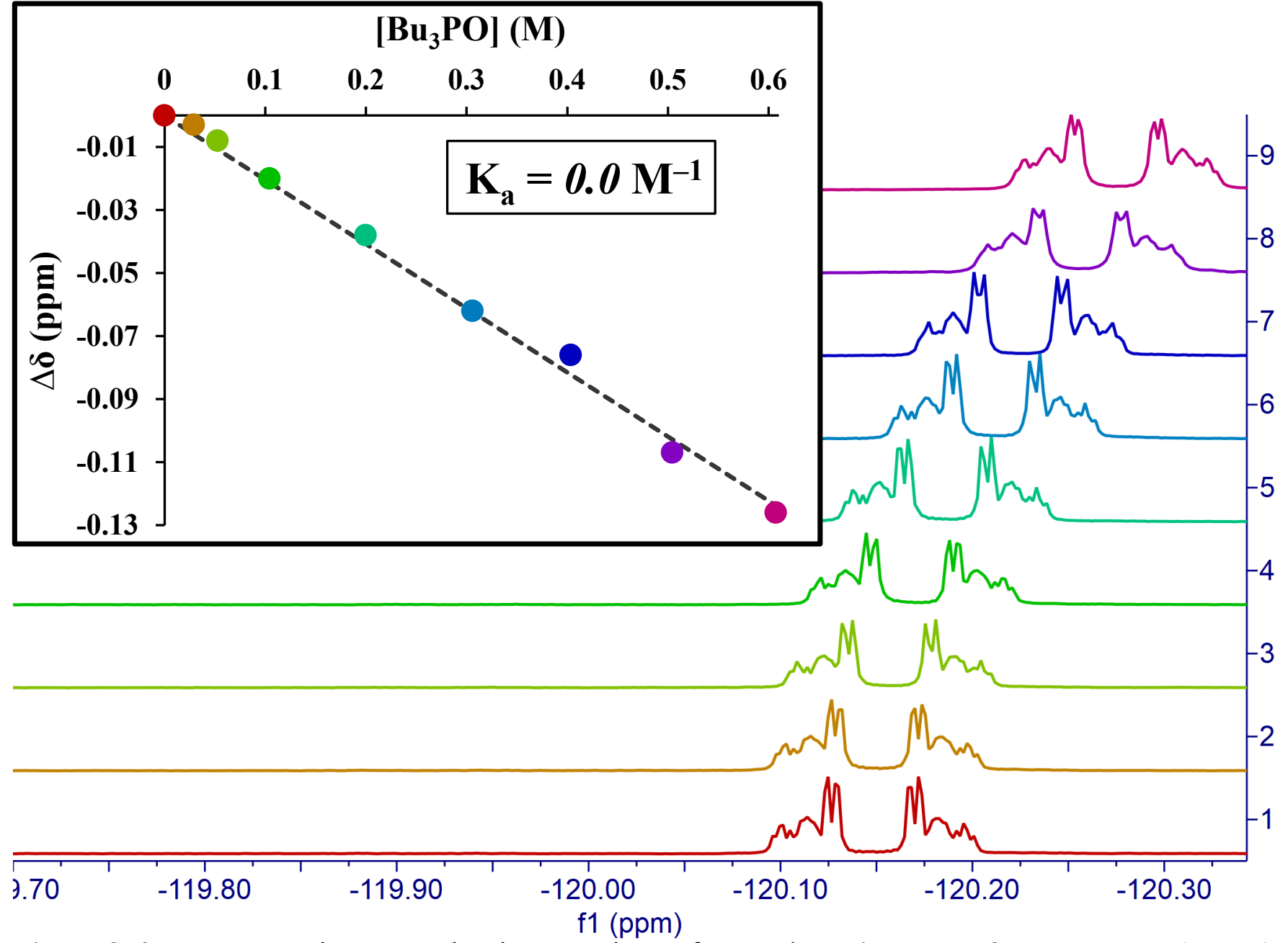

Figure S59. Representative NMR-titration experiment for XB donor iodopentafluorobenzene (I-PFB) $(0.0525 \mathrm{M})$ titrated with $\mathrm{XB}$ acceptor tributylphosphine oxide $\left(\mathbf{B u}_{\mathbf{3}} \mathbf{P O}\right)$ including $(\mathbf{A})$ initial ${ }^{19} \mathrm{H}$ NMR spectrum of I-PFB prior to titration and (B) the change in the ortho F resonance shifts during addition of increasing concentrations of $\mathbf{B u}_{\mathbf{3}} \mathbf{P O}$ and the corresponding binding isotherm (inset) used for nonlinear regression analysis and determination of the association constant $\left(\mathrm{K}_{\mathrm{a}}\right)$ that reflects XB interaction strength of the adduct (Solvent: chloroform). 


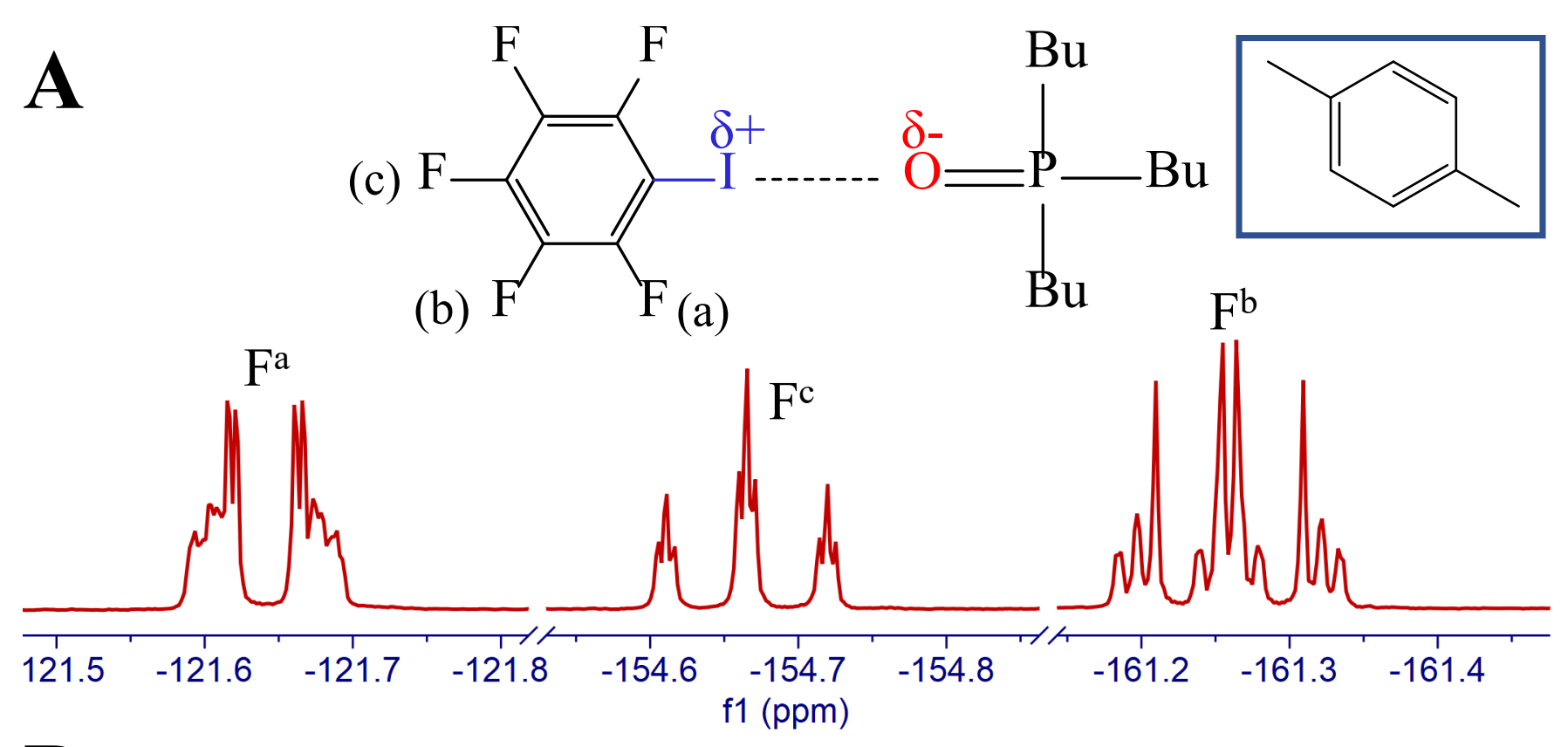

\section{B}

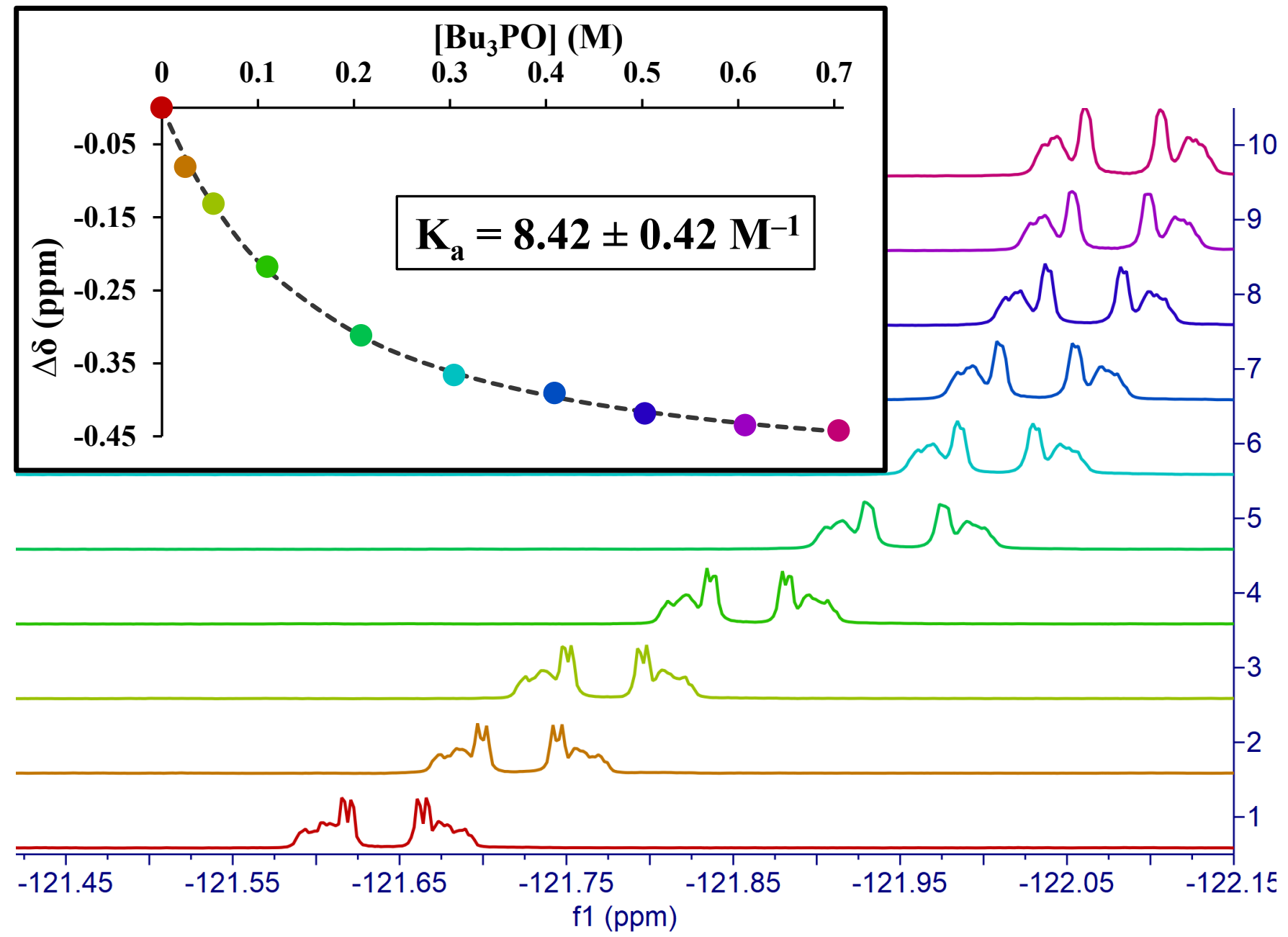

Figure S60. Representative NMR-titration experiment for XB donor iodopentafluorobenzene (I-PFB) $(0.0525 \mathrm{M})$ titrated with $\mathrm{XB}$ acceptor tributylphosphine oxide $\left(\mathbf{B u}_{\mathbf{3}} \mathbf{P O}\right)$ including $(\mathbf{A})$ initial ${ }^{19} \mathrm{H}$ NMR spectrum of I-PFB prior to titration and (B) the change in the ortho $F$ resonance shifts during addition of increasing concentrations of $\mathbf{B u}_{\mathbf{3}} \mathbf{P O}$ and the corresponding binding isotherm (inset) used for nonlinear regression analysis and determination of the association constant $\left(\mathrm{K}_{\mathrm{a}}\right)$ that reflects XB interaction strength of the adduct (Solvent: $\boldsymbol{p}$-xylene). 


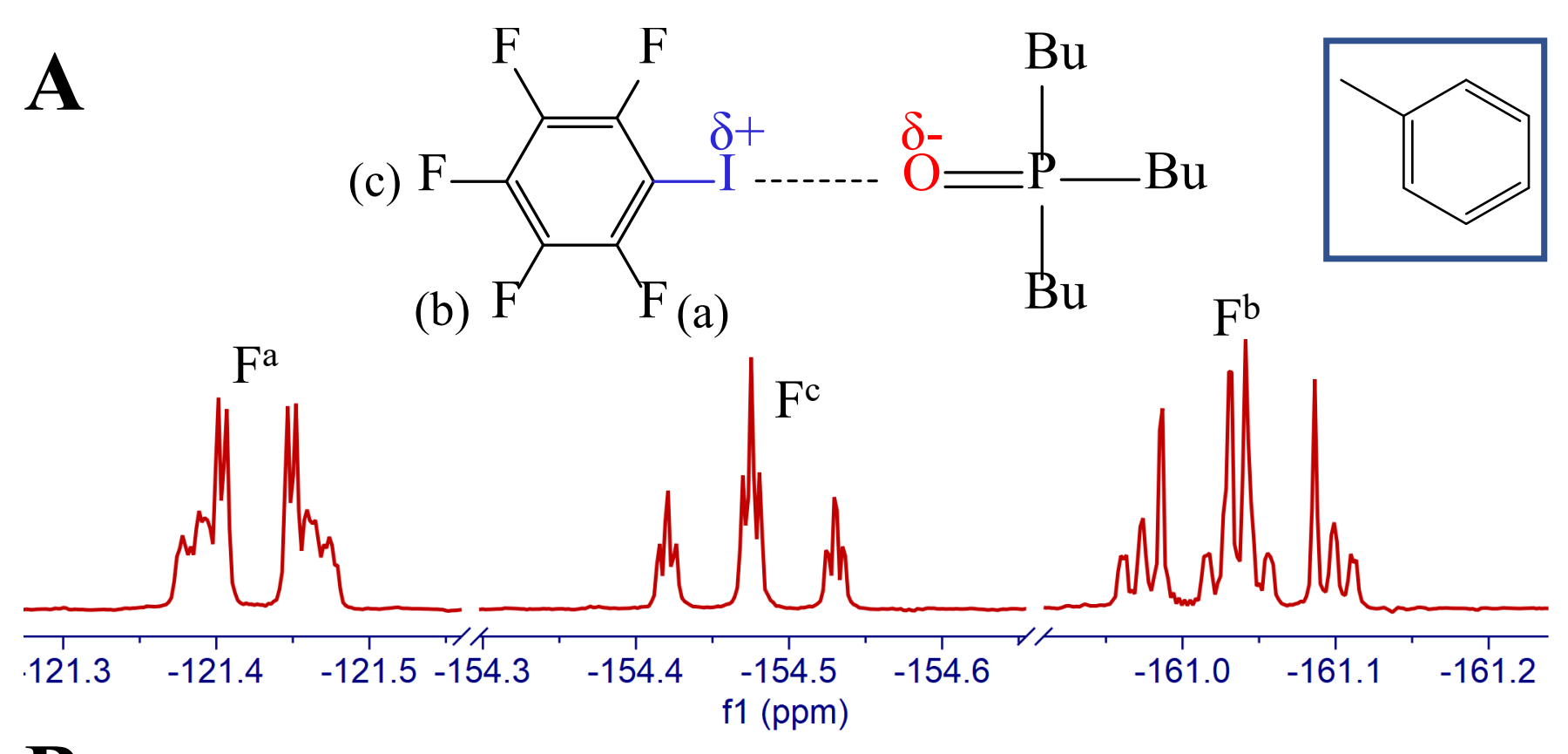

B

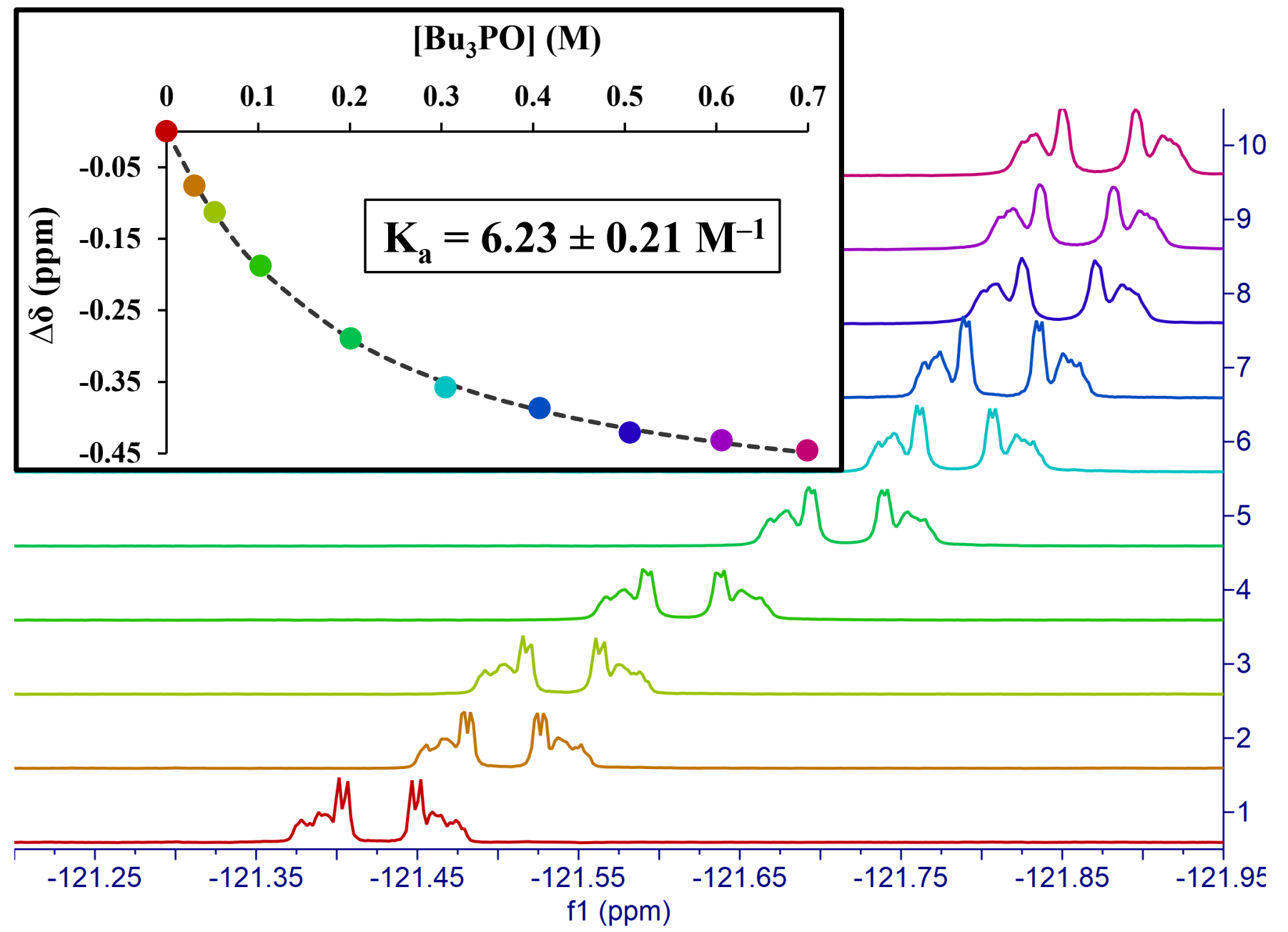

Figure S61. Representative NMR-titration experiment for XB donor iodopentafluorobenzene (I-PFB) $(0.0525 \mathrm{M})$ titrated with $\mathrm{XB}$ acceptor tributylphosphine oxide $\left(\mathbf{B u}_{\mathbf{3}} \mathbf{P O}\right)$ including $(\mathbf{A})$ initial ${ }^{19} \mathrm{H}$ NMR spectrum of I-PFB prior to titration and (B) the change in the ortho F resonance shifts during addition of increasing concentrations of $\mathbf{B u}_{\mathbf{3}} \mathbf{P O}$ and the corresponding binding isotherm (inset) used for nonlinear regression analysis and determination of the association constant $\left(\mathrm{K}_{\mathrm{a}}\right)$ that reflects XB interaction strength of the adduct (Solvent: toluene). 


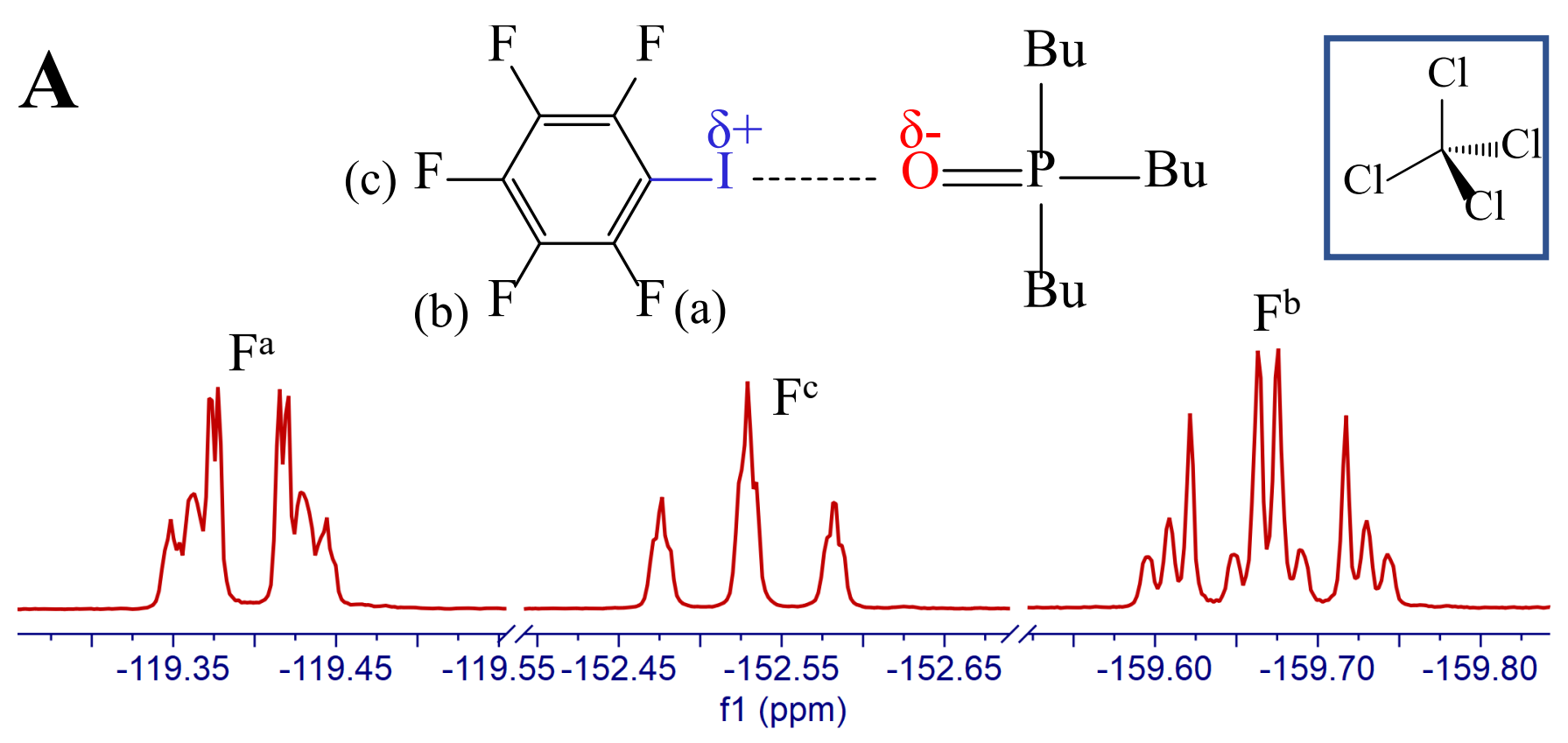

B

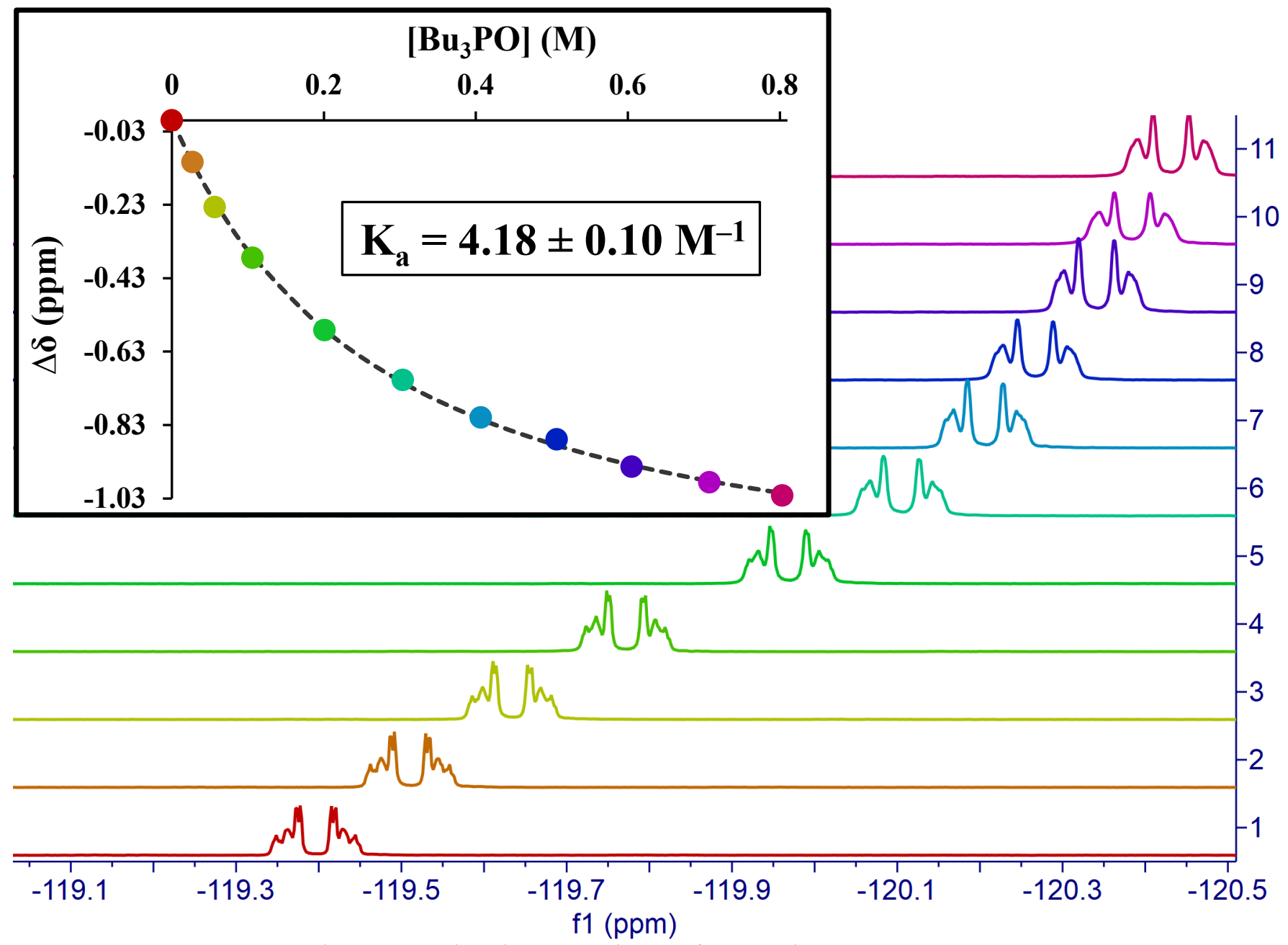

Figure S62. Representative NMR-titration experiment for XB donor iodopentafluorobenzene (I-PFB) $(0.0525 \mathrm{M})$ titrated with $\mathrm{XB}$ acceptor tributylphosphine oxide $\left(\mathbf{B u}_{\mathbf{3}} \mathbf{P O}\right)$ including $(\mathbf{A})$ initial ${ }^{19} \mathrm{H}$ NMR spectrum of I-PFB prior to titration and (B) the change in the ortho F resonance shifts during addition of increasing concentrations of $\mathbf{B u}_{\mathbf{3}} \mathbf{P O}$ and the corresponding binding isotherm (inset) used for nonlinear regression analysis and determination of the association constant $\left(\mathrm{K}_{\mathrm{a}}\right)$ that reflects XB interaction strength of the adduct (Solvent: carbon tetrachloride). 


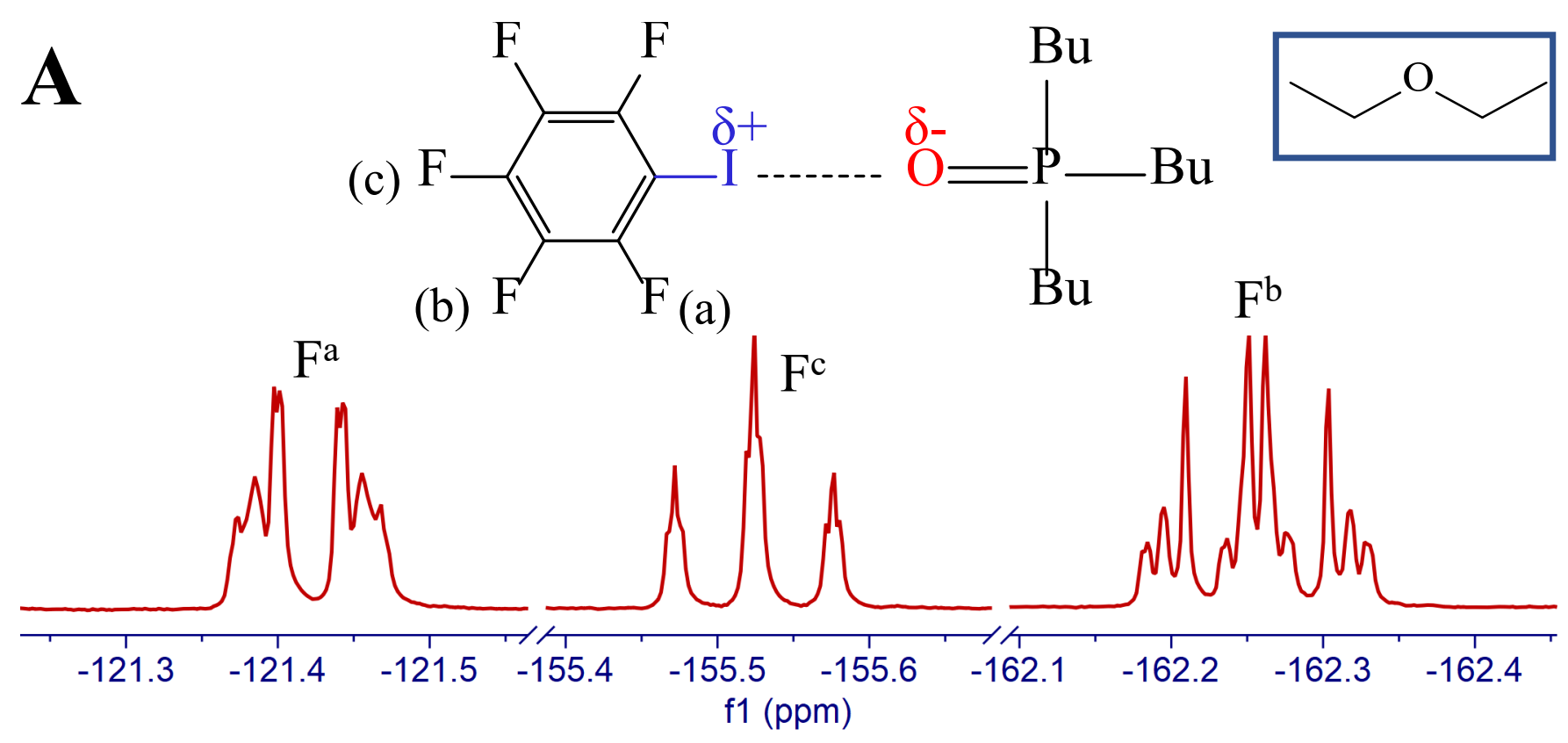

B

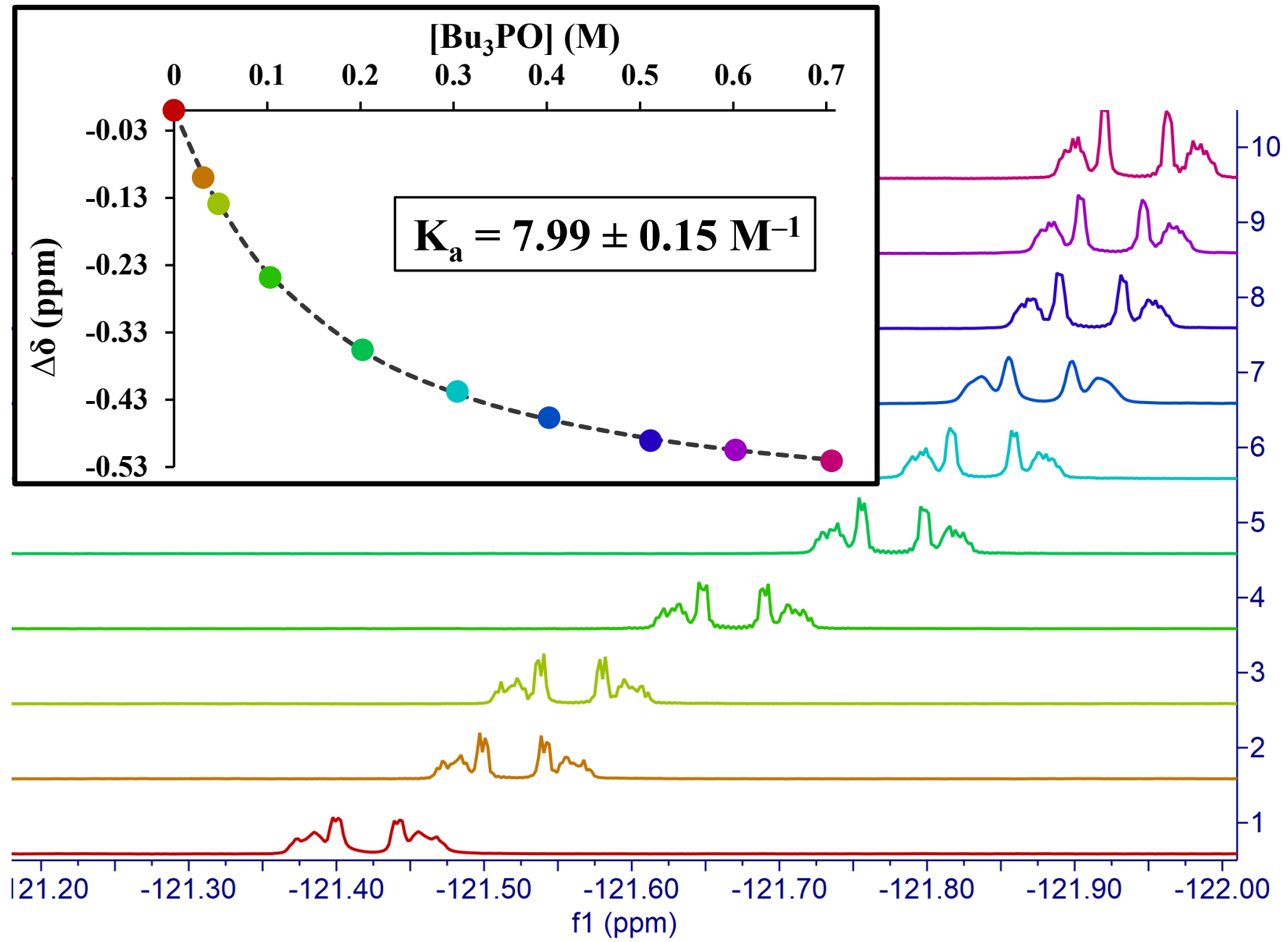

Figure S63. Representative NMR-titration experiment for XB donor iodopentafluorobenzene (I-PFB) $(0.0525 \mathrm{M})$ titrated with $\mathrm{XB}$ acceptor tributylphosphine oxide $\left(\mathbf{B u}_{\mathbf{3}} \mathbf{P O}\right)$ including (A) initial ${ }^{19} \mathrm{H}$ NMR spectrum of I-PFB prior to titration and (B) the change in the ortho F resonance shifts during addition of increasing concentrations of $\mathbf{B u}_{\mathbf{3}} \mathbf{P O}$ and the corresponding binding isotherm (inset) used for nonlinear regression analysis and determination of the association constant $\left(\mathrm{K}_{\mathrm{a}}\right)$ that reflects XB interaction strength of the adduct (Solvent: diethyl ether). 


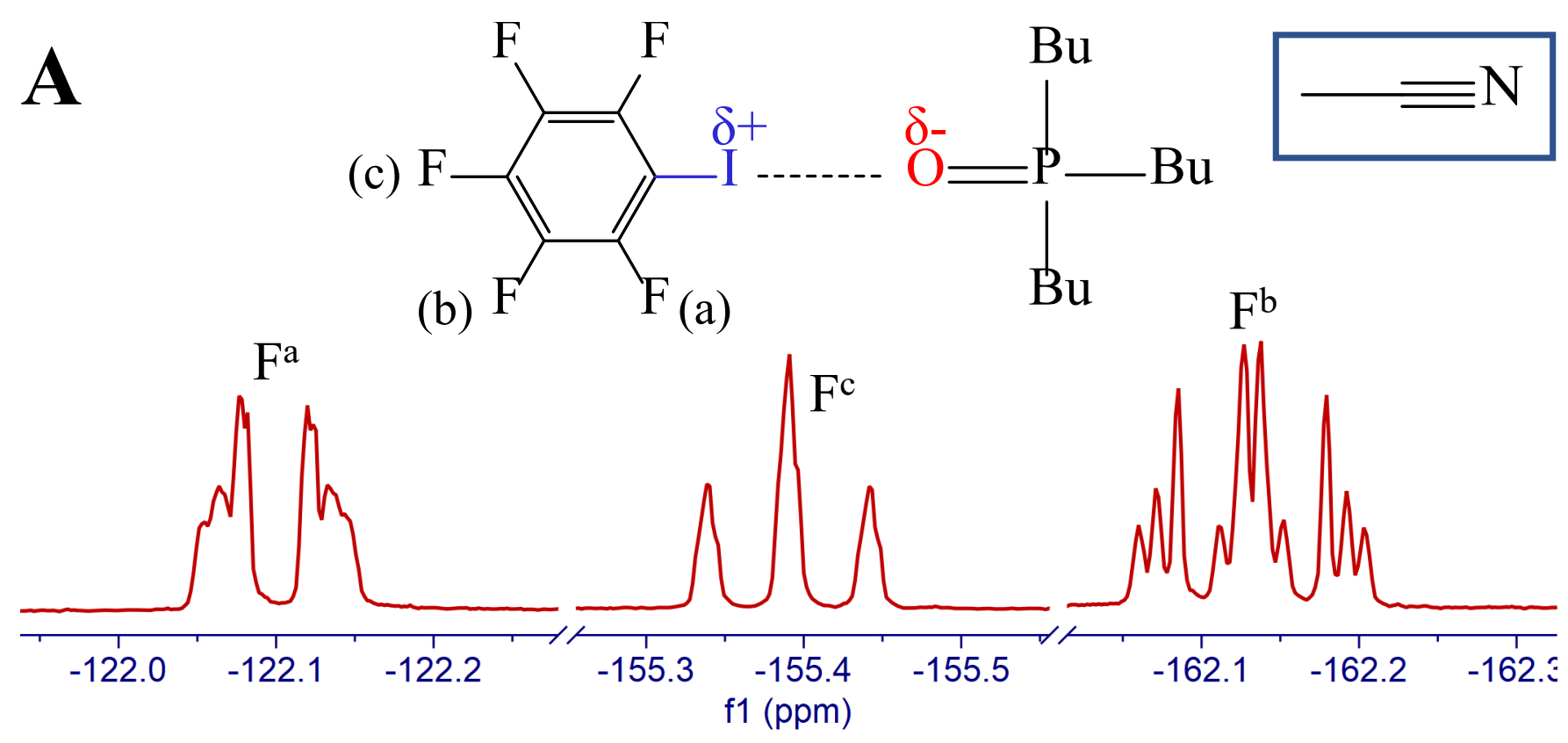

B

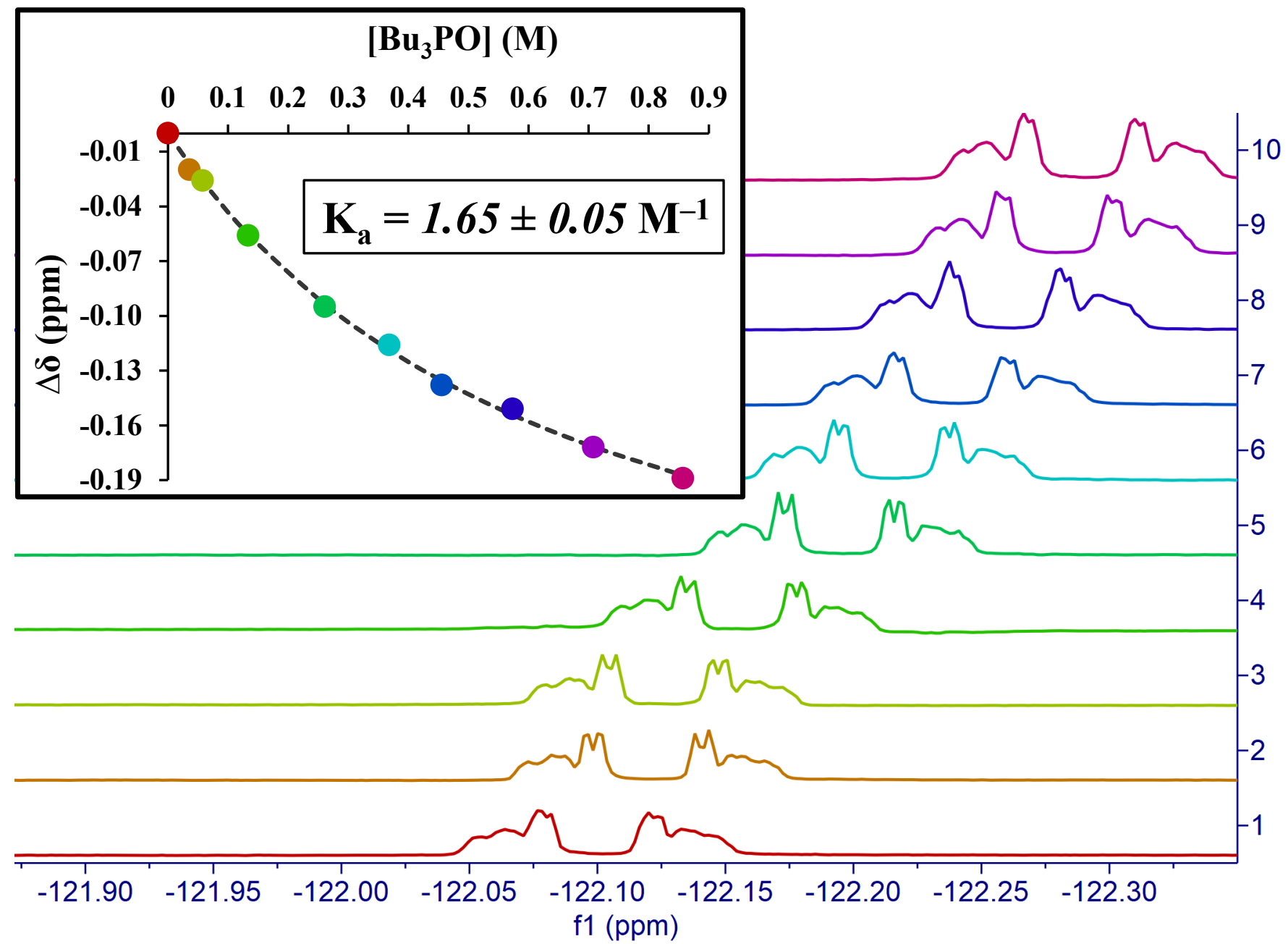

Figure S64. Representative NMR-titration experiment for XB donor iodopentafluorobenzene (I-PFB) $(0.0525 \mathrm{M})$ titrated with $\mathrm{XB}$ acceptor tributylphosphine oxide $\left(\mathbf{B u}_{\mathbf{3}} \mathbf{P O}\right)$ including $(\mathbf{A})$ initial ${ }^{19} \mathrm{H}$ NMR spectrum of I-PFB prior to titration and (B) the change in the ortho $F$ resonance shifts during addition of increasing concentrations of $\mathbf{B u}_{\mathbf{3}} \mathbf{P O}$ and the corresponding binding isotherm (inset) used for nonlinear regression analysis and determination of the association constant $\left(\mathrm{K}_{\mathrm{a}}\right)$ that reflects XB interaction strength of the adduct (Solvent: acetonitrile). 


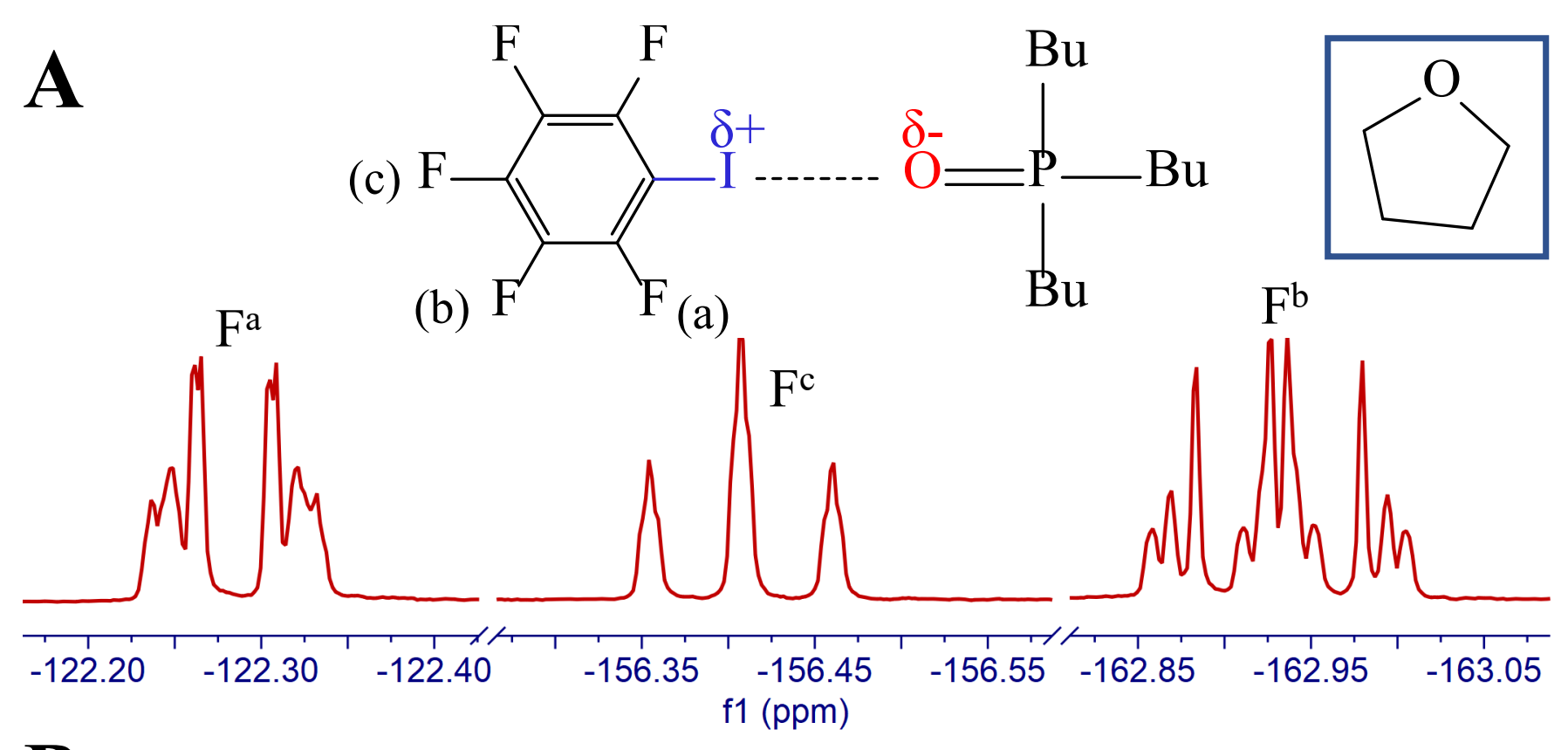

B

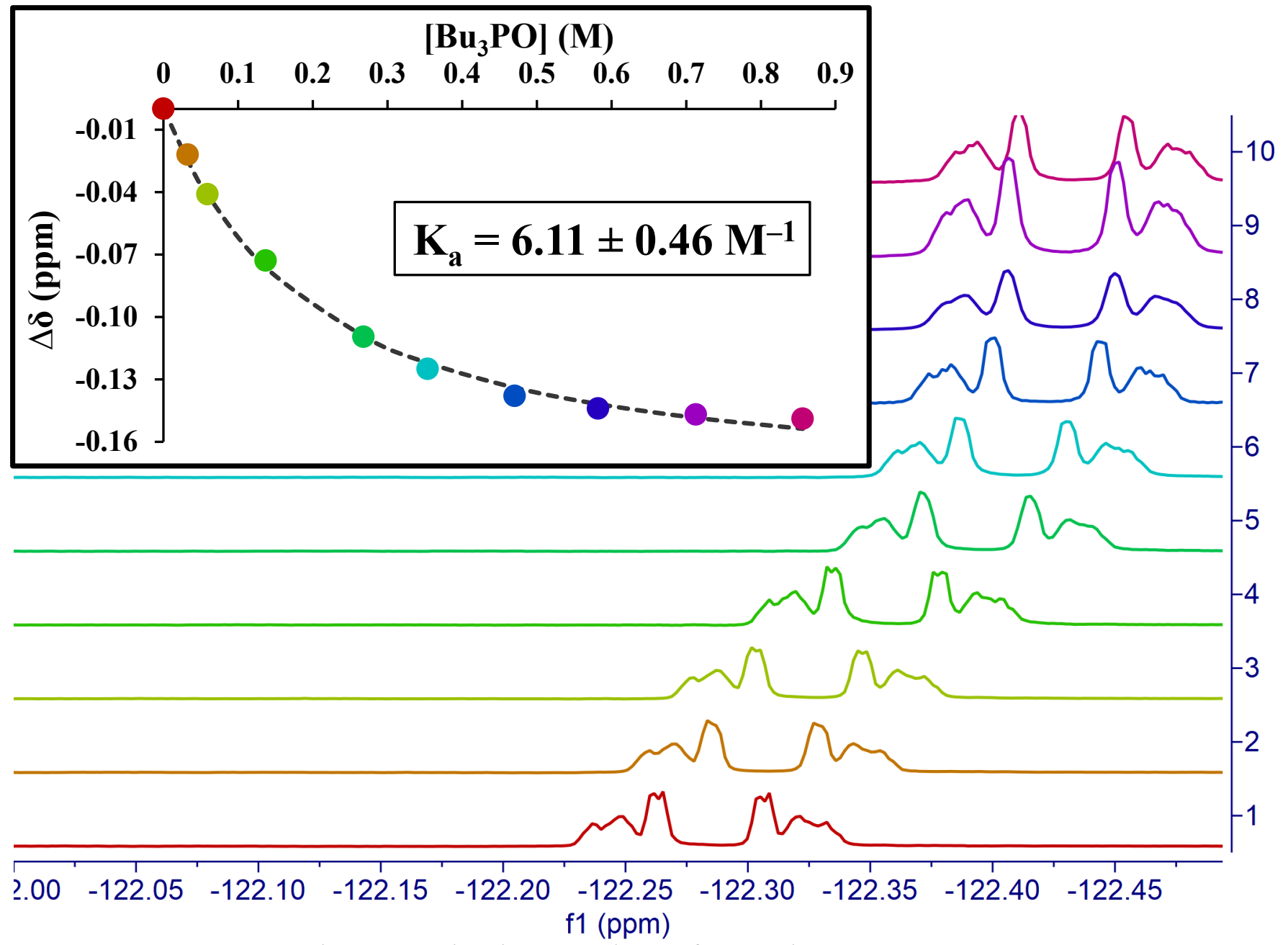

Figure S65. Representative NMR-titration experiment for XB donor iodopentafluorobenzene (I-PFB) $(0.0525 \mathrm{M})$ titrated with $\mathrm{XB}$ acceptor tributylphosphine oxide $\left(\mathbf{B u}_{\mathbf{3}} \mathbf{P O}\right)$ including $(\mathbf{A})$ initial ${ }^{19} \mathrm{H}$ NMR spectrum of I-PFB prior to titration and (B) the change in the ortho $F$ resonance shifts during addition of increasing concentrations of $\mathbf{B u}_{\mathbf{3}} \mathbf{P O}$ and the corresponding binding isotherm (inset) used for nonlinear regression analysis and determination of the association constant $\left(\mathrm{K}_{\mathrm{a}}\right)$ that reflects XB interaction strength of the adduct (Solvent: tetrahydrofuran). 


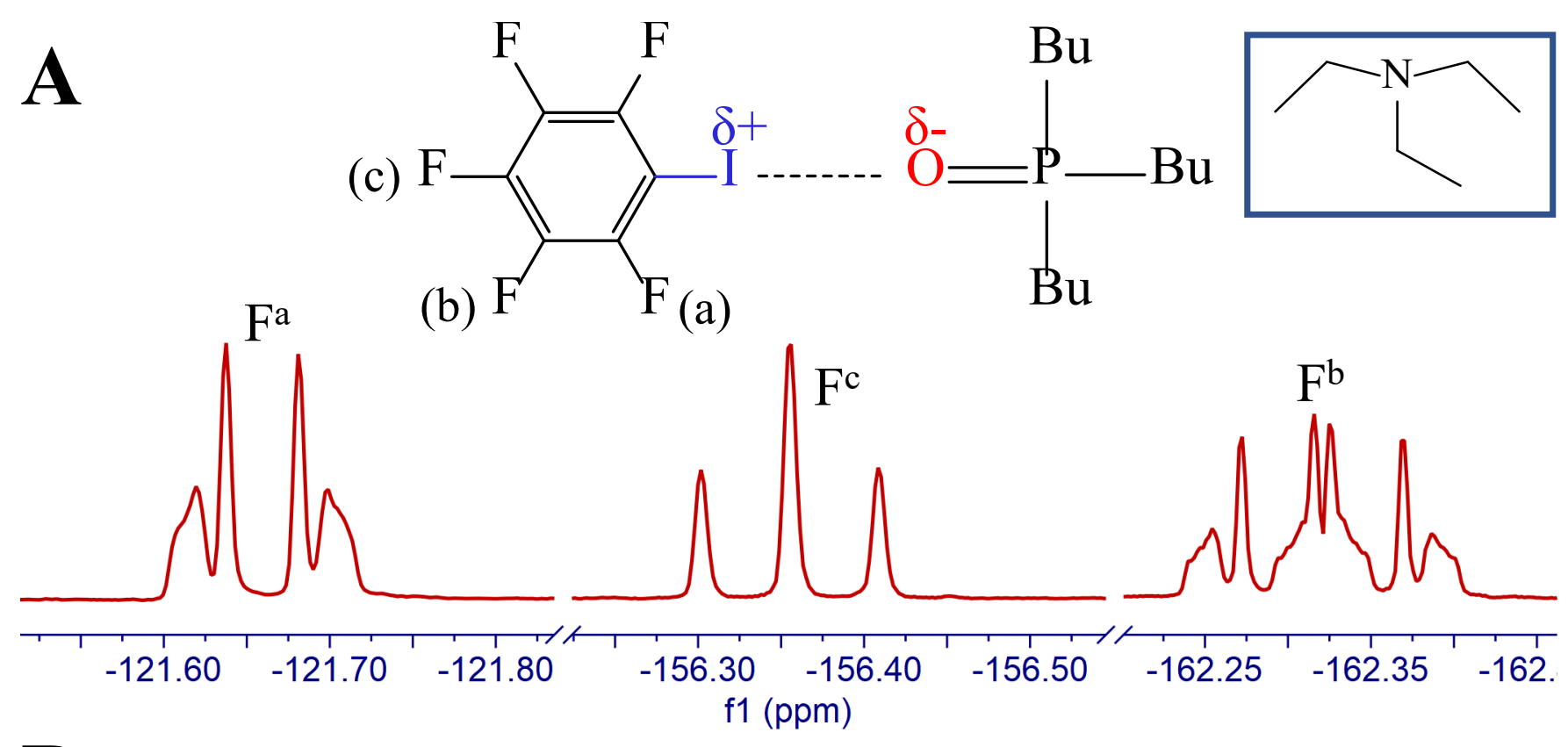

B

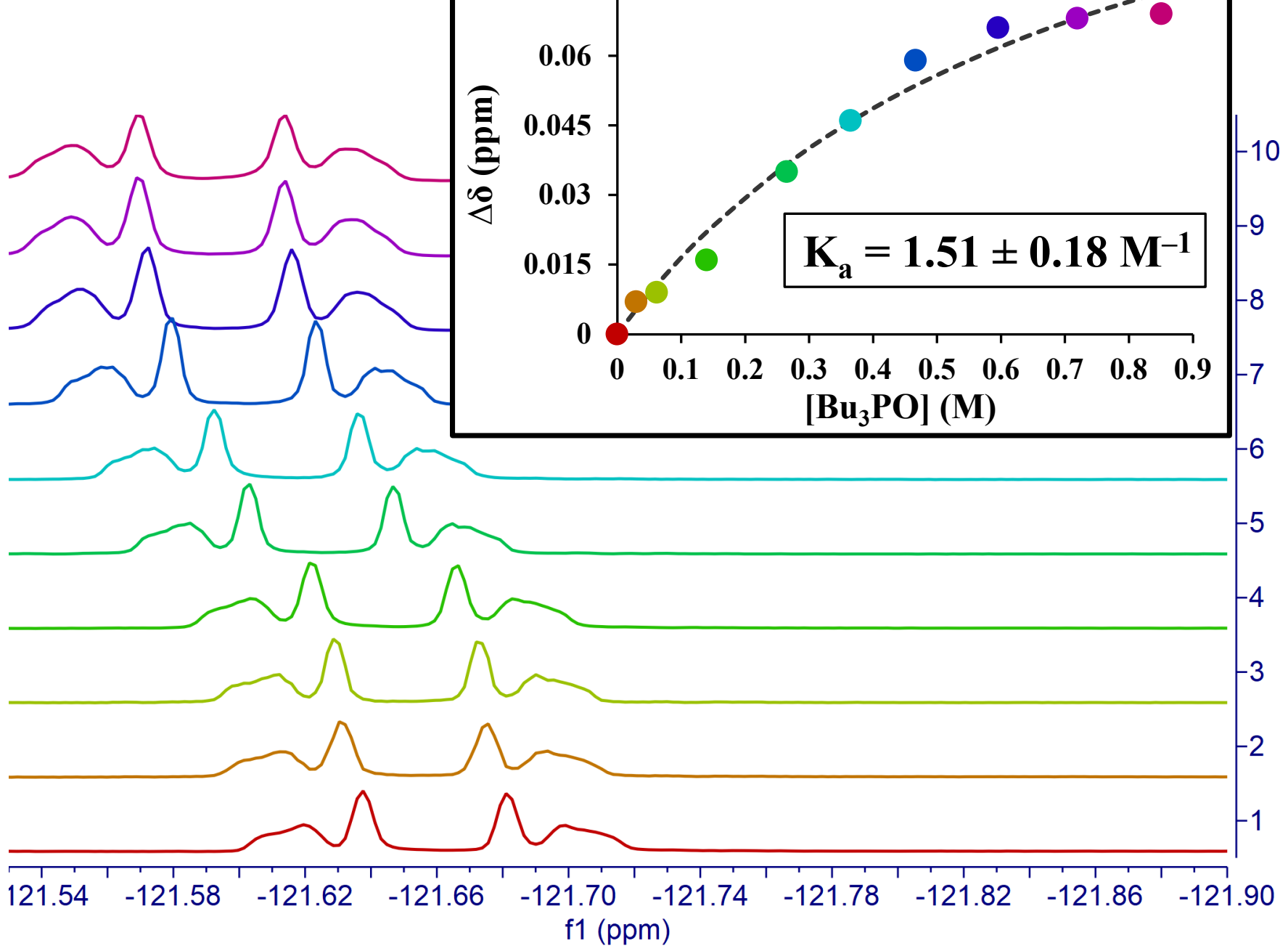

Figure S66. Representative NMR-titration experiment for XB donor iodopentafluorobenzene (I-PFB) $(0.0525 \mathrm{M})$ titrated with $\mathrm{XB}$ acceptor tributylphosphine oxide $\left(\mathbf{B u}_{\mathbf{3}} \mathbf{P O}\right)$ including $(\mathbf{A})$ initial ${ }^{19} \mathrm{H}$ NMR spectrum of I-PFB prior to titration and (B) the change in the ortho F resonance shifts during addition of increasing concentrations of $\mathbf{B u}_{\mathbf{3}} \mathbf{P O}$ and the corresponding binding isotherm (inset) used for nonlinear regression analysis and determination of the association constant $\left(\mathrm{K}_{\mathrm{a}}\right)$ that reflects XB interaction strength of the adduct (Solvent: triethylamine). 


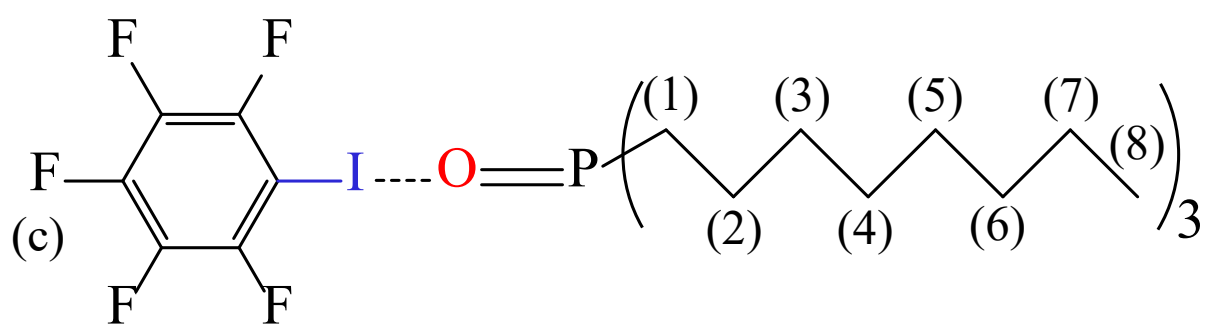

(b) (a)

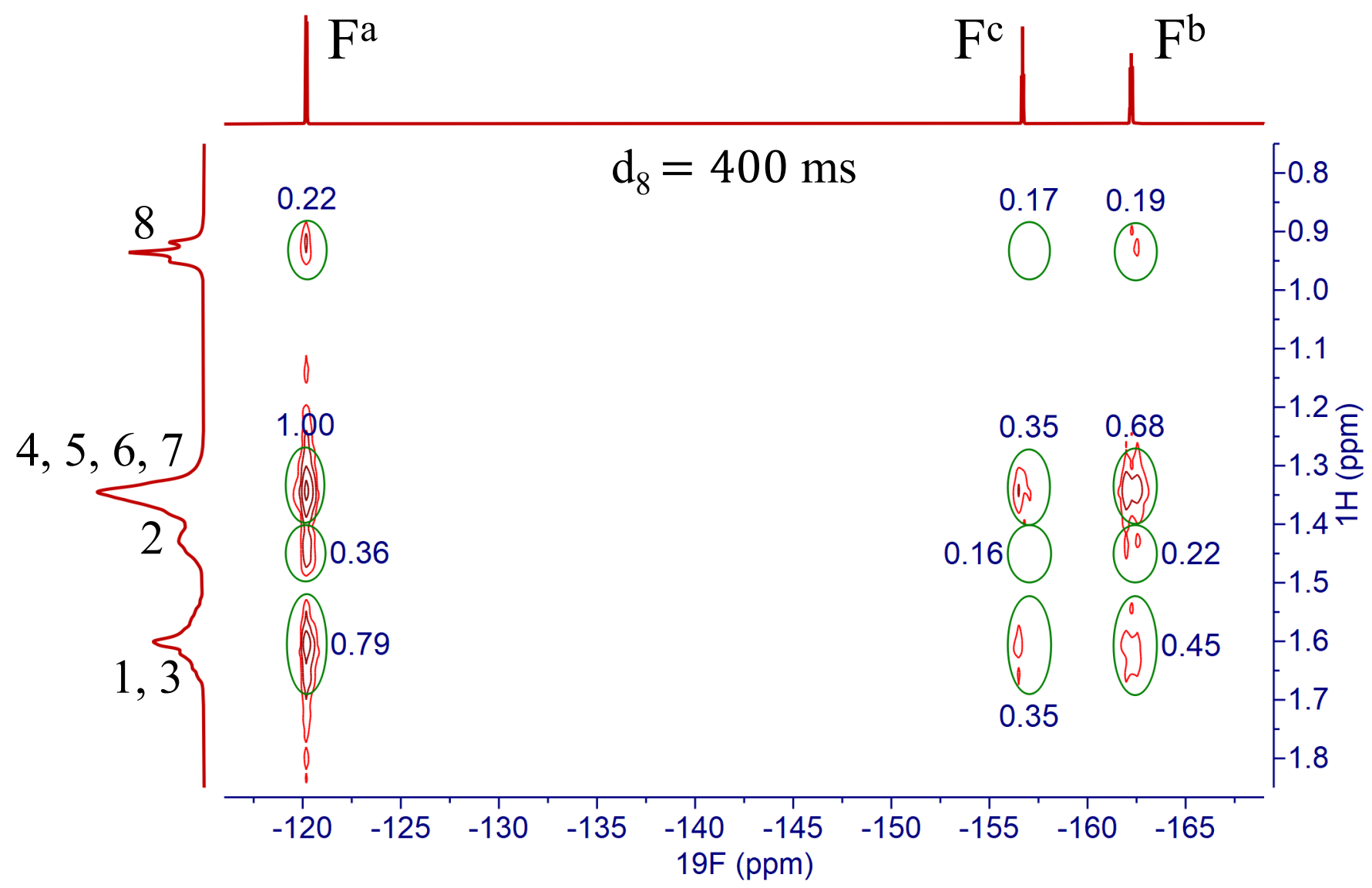

Figure S67. ${ }^{19} \mathrm{~F}-{ }^{1} \mathrm{H}$ HOESY spectrum with cross peaks representing the couplings of $0.0525 \mathrm{M}$ XB donor iodopentafluorobenzene (I-PFB)'s fluorines and $0.7 \mathrm{M} \mathrm{XB}$ acceptor trioctylphosphine oxide $\left(\mathbf{O c t}_{\mathbf{3}} \mathbf{P O}\right.$ )'s protons as a result of the formation of XB adduct IPFB-Oct ${ }_{3}$ PO. Mixing time $\mathrm{d}_{8}(\mathrm{NMR}$ parameter) $=400 \mathrm{~ms}$. 


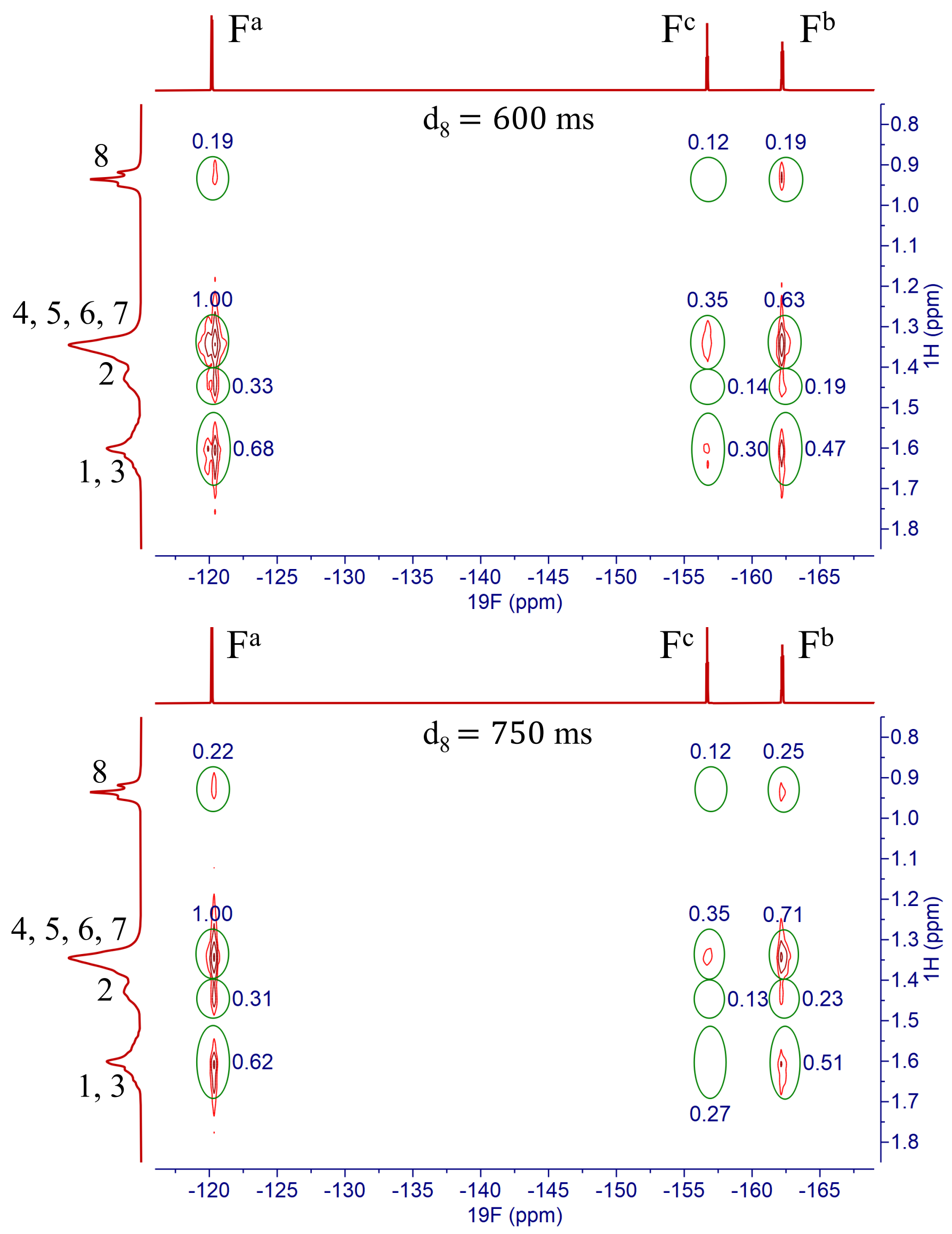

Figure S68. ${ }^{19} \mathrm{~F}-{ }^{1} \mathrm{H}$ HOESY spectra with cross peaks representing the couplings of $0.0525 \mathrm{M} \mathrm{XB}$ donor iodopentafluorobenzene (I-PFB)'s fluorines and $0.7 \mathrm{M} \mathrm{XB}$ acceptor trioctylphosphine oxide $\left(\mathbf{O c t}_{\mathbf{3}} \mathbf{P O}\right)$ 's protons as a result of the formation of XB adduct IPFB-Oct ${ }_{3}$ PO. Mixing time $\mathrm{d}_{8}(\mathrm{NMR}$ parameter) $=600 \mathrm{~ms}$ (top) and $750 \mathrm{~ms}$ (bottom). 


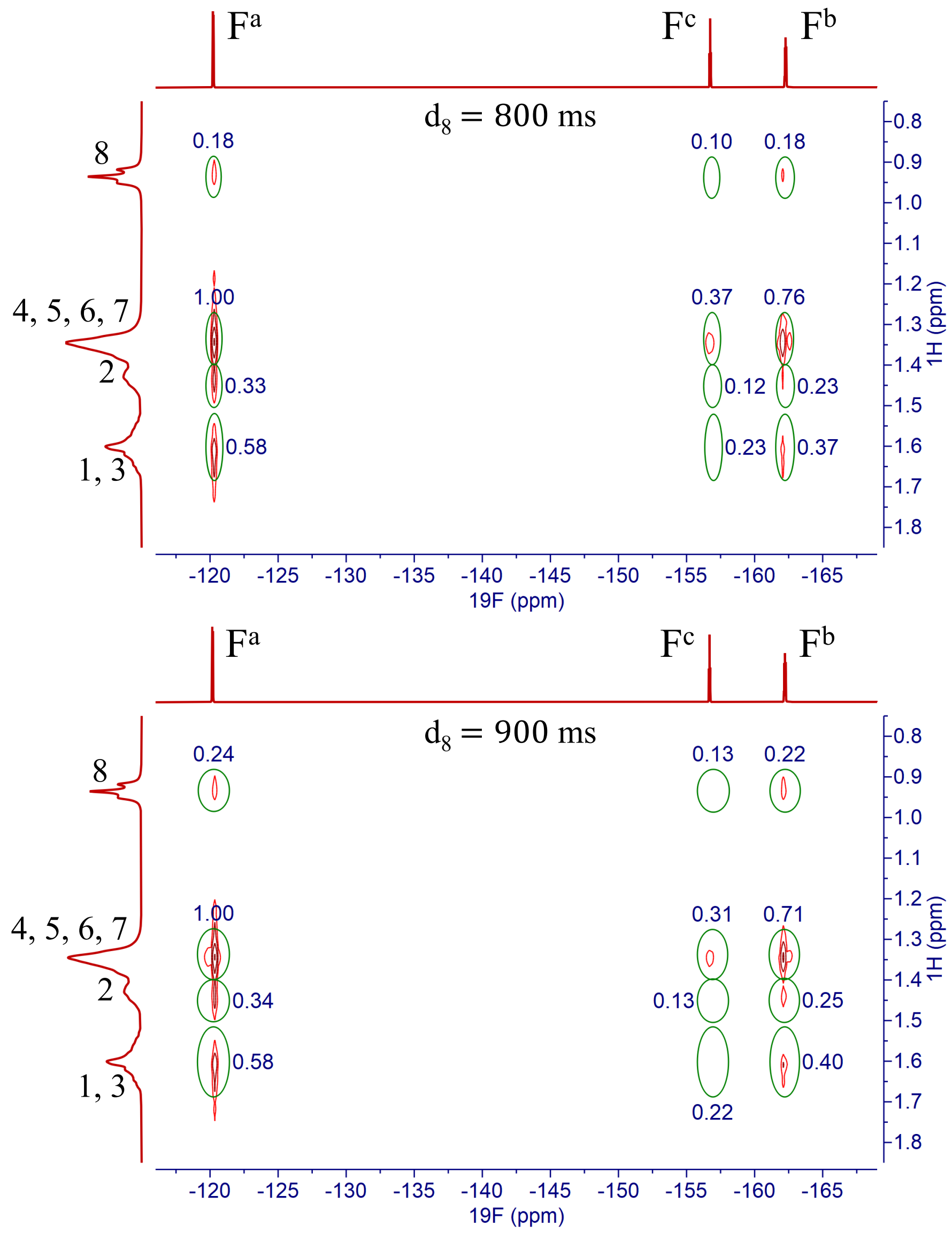

Figure S69. ${ }^{19} \mathrm{~F}-{ }^{1} \mathrm{H}$ HOESY spectra with cross peaks representing the couplings of $0.0525 \mathrm{M}$ XB donor iodopentafluorobenzene (I-PFB)'s fluorines and $0.7 \mathrm{M} \mathrm{XB}$ acceptor trioctylphosphine oxide (Oct $_{\mathbf{3}} \mathbf{P O}$ )'s protons as a result of the formation of XB adduct IPFB-Oct ${ }_{3}$ PO. Mixing time $\mathrm{d}_{8}(\mathrm{NMR}$ parameter) $=800 \mathrm{~ms}$ (top) and $900 \mathrm{~ms}$ (bottom). 


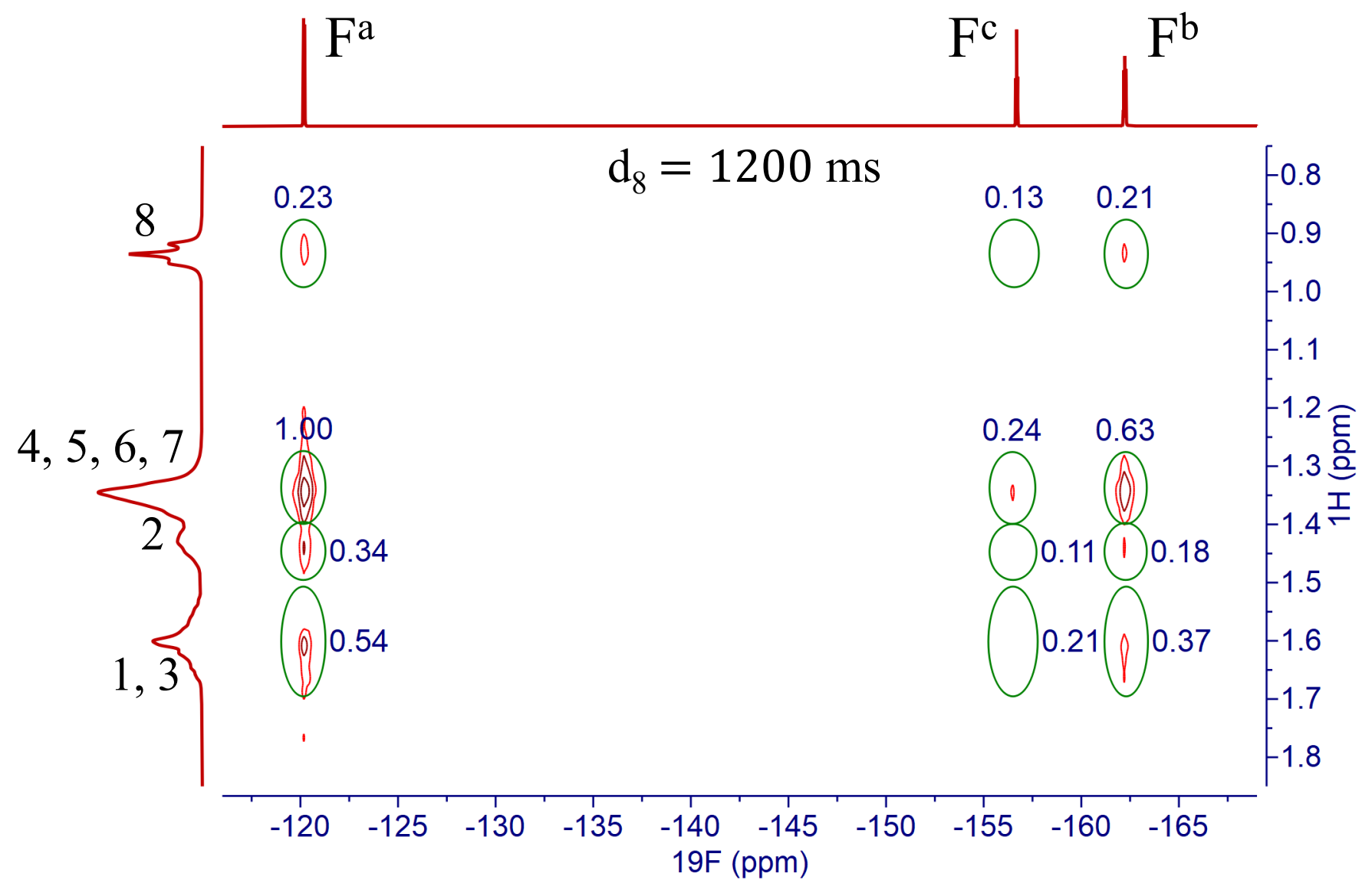

Figure S70. ${ }^{19} \mathrm{~F}-{ }^{1} \mathrm{H}$ HOESY spectra with cross peaks representing the couplings of $0.0525 \mathrm{M} \mathrm{XB}$ donor iodopentafluorobenzene (I-PFB)'s fluorines and $0.7 \mathrm{M} \mathrm{XB}$ acceptor trioctylphosphine oxide (Oct $_{\mathbf{3}} \mathbf{P O}$ )'s protons as a result of the formation of XB adduct IPFB-Oct ${ }_{3}$ PO. Mixing time $\mathrm{d}_{8}(\mathrm{NMR}$ parameter) $=1200 \mathrm{~ms}$. 


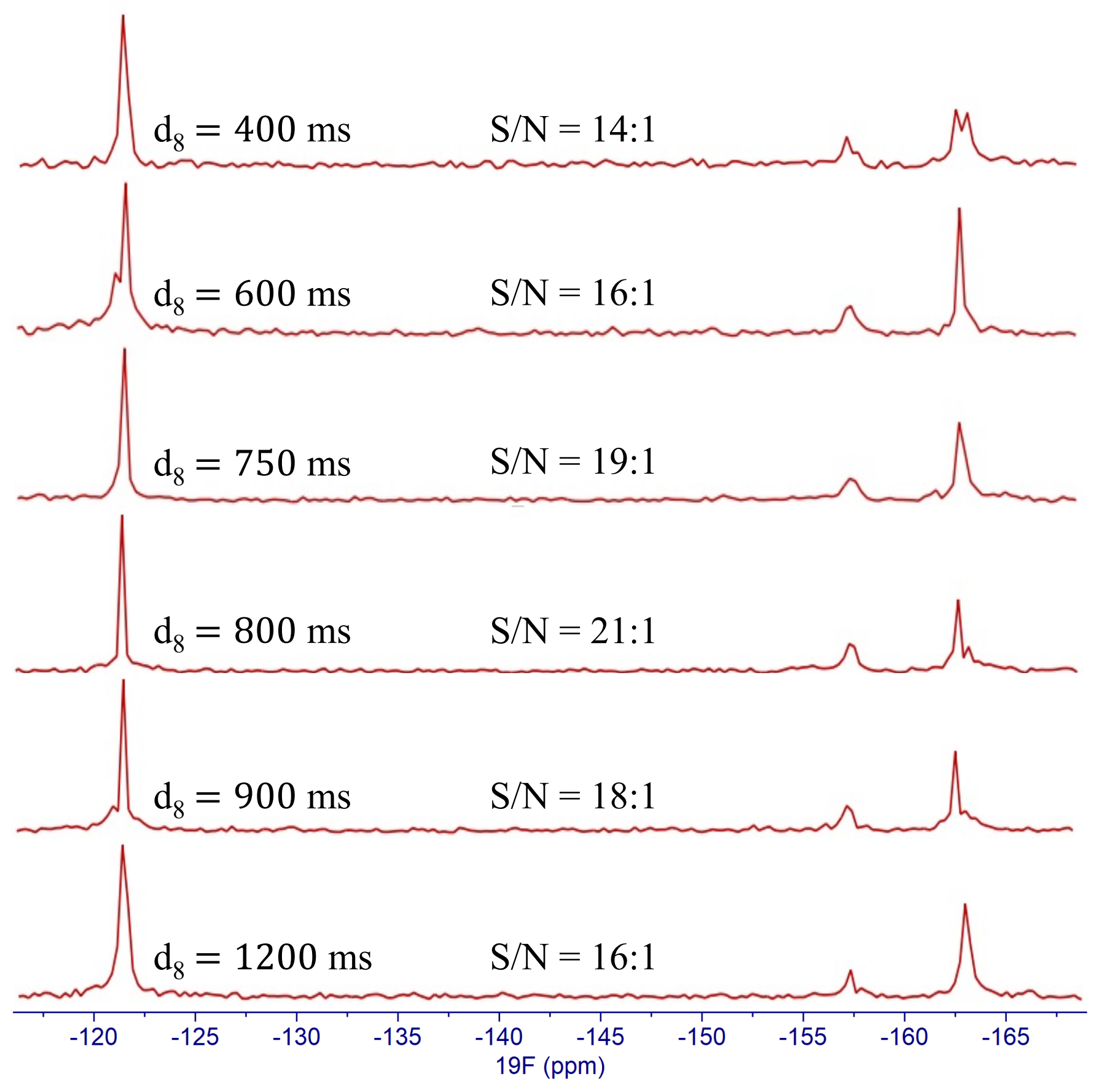

Figure S71. Horizontal graphical traces of the most intense cross peak (of $\mathrm{H}^{4,5,6,7}$ and $\mathrm{F}^{\mathrm{a}}$ ) of ${ }^{19} \mathrm{~F}-{ }^{1} \mathrm{H}$ HOESY spectra of the XB adduct of XB donor iodopentafluorobenzene (I-PFB) (0.0525 M) with XB acceptor trioctylphosphine oxide $\left(\mathbf{O c t}_{3} \mathbf{P O}\right)(0.7 \mathrm{M})$ across different $\mathrm{d}_{8}$ NMR mixing time along with the corresponding signal/noise $(\mathrm{s} / \mathrm{n})$ ratios. Note: The cross-peak integrals for each ${ }^{19} \mathrm{~F}-{ }^{1} \mathrm{H}$ pair of IPFB$\mathrm{Oct}_{3} \mathrm{PO}$ remain relatively consistent across six different $d_{8}$ values, which suggests that the volumes of the cross-peak signals are independent of varying $d_{8}$. Therefore, considering the extended time requirement of the HOESY NMR experiments, the optimal mixing time $d_{8}$ of $800 \mathrm{~ms}$ is applied to the measurements of other systems. The signal/noise ratios of the other systems conducted at $\mathrm{d}_{8}=800 \mathrm{~ms}$ vary from 16:1 to 20:1 (except for the IPFB-Bu 3 PO and IPFB - Oct ${ }_{3}$ PO systems in chloroform), which is comparable to $21: 1$ of IPFB-Oct 3 PO. 

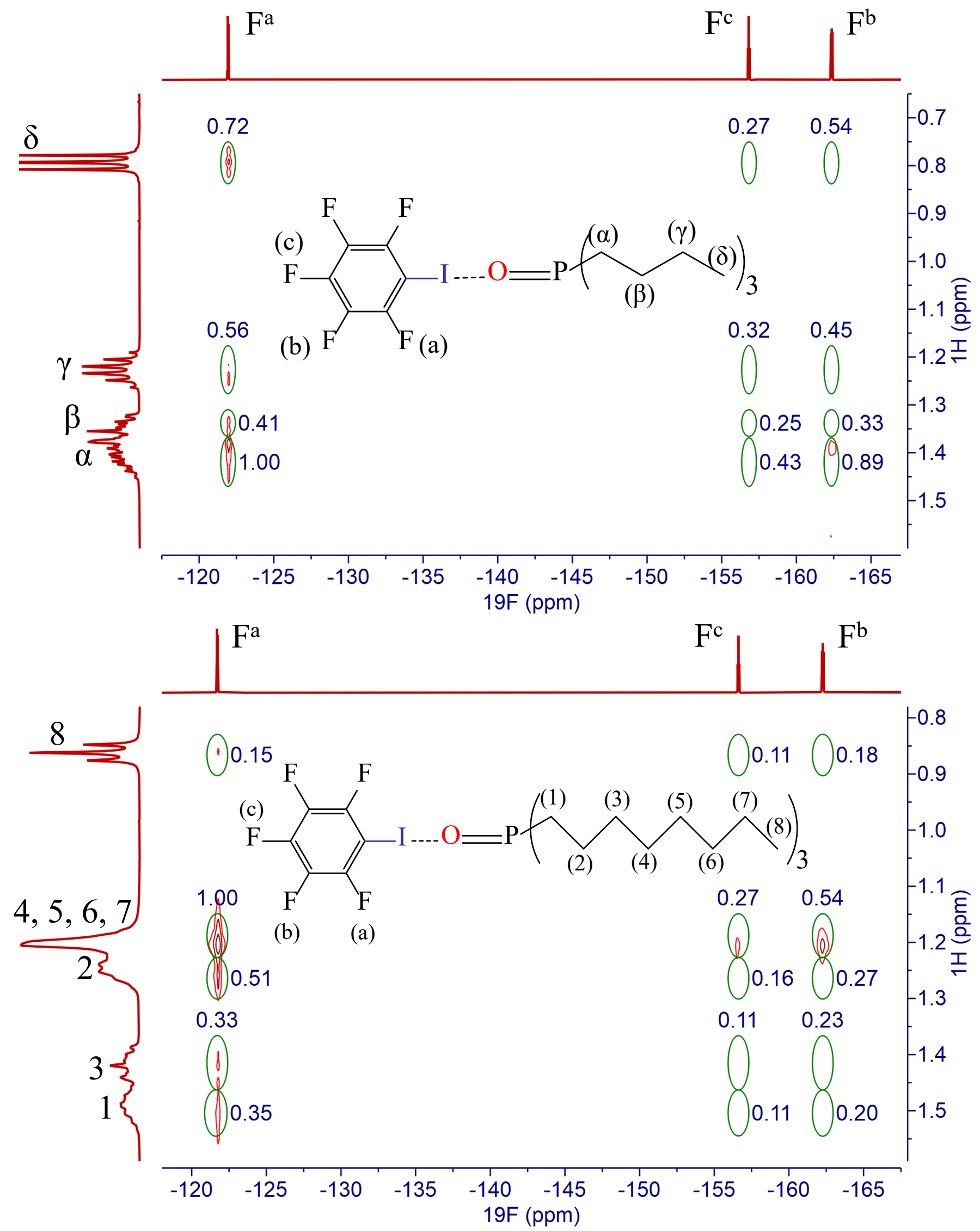

Figure S72. ${ }^{19} \mathrm{~F}-{ }^{1} \mathrm{H}$ HOESY spectra of the XB adduct of XB donor iodopentafluorobenzene (I-PFB) $(0.0525 \mathrm{M})$ with $\mathrm{XB}$ acceptor tributylphosphine oxide $\left(\mathbf{B u}_{\mathbf{3}} \mathbf{P O}\right)(1.0 \mathrm{M})$ (top) and trioctylphosphine oxide $\left(\mathbf{O c t}_{3} \mathbf{P O}\right)(0.7 \mathrm{M})$ (bottom) in benzene with cross peaks representing the couplings of ${ }^{19} \mathrm{~F}-{ }^{1} \mathrm{H}$ pairs and their cross-peak intensities. 

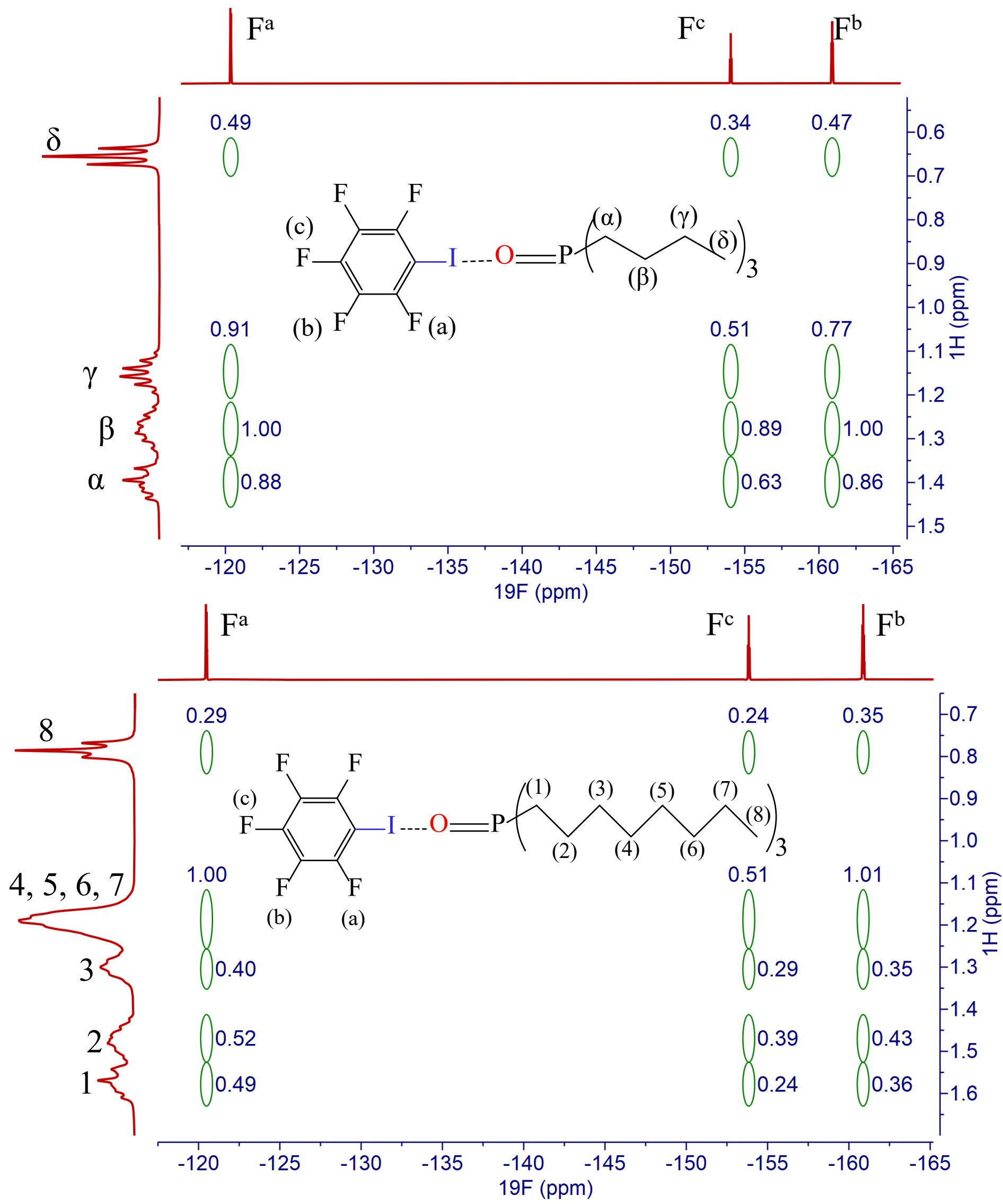

Figure S73. ${ }^{19} \mathrm{~F}-{ }^{1} \mathrm{H}$ HOESY spectra of the XB adduct of XB donor iodopentafluorobenzene (I-PFB) $(0.0525 \mathrm{M})$ with $\mathrm{XB}$ acceptor tributylphosphine oxide $\left(\mathbf{B u}_{3} \mathbf{P O}\right)(1.0 \mathrm{M})$ (top) and trioctylphosphine oxide $\left(\mathbf{O c t}_{3} \mathbf{P O}\right)(0.7 \mathrm{M})$ (bottom) in d-chloroform with cross peaks representing the couplings of ${ }^{19} \mathrm{~F}-$ ${ }^{1} \mathrm{H}$ pairs and their cross-peak intensities. 


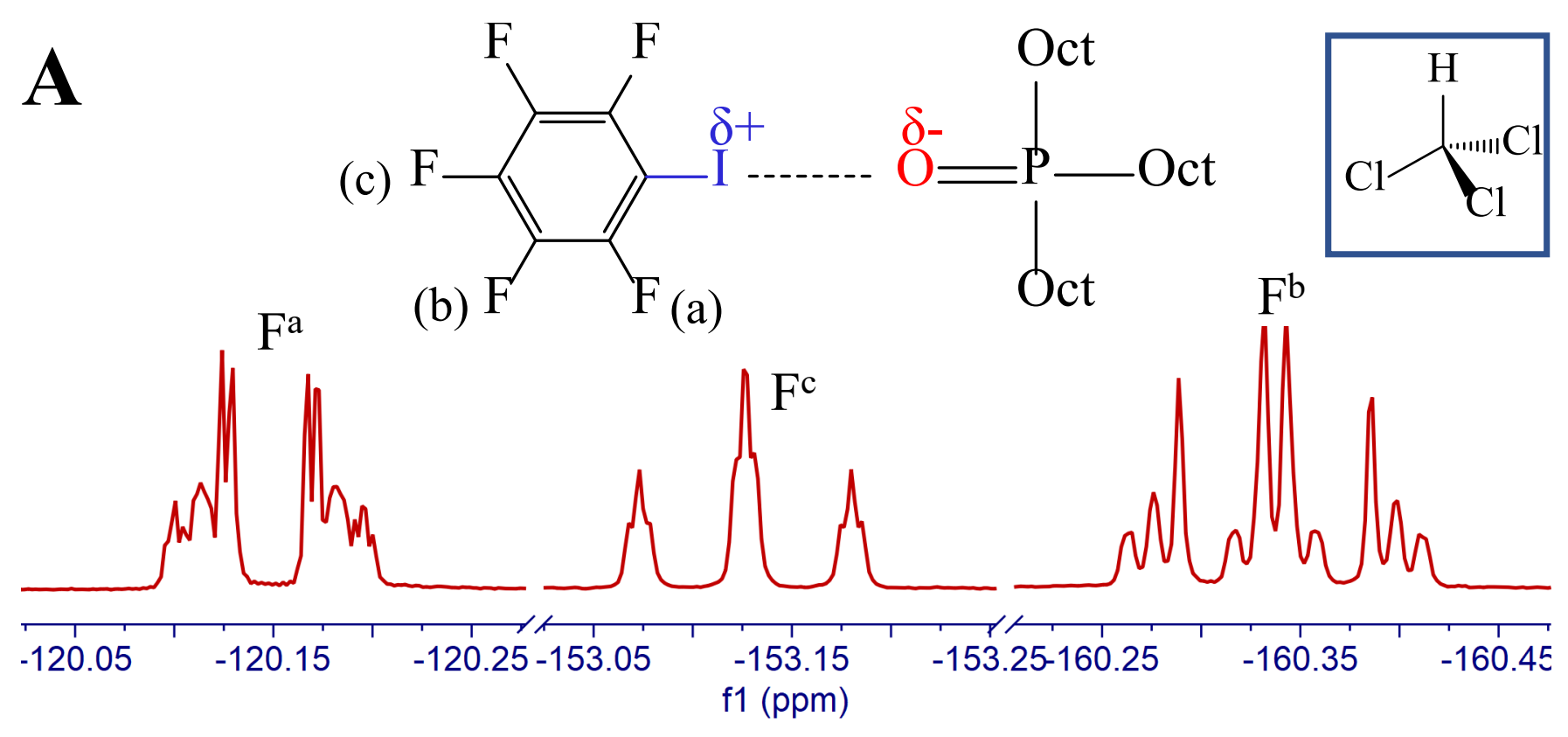

B

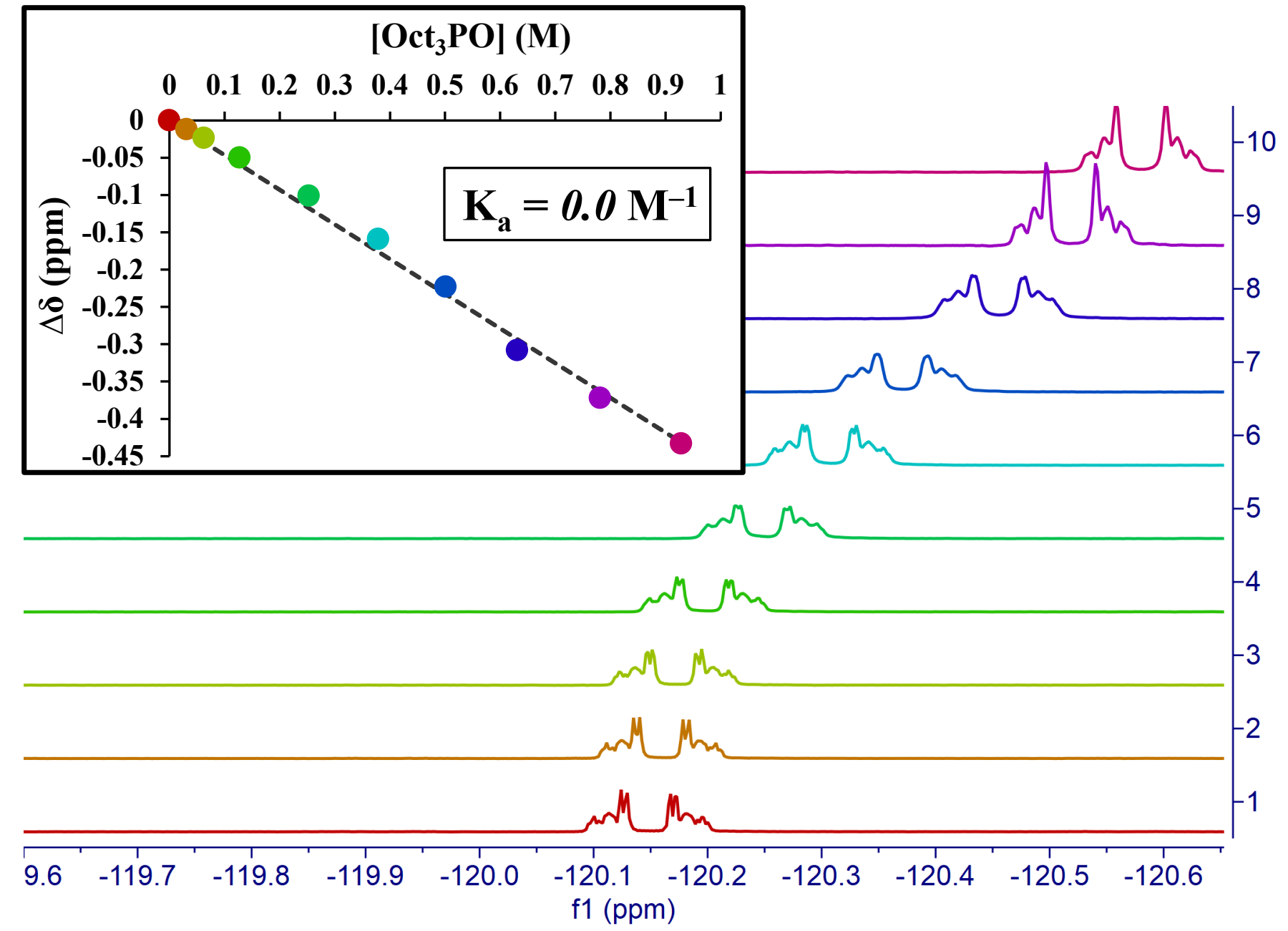

Figure S74. Representative NMR-titration experiment for XB donor iodopentafluorobenzene (I-PFB) $(0.0525 \mathrm{M})$ titrated with XB acceptor trioctylphosphine oxide $\left(\mathbf{O c t}_{\mathbf{3}} \mathbf{P O}\right)$ including (A) initial ${ }^{19} \mathrm{H}$ NMR spectrum of I-PFB prior to titration and (B) the change in the ortho $F$ resonance shifts during addition of increasing concentrations of $\mathbf{O c t}_{\mathbf{3}} \mathbf{P O}$ and the corresponding binding isotherm (inset) used for nonlinear regression analysis and determination of the association constant $\left(\mathrm{K}_{\mathrm{a}}\right)$ that reflects XB interaction strength of the adduct (Solvent: benzene). 


\section{References}

1. Thordarson, P., Determining Association Constants from Titration Experiments in Supramolecular Chemistry (Vol 40, Pg 1305, 2011). Chem Soc Rev 2011, 40, 5922-5923.

2. Sarwar, M. G.; Dragisic, B.; Salsberg, L. J.; Gouliaras, C.; Taylor, M. S., Thermodynamics of Halogen Bonding in Solution: Substituent, Structural, and Solvent Effects. Journal of the American Chemical Society 2010, 132, 1646-1653.

3. Hughes, M. P.; Smith, B. D., Enhanced Carboxylate Binding Using Urea and Amide-Based Receptors with Internal Lewis Acid Coordination: A Cooperative Polarization Effect. J Org Chem 1997, $62,4492-4499$. 